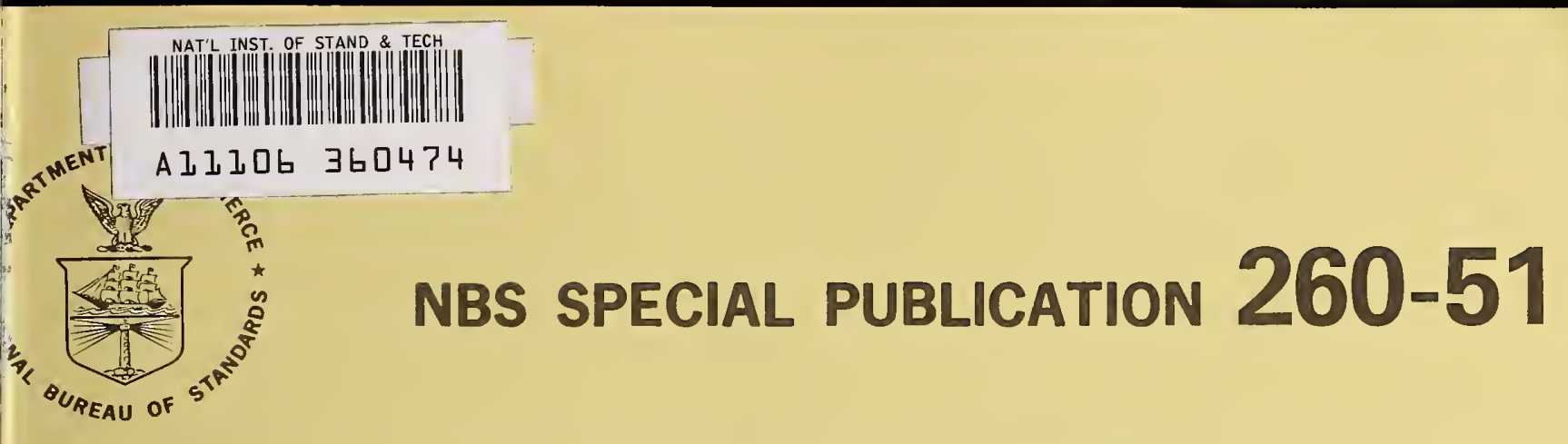

U.S. DEPARTMENT OF COMMERCE / National Bureau of Standards

Standard Reference Materials:

GLASS FILTERS AS A STANDARD REFERENCE MATERIAL FOR SPECTROPHOTOMETRY-SELECTION, PREPARATION, CERTIFICATION, USE SRM 930

\footnotetext{
$Q C$ 100

.457

no.260-51

1975

C. 2
} 
The National Bureau of Standards ${ }^{1}$ was established by an act of Congress March 3, 1901. The Bureau's overall goal is to strengthen and advance the Nation's science and technology and facilitate their effective application for public benefit. To this end, the Bureau conducts research and provides: (1) a basis for the Nation's physical measurement system, (2) scientific and technological services for industry and government, (3) a technical basis for equity in trade, and (4) technical services to promote public safety. The Bureau consists of the Institute for Basic Standards, the Institute for Materials Research, the Institute for Applied Technology, the Institute for Computer Sciences and Technology, and the Office for Information Programs.

THE INSTITUTE FOR BASIC STANDARDS provides the central basis within the United States of a complete and consistent system of physical measurement; coordinates that system with measurement systems of other nations; and furnishes essential services leading to accurate and uniform physical measurements throughout the Nation's scientific community, industry, and commerce. The Institute consists of the Office of Measurement Services, the Office of Radiation Measurement and the following Center and divisions:

Applied Mathematics - Electricity - Mechanics - Heat - Optical Physics - Center for Radiation Research: Nuclear Sciences; Applied Radiation — Laboratory Astrophysics ${ }^{2}$ - Cryogenics $^{2}$ - Electromagnetics ${ }^{2}$ - Time and Frequency ${ }^{2}$.

THE INSTITUTE FOR MATERIALS RESEARCH conducts materials research leading to improved methods of measurement, standards, and data on the properties of well-characterized materials needed by industry, commerce, educational institutions, and Government; provides advisory and research services to other Government agencies; and develops, produces, and distributes standard reference materials. The Institute consists of the Office of Standard Reference Materials, the Office of Air and Water Measurement, and the following divisions:

Analytical Chemistry - Polymers - Metallurgy - Inorganic Materials — Reactor Radiation - Physical Chemistry.

THE INSTITUTE FOR APPLIED TECHNOLOGY provides technical services to promote the use of available technology and to facilitate technological innovation in industry and Government; cooperates with public and private organizations leading to the development of technological standards (including mandatory safety standards), codes and methods of test; and provides technical advice and services to Government agencies upon request. The Institute consists of the following divisions and Centers:

Standards Application and Analysis - Electronic Technology - Center for Consumer Product Technology: Product Systems Analysis; Product Engineering — Center for Building Technology: Structures, Materials, and Life Safety; Building Environment; Technical Evaluation and Application - Center for Fire Research: Fire Science; Fire Safety Engineering.

THE INSTITUTE FOR COMPUTER SCIENCES AND TECHNOLOGY conducts research and provides technical services designed to aid Government agencies in improving cost effectiveness in the conduct of their programs through the selection, acquisition, and effective utilization of automatic data processing equipment; and serves as the principal focus within the executive branch for the development of Federal standards for automatic data processing equipment, techniques, and computer languages. The Institute consists of the following divisions:

Computer Services - Systems and Software - Computer Systems Engineering - Information Technology.

THE OFFICE FOR INFORMATION PROGRAMS promotes optimum dissemination and accessibility of scientific information generated within NBS and other agencies of the Federal Government; promotes the development of the National Standard Reference Data System and a system of information analysis centers dealing with the broader aspects of the National Measurement System; provides appropriate services to ensure that the NBS staff has optimum accessibility to the scientific information of the world. The Office consists of the following organizational units:

Office of Standard Reference Data - Office of Information Activities - Office of Technical Publications - Library - Office of International Relations - Office of International Standards.

1 Headquarters and Laboratories at Gaithersburg, Maryland, unless otherwise noted; mailing address Washington, D.C. 20234.

${ }^{3}$ Located at Boulder, Colorado 80302. 
Standard Reference Materials:

\section{Glass Filters as a Standard Reference Material for Spectrophotometry-Selection, Preparation, Certification, Use SRM 930}

R. Mavrodineanu

J. R. Baldwin

Analytical Chemistry Division Institute for Materials Research

National Bureau of Standards

Washington, D.C. 20234

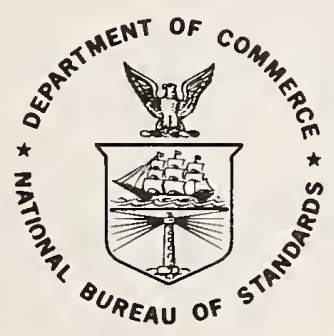

U.S. DEPARTMENT OF COMMERCE, Rogers C. B. Morton, Secretary James A. Baker, III, Under Secrefary

Dr. Betsy Ancker-Johnson, Assistant Secretary for Science and Technology

U.5 NATIONAL BUREAU OF STANDARDS, Ernest Ambler, Acting Director

Issued November 1975 


\section{Library of Congress Cataloging in Publication Data}

Mavrodineanu, Radu, 1910-

Glass Filters as a Standard Reference Material for Spectro. photometry.

(Standard Reference Materials) (NBS Special Publication; 260-51)

"CODEN : XNBSAV."

Bibliography: p.

Supt. of Docs. No.: C 13.10:260-51.

1. Spectrophotometer-Standards. 2. Light filters-Standards. 3. Glass, Optical - Standards. I. Baldwin, John Raymond, 1918 Joint Author. II. Series. United States. National Bureau of Standards. Standard Reference Materials. III. Series: United States. National Bureau of Standards. Special Publication; 260-51. QC100.U57 No. 260-5] [QC465] 389'.08s

[535’.84'028] 75-619308

\section{National Bureau of Standards Special Publication 260-51}

Nat. Bur. Stand. (U.S.), Spec. Publ. 260-5I, 118 pages (Nov. 1975)

CODEN: XNBSAV 
Standard Reference Materials (SRM's) as defined by the National Bureau of Standards are "we11-characterized materials, produced in quantity, that calibrate a measurement system to assure compatibility of measurement in the nation." SRM's are widely used as primary standards in many diverse fields in science, industry, and technology, both within the United States and throughout the world. In many industries traceability of their quality control process to the national measurement system is carried out through the mechanism and use of SRM's. For many of the nation's scientists and technologists it is therefore of more than passing interest to know the details of the measurements made at NBS in arriving at the certified values of the SRM's produced. An NBS series of papers, of which this publication is a member, called the NBS Special Publication - 260 Series is reserved for this purpose.

This 260 Series is dedicated to the dissemination of information on a 11 phases of the preparation, measurement, and certification of NBS-SRM's. In general, much more detail will be found in these papers than is generally allowed, or desirable, in scientific journal articles. This enables the user to assess the validity and accuracy of the measurement processes employed, to judge the statistical analysis, and to learn details of techniques and methods utilized for work entailing the greatest care and accuracy. It is also hoped that these papers will provide sufficient additional information not found on the certificate so that new applications in diverse fields not foreseen at the time the SRM was originally issued will be sought and found.

Inquiries concerning the technical content of this paper should be directed to the author(s). Other questions concerned with the availability, delivery, price, and so forth will receive prompt attention from:

Office of Standard Reference Materials

National Bureau of Standards

Washington, D.C. 20234

J. Paul Cali, Chief

Office of Standard Reference Materials 
NBS Spec. Publ. 260, Standard Referenee Mate- NBS Misc. Publ. 260-12, Standard Referenee rials: 1973 Catalog, A pril 1973, $\$ 1.25 \%$

NBS Misc. Publ. 260-1, Standard Reference Materials: Preparation of NBS White Cast Iron Spectrochemical Standards, June 1964. COM 74-1 $1061 . * \%$

NBS Misc. Publ. 260-2, Standard Reference Naterials: Preparation of NBS Copper-Base Spectrochemical Standards, Oetober 1964. COM 74-1 1063.*\%

NBS Visc. Publ. 260-3, Standard Reference, Materials: Hetallographic Characterization of an NBS Spretrometric Low-Alloy Steel Standard, October 1964. COM 74-11060\%*

NBS Mlise. PubI. 260-4, Standard Reference Materials: Sourees of Information on Standard Reference Materials. February 1965. COM 74-1 1059.*

NBS Misc. PubI. 260-5, Standard Referenec Materials: Accuracy of Solution X-Ray Spectrometric Analysis of Copper-Base Alloys. Narch I 96.5. 25 cents. (Out of print).

NBS Misc. Publ. 260-6, Standard Reference Materials: Methods for the Chemical Analysis of White Cast Iron Standards, July 1965. COM 74-1 1068.*

NBS Misc. Publ. 260-7, Standard Refercnce Materials: Methods for the Chemical Analysis of NBS Copper-Base Spectrochemical Standards, October 1965. COM 74-1 1067.**

NBS Misc. PubI. 260-8, Standard Reference Matcrials: Analysis of Uranium Concentrates at the National Burcau of Standards. December 1965. COM 74-1 1066.**

NBS Misc. Publ. 260-9, Standard Refcrence Materials: Half Lives of Materials Used in the Preparation of Standard Reference Materials of Nineteen Radioactive Nuclides Issued by the National Bureau of Standards, November 1965. COM 74-11065.**

NBS Misc. Publ. 260-10, Standard Reference Materials: Homogeneity Characterization on NBS Spectrometric Standards II: Cartridgc Brass and Low-Alloy Steel, December 1965. COM 74-1 1064.**

NBS Misc. Publ. 260-11, Standard Reference Materials: Viscosity of a Standard Lead-Silica Glass, November 1966. NBS Misc. Publ. 260-10.**

Materials: Homogeneity Characterization of NBS Spectrometric Standards III : White Cast Iron and Stainless Steel Powder Compact, Srptember 1966. NBS Misc. Publ. 260-12.* NBS Misc. Publ. 260-13, Standard Reference Naterials: Nosshauer Spectroscopy Standard for the Chemical Shift of Iron Compounds, July 1967. NBS Mise. Publ. 260-13.**

NBS ilise. Publ. 260-14, Standard Reference Vaterials: Determination of Oxygen in Forrous Materials - SR V 1090, 1091, and 1092, September 1966. NBS Misc. Publ. 260-14.*\% NBS Mlise. Publ. 260-15, Standard Reference Naterials: Recommended Nethod of Use of Standard Light-Sensitive Paper for Calibrating Carbon Ares Used in Testing Textiles for Colorfastness to Light, June 1967. (Replaced by Spec. Publ. 260-4I.)

NBS Spec. Publ. 260-16, Standard Reference Matcrials: Homogencity Characterization of NBS Spectrometric Standards IV: Preparation and Microprobe Characterization of W-20\% Ho Alloy Fabricated by Powder MetalIurgical Methods, January 1969. COM 74. 11062 . *

NBS Spec. PubI. 260-I7, Standard Reference Materials: Boric Acid; Isotopic and Assay Standard Reference Materials, February 1970. 65 cents. *

NBS Spec. Publ. 260-18, Standard Reference Materials: Calibration of NBS Secondary Standard Magnetic Tapc (Computer Amplitude Reference) Using the Reference Tape Amplitude Measurement "Process A," November 1969. (See Spec. Publ. 260-29.)

NBS Spec. Publ. 260-19, Standard Reference Materials: Analysis of Interlaboratory Measurements on the Vapor Pressure of Gold (Certification of Standard Reference Material 745), January 1970. PB 190071.**

NBS Spec. Publ. 260-21, Standard Reference Materials: Analysis of Interlaboratory Measurements on the Vapor Pressures of Cadmium and Silver, January 1971. COM 74. $11359 . * *$

NBS Spec. Publ. 260-22, Standard Reference Materials: Homogeneity Characterization of Fe-3Si Alloy, February 1971. COM 74- $11357 * *$ 
NRS Spec. Publ. 260-23, Standard Refcrence Materials: Viscosity of a Standard Borosilicate Glass, December 1970. 25 cents.*

NBS Spce. Publ. 260-24, Standard Refcrence Materials: Comparison of Redox Standards, January 1972. \$1.*

NBS Spec. Publ. 260-25, Standard Reference Materials: A standard Reference Material Containing Nominally Four Percent Austenite, February 1971. COM 74-11356.*

NBS Spec. Publ. 260-26, Standard Reference Materials: National Burean of Standards-U.S. Steel Corporation Joint Program for Determining Oxygen and Nitrogen in Stecl, Fel)ruary 1971.50 cents.*

NBS Spce. Publ. 260-27, Standard Reference Materials: Uranium lsotopic Standard Reference Materials, April 197I. COM 74-11358.**

NBS Spec. Publ. 260-28, Standard Reference Materials: Preparation and Evaluation of SR N's 481 and 482 Gold-Silver and GoldCopper Alloys for Nicroanalysis, August 1971. COM 71-50365.**

NBS Spee. Publ. 260-29, Standard Reference Matcrials: Calibration of NBS Secondary Standard Magnctic Tape (Computer Amplitude Reference) Using the Reference Tape Amplitude Measurcment "Process A-Model 2," June 1971. CON 71-50282.*

NBS Spec. Publ. 260-30, Standard Reference Materials: Standard Samples Issued in the USSR (A Translation from the Russian), Junc 1971. COM 71-50283.**

NBS Spec. Publ. 260-31, Standard Reference Materials: Thermal Conductivity of Electrolytic Iron SR M 734 from 4 to $300 \mathrm{~K}$, November 1971. COM 71-50563.**

NBS Spec. Publ. 260-32, Standard Reference Materials: Standard Quartz Cuvettes For High Accuracy Spectrophotometry. December 1973.55 cents.*

NBS Spec. Publ. 260-33, Standard Reference Materials: Comparison of Original and Supplemental SRM 705, Narrow Molecular Weight Distribution Polystyrene, H. L. Wagner, May 1972. COM 72-50526.**

NBS Spec. Publ. 260-34, Standard Reference Materials: Thermoelectric Voltage, April 1972. COM 72-50371.**
IBS Spee. Publ. 260-35, Standard Reference Materials: Thermal Conductivity of Austenitic Stainless Steel, SRM 735 from 5 to $280 \mathrm{~K}$, A pril 1972. 35 cents.*

NBS Spec. Publ. 260-36, Standard Reference Materials: A Referec Method for the Determination of Calcium in Serum. SRM 915, May 1972. CON 72-50527.*

NBS Spec. Publ. 260-37, Standard Reference Naterials: Methods of Analysis of NBS Clay Standards, June 1972. COM 72-50692.**

NIBS Spec. Publ. 260-38, Standard Reference Matcrials: Preparation and Calibration of Standards of Spcctral Specular Reflectance, May 1972.60 cents.*

NBSS Spec. Publ. 260-39, Standard Reference Materials: The Eddy Current Decay Method for Resistivity Characterization of HighPurity Metals, May 1972. 55 cents.*

NBS Spec. Publ. 260-40, Standard Reference Materials: Sclection of Thermal Analysis Temperature Standards Through a Cooperative Study (SRM 758, 759, 760), August 1972.65 cents. ${ }^{*}$

NBS Spec. Publ. 260-41, Standard Reference Materials: Use of Standard Light-Scnsitive Paper for Calibrating Carbon Ares used in Testing Textiles for Colorfastness to Light, August 1972. COM 72-50775.**

NBS Spec. Publ. 260-42, Standard Reference Materials: The Characterization of Linear Polyethylcne, SRM 1475, September 1972. 45 cents.*

NBS Spec. Publ. 260-43, Standard Reference Materials: Preparation and Homogeneity Characterization of an Austenitic IronChromium-Nickel Alloy, November 1972. 45 cents.*

NBS Spcc. Publ. 260-44, Standard Reference Materials: Preparation and Use of Superconductive Fixed Point Devices, SRM 767, December 1972.75 cents.*

NBS Spec. Publ. 260-45, Standard Reference Materials: Powdered Lead-Based Paint, SRM 1579, March 1973. COM 73-50226**

NBS Spec. Publ. 260-46, Standard Reference Materials: Thermal Conductivity and Electrical Resistivity Standard Reference Materials: Austenitic Stainless Steel, SRM's 735 and 798 , from 4 to $1200 \mathrm{~K}$, March $1975 . \$ 1.00$. 
NBS Spec. Publ. 260-47, Standard Refcrence Materials: Electrical Resistivity of Electrolytic Iron, SRM 797, and Austenitic Stainless Steel, SRM 798, from 5 to $280 \mathrm{~K}$, February 1974. 55 cents.*

NBS Spec. Publ. 260-48, Standard Reference Materials: Description and Use of Prccision Thermometers for the Clinical Laboratory, SRM 933 and SRM 934, May 1974. 60 cents.*

NBS Spec. Publ. 260-49, Standard Reference Materials: Calibrated Glass Standards for Fission Track Use, November 1974. 75 cents.*
NBS Spec. Publ. 260-50, Standard Reference Materials: Thermal Conductivity and Electrical Resistivity Standard Reference Materials: Electrolytic Iron, SRM's 734 and 797 from 4 to $1000 \mathrm{~K}$, June $1975 . \$ 1.00$

NBS Spec. Publ. 260-51, Standard Reference Materials: Glass Filters As a Standard Reference Material for Spectrophotometry; Selection, Prcparation, Certification, Use - SRM 930. (In press)

NBS Spec. Publ. 260-52, Standard Reference Materials: Thermal Conductivity and Electrical Resistivity Standard Reference Materials 730 and 799 , from 4 to $3000 \mathrm{~K}$. (In press)

*Send order with remittance to: Supcrintendent of Documents, U.S. Government Printing Offic Washington, D.C. 20402. Remittance from forcign countries should include an additional on fourth of the purchase pricc for postage.

**May be ordered from: National Technical Information Services (NTIS), Springfield, Virgin 22151 
1. GENERAL . . . . . . . . . . . . . . . . . . 2

2. INTRODUCTION. • . . . . . . . . . . . . . . . . 4

Factors Affecting the Proper Functioning of a Spectrophotometer . . . . . . . . . . .

3. MEANS AND PROCEDURES TO ASSESS AND CONTROL SOME OF THE FACTORS WHICH AFFECT THE PROPER FUNCTIONING AND ACCURACY OF A SPECTROPHOTOMETER • • • • • • • 5

3.1 The Short and Long Term Stability. . . . . 5

3.2 Wavelength Accuracy. . . . . . . . . 11

3.3 Spectral Bandpass. . . . . . . . . . 13

3.4 Stray Radiations. . . . . . . . . . 17

3.5 Accuracy of the Transmittance or Absorbance Scales............... .

4. STANDARD REFERENCE MATERIALS FOR TRANSMITTANCE IN SPECTROPHOTOMETRY . . . . . . . . . . . . . .

4.1 Selection and Preparation of Materials Which Can Be Used as Standard Reference Material in Spectrophotometry . . . . . . . . . .

4.2 Preparation of the Glass Filters . . . . . 24

4.3 Packaging of the Glass Filters . . . . . 31

5. RESULTS . . . . . . . . . . . . . 31

5.I Stability of SRM 930 . . . . . . . . . 31

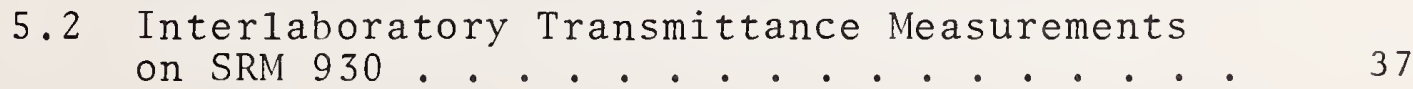

6. SUMMARIZING REMARKS . . . . . . . . . . . 44

7. REFERENCES . . . . . . . . . . . . . 47

8. APPENDICES. . . . . . . . . . . . . . 48

9. ACKNOWLEDGEMENT . . . . . . . . . . . 48 
1. Influence of temperature on the transmittance (T) of seven Schott NG-4 glass filters at five

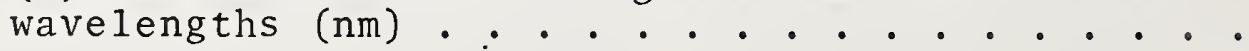

2. Percent transmittance of three Schott NG-4 neutral glass filters before and after exposures to accelerated radiation tests..........

3. Stability of transmittance (T) as a function of time, measured on SRM 930... . . . . . . . . .

4. Comparison of percent transmittance $(\% \mathrm{~T})$ measurements performed on a set of three Schott NG-4 glass filters over a period of two years...

5. Comparison between the percent transmittances $(\% \mathrm{~T})$ measured on three Schott NG-4 glass filters at NPL and NBS in 1971, 1973, and 1975 . . . .

6. Comparative transmittance measurements performed by four laboratories on three Schott NG-4 colored glass filters............... 39,40

7. Transmittance of SRM 930, set 106, after two years of use in a laboratory . . . . . . . . .

8. Comparison of $\% \mathrm{~T}$ measurements performed on a Schott NG-4 filter using the NBS high-accuracy instrument and a conventional spectrophotometer. .

$$
\text { LIST OF FIGURES }
$$

Figure

1a, Contrul chart for a spectrophotometer showing

Ib. the variation of transmittance as a function of time for a neutral glass filter at $635.0 \mathrm{~nm}$

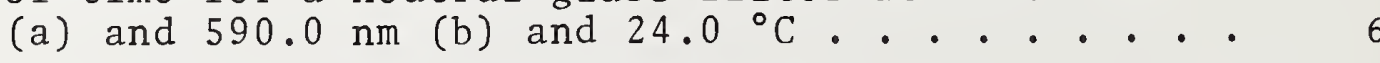

2. Transmittance of a didymium glass filter . . . . 9

3. Transmittance of a holmium oxide glass filter. • 10

4. Spectral characteristics for five transparent materials from $200 \mathrm{~nm}$ to $700 \mathrm{~nm}$. . . . . . 
Figure

5. Influence of spectral bandpass on the transmittance of a Chance $O N-10$ glass filter measured at $400 \mathrm{~nm} ; 445 \mathrm{~nm} ; 490 \mathrm{~nm}$; and $590 \mathrm{~nm}$. . . . .

6. Influence of spectral bandpass on the transmittance of a Schott NG-4 glass filter measured at $440 \mathrm{~nm} ; 465 \mathrm{~nm} ; 590 \mathrm{~nm}$; and $635 \mathrm{~nm}$......

7. Illustration of the relation between radiation flux intensities $F$ and corresponding photocurrent I in an ideal case . . . . . . . . . . . . .

8. Instrumentation to examine, clean, and mount the glass filters used to produce SRM 930, a, b. . .

9. Stainless steel holder for six $50 \mathrm{~mm}$ by $50 \mathrm{~mm}$, and twelve $30 \mathrm{~mm}$ by $10 \mathrm{~mm}$ glass filters. . . .

10. Soxhlet extractors used for the final cleaning of the $50 \mathrm{~mm}$ by $50 \mathrm{~mm}$, and $30 \mathrm{~mm}$ by $10 \mathrm{~mm}$ glass filters, using isopropyl alcohol (electronic grade)

11. Schematic description of the aluminum alloy holder with its bronze retaining spring used to hold the glass filters............

12. View of the assembled and unassembled glass filter holder. . . . . . . . . . . . . . .

13. Plastic box for SRM 930 b containing the three glass filters in their holders.......... 

G1ass Filters as a Standard Reference Material for spectrophotometry

Selection, Preparation, Certification, Use SRM 930

\author{
R. Mavrodineanu and $J$. R. Ba1dwin \\ Ana1ytical Chemistry Division \\ Institute for Materials Research \\ National Bureau of Standards \\ Washington, D.C. 20234
}

This publication describes various factors which can affect the proper functioning of a spectrophotometer and suggests means and procedures to assess and control these factors. Particular consideration is given to the long and short term stability of a spectrophotometer, to the wavelength accuracy, the spectral bandpass, the stray radiation, and the accuracy of the transmittance or absorbance scale. A description is given of the means and Standard Reference Materials (SRM's) which can be used to control these factors, together with the methods for the preparation, certification, and use of such materials (SRM 930). The results obtained in actual use of SRM 930 are examined in some detail. An Appendix contains the reproduction of several publications relevant to the subject discussed in this work.

Key Words: Accuracy in spectrophotometry; glass filters; spectral bandpass; spectrophotometry; standard reference materials; stray radiation; testing of spectrophotometers; transmittance (absorbance) accuracy; wavelength accuracy. 
Among the measuring techniques available to the analyst for the detection and determination of a large number of chemical species in a large variety of matrices, spectrophotometry constitutes a valuable tool of major significance. This is due largely to the inherent characteristics of high sensitivity and good specificity of the method, associated with the need for only relatively simple instrumentation and straightforward sample preparation methodology. For these reasons spectrophotometric procedures are used in practically all fields of science, where chemical analytical measurements are required. As mentioned by Rand (1) of 147 analytical procedures used in clinical chemistry laboratories, 84 require the use of spectrophotometry, and of 430,000 analyses per year, performed only in one hospital, 300,000 required measurements by spectrophotometric procedures. In such a laboratory, 800 to 1,000 determinations are made daily by spectrophotometry.

From the information given by Rand in 1972 (1), a conservative estimate of analyses made by spectrophotometry indicates that more than 1,000,000 such tests are performed daily in the clinical laboratories in this country, and this figure increases by approximately 15 percent per year.

These considerations refer to clinical laboratories, alone, and to these one should add the numerous other areas such as the general field of scientific research, industry, agriculture, environmental sciences, etc., where spectrophotometry represents a major analytical technique.

In spite of this wide use of spectrophotometry, no suitable standards were available to verify the stability of the spectrophotometer, and no adequate reference material was available to verify the accuracy of the transmittance or absorbance scale of the instrument. This situation is even more surprising when one considers the wide discrepancies obtained in interlaboratory comparisons of spectrophotometric data $(2,3,4,5,6,7)$. Under these circumstances a program was initiated at the National Bureau of Standards (NBS) in the Analytical Chemistry Division of the Institute for Materials Research in July 1969, with the objective to provide the analytical chemist with means to verify that his spectrophotometer functions properly and that it produces reliable and meaningful data. This decision was taken in response to the requests received from scientists using spectrophotometry in all areas of science, and more specifically from the analytical chemists who use spectrophotometry in clinical and pathological laboratories (8). 
The planned program was implemented in 1970 through the design and construction, in the Analytical Chemistry Division, of a high-accuracy spectrophotometer $(8,10)$ which was used to produce two Standard Reference Materials (SRM's), SRM 930 (a and b), Glass Filters for Spectrophotometry, and SRM 931, Liquid Filters for Spectrophotometry. These SRM's were issued in 1971. A third SRM 932, Quartz Cuvettes for Spectrophotometry, was added in 1973 and was produced in association with the Optical Physics Division of the Institute for Basic Standards at NBS. SRM 932 was intended to be used in association with SRM 931 and for all measurements requiring accuracy in the determination of transmittance in solutions. A detailed description of this SRM and of the techniques developed at NBS for its production and certification is given in reference 9 which is reproduced in the NBS Special Publication 260-32, issued in December 1973. This publication is available from the U. S. Government Printing Office, Washington, D.C. 20402, under SD Catalog No. C13.10:260-32, price 55 cents.*

SRM 930 (a,b) consists of a set of three glass filters having nominal transmittances of 10,20 , and 30 percent from $440 \mathrm{~nm}$ to $635 \mathrm{~nm}$. These glasses are calibrated and certified for optical transmittance at $440.0 \mathrm{~nm} ; 465.0 \mathrm{~nm} ; 590.0 \mathrm{~nm}$; and $635.0 \mathrm{~nm}$. These wavelengths were selected in accordance with the transmission characteristics of the glass. An additional certification at $546.1 \mathrm{~nm}$, corresponding to the mercury green radiation, was provided with the more recent SRM 930b. SRM 930 is a transfer standard reference material which can be used to determine and monitor the short and long term stability of a spectrophotometer and to verify the accuracy. of its transmittance and absorbance scales.

This publication is intended as a practical guide for the proper calibration of spectrophotometers and the use of SRM 930 and contains data presented in a simple and straightforward manner. The reader interested in the more fundamental problems associated with high-accuracy spectrophotometry and luminescence measurements is advised to consult the publications listed in reference 10 together with the papers mentioned in those publications. Reprints from several papers closely related to the subject discussed in this publication are reproduced here in the Appendix Section as a convenience to the reader.

* See Appendix 1 for NBS-SRM ordering information. 
Factors Affecting the Proper Functioning of a

Spectrophotometer

There are a number of factors which can affect the proper functioning of a spectrophotometer and prevent the acquisition of meaningful data. Some of these factors are:

a. The short and long term stability.

It is related to the instruments mechanical, optical, and radiation measuring design and to the quality of the materials and workmanship used to implement the design. The conditions under which the instrument is operated, such as vibration, humidity and temperature, dust and corrosion, will also affect its stability. Other critical factors are the short and long term stability of the radiation source, the reproducibility of the positioning of the sample holder and carriage, and the stability of the read-out system.

b. The wavelength accuracy.

This is a function of the stability of the optical system and of the accuracy of the wavelength scale, or wavelength cam, and its reproducibility.

c. The spectral bandpass of a spectrophotometer.

This is the spectral interval $\Delta \lambda$ in wavelength which emerges through the exit slit $w$ of the instrument: $\Delta \lambda=\mathrm{w} \frac{\mathrm{d} \lambda}{\mathrm{dx}}$, where $\frac{d \lambda}{d x}$ is the linear dispersion of the spectrophotometer. It is a parameter which depends on the optical design and of the associated elements: grating, prism, or filters used in the instrument. The magnitude of the spectral bandpass for a specific spectrophotometer over the whole spectral range of the instrument is important information that is provided by the manufacturers of the particular instrument.

d. The accuracy of the transmittance or absorbance scales.

This is the capability of a spectrophotometer to measure ratios of radiant fluxes with a known accuracy and to produce true transmittance (T) or absorbance (A) measurements. This fundamental parameter is determined ultimately by the linearity of the detection system, when the other parameters such as wavelength accuracy, adequate spectral bandpass, and photometric precision are under control. 
e. Stray radiations.

They can originate in the spectrometer and in the sample compartment. The stray radiation produced in the spectrometer is the radiant energy at wavelengths different from those of the nominal spectral bandpass transmitted through the instrument at a particular wavelength. The stray radiation in the sample compartment is the radiant energy which falls on the photosensitive detector without passing through the absorbing sample.

f. Conditions associated with the stability of the analytical sample (color reaction) and its homogeneity.

Dissociation and association reactions, radiation scatter inside the sample, polarization, fluorescence, temperature, particulate matter, and surface conditions can affect, in a significant manner, the accuracy of the measurements.

These conditions are characteristics of the analytical sample and of the chemical reactions involved in the spectrophotometric process and are to a large extent independent of the spectrophotometer used for the measurements. However, since these factors can affect the precision and accuracy of the measurement, they are mentioned here to remind the analytical chemist that he must be aware of their existence, and that he must evaluate their magnitude in the particular analytical process considered before proceeding with the actual measurement. As a result of his knowledge, he must be able to select the most adequate analytical procedure for the matrix and chemical species under consideration, and to establish ways to eliminate, minimize, or compensate for these causes of errors.

From the factors mentioned above, those which are relevant to the subject discussed in this publication will be examined in more detail.

3. MEANS AND PROCEDURES TO ASSESS AND CONTROL SOME OF THE FACTORS WHICH AFFECT THE PROPER FUNCTIONING AND ACCURACY OF A SPECTROPHOTOMETER.

3.1 Short and Long Term Stability

The short and long term stability of a spectrophotometer can be verified and monitored by using glass filters specially selected for this purpose. Stable radiation sources, such as tritium-activated luminescent materials, could be considered for the same purpose (11). The use of such a source, however, is not always possible due mainly to problems associated with the design and operation of the instrument. 

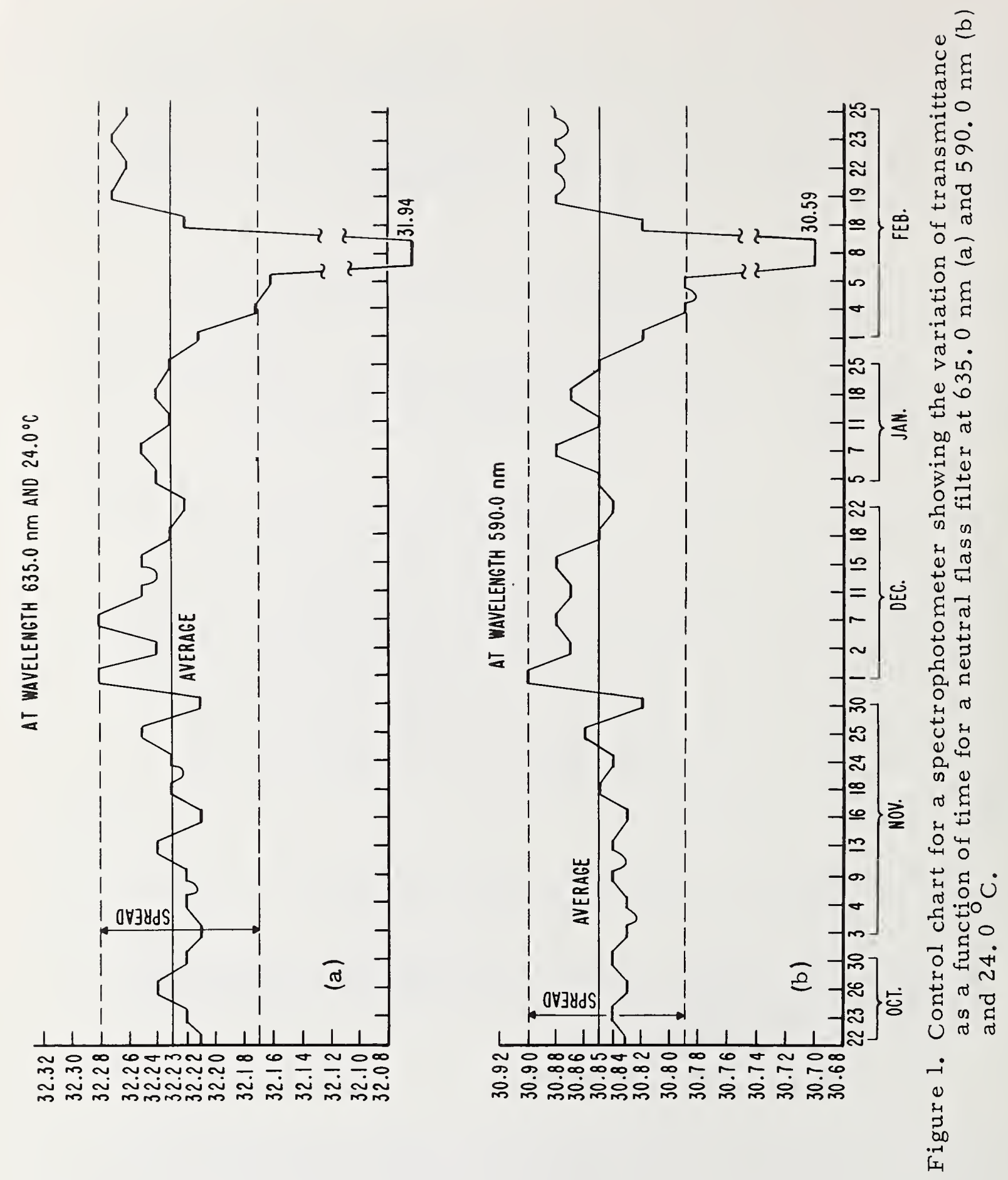
From the several kinds of glass filters which can be used, those constituting SRM 930 ( $a$ or b) are most suitable. The optical characteristics of these glass filters are discussed in Section 4; however, since the stability of a spectrophotometer is the first test which should be carried out, we will describe their use now.

As a general rule, it is desirable to place the spectrophotometer in a clean laboratory and in an area where the temperature is as constant and reproducible as possible, protected from direct sunlight, sudden changes of temperature, corrosive atmosphere, dust, and vibration.

The tests should be carried out after the instrument was verified by the manufacturer, and was found to perform well and to meet all the required specifications. After an initial warming-up period, the "0" and "l00" reading on the scale is verified, following the procedure described by the manufacturer of the particular instrument, the wavelength dial is set at a selected value, usually the one at which the transmittance of the analytical sample will be determined, e.g. $635.0 \mathrm{~nm}$, and one of the glass filters in its metal holder having the nominal transmittance of 30 percent is inserted in the sample compartment. The reference compartment or "blank" is left empty. The transmittance of the glass filter is measured following the method specified by the manufacturer, and the results recorded. This procedure is repeated at all wavelengths at which the analytical samples will be measured. Similar transmittance measurements are performed using the glass filters having a nominal transmittance of 20 percent and 10 percent. The temperature at which these measurements are made should also be recorded. In this manner, the performance of the instrument is determined over the working spectral range for a transmittance interval and at a temperature which covers most of the conditions of analytical determinations under consideration.

The values obtained are then displayed in a graphical form, by plotting the transmittance found for every wavelength on the ordinate, and on the abscissa the date at which these measurements were made. An example of such a graph is given in figures $1 \mathrm{a}$ and $\mathrm{b}$ for only two wavelengths: $635.0 \mathrm{~nm}$ and $590.0 \mathrm{~nm}$. Similar graphs should be made for the wavelengths of interest and for the 10 percent, 20 percent, and the 30 percent nominal transmittance filters. Since the laboratory in which the measurements shown in figure 1 were made is provided with controls which maintain the surrounding temperature at $24.0{ }^{\circ} \mathrm{C} \pm 1{ }^{\circ} \mathrm{C}$, this was recorded on the graphs as a common value for all measurements. When solutions are used, the temperature of the liquid in the cuvette should be determined. Where the temperature changes from measurement 
to measurement, its value should be recorded and written on the graph under the corresponding transmittance value. The procedure described above should be performed every time the spectrophotometer is used, before, and preferably after, the analytical work is carried out.

The data plotted in figures $1 \mathrm{a}$ and $1 \mathrm{~b}$ were obtained with a commercial spectrophotometer provided with a quartz prism double spectrometer, and a transmittance scale divided in 1000 units between 0 and 100 transmittance readings. The size of each division and the stability and reproducibility of the instrument is such that it permits visual interpolation between each division, to fractions of a division; hence, the ordinate scale on the graphs (figs. la and b) was selected to reflect this resolution.

An examination of the data shows that the stability of the instrument as expressed by the transmittance value, operated at $24.0^{\circ} \mathrm{C}$, and from october 22 to February 5 , varied from 32.17 percent $\mathrm{T}$ to 32.28 percent $\mathrm{T}$ with an average of $32.23 \mathrm{~T}$ percent at $635.0 \mathrm{~nm}$. At $590.0 \mathrm{~nm}$ the equivalent values were 30.79 percent $T$ and 30.90 percent $T$ with an average of 30.85 percent $T$. The spread is in both cases 0.11 percent of $T$. This spread results from the inherent instability of the instrument and of the glass filters used. This situation changed markedly on February 8 when a transmittance of 31.94 percent and 30.59 was found at $635.0 \mathrm{~nm}$ and $590.0 \mathrm{~nm}$ respectively. Since these values largely exceeded the specified spread established for this particular instrument by the manufacturer, a field engineer from the manufacturer was called in. An examination of the spectrophotometer revealed that a potentiometer was malfunctioning. After replacement of this faulty part the instrument was tested again on February 18 , and the transmittance values, measured on the same glass filters, were within the established spread of the instrument, as seen in figures $1 \mathrm{a}$ and $1 \mathrm{~b}$, indicating that the spectrophotometer was again performing according to its specifications. This example illustrates the usefulness of the short and long term stability tests described in this paragraph since this permits detection and diagnosis of possible malfunctions in an instrument before such malfunctions would affect the validity of measurements. It is obvious that similar control charts can be prepared using absorbance values.

The periodic verification of the stability of spectrophotometers as described above and illustrated in figures la and $1 \mathrm{~b}$, is used in these laboratories routinely. This procedure is highly recommended to all users of such instruments, and is performed, as has already been mentioned, with the help of specially selected glass filters. It should be added here that the precision of such tests, however, cannot exceed the 

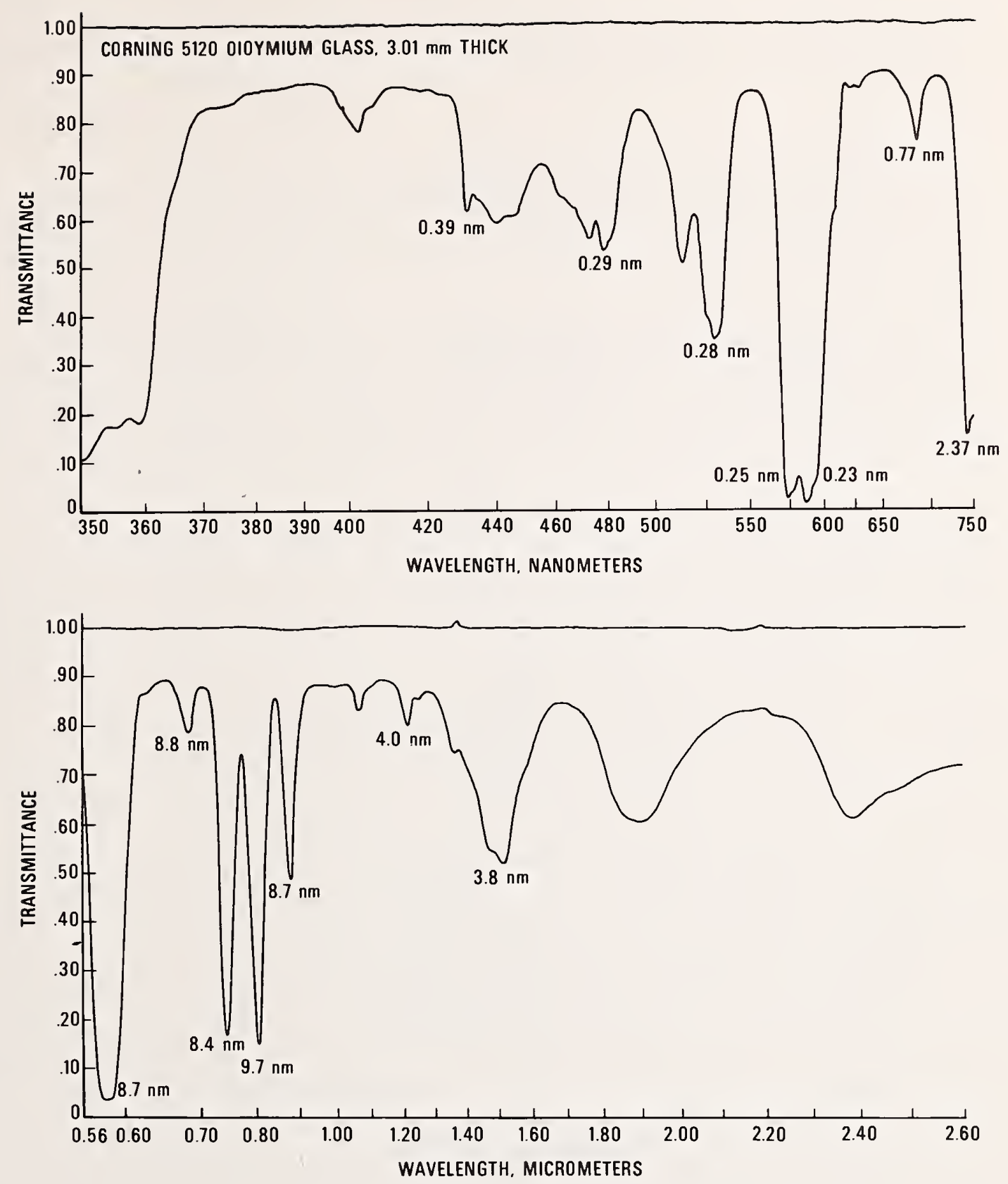

Figure 2. Transmittance of a didymium glass filter. The spectral bandpass used is marked at the corresponding transmittance minimum. Courtesy Corning Glass Works. 

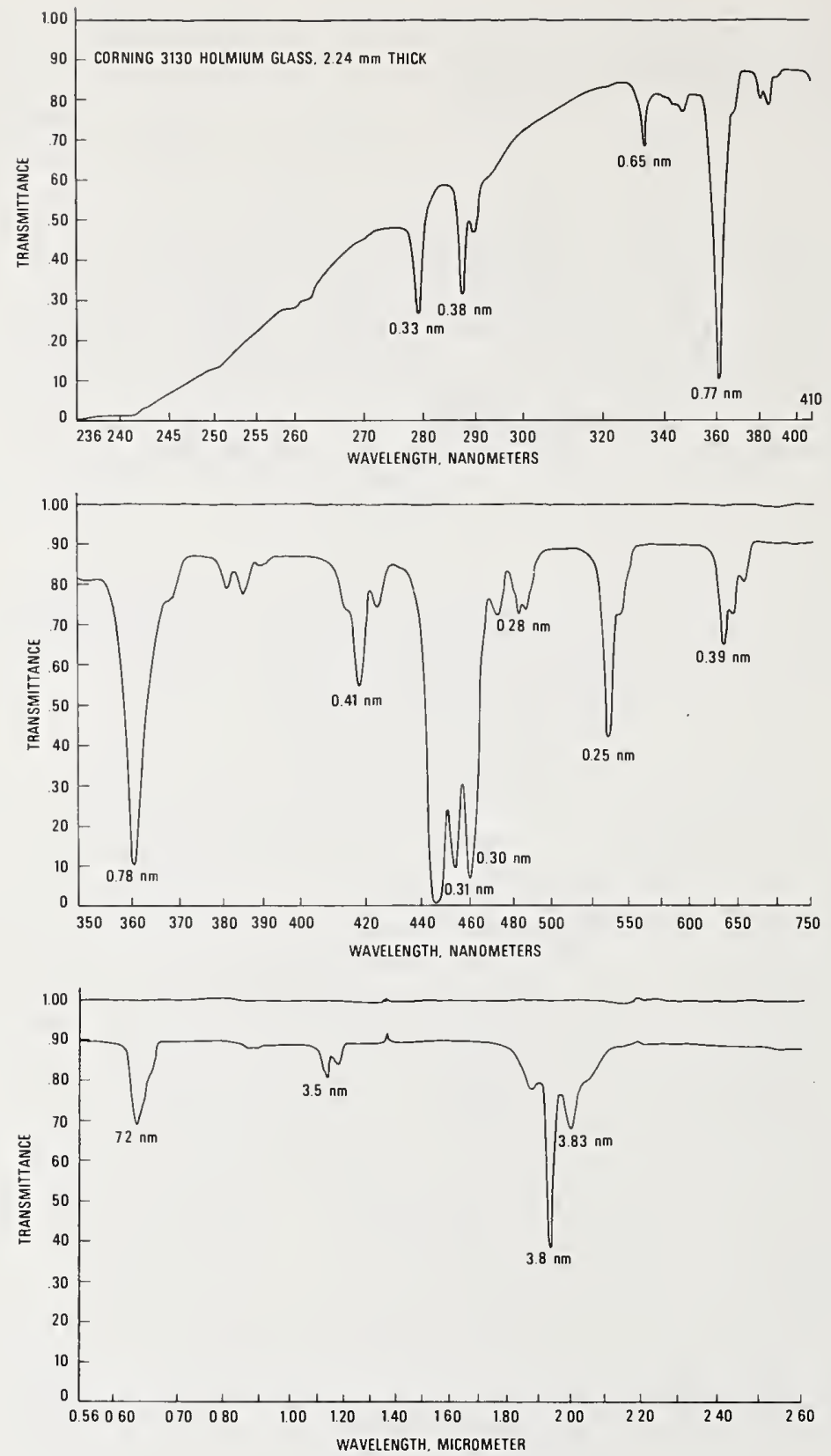

Figure 3. Transmittance of a holmium oxide glass filter. The spectral bandpass used is marked at the corresponding transmittance minimum. Courtesy Carning Glass Works. 
stability of the glass filters; this parameter will be discussed in Section 5.1 for the material used in this work.

\subsection{Wavelength Accuracy}

Although the test discussed in paragraph 3.1, may show that a spectrophotometer exhibits a good stability, large errors in the accuracy of its wavelength scale may produce unreliable measurements.

The wavelength accuracy of a spectrophotometer can be verified by the use of (a) an emission source capable of producing discrete radiations of suitable intensity and adequately spaced throughout the spectral range of interest, e.g., 200 to $800 \mathrm{~nm}$, or (b) by using glass filters with sharp absorption bands.

(a) Adequate sources of discrete radiation, of we11known wavelengths, most suitable for use in the calibration of the wavelength scale of a spectrophotometer, are the low pressure quartz discharge tubes containing mercury vapor, helium, or neon. Such tubes are available commercially from the manufacturers of laboratory instrumentation at reasonable prices. The discharge tube has a cylindrical shape with a total length of $120 \mathrm{~mm}$ from which a $50 \mathrm{~mm}$ portion constitutes the quartz discharge tube; this tube should be placed immediately in front of the entrance slit of the spectrometer.

(b) Wavelength calibrations can be made by using a glass filter having a number of strong and narrow absorption or transmission bands suitably spaced over the spectral range of interest. Two materials have been used or suggested for this purpose: glasses containing rare-earth oxides, such as didymium glasses and holmium oxide glasses. They have been used for many years at the National Bureau of Standards. The transmission characteristics of these two glasses are illustrated in figures 2 and 3.

A detailed description of the properties and use of low pressure discharge tubes and of glass filters with sharp absorption bands is given in an NBS Letter Circular LC-1017: "Standards for Checking the Calibration of Spectrophotometers" by K. S. Gibson, H. J. Keegan, and J. C. Schleter, reissued in January 1967. Part of this paper is reproduced in the Appendix Section of this publication (reprint 3). Further recommended practice can be found in the Manual on Recommended Practices in Spectrophotometry published by the American Society for Testing and Materials, 1916 Race Street, Philadelphia, Pa., 19103. 


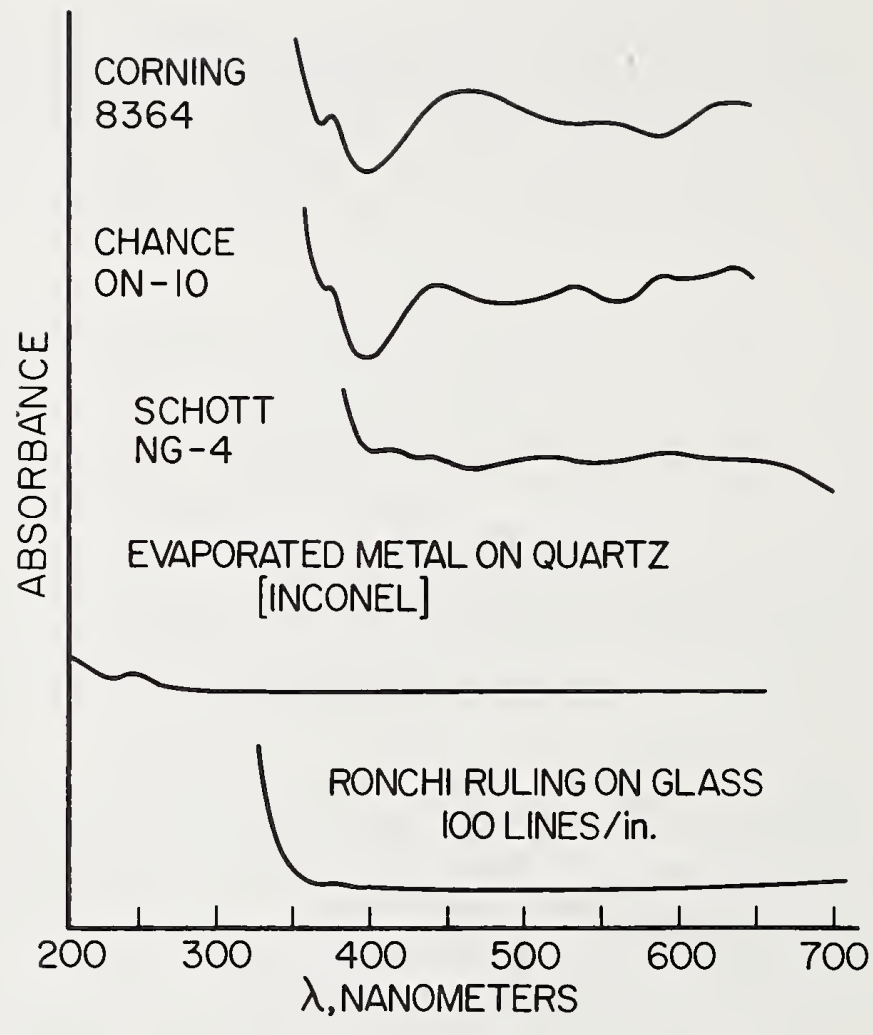

Figure 4. Spectral characteristics for five transparent materials from $200 \mathrm{~nm}$ to $700 \mathrm{~nm}$ (8). 
The Bureau is in the process of certifying as Standard Reference Materials didymium and holmium oxide glasses. These SRM's will have increased wavelength accuracy in comparison to and will replace the didymium and holmium oxide glasses offered by NBS through the Office of Measurement Services. For those who wish further information on this subject, the reader should consult W. H. Venable of the Institute for Basic Standards at NBS.

\subsection{Spectral Bandpass}

As mentioned in Section 2, the spectral bandpass over the entire spectral range for various slit widths is an instrumental parameter which should be provided by the manufacturer. For spectrophotometers with prisms or gratings, the spectral bandpass $(\Delta \lambda)$ is related to reciprocal linear dispersion $(d \lambda / d x)$ and slit width $(w)$ by $\Delta \lambda=w d \lambda / d x$. For example, for an instrument with a reciprocal dispersion of $15 \mathrm{~nm} / \mathrm{mm}$ and a slit width of $0.2 \mathrm{~mm}$, the bandpass is $3.0 \mathrm{~nm}$. For prism instruments, the reciprocal dispersion and therefore the bandpass vary with wavelength. The following discussion will be limited to the influence of this often neglected and important parameter on the measurements of transmittance for the glass filters discussed in this publication.

Two types of filters were used having a transmittance which varies only moderately with wavelength: the Chance* ON-10 and Schott NG-4 optically neutral glasses. A neutral glass \#8364 produced by Corning was also included in this study. However since this filter produced results similar to those found for the Chance ON-10 glass it will be discussed together with the later glass filter.

The transmission characteristics of these glasses as a function of wavelength in the spectral interval of $350 \mathrm{~nm}$ to $700 \mathrm{~nm}$ were obtained using a Cary 14 spectrophotometer and an adequate instrumental bandpass. The results are illustrated in figure 4, where it can be seen that the Corning 8364 and Chance ON-10 glasses exhibit similar characteristics. Figure 4 also shows that these glasses have an absorbance, or transmittance, more dependent on wavelength than the Schott NG-4 glass. The transmittance of these last two glasses was then

* The identification of commercial instruments and products is given only to permit reproduction of the work described in this publication. In no instances does such identification imply recommendation or endorsement by the National Bureau of Standards, nor does it imply that the particular equipment or product is necessarily the best available for the purpose. 


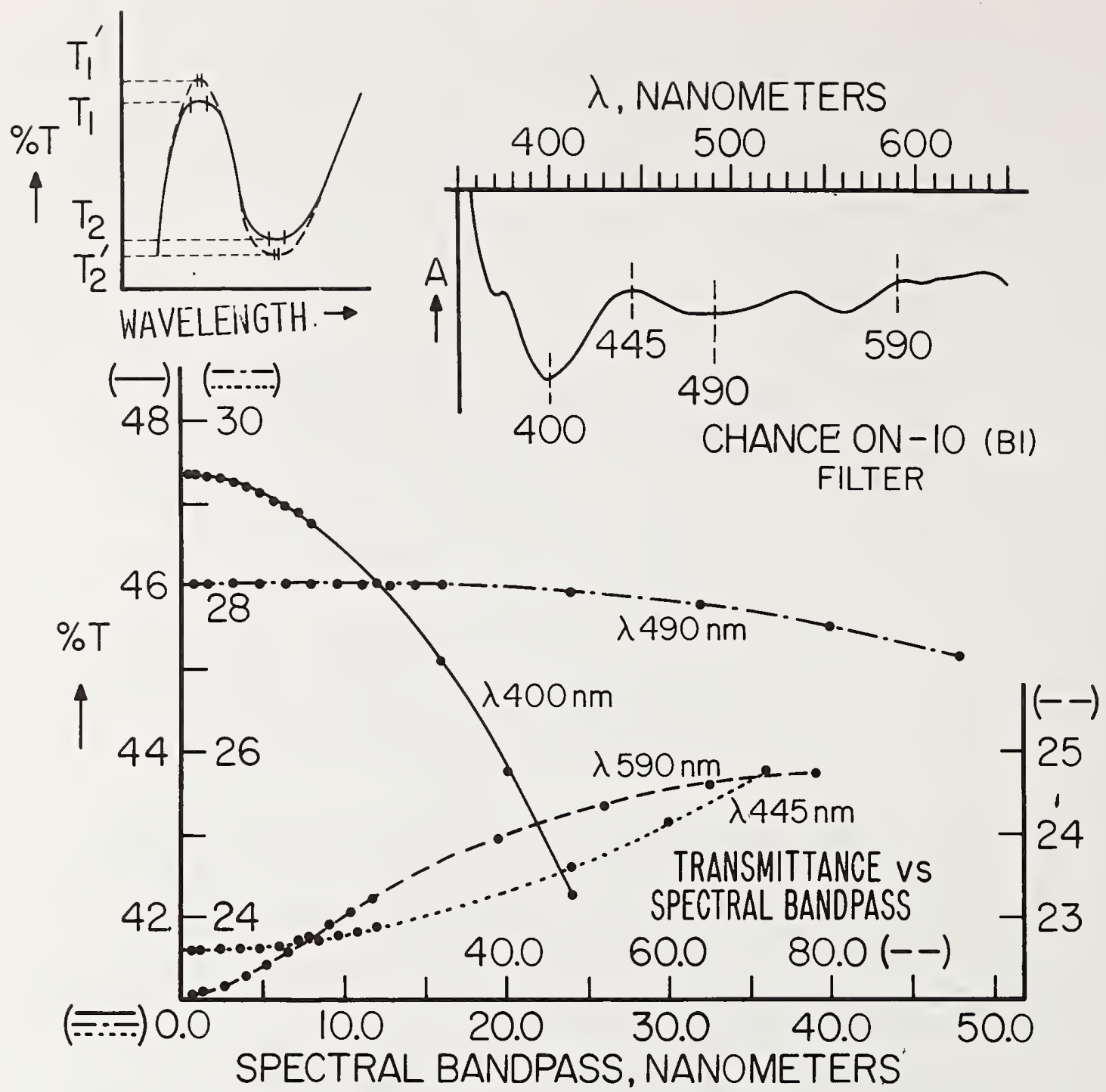

Figure 5. Influence of spectral bandpass on the transmittance of a Chance ON-10 glass filter measured at $400 \mathrm{~nm} ; 445 \mathrm{~nm}$; $490 \mathrm{~nm}$; and $590 \mathrm{~nm}$. The graph at, left, upper corner, describes in general the relation between spectral transmittance and spectral bandpass. Measurements made with a smaller bandpass 1 are susceptible to provide accurate $T$ values when compared with those made with a larger spectral bandpass $\mid$ (8). 
SCHOTT GLASS FILTER NG-4

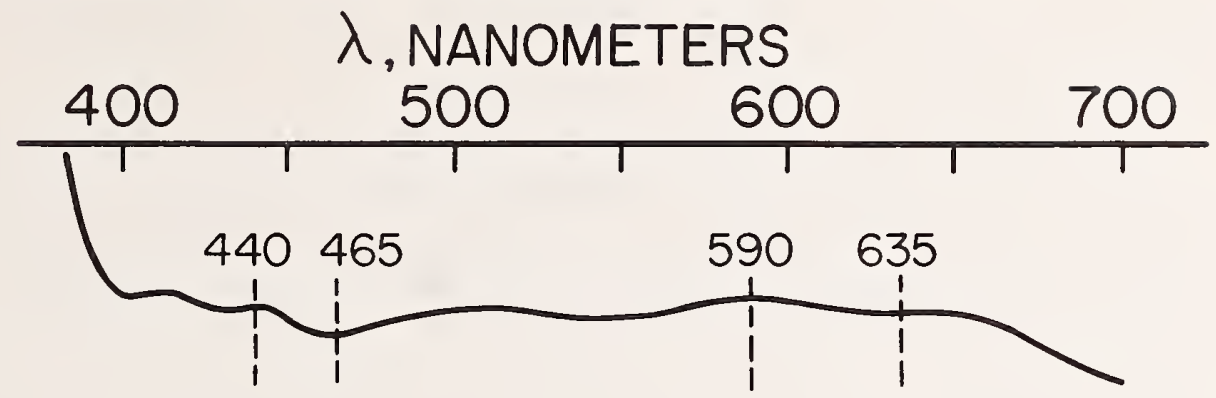

OPTICAL TRANSMITTANCE VERSUS SPECTRAL BANDPASS FORA SCHOTT GLASS FILTER NG-4

$\begin{array}{llllllll}0.0 & 5.0 & 10.0 & 15.0 & 20.0 & 25.0 & 30.0 & 35.0\end{array}$

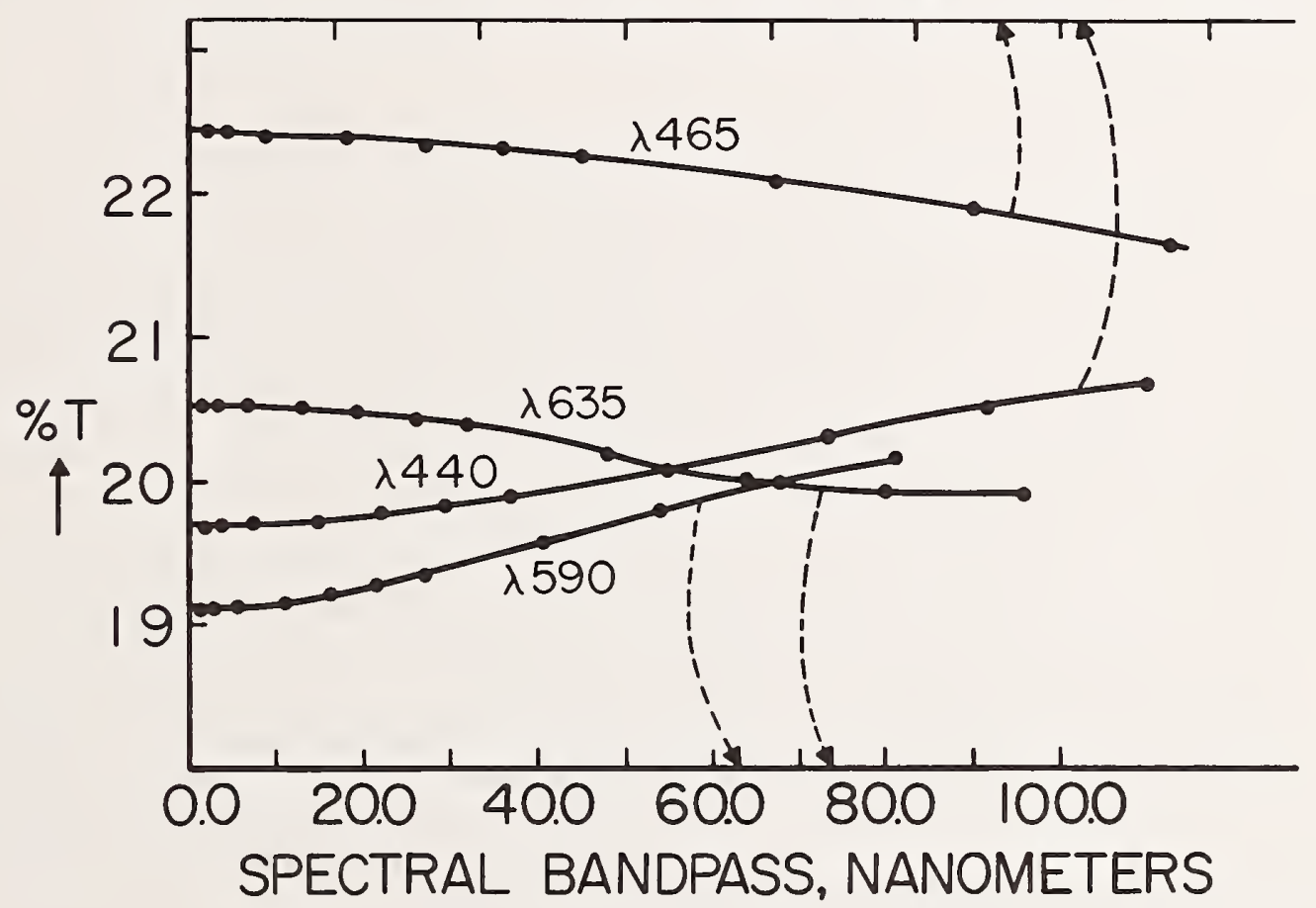

Figure 6. Influence of spectral bandpass on the transmittance of a Schott $\mathrm{NG}-4$ glass filter measured at $440 \mathrm{~nm}$; $465 \mathrm{~nm} ; 590 \mathrm{~nm}$; and $635 \mathrm{~nm}$ (8). 
measured at four wavelengths as indicated in figure 5 and 6 , using this time variable slit widths, and consequently various spectral bandpasses, from $0.5 \mathrm{~nm}$ to $100.0 \mathrm{~nm}$, using a Cary 16 spectrophotometer.

Figure 5 illustrates the dependence of the transmittance for the Chance $\mathrm{ON}-10$ (and Corning 8364) on the spectral bandpass at $400.0 ; 445.0 ; 490.0$; and $590.0 \mathrm{~nm}$. It can be seen that the transmittance varies with the bandpass, and that this dependence is stronger at the wavelengths where the glass has a stronger and sharper absorption band. For instance, at $400.0 \mathrm{~nm}$ a rather narrow spectral bandpass of $0.5 \mathrm{~nm}$ will be required for this type of glass to obtain an accurate transmittance value, everything else being equal and in particular the wavelength and photometric scale accuracy, while at $490.0 \mathrm{~nm}$ a spectral bandpass of $15 \mathrm{~nm}$ would be adequate. The same dependence, but to a smaller extent, is illustrated in figure 6 for a Schott NG-4 glass, and here it can be seen that larger spectral bandpasses could be used to produce accurate transmittance values.

This transmittance-spectral bandpass dependence is summarized in the graph from figure 5 at the upper left corner, where it can be seen that the use of wider spectral bandpasses will produce the inaccurate $\mathrm{T}_{1}$ and $\mathrm{T}_{2}$ values when compared with $\mathrm{T}_{1}^{\prime}$ and $\mathrm{T}_{2}^{\prime}$, which are theoretically the correct values. As a general rule the value of the spectral bandpass required to produce accurate transmittance measurements with an uncertainty not greater than 0.1 percent, should be $\frac{1}{20}$ of the symmetrical natural spectral bandwidth, at half intensity, of the material to be analyzed and at the wavelength at which the measurement is performed. When this information is not available, it can be determined by measuring the transmittance (or absorbance) of the material at the wavelength of interest, using various spectral bandpasses (or slit widths) as illustrated in figures 5 and 6 . The largest bandpass or slit width which can be used is given by the value found at the end of the horizontal portion of the transmittance-spectral bandpass curve.

The selection and use of adequate spectral bandpass is one of the indispensable conditions which must be fulfilled to obtain true transmittance values. 
3.4 Stray Radiations

The measurement of stray radiation in the monochromator, that is, the radiation energy at wavelengths different from those of the nominal spectral bandpass transmitted through the instrument, is not easy or infallible. A detailed discussion of this instrumental parameter was given in an ASTM Standard Method (13), which is reprinted in the Appendix, reprint 7 . The procedure recommended in this work should be used to determine this parameter in the spectral range of interest.

The stray radiation generated inside the photometric system is defined as the radiant energy which falls on the photosensitive detector without passing through the absorbing sample. This stray radiation is usually produced by reflections and scattering of radiations on the optical and mechanical parts located between the exit slit of the monochromator and the photodetector. The measurements can be performed using a maximum slit opening and by placing a front surface mirror at the sample position, which reflects to the instrument al1 radiations received from the exit slit imaged at the mirror surface. In this way, a maximum stray radiation condition will be generated in the spectrophotometer. The measurements should be performed at the wavelength of interest by determining the dark current of the photomultiplier with the shutter in the closed position at the photodetector. The mirror is then placed at the sample position, the shutter is opened and measurements should be made again. The differences between the two measurements are an indication for the presence and amount of stray radiation generated under these circumstances in the sample compartment of the -spectrophotometer.

\subsection{Accuracy of the Transmittance or Absorbance Scales}

This is an essential condition which must be fulfilled by a spectrophotometer for production of accurate transmittance or absorbance values.

Optical transmittance is due to an intrinsic property of matter and characterizes a particular transparent material. Since this parameter is not known a priori, it must be determined by experimental procedures.

True transmittance values can be obtained only by using accurate measuring techniques and by taking into consideration all factors which can affect and distort the data. In this discussion the optical transmittance $T$ of a solid material includes the reflection losses which occur at the airsolid interface. The internal transmittance $\mathrm{Ti}$ is defined 
as the transmittance of the material corrected for reflection losses. This internal transmittance can be calculated in principle from the transmittance by using the well-known Fresnel equations as shown in reprint 4 in the Appendix. The internal transmittance is obtained experimentally when the measurements are made using a blank sample in the reference beam of the spectrophotometer. When a blank is not available, as in the case of SRM 930, the measurements are made against air in the reference beam. Under these circumstances the resulting transmittance value includes the reflection losses (which are about 8 percent for a glass filter having an index refraction of 1.5). A discussion of this subject by Mielenz is given in reference 10 . The absorbance $A$ of a material is related to the internal transmittance $\mathrm{Ti}$ by the expression $A=-\log _{10} \mathrm{Ti}$ while the optical density $\mathrm{D}$. is related to the transmittance $\mathrm{T}$ by the expression $\mathrm{D}=-\log _{10} \mathrm{~T}$.

Transmittance is the ratio of two radiant fluxes. It is therefore necessary that the transmittance scale of the spectrophotometer be accurate. The transmittance of a particular material is also a function of wavelength; hence the wavelength scale of the monochromator should also be accurate, and appropriate spectral bandpasses should be used. These conditions were examined in the previous paragraphs. The measurements should be made using collimated radiation. Such radiations define unambiguously the actual path length through the transmitting medium, the reflection losses, and eliminate the effects of polarized radiations that are produced at the surface of the sample (See Appendix, reprints 4 and 5). Other important factors, already mentioned, which must be considered are: homogeneity and stability of the sample, radiation scatter inside the sample, interference phenomena, stray radiation, polarization, fluorescence, temperature, particulate matter, and surface conditions. Since transmittance measurements depend on a diversity of factors, meaningful values can be obtained only by defining the experimental conditions for obtaining transmittance data.

Spectrophotometers are used to perform two types of measurements:

(1) Quantitative determination of chemical species using the relation between optical transmission of the material, and the concentration as a measuring parameter. Under these circumstances, the photometric scale of the spectrophotometer is calibrated in meaningful units, using a series of reference solutions having known concentrations of the species to be determined, rather than values of optical transmittance.

The accuracy of the measurements is related solely to the accuracy with which the concentration of the reference 


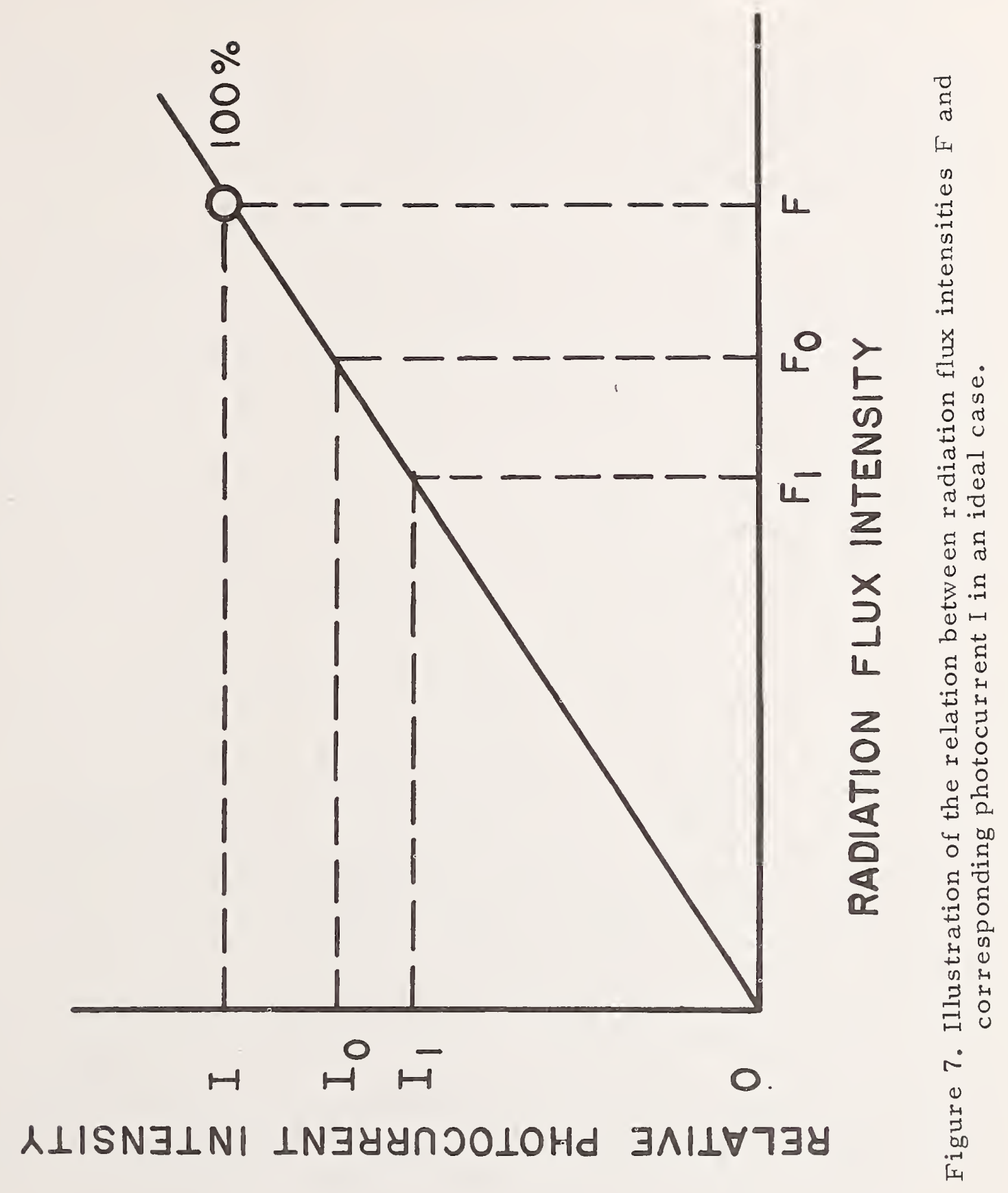


solutions is known and to the precision (stability, sensitivity) of the spectrophotometric method and instrument used. The accuracy of the transmittance or absorbance scale per se, is not a critical factor in such measurements.

The precision and stability of the instrument are, however, important parameters which should be verified before and after each series of measurements. This can be done, as already discussed, by the careful use of selected solid or liquid reference filters having well established and stable transmittance values.

(2) Determination of the optical transmission characteristics of solid or liquid materials, and the determination of certain physicochemical constants such as molar absorptivity and equilibrium constants. In all of these cases the accuracy of the transmittance or absorbance scales of the measuring instrument, among other things, is essential to provide true values. Ways to establish and check this important parameter are critically needed. For example, current interest in molar absorptivity values, as an index of the purity of biological clinical materials, requires greater accuracy of measurement. Also, the accuracy of the determination of equilibrium constants of chemical reactions in solutions and the determination of enzyme activity in international units is dependent on true values of their molar absorptivities.

Since transmittance is the ratio of two radiant fluxes intensities, true transmittance values will be produced only when this ratio is measured accurately. These measurements are usually performed by using photodetectors capable of generating signals proportional to the two fluxes. Transmittances are measured accurately when there is a linear relation between the two radiant fluxes and the resulting photoelectric signals. Hence, linear photoelectric measurements result in accurate transmittance values. This is illustrated in the simple graph (fig. 7) on which the abscissa represents arbitrary radiation flux intensities $F$ with the relative intensities $I$ on the ordinate. In an ideal case, when $F=0, I=0$; for a certain value of $F$, called here arbitrarily 100 percent, there corresponds a maximum. value of the photocurrent, I. These determine two fixed points on the graph, and any measurement of radiant flux intensity will be accurate if it falls on the straight line Which connects the origin 0 with the 100 percent point.

Photodetector linearity can be measured by various methods (11), but of these only the use of the inverse square law and the radiation addition principle using a plurality of sources or multiple apertures will be mentioned here. This last method was selected and used in conjunction with a spectrophotometer designed and built in the Analytical 
Chemistry Division at NBS (14). This instrument is described in detail in the Appendix (reprint 4). Its adaptation for work in the ultraviolet is described in reprint 6 of the Appendix.

Using this high-accuracy spectrophotometer, a series of glass filters was developed as Standard Reference Materials and were issued as SRM 930. SRM 930 consists of three neutral glass filters having transmittances of approximately 10,20 , and 30 percent. Each filter is individually calibrated and certified for transmittance over a spectral wavelength range from 440 to $635 \mathrm{~nm}$. These filters are intended to verify the accuracy of the transmittance or absorbance scales of spectrophotometers as well as their short and long term stability and to provide a means for interlaboratory comparisons of data. A further purpose of these filters is to assure that systematic errors due to a particular characteristic or condition of an instrument can be recognized.

SRM 930 ( $a$ and b) should be valuable in checking the calibration of instruments used to obtain accurate physicochemical constants such as molar absorptivity and equilibrium constants. For example, current interest in molar absorptivity values, as an index of the purity of biological clinical materials, requires greater accuracy of measurement. Also, as discussed earlier in this section, the accuracy in the determination of equilibrium constants of chemical reactions in solutions is dependent on true values of their molar absorptivities.

4. STANDARD REFERENCE MATERIALS FOR TRANSMITTANCE IN SPECTROPHOTOMETRY.

4.1 Selection and Preparation of Materials Which Can Be Used as Standard Reference Material in Spectrophotometry.

Such materials should fulfill the following conditions: (a) be transparent in the spectral range of interest, usually between $200 \mathrm{~nm}$ and $800 \mathrm{~nm}$; (b) have a transmittance independent of wavelength (optically neutral); (c) have a spectral transmittance independent of temperature; (d) have low reflectance and be free of interferences; (e) be non-fluorescent; (f) be stable, homogeneous, and free of strain; (g) have mechanical stability for the size used (thickness, length, width) and be easy to fabricate by conventional techniques used in optical shops; (h) be simple to use in conjunction with the conventional spectrophotometers available today in analytical laboratories; (i) be readily available and relatively inexpensive. 
These conditions are fulfilled to a smaller or larger extent by the following materials:

Transparent solids

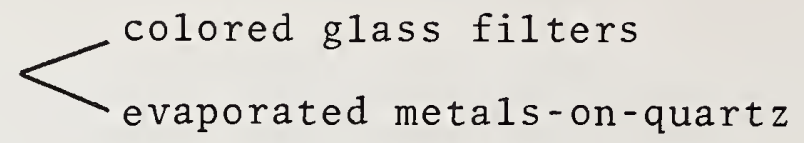

Transparent liquids

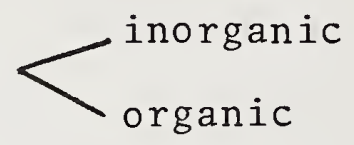

Grids

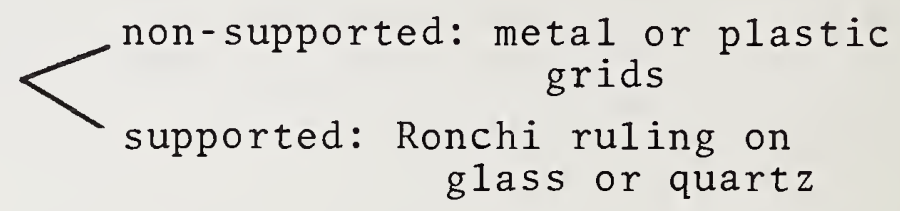

Rotating

Sectors

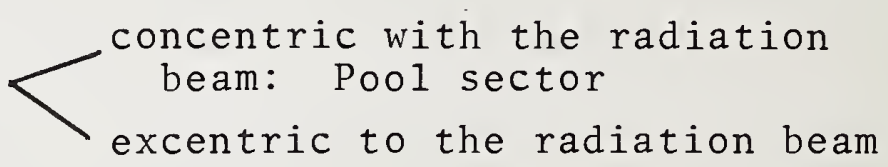

Polarizers

From these materials, the colored glass filters, mentioned in the first group, most nearly satisfied the required conditions and constitute the most acceptable compromise when compared with the other materials mentioned above.

Several colored glasses were examined, and from these the Corning 8364, the Chance ON-10, and the Schott NG-4 were initially selected. The spectral transmittance of these glasses is illustrated in figure 4 in comparison with an evaporated metal-on-quartz filter (non-fluorescent fused silica of optical quality) and a Ronchi ruling on a glass substrate. The transmittance of these two last materials exhibits the least dependence of wavelength from $200 \mathrm{~nm}$ to over $700 \mathrm{~nm}$ (the Ronchi ruling transmittance below $350 \mathrm{~nm}$ is limited only by the transmittance of the glass substrate and not by the nature of the ruling itself). However, since the attenuation of radiations is produced by the evaporated metal-on-quartz, through reflection rather than absorption, this material was not selected for the purpose considered here, since there is a possibility that reflected radiation is generated in conventional spectrophotometers. The Ronchi ruling was rejected since it is subjected, by its nature, to 


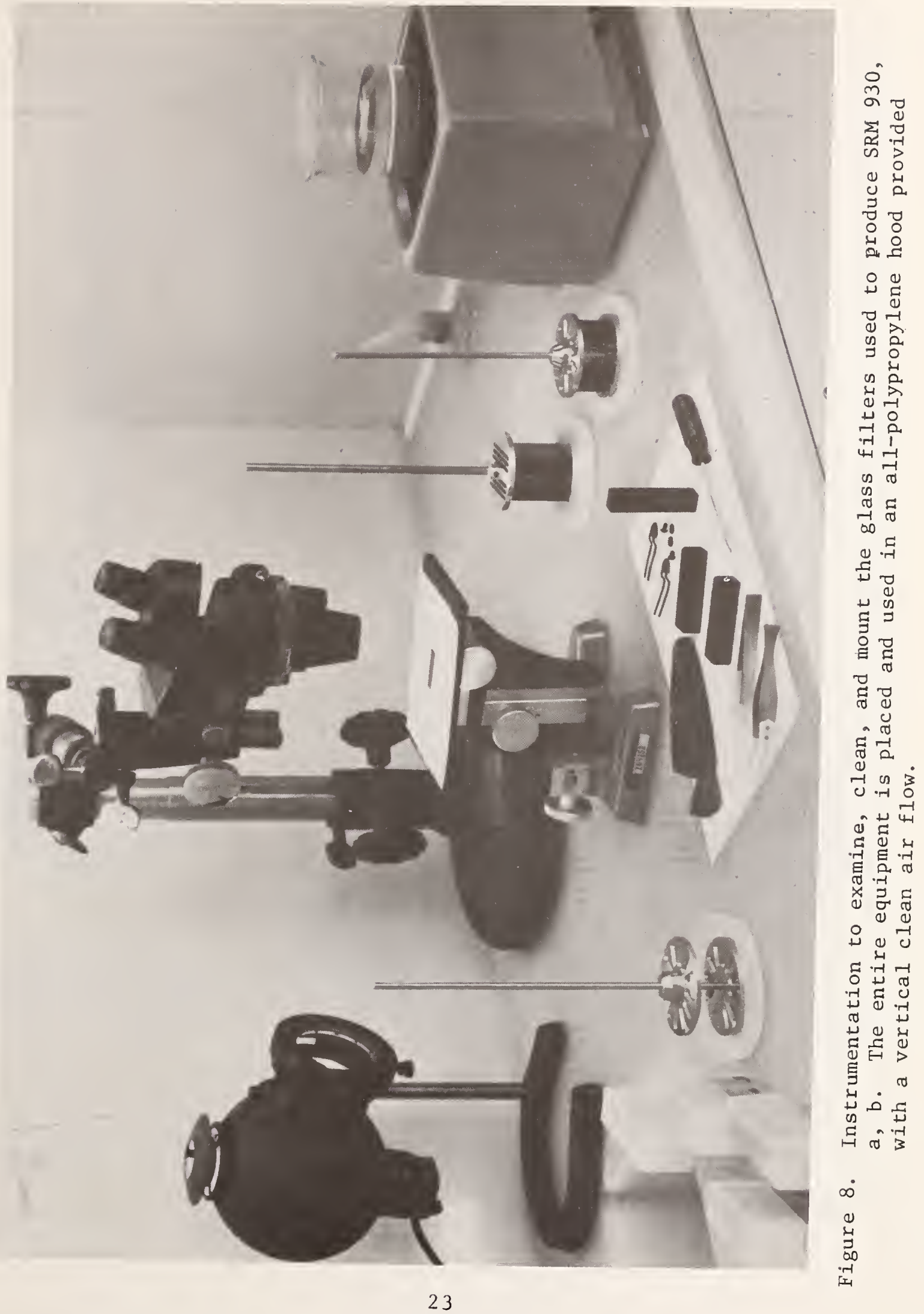


diffraction phenomena. From the remaining glasses, the Schott NG-4 type was finally selected since this material exhibits the best optical neutrality, and, excluding its limited spectral transmittance range to the visible and near-infrared spectral domain, it is the best material which satisfies the other conditions enumerated above.

A number of procedures were developed and used for the preparation of SRM 930 ( $a$ and $b$ ) and were tested in a variety of conditions. From these, only those which were finally selected and are used currently for the preparation of this SRM will be described here.

The optically neutral NG-4 and NG-5 glasses for the filters were produced by Schott of Mainz, Germany, and are designated as "Jena Colored and Filter Giass." The NG-5 glass is similar to the NG-4 glass in its spectral transmittance but is less absorbing. This permits the use of a thicker glass $(1.5 \mathrm{~mm})$ for the nominal 30 percent filter. These glasses are provided by the Fish-Schurman Corp., 70 Portman Road, New Rochelle, New York, 10802, in the form of rectangular pieces $30.5 \mathrm{~mm}$ long, $10.4 \mathrm{~mm}$ wide and $2.0 \mathrm{~mm}$ and $1.5 \mathrm{~mm}$ thick for the $\mathrm{NG}-4 \mathrm{glass}$ and $1.5 \mathrm{~mm}$ thick for the NG-5 glass. Corresponding to these thicknesses are nominal transmittances of 10,20 , and 30 percent, respectively. These transmittances were selected to provide a means to verify the short and long term stability of the instrument, and the accuracy of its transmittance or absorbance scale at the three different levels of transmittance at which most spectrochemical analyses are performed. A further specification for these filters is freedom of visible defects such as inhomogeneity, stains, inclusions and scratches. The parallelism should be within $0.02 \mathrm{~mm}$ and flatness should not exceed three fringes (mercury $546.1 \mathrm{~nm}$ radiation) over the entire glass surface.

\subsection{Preparation of the Glass Filters}

The glass filters are received from the supplier wrapped individually in lens paper and contained in small individual envelopes to avoid damage during transportation. Each glass filter is submitted to a preliminary manual cleaning, with distilled water using a piece of lens paper. This is followed by a preliminary examination for defects using a stereomicroscope with a magnification X12. This examination as well as the following cleaning procedures are performed in an all-polypropylene hood provided with a vertical laminar flow of filtered air, illustrated in figure 8. 


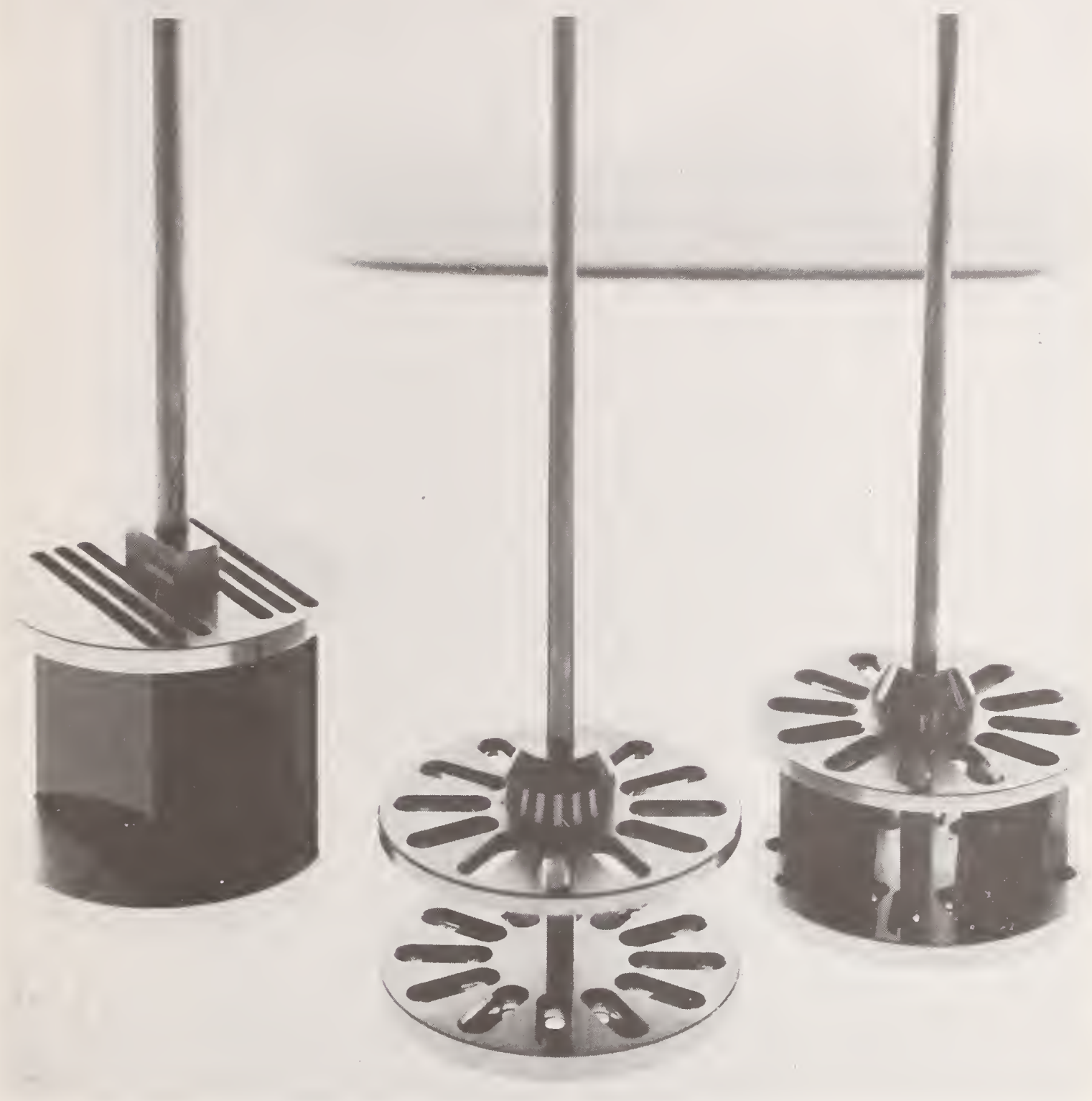

Figure 9. Stainless steel holders for six $50 \mathrm{~mm}$ by $50 \mathrm{~mm}$, and twelve $30 \mathrm{~mm}$ by $10 \mathrm{~mm}$ glass filters. 


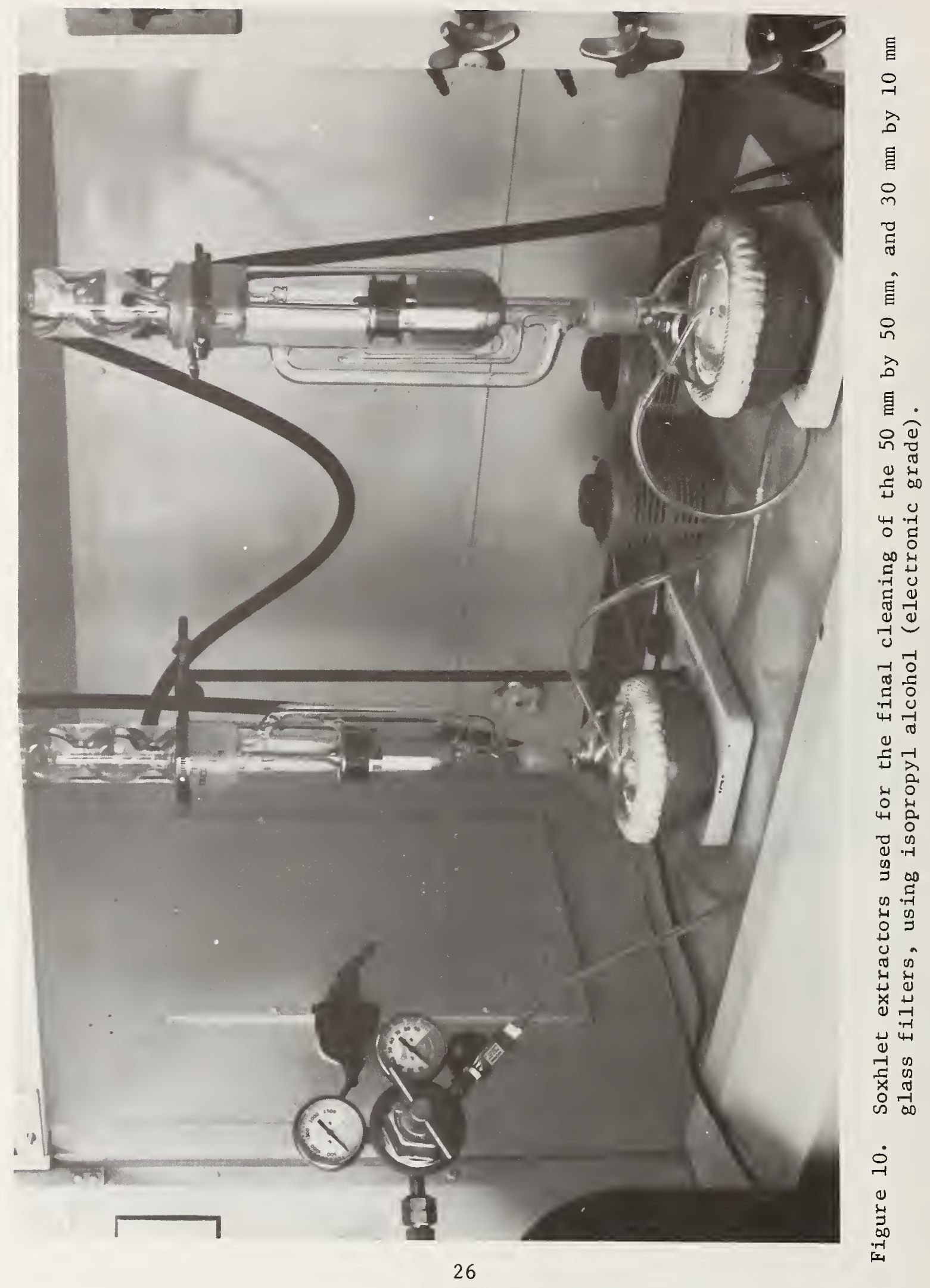


Each glass filter which has passed this initial examination is engraved at its upper end with a serial number using a diamond scriber and is placed in a stainless steel holder. Two types of such holders were developed and are illustrated in figure 8 , at left and lower right for twelve $30 \mathrm{~mm}$ by $10 \mathrm{~mm}$ units and at rear right for six $50 \mathrm{~mm}$ by $50 \mathrm{~mm}$ glass filters. These filter holders are shown in more detail in figure 9 , at left for the $50 \mathrm{~mm}$ by $50 \mathrm{~mm}$ and at right for the $30 \mathrm{~mm}$ by $10 \mathrm{~mm}$ glass filters. The holder is placed, in a borosilicate beaker which is then placed in an ultrasonic bath $(80 \mathrm{w})$ containing distilled water (shown at right in the figure (fig. 8)). Isopropyl alcohol of electronic grade is added to the beaker to cover the filters and the unit is operated for $5 \mathrm{~min}$. This operation eliminates all the glass particles produced by the engraving which could damage the glass surface of the filter during the subsequent cleaning operations. Each glass filter is then washed manually with a diluted aqueous solution of a nonionic detergent such as the alkyl phenoxy polyethoxy ethanol (Triton X-100, Rohm and Haas), rinsed with distilled water, and dried in air.

Each glass filter is then re-examined carefully under the stereomicroscope, and those which pass this final inspection are transferred in the 12 unit stainless steel holder and placed in a Soxhlet extractor illustrated in figure 10. An aluminum slug is inserted at the bottom of each extraction flask to reduce the volume of solvent required for the functioning of the extractor and to shorten the syphoning time. To avoid bumpy boiling, followed sometimes by an undesirable overflow of the isopropyl alcohol from the boiling flask into the extraction vessel, a side tube provided at the bottom with a coarse glass frit is inserted through the side of each flask. A steady stream of clean air from a compressed gas cylinder equipped with a gas regulator and needle valve, is passed through the tube to produce a continuous and gentle bubbling. The glass filters are then washed for 3 hours, at a rate of three syphoning per hour, using isopropyl alcohol of electronic grade. After this period the glass filters are dried in air in the laminar flow hood, placed individually in the special aluminum alloy holder designed in collaboration with $\mathrm{L}$. Monostori and made at NBS in the Instrument Shops. This operation is performed by using the tools illustrated in figure 8 , which includes an antistatic brush and plastictipped tweezers. The mounted filters, placed in a covered plexiglass box, are aged for at least two weeks in the laminar flow hood where they are exposed continuously to the radiation of the three fluorescent lamps provided at the top (total $120 \mathrm{w}$, arbitrarily chosen). Since the individual glass filter metal holder contributes significantly to the usefulness of the filters, it will be described below. 


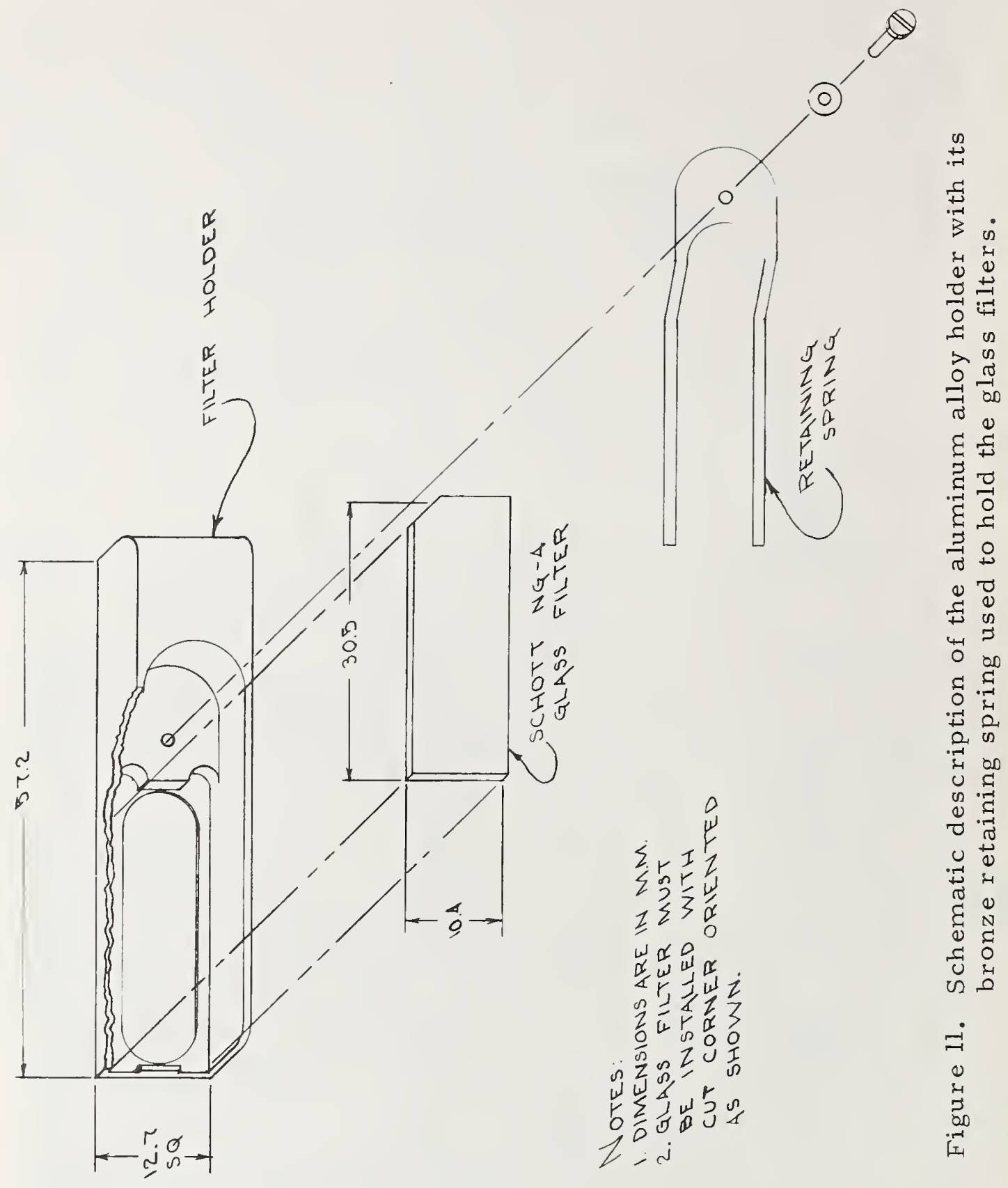




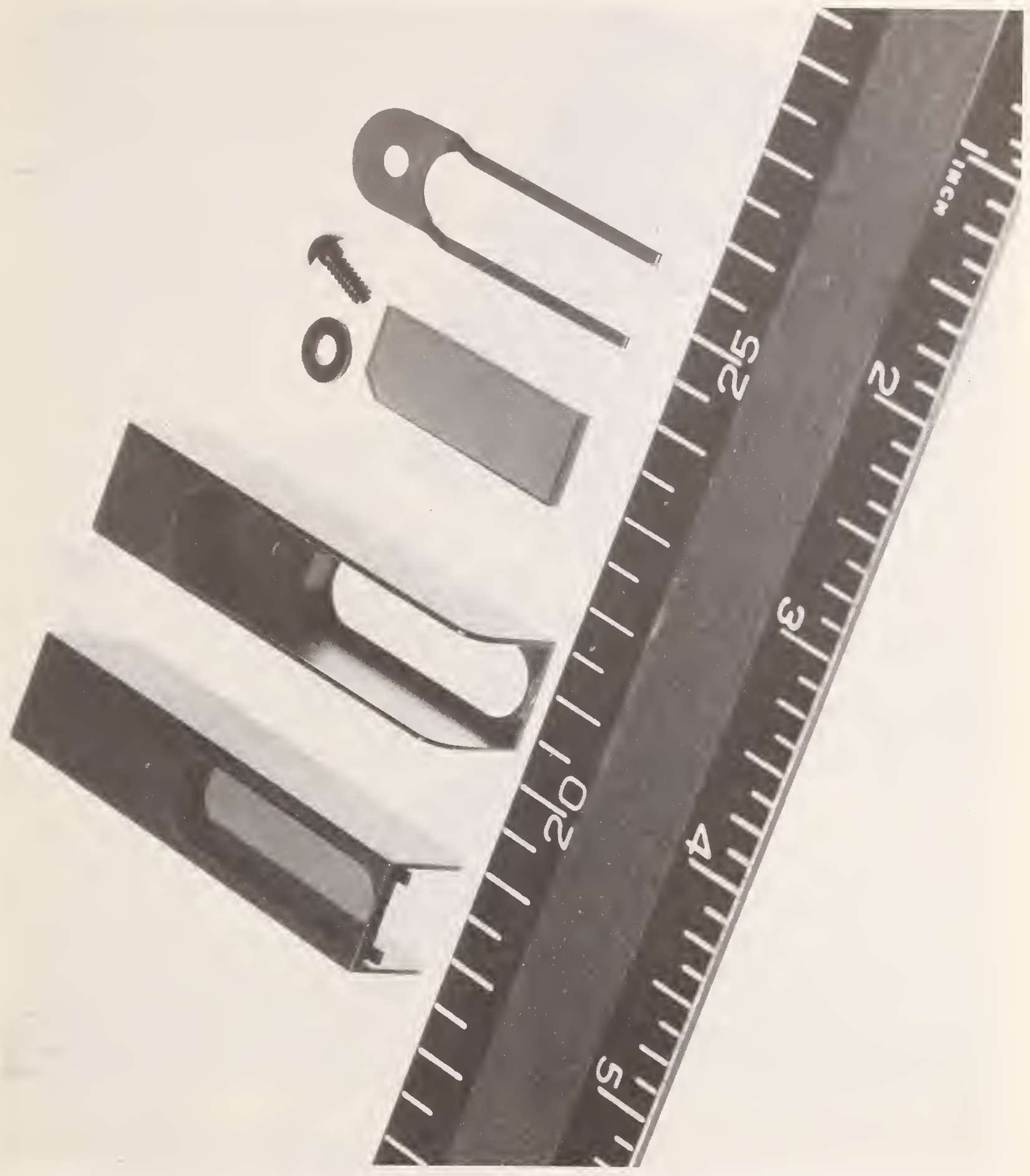

Figure 12. View of the assembled and unassembled glass filter holder. 


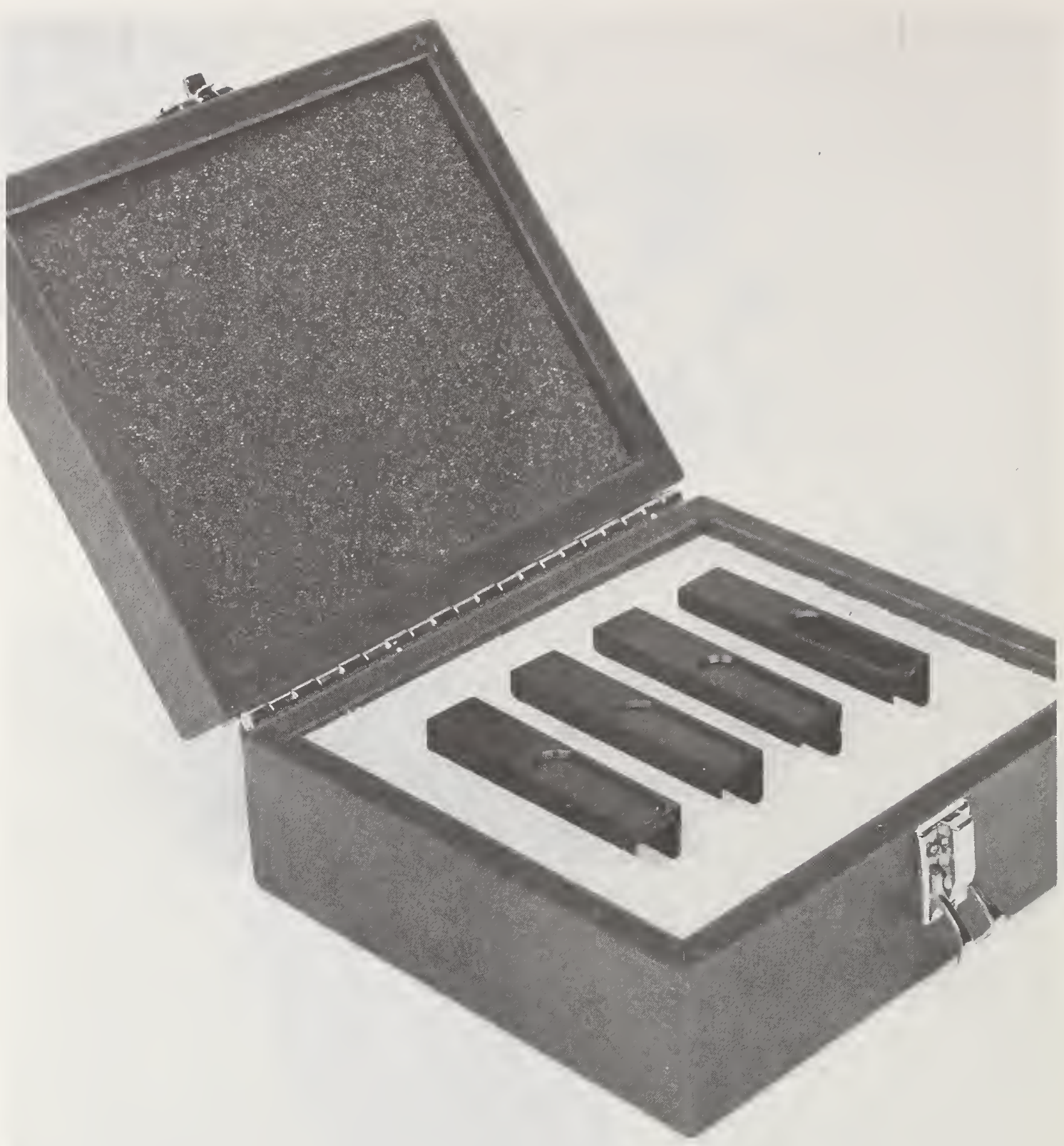

Figure 13. Plastic box for SRM 930 b containing the three glass filters in their holders. A fourth empty holder is provided for use in the reference beam. The grooved insert is made of polypropylene. 
The shape and dimensions of these metal holders are given in figures 11 and 12. They were established in conformance to the dimensions of the rectangular sample compartments of most conventional spectrophotometers, and were designed to hold the glass filters without producing mechanical strains in the material, as indicated by a polariscope examination. The metal used for the holder is an aluminum alloy $2024(4.5 \% \mathrm{Cu} ; 1.5 \% \mathrm{Mg} ; 0.6 \% \mathrm{Mn})$; the retaining two-pronged spring is made of phosphor bronze, and both parts are anodized black (flat). The spring is secured by a screw and washer made of nylon (black). The dimensions and shape of the window were selected to avoid vignetting even for spectrophotometers having a low pass radiation beam.

\subsection{Packaging of the Glass Filters}

Each set, consisting of three glass filters in their metal holder and having a nominal transmittance of 10,20 , and 30 percent, is placed in a plastic box similar to that shown in figure 13. The insert is made of polypropylene and the glass filters are placed in the metal holder described in figures 11 and 12; this constitutes SRM $930 \mathrm{~b}$.

This SRM is produced currently, and replaces SRM's 930 and $930 \mathrm{a}$. It differs from SRM 930 and $930 \mathrm{a}$ by an additional metal holder without glass filters. This empty filter holder should be placed in the reference beam when performing measurements. SRM's 930 and 930 a were certified at $440.0 \mathrm{~nm}$; $465.0 \mathrm{~nm} ; 590.0 \mathrm{~nm}$; and $635.0 \mathrm{~nm}$. An additional measurement at $546.1 \mathrm{~nm}$ was included for SRM $930 \mathrm{~b}$.

5. RESULTS

The transmittance measurements used in the certification of the glass filters discussed previously as well as those measurements which were made to assess the various characteristics of this material, together with interlaboratory comparative transmittance measurements, were made with the high-accuracy spectrophotometer described in Appendix 4, except the data from table 6 . Some of the measurements relevant to the topic covered in this publication will be given here.

\subsection{Stability of SRM 930}

As a rule, before taking measurements with the spectrophotometer, a warmup period of one hour is required. The room temperature is kept at $24 \pm 1{ }^{\circ} \mathrm{C}$, and the relative humidity is 35 percent: The particulate matter is controlled through special filters which rates the room in the 100,000 class. 
ahle 1. Influence of temperature on the transmittance (T) of seven Schott vis-4 glass filters at five wavelengths (nm).

T $:$ at

$25.5^{\circ} \mathrm{C} \quad 2 \cap .5^{\circ} \mathrm{C}$

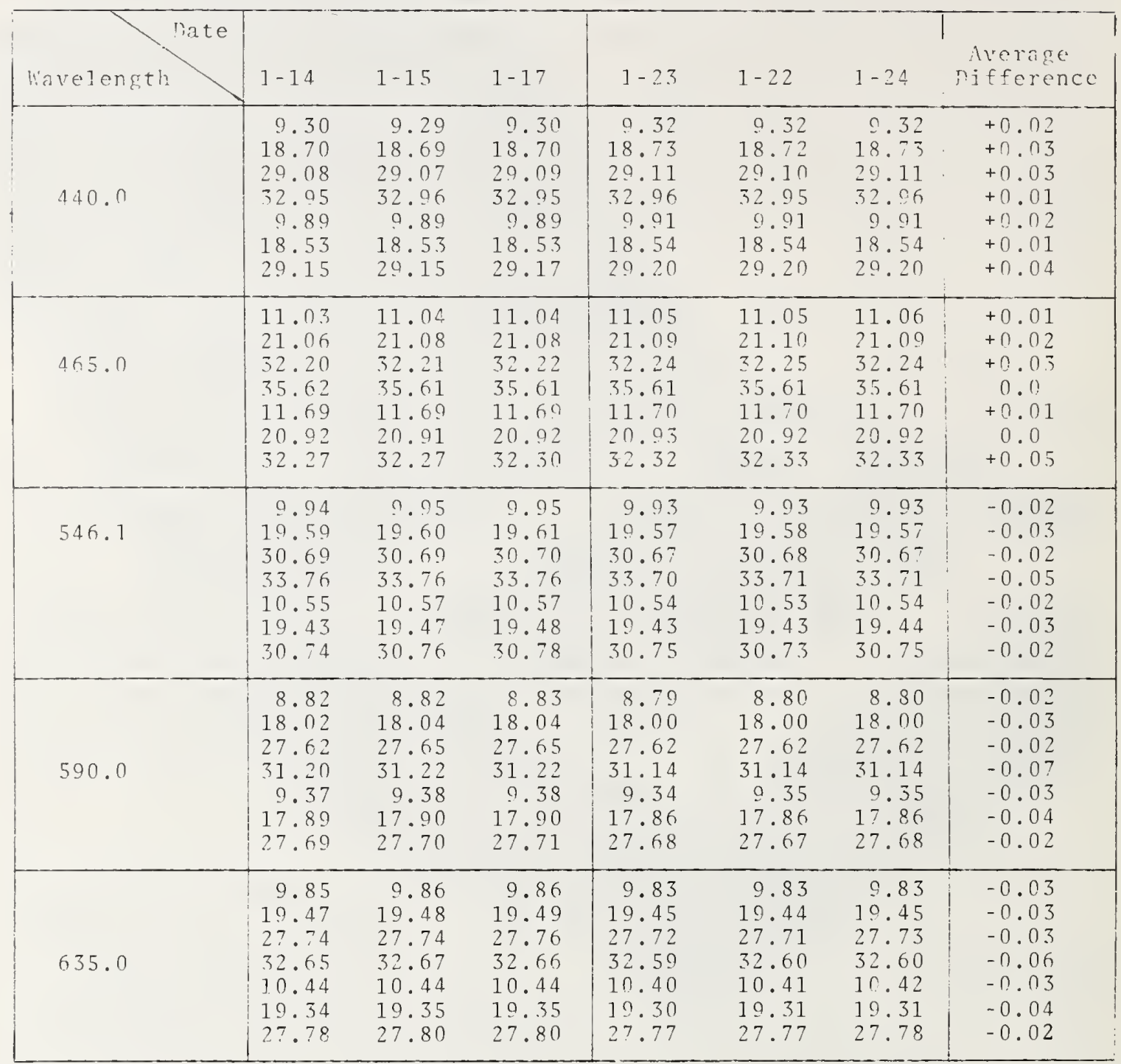


$\underset{4}{4}$
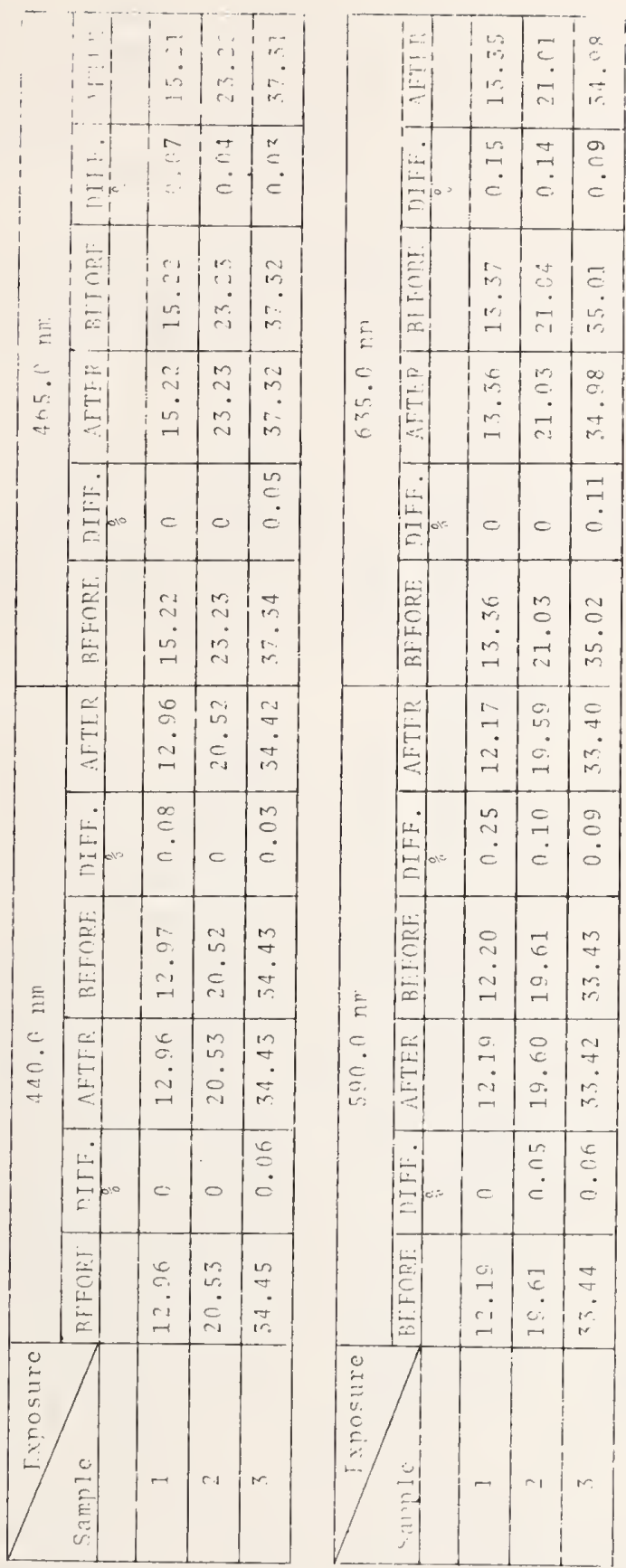
Seven glass filters were placed in the sample holder of the high-accuracy spectrophotometer and measured in six replications. The results are given in table 5 (see Appendix 4 ) and show that these measurements can be reproduced with a pooled relative standard deviation of 0.010 percent.

The temperature dependence of the transmittance was measured for the same type of glass by determining this value at a room temperature of $20.5^{\circ} \mathrm{C}$ and $25.5{ }^{\circ} \mathrm{C}$ and at $440.0 \mathrm{~nm} ; 465.0 \mathrm{~nm} ; 546.1 \mathrm{~nm} ; 590.0 \mathrm{~nm} ;$ and $635.0 \mathrm{~nm}$; and table 1 gives the results.

From these data it can be concluded that the transmittance dependence on temperature over the tested temperature range, in the spectral interval from $440.0 \mathrm{~nm}$ to $635.0 \mathrm{~nm}$, for the type of glass used is insignificant at the .95 confidence leve1. For a variation of $\pm 1{ }^{\circ} \mathrm{C}$ to $2{ }^{\circ} \mathrm{C}$ the dependance is minimal and averaged less than 0.2 percent of the measured transmittance values.

The stability of the Schott NG type of glass to visible radiations was tested by exposing three filters having a nominal transmittance of 10,20 , and 30 percent to the high intensity radiation of a source with a spectral distribution similar to the conventional fluorescent lamps used for illumination of laboratories. Each high intensity exposure lasted 21 hours and was equivalent to 21,000 hours of normal exposure. The transmittance measurements assembled in table 2 were made before and after each of the two exposures. Column 2 gives the transmittance of the glass filters at $440.0 \mathrm{~nm}$ before the exposure; column 4 gives the same measurements after the 21 hours of accelerated exposure. The difference between these two measurements is given in column 3. The same filters were exposed again for another 21 hours, and column 5 contains the transmittance values before this exposure, while column 7 gives these values after this second 21 hours exposure. The difference between these data (columns 5 and 7 ) is given in column 6. Measurements were also made at $465.0 \mathrm{~nm}, 590.0 \mathrm{~nm}$, and $635.0 \mathrm{~nm}$. From these data it can be concluded that the type of glass tested exhibits an acceptable stability when exposed to the visible radiation experiment described. Similar stability tests performed on other neutral glasses have indicated that these glasses were less stable by a factor of four when compared with the Schott NG-4 glass, and consequently this latter material was selected for SRM 930 (a and b). 
Table 3. Stability of transmittance ( $T$ ) as a function of time, measured on SRM 930 .

\begin{tabular}{|c|c|c|c|c|}
\hline \multirow{2}{*}{$\begin{array}{c}\text { liavelength } \\
\text { nm }\end{array}$} & \multicolumn{4}{|c|}{ 范 } \\
\hline & 1. & 2 & 3 & IАTE \\
\hline 440.0 & $\begin{array}{l}32.87 \\
32.88 \\
32.91 \\
32.96 \\
32.98 \\
32.94 \\
32.95\end{array}$ & $\begin{array}{l}19.80 \\
19.83 \\
19.81 \\
19.84 \\
19.84 \\
19.84 \\
19.84\end{array}$ & $\begin{array}{l}11.50 \\
11.62 \\
11.50 \\
11.61 \\
11.62 \\
11.61 \\
11.62\end{array}$ & $\begin{array}{r}5-18-71 \\
7-12-72 \\
8-30-73 \\
11-16-73 \\
1-9-74 \\
8-1-74 \\
1-13-75\end{array}$ \\
\hline 465.0 & $\begin{array}{l}35.53 \\
35.54 \\
35.54 \\
35.62 \\
35.63 \\
35.60 \\
35.60\end{array}$ & $\begin{array}{l}22.59 \\
22.62 \\
22.62 \\
22.62 \\
22.63 \\
22.62 \\
22.62\end{array}$ & $\begin{array}{l}13.56 \\
13.59 \\
13.59 \\
13.58 \\
13.58 \\
13.57 \\
13.58\end{array}$ & $\begin{array}{r}5-18-71 \\
7-12-72 \\
8-30-73 \\
11-16-73 \\
1-9-74 \\
8-1-74 \\
1-13-75\end{array}$ \\
\hline 590.0 & $\begin{array}{l}31.13 \\
31.14 \\
31.14 \\
31.21 \\
31.21 \\
31.18 \\
31.19\end{array}$ & $\begin{array}{l}19.16 \\
19.20 \\
19.20 \\
19.19 \\
19.20 \\
19.20 \\
19.20\end{array}$ & $\begin{array}{l}10.37 \\
10.41 \\
10.41 \\
10.40 \\
10.41 \\
10.40 \\
10.41\end{array}$ & $\begin{array}{r}5-18-71 \\
7-12-72 \\
8-30-73 \\
11-16-73 \\
1-9-74 \\
8-1-74 \\
1-13-75\end{array}$ \\
\hline 635.0 & $\begin{array}{l}32.55 \\
32.59 \\
32.59 \\
32.66 \\
32.68 \\
32.63 \\
32.64\end{array}$ & $\begin{array}{l}20.60 \\
20.65 \\
20.65 \\
20.65 \\
20.67 \\
20.66 \\
20.66\end{array}$ & $\begin{array}{l}11.37 \\
11.39 \\
11.39 \\
11.40 \\
11.41 \\
11.41 \\
11.40\end{array}$ & $\begin{array}{r}5-18-71 \\
7-12-72 \\
8-30-73 \\
11-16-73 \\
1-9-74 \\
8-1-74 \\
1-13-75\end{array}$ \\
\hline
\end{tabular}


Table 4. Comparison of percert transnittunce (s) reaslenents

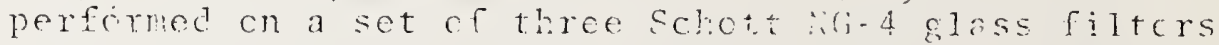
over a perici of tuo years.

\begin{tabular}{|c|c|c|c|c|}
\hline \multirow[b]{2}{*}{$\begin{array}{c}\text { Filter } \\
\text { Identification }\end{array}$} & \multirow[b]{2}{*}{$\begin{array}{l}\text { Wavelens,th } \\
\text { (nm) }\end{array}$} & \multicolumn{3}{|c|}{$\subseteq ?$} \\
\hline & & $\begin{array}{l}1971 . \\
912 y\end{array}$ & $\begin{array}{c}1072 \\
\text { Decemter }\end{array}$ & $\begin{array}{l}10 ? \overline{3} \\
\text { Aprit }\end{array}$ \\
\hline \multirow{4}{*}{$10 \%$} & 440.0 & 11.59 & 11.62 & 11.60 \\
\hline & $465 . n$ & 13.56 & 1.3 .59 & 13.57 \\
\hline & 500.0 & .10 .37 & 10.40 & 10.39 \\
\hline & 635.0 & 11.36 & 11.40 & 11.39 \\
\hline \multirow{4}{*}{$20 \%$} & 440.0 & 19.80 & 19.83 & 19.81 \\
\hline & 465.0 & 22.59 & 22.62 & 22.60 \\
\hline & 590.0 & 19.16 & 19.20 & 19.19 \\
\hline & 6.35 .0 & 20.60 & 20.65 & 20.65 \\
\hline \multirow{4}{*}{$30 \%$} & 440.0 & 32.87 & 32.88 & 32.92 \\
\hline & 465.0 & 35.53 & 35.54 & 35.59 \\
\hline & 590.0 & 31.13 & 31.14 & 31.20 \\
\hline & 635.0 & 32.55 & 32.58 & 32.64 \\
\hline
\end{tabular}


The variation of transmittance as a function of time for the Schott NG type glasses (NG-4 and NG-5) was determined by using three filters which constitute our own reference set, and measuring them over a period of 4 years. Table 3 presents the results obtained at $440.0 \mathrm{~nm}, 465.0 \mathrm{~nm}$, $590.0 \mathrm{~nm}$, and $635.0 \mathrm{~nm}$. The largest difference observed after 4 years of use did not exceed about 3 parts in 1000 . The measurements also seem to indicate a trend toward an increase of the transmittance of these glass filters which are in accordance with the known property of glass surfaces to produce a layer of SiO at its surface when exposed to atmospheric conditions. This phenomena is called "blooming" of the glass, and the thin SiO deposit which is formed acts as an antireflection layer which results in an apparent increase of the transmittance of the glass. Similar measurements were made on another set of three glass filters over a period of two years; table 4 contains the resulting transmittances, which confirm the previous data.

\subsection{Interlaboratory Transmittance Measurements on SRM 930}

A set of SRM 930 was measured at NBS and at the National Physical Laboratory (NPL) in England by F. J. J. Clarke and his associates using their high-accuracy instrument. These measurements were made with noncollimated convergent beam geometry. A rectangular surface of the filter about $3 \mathrm{~mm}$ by $8 \mathrm{~mm}$ was used at NPL and the beam was only slightly convergent. At NBS an area of about $8 \mathrm{~mm}$ by $0.5 \mathrm{~mm}$ was used for the transmittance measurements. The results given in table 5 indicate that an average difference of about 0.20 percent of the measured values was obtained between the measurements carried out at NPL and at NBS. Agreement to within the instrumental accuracy of about 1 part in $10^{4}$ was also obtained in comparative measurements, using another highaccuracy spectrophotometer built at NBS (See Mielenz in reference 10). The average reproducibility of these measurements performed in 1971 and repeated in 1973 and 1975 was within this value. 
Table 5. Comparison between the percent transmittances $(\% \mathrm{~T})$ measured on three Schott NG-4 glass filters at NPL and NBS in 1971, 1973, and 1975.

\begin{tabular}{ccccc}
$\begin{array}{c}\text { Wavelength } \\
\mathrm{nm}\end{array}$ & $\begin{array}{c}\text { NBS, } \\
1971\end{array}$ & $\begin{array}{c}\text { NPL, } \\
1971\end{array}$ & $\begin{array}{c}\text { NBS } \\
1973\end{array}$ & 1975 \\
\hline 440.0 & 12.91 & 12.93 & 12.91 & 12.90 \\
465.0 & 14.97 & 15.01 & 14.98 & 14.97 \\
590.0 & 11.67 & 11.67 & 11.65 & 11.62 \\
635.0 & 12.70 & 12.72 & 12.71 & 12.69 \\
& & & & \\
440.0 & 19.60 & 19.62 & 19.60 & 19.56 \\
465.0 & 22.37 & 22.43 & 22.39 & 22.34 \\
590.0 & 19.00 & 19.01 & 19.00 & 18.94 \\
635.0 & 20.41 & 20.47 & 20.46 & 20.40 \\
& & & & \\
440.0 & 32.87 & 32.98 & 32.86 & 32.87 \\
465.0 & 35.53 & 35.66 & 35.52 & 35.51 \\
590.0 & 31.13 & 31.21 & 31.11 & 31.07 \\
635.0 & 32.54 & 32.62 & 32.57 & 32.53
\end{tabular}

Another comparative study was performed to include three clinical laboratories to determine the reproducibility of transmittance measurements on the Schott NG-4 neutral glass filters. Again three filters having nominal transmittances of 10,20 , and 30 percent were measured at four wavelengths on a conventional spectrophotometer at the NBS. This instrument included a double monochromator with quartz prisms used in a double beam mode, and a transmittance scale with 1000 divisions between 0 and 100 percent transmittance. The transmittance accuracy of this scale was established with SRM 930. The same filters were then sent to laboratories A, $B$ and $C$ describing the technique to be used in measuring their transmittances. The results obtained are summarized in table 6 and include the percent transmittance $(\% \mathrm{~T})$ values, the standard deviation (S. D.), the percent standard deviation $(\%$ S. D.), and the percent difference ( $\%$ difference). This difference was calculated using the NBS data as a reference. 
Table 6. Comparative transmittance measurements perforned by four laboratoriess on three schott $N C-4$ colored glass filters.

\begin{tabular}{|c|c|c|c|c|c|}
\hline \multicolumn{2}{|c|}{ Laboratory } & \multicolumn{4}{|c|}{ A } \\
\hline \multicolumn{2}{|c|}{ "easurement } & \multicolumn{4}{|c|}{$\because \mathrm{T}$} \\
\hline No. & & $440 \mathrm{~nm}$ & $465 \mathrm{~nm}$ & $590 \mathrm{~nm}$ & $6.35 \mathrm{~nm}$ \\
\hline 1 & $\begin{array}{l}\text { Ave. } \\
\text { S. D. } \\
\text { Diff. } \\
\text { חif. }\end{array}$ & $\begin{array}{c}12.91 \\
0.0063 \\
-.049 \\
-\quad .4\end{array}$ & $\begin{array}{c}14.99 \\
0.004 \\
.027 \\
-\quad .07\end{array}$ & $\begin{array}{c}11.68 \\
0.008 \\
.070 \\
-\quad .6\end{array}$ & $\begin{aligned} 12.71 \\
0.005 \\
.041 \\
-\quad .5\end{aligned}$ \\
\hline 2 & $\begin{array}{l}\text { Ave. } \\
\text { S.D. } \\
\text { D. S.D. } \\
\text { Diff. }\end{array}$ & $\begin{array}{c}19.61 \\
0.004 \\
.021 \\
-\quad .5\end{array}$ & $\begin{array}{r}22.37 \\
0.010 \\
.046 \\
-\quad .3\end{array}$ & $\begin{array}{c}19.06 \\
0.004 \\
.022 \\
-\quad .3\end{array}$ & $\begin{array}{c}20.50 \\
- \\
- \\
-0.1\end{array}$ \\
\hline 3 & $\begin{array}{l}\text { Ave. } \\
\text { S. D. } \\
\text { Diff. } \\
\text { Dif. }\end{array}$ & $\begin{aligned} 32.81 \\
0.0080 \\
.023 \\
+\quad .3\end{aligned}$ & $\begin{array}{c}35.44 \\
0.0080 \\
.023 \\
+\quad .3\end{array}$ & $\begin{array}{c}31.12 \\
0.0050 \\
+.017 \\
+\quad .1\end{array}$ & $\begin{aligned} 32.58 \\
0.0050 \\
.016 \\
+\quad .2\end{aligned}$ \\
\hline
\end{tabular}

\begin{tabular}{|c|c|c|c|c|c|}
\hline \multicolumn{2}{|c|}{ Laboratory } & \multicolumn{4}{|c|}{$B$} \\
\hline \multicolumn{2}{|c|}{ Ye asurement } & \multicolumn{4}{|c|}{$\because \mathrm{T}$} \\
\hline No. & & $440 \mathrm{~nm}$ & $465 \mathrm{~nm}$ & $590 \mathrm{~nm}$ & $635 \mathrm{~nm}$ \\
\hline 1 & $\begin{array}{l}\text { Ave. } \\
\text { S.D. } \\
\text { o. S. } \\
\text { Diff. }\end{array}$ & $\begin{array}{c}12.91 \\
- \\
- \\
-0.4\end{array}$ & $\begin{aligned} 14.87 \\
0.041 \\
. .276 \\
-\quad .9\end{aligned}$ & $\begin{array}{c}11.56 \\
0.041 \\
.36 \\
-1.6\end{array}$ & $\begin{array}{c}12.59 \\
- \\
- \\
-1.4\end{array}$ \\
\hline 2 & $\begin{array}{l}\text { Ave. } \\
\text { S.D. } \\
\text { S.D. } \\
\text { Diff. }\end{array}$ & $\begin{array}{c}19.59 \\
- \\
-0.6\end{array}$ & $\begin{array}{c}22.39 \\
- \\
- \\
-0.2\end{array}$ & $\begin{array}{c}18.90 \\
0.053 \\
.281 \\
-1.1\end{array}$ & $\begin{array}{c}20.51 \\
- \\
- \\
-0.05\end{array}$ \\
\hline 3 & $\begin{array}{l}\text { Ave. } \\
\text { S.D. } \\
\% \text { S.D. } \\
\text { Diff. }\end{array}$ & $\begin{array}{c}32.58 \\
- \\
-0.4\end{array}$ & $\begin{aligned} 35.23 \\
0.093 \\
. .264 \\
-\quad .3\end{aligned}$ & $\begin{array}{c}30.90 \\
- \\
-0.6\end{array}$ & $\begin{array}{c}32.36 \\
- \\
- \\
-0.4\end{array}$ \\
\hline
\end{tabular}


Table 6 (cont'd)

Laboratory

\begin{tabular}{|c|c|c|c|c|c|}
\hline \multicolumn{3}{|c|}{ Neasurement } & \multicolumn{2}{|c|}{$\because 7$} & \multirow[b]{2}{*}{$5: 5 \mathrm{~nm}$} \\
\hline Yo. & & $440 \mathrm{~nm}$ & $465 \mathrm{~nm}$ & $590 \mathrm{~nm}$ & \\
\hline 1 & $\begin{array}{l}\text { Ave. } \\
\text { s.n. } \\
\text { niff. }\end{array}$ & $\begin{array}{c}12.88 \\
- \\
- \\
-0.6\end{array}$ & $\begin{array}{c}14.96 \\
0.014 \\
.09 \\
-\quad .3\end{array}$ & $\begin{array}{c}1] .66 \\
0.011 \\
.09 \\
-.8\end{array}$ & $\begin{array}{c}12.05 \\
0.018 \\
.15 \\
-\quad .0\end{array}$ \\
\hline 2 & $\begin{array}{l}\text { Ave. } \\
\text { S.D. } \\
\text { Diff. } \\
\text { Dif. }\end{array}$ & $\begin{array}{c}19.54 \\
- \\
-0.9\end{array}$ & $\begin{array}{c}22.34 \\
- \\
- \\
-0.4\end{array}$ & $\begin{array}{r}19.12 \\
0.024 \\
.13 \\
+\quad .05\end{array}$ & $\begin{array}{c}20.37 \\
- \\
- \\
-0.7\end{array}$ \\
\hline 3 & $\begin{array}{l}\text { Ave. } \\
\text { s.n. } \\
\text { o s.n. } \\
\text { niff. }\end{array}$ & $\begin{array}{c}32.88 \\
- \\
- \\
+0.5\end{array}$ & $\begin{array}{c}35.40 \\
- \\
- \\
+0.1\end{array}$ & $\begin{array}{c}30.97 \\
- \\
-0.4\end{array}$ & $\begin{array}{c}32.43 \\
- \\
- \\
-0.2\end{array}$ \\
\hline
\end{tabular}

Laboratory NBS

\begin{tabular}{|c|c|c|c|c|c|}
\hline \multicolumn{2}{|c|}{ Heasurement } & \multicolumn{3}{|c|}{$\div \mathrm{T}$} & \\
\hline No. & & $440 \mathrm{~nm}$ & $465 \mathrm{~nm}$ & $590 \mathrm{~nm}$ & $635 \mathrm{~nm}$ \\
\hline 1 & $\begin{array}{l}\text { Ave. } \\
\text { S.D. } \\
\% \text { S.D. } \\
\text { Diff. }\end{array}$ & $\begin{array}{c}12.96 \\
0.0053 \\
.041 \\
-\end{array}$ & $\begin{array}{c}15.00 \\
0.0037 \\
.025 \\
-\end{array}$ & $\begin{array}{c}11.75 \\
0.0048 \\
.041 \\
-\end{array}$ & $\begin{array}{c}12.77 \\
0.0057 \\
.045 \\
-\end{array}$ \\
\hline 2 & $\begin{array}{l}\text { Ave. } \\
\text { S.D. } \\
\text { \% S.D. } \\
\text { niff. }\end{array}$ & $\begin{array}{c}19.71 \\
0.0049 \\
.025\end{array}$ & $\begin{array}{c}22.44 \\
0.0052 \\
.023\end{array}$ & $\begin{array}{c}19.11 \\
0.0038 \\
.020 \\
-\end{array}$ & $\begin{array}{c}20.52 \\
0.0049 \\
.024 \\
-\end{array}$ \\
\hline 3 & $\begin{array}{l}\text { Ave. } \\
\text { S. D. } \\
\text { Diff. D. } \\
\text { Dif. }\end{array}$ & $\begin{array}{c}32.72 \\
0.0045 \\
.014 \\
-\end{array}$ & $\begin{array}{c}35.35 \\
0.0056 \\
.016 \\
-\end{array}$ & $\begin{array}{c}31.09 \\
0.0040 \\
.013 \\
-\end{array}$ & $\begin{array}{c}32.50 \\
0.004 .3 \\
.013 \\
-\end{array}$ \\
\hline
\end{tabular}


In this study, the cooperation of George N. Bowers, Jr., M. D., of Hartford Hospital, Hartford, Connecticut, Royden N. Rand, Ph.D., of the Hospital of the University of Pennsylvania, Philadelphia, Pennsylvania*, and Donald S. Young, M. D., Ph.D., of the National Institutes of Health, Bethesda, Maryland, is gratefully acknowledged.

This study demonstrates that transmittance data can be reproduced in actual laboratory conditions with a general uncertainty of less than one percent. From the total of 36 transmittance measurements only 3 exceed this value, and this was due probably to limitations in the spectral bandpass of the particular spectrophotometer used.

The transmittances of several sets of SRM 930 were determined, after several years of use in routine laboratory conditions, to assess the effect of time and handling on this parameter. Table 7 presents the results obtained on set no. 106 certified in 1972. The column marked 1 contains the transmittance values as certified in November $29,1972$. This set was measured again in February 27,1974 , in an "as received" condition, and the transmittance values obtained are given in the column marked 2. The difference between these measurements is given in the column marked 3 . As it can be seen, the transmittance of these glass filters, after about two years of use in a laboratory, is lower than the certified values, suggesting a possible contamination of the glass surface. This supposition was verified by submitting the filters to the cleaning procedure described previously. The filters were remeasured, and the data obtained are given in the column marked 4, which present the average of four series of measurements carried out over a period of three days. These results, which indicate this time a positive difference, given in the column marked 5 , confirm the hypothesis of a surface contamination of the glass during their use, and verify the tendency of the glass to cover itself with a layer of SiO as was already discussed. The results of this phenomenon is an apparent increase of the transmission of the material.

* Present address: Eastman Kodak Company, Research Laboratories, Rochester, New York, 14650. 


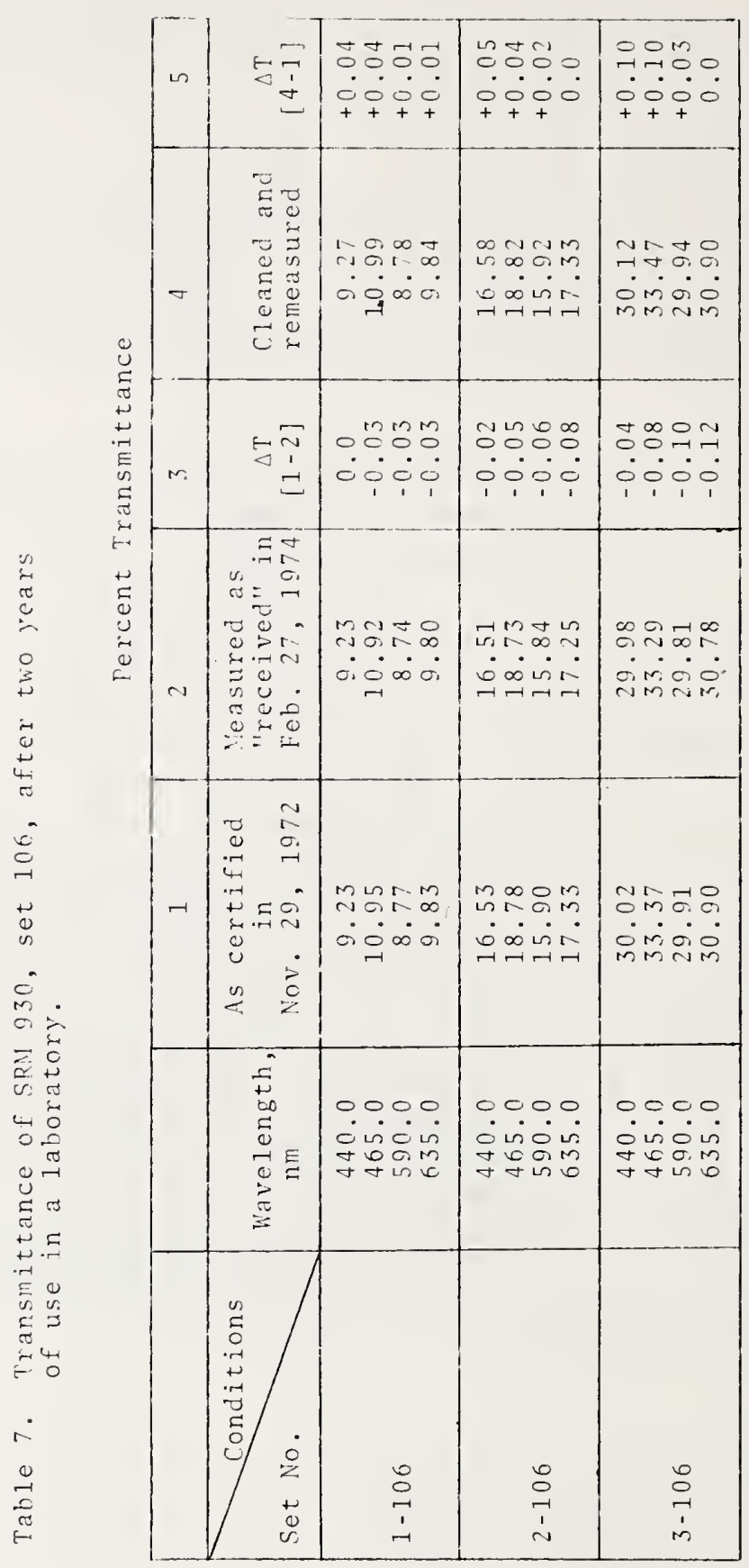


In another series of tests, a set of SRM 930 was used to verify and correct the transmittance scale of a conventional spectrophotometer, by measuring the transmittance of the certified glass filters on the tested instrument, and by comparing the results with the certified values, and Table 8 presents these results.

Table 8. Comparison of $\%$ T measurements performed on a Schott NG-4 filter using the NBS high-accuracy instrument and a conventional spectrophotometer.

\begin{tabular}{cccccc}
$\begin{array}{c}\text { Wavelength } \\
\text { nm }\end{array}$ & $\begin{array}{c}\text { NBS } \\
\text { Instrument }\end{array}$ & $\begin{array}{c}\text { Conventional } \\
\text { Instrument }\end{array}$ Diff: & $\begin{array}{c}\text { Relative } \\
\text { o Diff. }\end{array}$ & $\begin{array}{c}\text { Average } \\
\text { Relative } \\
\text { Diff. }\end{array}$ \\
\hline 440.0 & 32.82 & 32.75 & +0.07 & +0.21 & \\
465.0 & 35.51 & 35.40 & +.11 & +.31 & +0.22 \\
590.0 & 30.98 & 30.93 & +.05 & +.16 & \\
635.0 & 32.38 & 32.32 & +.06 & +.19 &
\end{tabular}

From these data it can be concluded that the transmittance scale of the conventional spectrophotometer provides transmittances which are lower than the accurate values by an average difference of 0.22 percent. This average difference can be added to the measurements made with the conventional instrument, to obtain the accurate transmittance value. Another method to perform the correction is to use an interpolation procedure using a graph established by plotting on the abscissa the accurate transmittance (or absorbance) values of SRM 930 and on the ordinate the values found on the instrument for this material. In this discussion it was implicitly assumed that all other parameters which can affect the transmittance accuracy have been considered and minimized, and especially the stability of the instrument, the wavelength accuracy, the spectral bandpass, and temperature. Correction of the transmittance or absorbance scale of a spectrophotometer should be applied only when these conditions are fulfilled.

The glass which is used to produce SRM 930 has a spectral transmittance limited to the visible range from about $400 \mathrm{~nm}$ to $800 \mathrm{~nm}$, as illustrated in figures 4 and 6 , and this obviously limits the usefulness of this standard reference material. Appreciable efforts have been made at NBS in the past and are continuing now, to find a transparent material which could extend this spectral range to the ultraviolet. At the present time, however, only one material has been found which satisfies these required characteristics; this material is the evaporated metal-on-quartz filter which was already discussed (figure 4). The evaporated metal-on-quartz filter meets the 
requirements for spectral neutrality and good stability and is not susceptible to the production of an Sio layer. When chromium is used to produce the evaporated metal layer, the filter exhibits a good resistance to abrasion. The only limitation of the evaporated metal-on-quartz results from its intrinsic property of attenuating the incident radiation by reflecting part of it rather than by absorbing it. Although interlaboratory tests between NBS and NPL, in which evaporated metal-on-quartz filters have been used, have produced results similar to those obtained with the glass filters used in SRM 930, it should be noted that these results were obtained with specially designed high-accuracy spectrophotometers. The use of such filters in conjunction with the large variety of conventional instruments is now being studied to determine to what extent and under what circumstances the metal-on-quartz filters could be used as standard reference material in spectrophotometry.

6. SUMMARIZING REMARKS

The acquisition of meaningful measurements by spectrophotometry requires that every phase of the chemical processes involved in the analytical procedure, and every parameter of the instrumental spectrophotometric technique be well-known and understood, and under the complete control of the analytical chemist. He must be able to assess the importance of these two factors in a quantitative manner, and to evaluate their individual contribution to the uncertainty of the final measurement. Some of the parameters involved in the instrumental spectrophotometric technique have been examined in this publication, and particular attention was given to those instrumental parameters which play a more significant role: the short and long term instrumental stability, the wavelength accuracy, the spectral bandpass problem, and the transmittance accuracy. Means and methods have been discussed, and, standard reference materials have been described and produced, which permit to determine to a large extent the magnitude of these important parameters and to assess and correct their individual contributions toward the deterioration of spectrophotometric precision and accuracy.

While the use of SRM $930 \mathrm{a}$ and b does not solve all problems in spectrophotometry, its availability should contribute appreciably to the production of more accurate and therefore more meaningful measurements in all fields where spectrophotometry is applied.

Instrumental stability, wavelength accuracy, adequate spectral bandpass, and transmittance accuracy are basic parameters which play a determinant role in the production of accurate transmittance measurements of a transparent material 
in the spectral range of interest. Without the fulfillment of these conditions no accurate transmittance measurements could be performed. SRM 930 seems to be a useful means to assume that the measurements are accurate.

The production of accurate chemical analytical data, that is the capability to determine accurately the amount of a particular chemical element in a given matrix, requires, on the other hand, only spectrophotometric precision, as determined by the instrumental stability and sensitivity. The accuracy of the analytical measurements is determined in this case solely by the accuracy achieved in the preparation of the analytical samples and in the establishment of the reference curve. These in turn depend on the stability of the chemical reactions involved in the spectrophotometric process, and on the ability to prepare adequate reference solutions having accurately known concentrations of the chemical element of interest in a matrix identical to that of the analytical sample. Under these circumstances, analytical accuracy can be achieved using spectrophotometers which exhibit good stability and sensitivity. The wavelength accuracy, the spectral bandpass, and the accuracy of the transmittance or absorbance scale play a secondary role in this analytical application. The lack of accuracy of these parameters could affect the sensitivity and linearity, and in some cases, the specificity of spectrophotochemical analyses, rather than their chemical accuracy.

Standard Reference Material, "SRM 930, a and b, G1ass Filters for spectrophotometry," is a transfer standard which was calibrated for transmittance in the spectral range of $440.0 \mathrm{~nm}$ to $635.0 \mathrm{~nm}$, with a high-accuracy spectrophotometer which represents the primary transmittance standard. The transmittance values were certified with an uncertainty of 0.5 percent. The validity of these transmittance values with time will depend on the stability of the glass and the conditions under which it is used. The measurements from table 3 prove that the stability of the certified transmittance values are reproducible, within the uncertainty indicated, over a length of time exceeding 4 years. This assumes that the filters have been used with proper care, following the instructions given in the certificate. Deviations from these instructions could result in degradation or loss of accuracy. In particular, the glass surface should never be touched with the fingers, the filters should not be exposed to dust or corrosive reagents, and when not in use they should be kept always in the box provided for this purpose. Should the glass surface of the filters become accidentally contaminated, no attempts should be made to wash it, since the user does not have means to determine if this cleaning treatment has not altered the properties of 
the glass surface and degraded the accuracy of the certified transmittance values. Since SRM 930 is a transfer standard, the only means available to determine its integrity is by remeasuring its transmittance with a primary standard instrument, and this can be done only with the high-accuracy spectrophotometer described in this work. Should there be a need to verify the accuracy of the certified transmittance data, the glass filters should be returned to NBS for verification of the transmittance data assigned to that particular set, and for cleaning and recalibration if necessary. It is recommended that before sending the glass filters, proper arrangements be made by writing the Office of Standard Reference Materials at NBS to establish the best conditions in which such a verification can be made.

SRM 930 is a delicate and costly unit which has required an appreciable amount of careful work for its preparation and certification. This material should be handled with great attention to insure production of accurate measurements and long life. This is particularly true when the working conditions in certain laboratories require frequent use of SRM 930. To protect this reference material it might prove desirable in such cases to produce "in house" secondary glass standards derived from SRM 930, and use these secondary standards for daily control of the spectrophotometers used in the laboratory. When these standards indicate a significant change in the measurements, only then should SRM 930 be used as a final verification of the data.

Secondary glass standards could be produced by purchasing the optically neutral glass used for the production of SRM 930, cut to size as described in this publication and placed in holders similar to those illustrated in detail in figures 11 and 12 . The transmittance of these filters should be established at the desired wavelengths with the best spectrophotometer available in the laboratory after its transmittance scale was verified with SRM 930 (a or b). 
1. Rand, R. N., J. Res. Nat. Bur. Stand. (U.S.) 76A, No. 5, 499 (1972).

2. Be1k, W. P., and Sunderman, F. W., Amer. J. Clin. Pathol. 17, 853 (1947).

3. Wooton, I. D. P., and King, E. J., Lancet I, 470 (1953).

4. Hendry, P. I. A., Report Adelaide Meeting, p. 8. College of Pathologists of Australia (1961).

5. Tonks, D. B., C1in. Chem. $\underline{9}, 217$ (1963).

6. Desmond, F. B., New Zealand Med. J. 63, 716 (1964).

7. Rand, R. N., C1in. Chem. 15, 839 (1969).

8. Mavrodineanu, R., in NBS Technical Note 544, 6-17 (July 1969 - June 1970); and 584, 2-21 (Ju1y 1970 - June 1971).

9. Mavrodineanu, R., and Lazar, J. W., Clin. Chem. 19, No. 9, 1053-1057 (1973).

10. NBS Special Publication 378, "Accuracy in Spectrophotometry and Luminescence Measurements," 255 pp. (1973). R. Mavrodineanu, J. I. Shultz, and O. Menis, editors. This volume contains the 18 papers presented at the Conference on "Accuracy in Spectrophotometry and Luminescence Measurements" held at NBS from March 22 to 24 (1972). The same papers were published previously in: J.-Res. Nat. Bur. Stand. (U.S.) 76A, Nos. 5 and 6, 375-510; 547-654 (1972).

11. Mavrodineanu, R., in ref. 10 .

12. Gibson, K. S., "Spectrophotometry," NBS Circular 484, 48 pages (1949).

13. ASTM Standard Method of Estimating Stray Radiant Energy, ASTM: E387-72, in "1972 Annual Book of ASTM Standards."

14. Mavrodineanu, R., in ref. 10 . 
These appendices contain a reproduction of the notice introducing the Standard Reference Material 930, and the calibration certificate issued for SRM 930b. It differs from SRM 930 and $930 \mathrm{a}$ by the addition of an empty filter holder and an additional transmittance certification at $546.1 \mathrm{~nm}$. Also included are reprints from five publications which should provide further and more detailed. information on the subject discussed in this publication.

\section{ACKNOWLEDGEMENT}

The authors gratefully acknowledge the assistance of the following persons:

- J. R. DeVoe, Chief, Special Analytical Instrumentation Section; R. W. Burke, Research Chemist; K. D. Mielenz, Analytical Chemistry Division, NBS; T. W. Mears, Standards Coordinator, Office of Standard Reference Materials, NBS; and R. N. Rand of Eastman Kodak, Research Laboratories, and President Elect, American Association of Clinical Chemists, for reviewing the manuscript and for making many valuable comments and constructive suggestions.

- H. L. Hoover, Corning Glass Works, for providing the transmittance information of the didymium and holmium oxide glass filters.

- American Society for Testing and Materials for permission to reproduce "Standard Method of Estimating Stray Radiant Energy" reprint for Appendix 7 . 


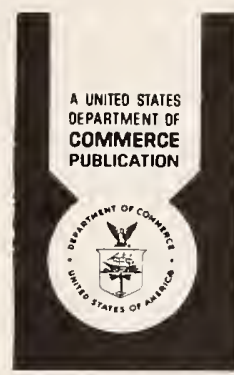

\section{NBS STANDARD REFERENCE MATERIALS
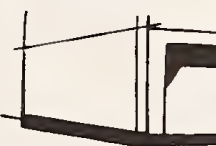

U.S. DEPARTMENT OF COMMERCE/National Bureau of Standards

March 26, 1971

\section{Standard Reference Material 930}

\section{Glass Filters for Spectrophotometry}

The Office of Standard Reference Materials announces the availability of Standard Reference Material 930, Glass Filters for Spectrophotometry. This SRM consists of three glass filters having transmittances of approximately 10, 20 , and 30 percent. Each filter is individually calibrated and certified for absorbance and transmittance over a spectral wavelength range from 440 to 635 nanometers.

These filters are intended to check the accuracy of the photometric scale of spectrophotometers, and to provide a means of interlaboratory comparisons of spectrophotometric data. It is probable that in the field of clinical chemistry a large amount of data are being obtained on precise instruments whose accuracy is unknown. To make these data more meaningful and universally applicable, the biases between instruments must be eliminated or at least determined. I. major purpose of these filters will be to assure that systematic errors due to a particular characteristic or condition of an instrument can be recognized.

This SRM should be valuable in the calibration of instruments used to obtain accurate physico-chemical constants such as molar absorptivity and equilibrium constants. For example, current interest in molar absorptivity values, as an index of the purity of biological clinical materials, requires greater accuracy of measurement. Also, the accuracy in the determination of equilibrium constants of chemical reactions in solutions, is dependent on true values of their molar absorptivities.

Standard Reference Material 930 is available from the office of Standard Reference Materials, National Bureau of Standards, Washington, D. C. 20234. The price is $\$ 395$. for a unit of three filters. 


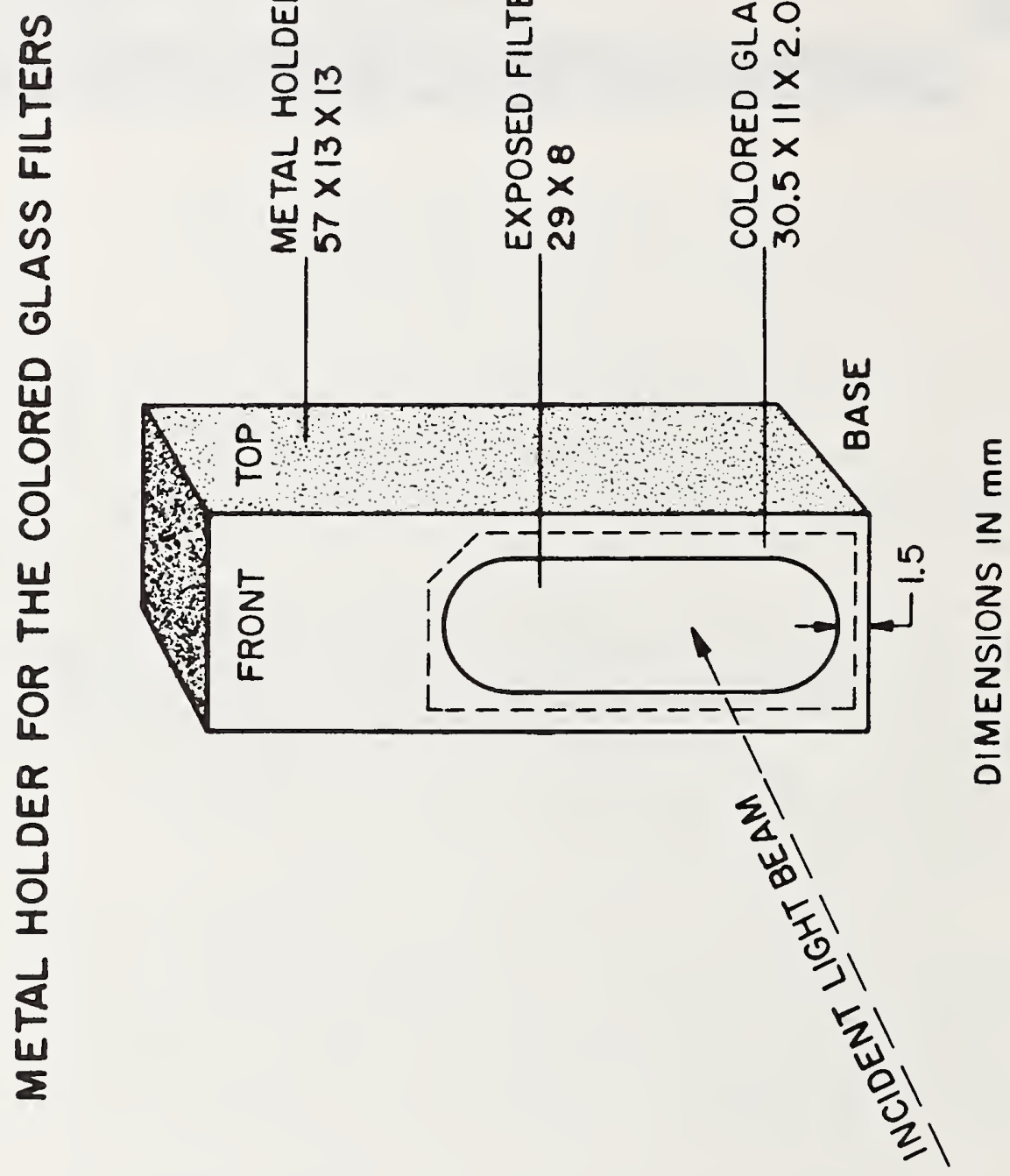




\section{U. S. Department of Commerce \\ Frederick B. Dent \\ Secretary \\ National Burean of Standerds Ricbard W. Roberts, Director

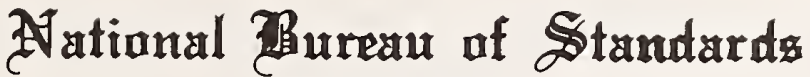 UTertificate \\ Standard Reference Material 930b \\ Glass Filters for Spectrophotometry \\ R. Mavrodineanu and J. R. Baldwin}

This Standard Reference Material is intended as a reference source for the calibration of the photometric scale of spectrophotoneters. It consists of three individual filters and one empty filter holder. Each filter bears an identification number, and the upper left comer has been removed to indicate correct placing in the metal holder.

\begin{tabular}{|c|c|c|c|c|c|c|c|c|c|c|}
\hline \multirow{3}{*}{$\begin{array}{l}\text { Filter } \\
\text { \& Set } \\
\text { Ident. } \\
\text { Number }\end{array}$} & \multicolumn{5}{|c|}{ ABSORBANCE (A) } & \multicolumn{5}{|c|}{ TRANSMITTANCE $(\% \mathrm{~T})$} \\
\hline & \multicolumn{5}{|c|}{$\begin{array}{l}\text { Wavelength and (Bandpass) } \\
\qquad \mathrm{nm}\end{array}$} & \multicolumn{5}{|c|}{$\begin{array}{l}\text { Wavelength and (Bandpass) } \\
\mathrm{nm}\end{array}$} \\
\hline & $\begin{array}{l}440.0 \\
(2.2)\end{array}$ & $\begin{array}{l}465.0 \\
(2.7)\end{array}$ & $\begin{array}{l}546.1 \\
(6.5)\end{array}$ & $\begin{array}{l}590.0 \\
(5.4)\end{array}$ & $\begin{array}{c}6.35 .0 \\
(6.0) \\
\end{array}$ & $\begin{array}{l}440.0 \\
(2.2)\end{array}$ & $\begin{array}{l}465.0 \\
(2.7)\end{array}$ & $\begin{array}{l}546.1 \\
(6.5)\end{array}$ & $\begin{array}{l}590.0 \\
(5.4)\end{array}$ & $\begin{array}{l}635,0 \\
(6.0) \\
\end{array}$ \\
\hline & & & & & & & & & & \\
\hline & & & & & & & & & & \\
\hline & & & & & & & & & & \\
\hline & & & & & & & & & & \\
\hline & & & & & & & & & & \\
\hline
\end{tabular}

The Iransmittanee values given are certified with a relalive unecrtainty of \pm 0.5 percent (example: a nominal value of absorbaner of $0.500 \pm 0.0022$ ). This uncertainty is the sum of the random crror of \pm 0.1 pereent ( $2 \mathrm{Sl})$ limil) and of estimated liases which are \pm 0.4 pereent. These biases are due $(1)$ possible svatematie errors. Veasurements were made at $25^{\circ} \mathrm{C}$. Room temperature variations within several degrees Celsius of this temperalure will not signifieantly affect the ealibration of these filters.

It is recommended that llae filters be landled only ly the colges and with soft plastic (poly-

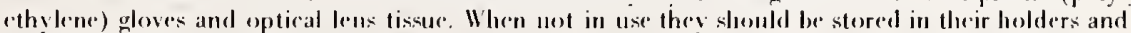
in the los provided for this purpose. Extended expesure lo laberators at mosphere and dusty sur roundings should lee aveided.

The overall direction and coordination of the terhnical mousurements leading lo certifieation were performed under the (hairmanship of 0 . Menis and J. I. Shultz.

The terhnical and sapport aspects involued in the preparalion. certification, and issuance of this Standarel Reference Valerial were courdinated llerough the Offiee of Standard Reference Vaterials b. T. W. Vlears.

Washington, I). (:. 20234

J. P'alıl Cali, Chief

Foloruan: 24,1975

(aver)

Offien of Simdiart Reference Vaterials 
The transmittance measurcments were made with the high-accuracy spcctrophotometer designed and constructed at the National Bureau of Standards [1]. The aceuraey of this instrument was established by light-addition measurements.

The neutral NG-4 and NG-5 glasses for the filters were provided by Schott of Mainz, Germany, and are designatcd as "Jena Colored and Filter Glass." Nominal transmittance for a filter $1.5 \mathrm{~mm}$ thick is 20 percent at $400.0 \mathrm{~nm}$ wavelength and 32 percent at $700.0 \mathrm{~nm}$ wavelength. Betwecn these limits the transmittance varies in a monotonie manner [2].

The filter holder is blaek anodized aluminum alloy and has the following nominal dimensions: height: $57 \mathrm{~mm}$, width $13 \mathrm{~mm}$, dcpth: $13 \mathrm{~mm}$. This holder and the size and shape of the filters were selected to conform to the dimensions of the sample compartment of most conventional speetrophotometers. The filters are approximately $30.5 \mathrm{~mm}$ long, $11 \mathrm{~mm}$ wide, and $2.0 \mathrm{~mm}$ and $1.5 \mathrm{~mm}$ thick for the NG-4 glass and $1.5 \mathrm{~mm}$ thick for the NG -5 glass. Corresponding to these thicknesses are nominal transmittances of 10,20 , and 30 percent, respectively. These thicknesses were selectcd to provide a means for calibrating the photometric scale at three different levels. The exposed surface of the glass filter is approximately $29 \mathrm{~mm}$ by $8 \mathrm{~mm}$, starting from a distance of $1.5 \mathrm{~mm}$ from the filter holder base (see figure).

The transmittance of filters depends on the intrinsic properties of the matcrial. Spectral bandpass, wavelength $[2,3,5]$, geometry of the optical beam, surface conditions, and positioning of the filter also affect the transmittance values, and can lead to further biases. The certified data will be reproduced when transmittance measurements are made under similar conditions. The effective spectral bandpasses used to determine the certified values are given on the facc of the certificate and the transmittance measurements are made by producing the vertical image of the slit (about $8 \mathrm{~mm}$ by $0.5 \mathrm{~mm}$ ), using a convergent beam geometry with an opening of f:10, in the middle of the entrance face of the glass filter. (The filter should he positioncd in the spcctrophotometer as shown in the figure, to obtain correct values.)

Prior to the certification measurements, each filter was examined for surface defccts and then thoroughly cleancd. If, through handling, the surfaee of the filter becomes contaminated with dust, it may be cleaned with a small soft brush attached to a rubher tube conneeterl to a vacuum source $[2,4]$. If the surface becomes contaminated with fingerprints, they must be climinated before making measurements. This may be accomplished by removing the filter from its holder. brcathing lightly on it, and rubbing the surfacc gently with optical lens tissuc. The clcan filter is then replaced in its proper position in its holder. To remove and replace the filter in the metal holder, the spring-loaded plate should be removed with carc to prevent damage to the filter. As little handling as possible is recommended.

NOTE: The check of the calibration of photometric scales defines only one of the parameters required for obtaining accurate transmittance values and molar absorptivities. Other factors that also must be established are wavelength accuracy, stray light, ccll parameters, fluorescence, polarization, reflection, and tempcrature coefficient. Some of these variables are discussed in NBS puhlications $[1,2,5]$. It is planned to summarize various aspects of accurate spectrophometric measurements in an NBS-260 Spccial Publication that would provide additional data on specific Standard Reference Materials. In the interim. SRM 930h, should be used as described in the ccrtificate. Consult the manufacturer of the instrument if differences are obtained that execed those specified by the inanifacturer.

We wish to aleknowledge the cooperation of George N. Bowers, Jr., M.I)., of Il art ford Hospital. Hartford, Connecticut: Royden N. Rand, Ph.D., of the Hospital of the University of Pennsylvania, Philadelphia, Pennsylvania; and Donald S. Young, M.B.. Ph.D., of the National Institutes of Health, Bethesda, Maryland. 
1. R. Mavrodincanu, In Accurate Spectrophotometer for Measuring the Transmittanee of Solid and I.iquid Materials, NBS Journal of Researeh 76A, No. 5, 405-425 (1972).

2. R. Mavrodincanu, Solid Materials to Check the Photometric Scale of Speetrophotometcrs, NBS Terh. Note 544, 0. Menis and J. I. Shultz, ed., pp 6-17, U.S. Government Printing Office, Washington, D.C. 20402 (Sept. 1970), ibid NBS Tech. Note 584, pp. 2-21 (December 1971).

3. K. S. Gibson, Spectrophotometry. NBS Circ. 484 (Sept. 1949).

4. J. R. Edisbury, Practical llints on Absorption Spectrophotometry, Plenum Press, New York $(1967)$.

5. Collected Papers from VBS Conference on Aceuracy in Spertrophotometry and Luminescence Irasurements, NiSS Journal of Research 76A, No. 5, 375-510 (1972).

\section{METAL HOLDER FOR THE COLORED GLASS FILTERS}

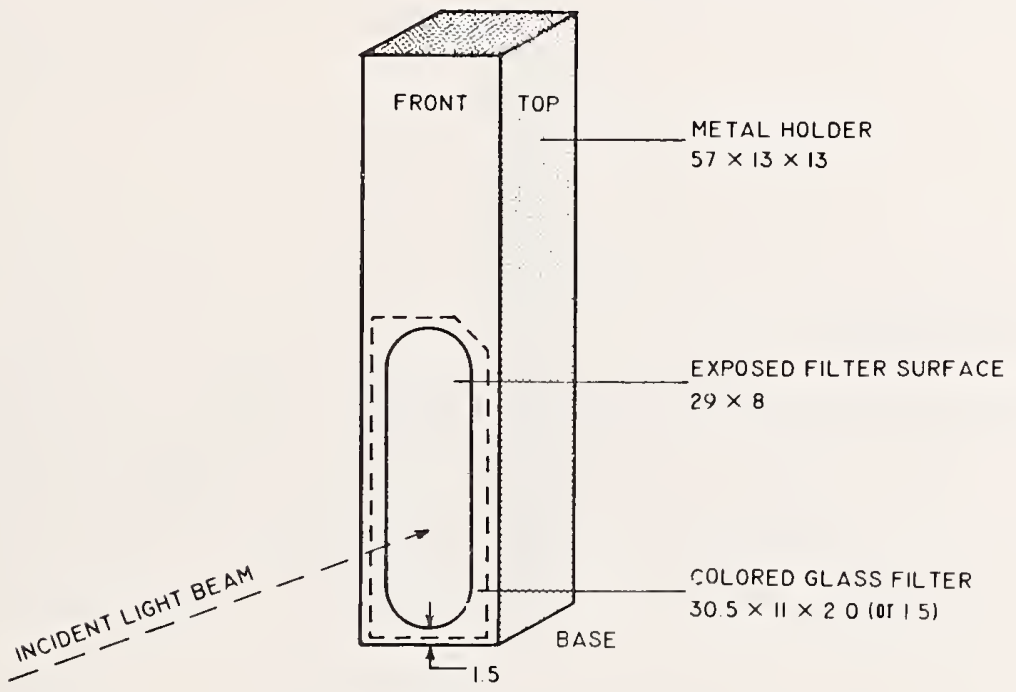

DIMENSIONS IN mm 


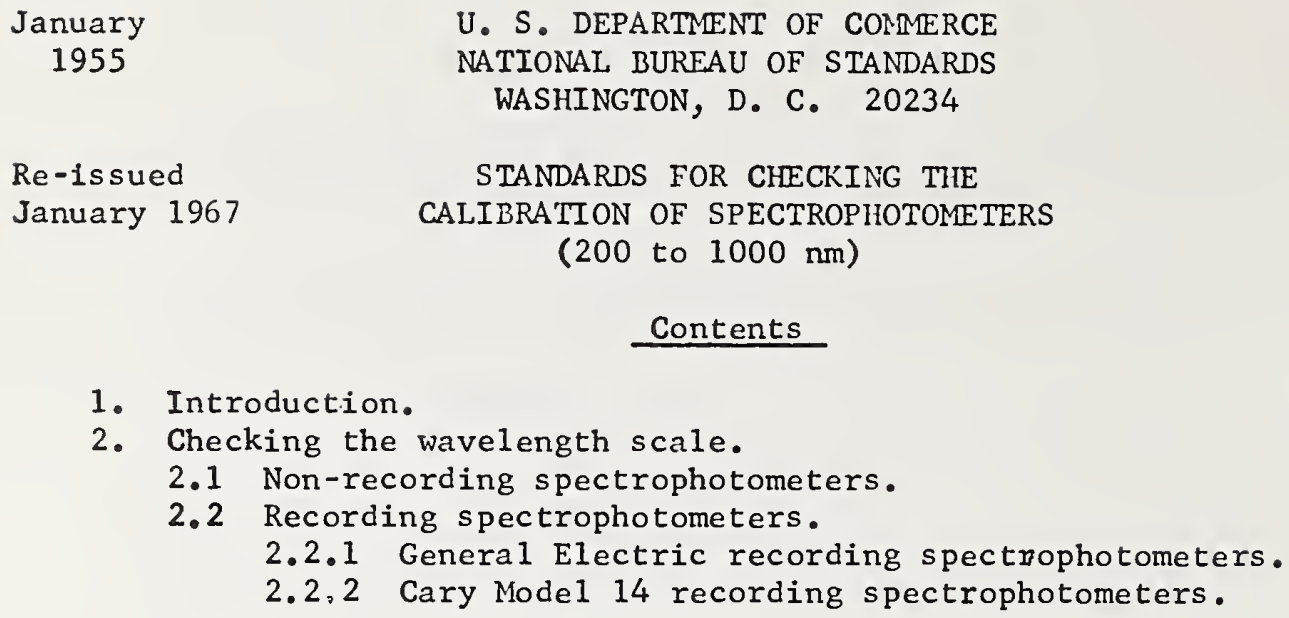

Letter

Circular

LC-1017
Re-issued

January 1967
STANDARDS FOR CHECKING THE

TION OF SPECTROPHOTOMETERS

Contents

1. Introduction.

2.1 Non-recording spectrophotometers.

2.2.1 General Electric recording spectnophotometers.

2.2.2 Cary Model 14 recording spectrophotometers.

\section{References.}

1. Introduction.

In continuation of a type of activity carried on for many years at the National Bureau of Standards, there is described in this letter circular the various types of standards that are available for issuance by the Bureau for the purpose of checking or maintaining the over-all reliability of spectrophotometers in the ultraviolet, visible and near-infrared regions of the spectrum. Certain other information of similar purpose is also included.

Experience has shown that spectrophotometers can easily get out of adjustment. Although repeated trials may give the same values over and over again, indicating high sensitivity and precision, and the instrument may otherwise appear to be functioning perfectly, gross errors in wavelength may nevertheless be rendering the values obtained highly unreliable. Other causes of error may likewise be present and unsuspected, particularIy with the photoclectric spectrophotometers now comprising so large a percentage of the total in use. The use of the various standards described herein has been found of considerable assistance in detecting and eliminating errors that would otherwise be present, or in confirming that the instrument is in fact giving reliable results.

Reference is made in this letter circular to the NBS test fee schedules currently in effect. Those relating to spectrophotometry are designated as 202.105, Spectrophotometric Standards, and 202.106, Spectrophotometric Measurements. These schedules are obtainable from the National Bureau of Standards. 
2. Checking the Wavelength Scale.

Most of the present-day spectrophotometers have a direct-reading wavelength scale; that is, the scale, instead of being divided in uniform linear or circular measure, is divided and engraved directly in nanometers (formerly called millimicrons). This greatly facilitates setting the instrument at any desired wavelength. The accuracy of many of these direct-reading wavelength scales is remarkably good, when put in the best average adjustment, considering the difficulties of quantity production of such scales. When so adjusted, it is not uncommon to find them in error by not more than $1 \mathrm{~nm}$ throughout the ultraviolet and visible spectrum. However, if one wishes the uncertainties in his wavelength settings to be of the order of $0.1 \mathrm{~nm}$, a careful check of these direct-reading scales is necessary.

Certain sources and wavelengths that have proved especially suitable for the calibration of various types of spectrophotometers are listed in tables $l a$ and $1 b$ which are similar in scope and purpose to table 1 of Circular 484 (1)*.

*Numbers in parentheses refer to the References.

All values of tables $1 a$ and $1 b$ are consistent with those published in the M.I.T. wavelength tables (2). Which of these sources to use, and which wavelengths of the several sources are the most suitable, will depend on the type of instrument. Furthermore, the procedure will vary importantly depending on whether the instrument is a non-recording or a recording spectrophotometer. 
Table 1a. Wavelengths of Sources Suitable for Calibration of Spectrophotometers.

$\frac{\text { Wavelength }}{(\mathrm{mm})} \quad$ Note $\quad \frac{\text { Wavelength }}{(\mathrm{mm})} \quad$ Note $\frac{\text { Wavelength }}{(\mathrm{nm})}$ Note $\frac{\text { Wavelength }}{(\mathrm{m})}$ Note Mercury Arc in Quartz (Same wavelengths in glass above $300 \mathrm{~mm}$ )

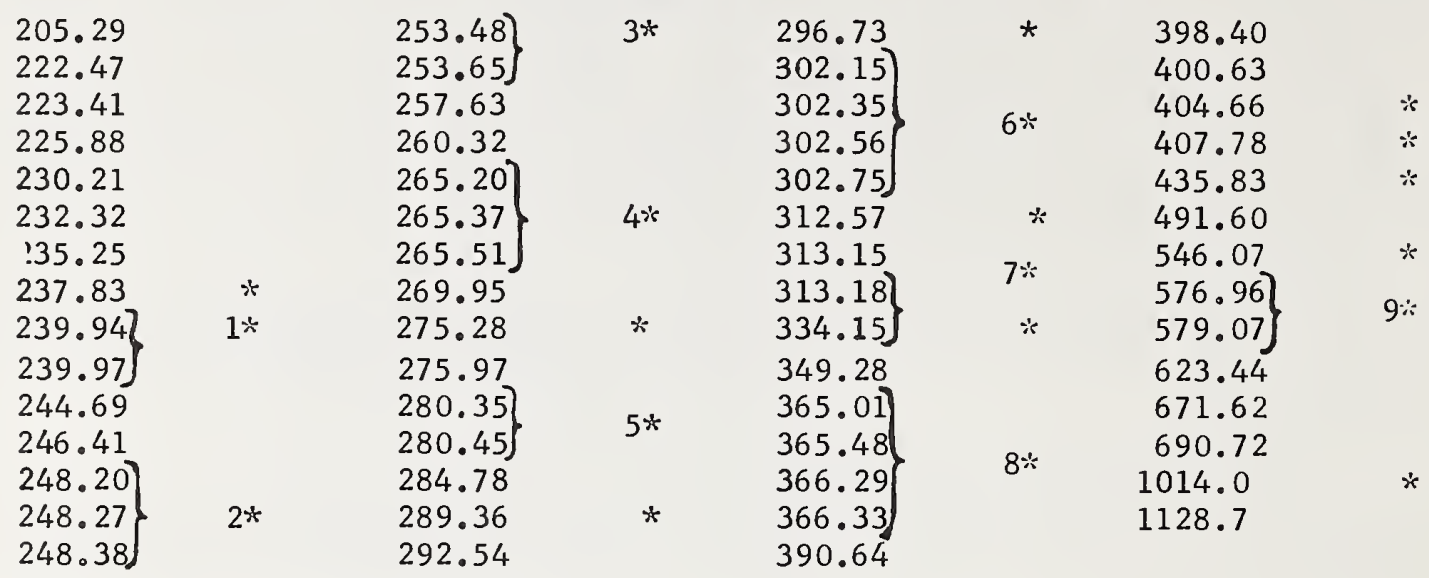

lielium Discharge Tube in Glass

$\begin{array}{llllrl}318.77 & 396.47 & 447.15 & * & 667.81 & * \\ 361.36 & 402.62 & 471.31 & * & 706.52 & * \\ 363.42 & 412.08 & 492.19 & & 728.13 & \\ 370.50 & 414.38 & 501.57 & * & 1083.0 & * \\ 381.96 & 438.79 & 504.77 & & & \\ 388.86 & * & 443.75 & 587.56 & * & \end{array}$

* These lines have been found most useful on the Beckman DU spectrophotometer.

1. A value of 239.95 is recommended for the unresolved pair.

2. A value of 248.3 is recommended when the 3 lines are unresolved.

3. The intensity of 253.48 is negligible compared to that of 253.65 .

The latter value should be used when the lines are unresolved.

4. The 265.20 line is somewhat stronger than the others and a value of 265.3 is recommended when the three lines are unresolved.

5. These two lines are of approximately the same intensity and a value of 280.40 is recommended for the unresolved pair.

6. The two shorter lines are considerably stronger than the other two. It is probable that a value of 302.25 should be used for the unresolved lines.

7. A value of 313.16 is recommended for the unresolved pair.

8. With the arc used on the Beckman DU spectrophotometer the ratio of Intensities for $365.01: 365.48: 366.33$ is $100: 48: 36$, approximately. The intensity of the 366.29 line appears negligible relative to that of 366.33.

9. These two lines are of approximately the same intensity and a value of 578.0 is recommended for the unresolved pair. 
Table 1b. Wavelengths of Sources Suitable for Calibration of Spectrophotometers

Neon Discharge Tube

$\begin{array}{ll}\begin{array}{l}\text { Wave- } \\ \text { length }\end{array} & \begin{array}{l}\text { Relative } \\ \text { Intensity }\end{array} \\ & \end{array}$

585.25

588.19

594.48

597.55

603.00

607.43

609.62

614.31

616.36

621.73

626.65

630.48

633.44

638.30

640.22

650.65

653.29

659.90

667.83

671.70

692.95

702.41

703.24

705.91

717.39

724.52

743.89

748.89

753.89

754.40
Aluminum Spark in Air

Wavelength

(nm)

216.88

217.40

220.46

221.00

226.35

226.91

236.71

237.21

237.31

237.34

237.84

256.80

257.51

257.54

263.16

265.25

266.04

281.62

308.22

309.27

358.69

394.40

396.15
Hydrogen Arc

Wavelength (nm)

$$
\begin{aligned}
& 434.05 \\
& 486.13 \\
& 656.28
\end{aligned}
$$

Sodium Arc

Wavelength

(nm)

589.00

589.59

Cesium Arc

Wavelength

(nm)

852.11

894.35 
The best procedure for checking the wavelength scale of a nonrecording spectrophotometer is by direct use of a source of radiant energy having spectral lines of suitable intensity and adequately spaced throughout the spectral range of interest. Various sources are available and can be recommended for such purpose. How many sources, or how many wavelengths, to use in such a calibration depends, of course, on the desires of the individual investigator.

In this connection it should be noted that the number of significant figures of importance in spectrophotometry (including "absorption spectroscopy") is of a different order of magnitude than that used in emission spectroscopy or in standard wavelength tables. In the visible spectrum with the usual type of spectrophotometer it seems impossible to maintain the wavelength calibration with uncertainties less than about $0.1 \mathrm{~nm}$. While the uncertainty may be less in the ultraviolet with a prism instrument, there seems no purpose served in giving standard wavelengths to better than $0.01 \mathrm{~nm}$ for spectrophotometric calibration.

Two suitable sources for wavelength calibration are the mercury lamp and the helium lamp. A mercury lamp in a quartz envelope is by far the best single source for wavelength calibration from 205 to $1014 \mathrm{~nm}$. A mercury lamp in a glass envelope provides the same spectral lines except tirat below about $300 \mathrm{~nm}$ they are not transmitted by the glass envelope.

The helium lines are especially well placed for wavelength calibration in the visible spectrum, and the strong lines at 388 and $1083 \mathrm{~nm}$ are also often very useful. Many other sources, flame or aíc, are available for visual wavelength calibration $(2,3)$ but most of these are too unstable for accurate calibration with a photoelectric detector.

These same sources and many others are also useful for the wavelength calibration of spectrographs used in photographic spectrophotometry. Between 200 and $400 \mathrm{~nm}$ the series of doublets obtained from the aluminum spark in air is very useful because they are so readily recognized.

Not all of the lines for any of the sources are given in tables la and $1 \mathrm{~b}$ but only those that are considered especially suitable for the purpose. Furthermore, not even all of those listed for any one source may be suitable for any one particular instrument. The mercury arc in quartz is an example. All of the lines listed (and still others) can be used for wavelength calibration of a photographic spectrophotometer over the range of sensitivity of the plate used. The lines from 404.7 to $690.7 \mathrm{~nm}$ can be used for visual calibration of a spectrophotometer. But not all of the lines are suitable for calibration of a photoelectric instrument, and those that prove adequate will depend on the sensitivity and slit widths characteristic of any particular instrument. One must be very careful that other lines are not included, in addition to the one on which the settings are supposedly being made, of sufficient intensity to affect the wavelength setting. 
Special attention should perhaps be called to the use of a cesium arc at 852.1 and $894.3 \mathrm{~nm}$ (4). From tables la and $1 \mathrm{~b}$ it is apparent that there are few suitable lines between 706.5 and $1014.0 \mathrm{~nm}$, particularly from steady sources necessary or desirable in the calibration of photoelectric spectrophotometers. The neon discharge tube gives many lines between 750 and $1000 \mathrm{~nm}$ (2) but these have not been found satisfactory in the calibration of photoelectric spectrophotometers. In the orange and red the neon lines are useful for visual calibration and many of these can be used to calibrate photoelectric spectrophotometers (5) if the sensitivity is such that very narrow slits can be used. The relative intensities (6) given in table 1b will help in case of overlapping.

The best technique to use in wavelength calibration of non-recording spectrophotometers, given a suitable source, will vary from instrument to instrument and method to method. A few general principles can be given here, however.

In photographic spectrophotometry it usually is sufficient to photograph a known spectrum at the top and bottom of the plate, unless the source used for the absorption spectra itself carries such known reference lines. A few of these reference lines will then serve to correlate that particular plate with whatever complete calibration curve has previously been established by more extensive measurements, with the various sources.

On visual and photoelectric non-recording spectrophotometers, it usually is necessary, for highest precision, to have a basic reference line to which all of the other wavelengths are compared by direct check. At the Bureau the $\mathrm{Hg}$ yellow lines have proved most suitable for the König-Martens visual spectrophotomęter (7). At the slit widths used the overlapping of the two lines gives a central brighter "line" taken as $578.0 \mathrm{~nm}$ with a luminous background against which the slit jaws are readily seen. A luminous background, or slight illumination of the ocular slit, always facilitates calibration when an eyepiece is used. Visua1 calibration without an eyepiece is usually less precise unless very narrow slits are used.

Two techniques have been used at the Bureau in the calibration of non-recording photoelectric spectrophotometers. On the Gibson spectrophotometer (8) the slits are always $0.1 \mathrm{~mm}$ wide or greater and the most reliable calibration is obtained by plotting galvanometer deflections at closely adjacent wavelengths. The most probably value for the wavelength reading is given by the intersection of the two straight lines resulting from a plot of the data for any given line, the correction being given by the difference between this value and the true wavelength. This is illustrated in reference (1). 
On the Beckman DU spectrophotometer the same method has been used (9), but at the Bureau it has seemed preferable and is much more rapid, to calibrate with a narrow slit and record the wavelength dial reading for the maximum left deflection of the galvanometer needle as the wavelength dial is slowly turned. The most suitable reference line on two of the Bureau's instruments has proved to be the Hg green line at $546.07 \mathrm{~nm}(5)$.

\section{$\underline{2.2}$ Recording Spectrophotometers.}

The initial wavelength calibration of a recording spectrophotometer, such as the manufacturer must,carry out in connection with cutting his cams or preparing his reading scale, is not here considered, but only the check of such a calibration by the user of the instrument.

Such a user can, of course, follow the procedure prescribed above for checking the wavelength calibration of non-recording spectrophotometers. However, there are two important reasons for following a different procedure for recording spectrophotometers. For such instruments it is desirable to have a calibration that is made with the instrument operating. It is further desirable in most kinds of work to have this calibration appear on the graph sheet so that difficulties connected rith positioning of the sheet, expansion or contracticn of the paper with humidity or temperature, or instrumental variations can be eliminated.

Wavelength calibrations of this kind can be made if a material is available having a number of strong and narrow absorpion or transmission bands suitably spaced over the spectral range of interest. Two materials have been used or suggested for this purpose: (a) Glasses containing rare-earth oxides, such as didymium glasses and holmium oxide glasses, have been used for many years at the National Bureau of Standards (10, 11), (b) quartz-Polaroid combinations have been proposed (12) and may prove useful for such work.

The use of a didymium glass or a holmium oxide glass in this manner would not in general be accurate unless it is calibrated at nearly the same slit widths as are to be used. Most of the absorption bands that are usable for the purpose are multiple bands and the wavelengths of maximum absorption often depend on the slit widths. This has been illustrated in previous publications $(1,10)$.

While the use of a didymium glass or a holmium oxide glass for checkIng the wavelength calibrations of a recording spectrophotometer is highly recommended, there are two other uses of these glasses which are not recommended. First, these glasses are not well suited for checking the photometric scale of any spectrophotometer, recording or non-recording. Transmitances at the peaks of the absorption bands are too dependent on slit widths, and transmittances on the steep parts of the curve are too dependent on slight wavelength errors, both as illustrated in Fig. 1 of reference (10) and in Fig. 8 of reference (1). Second, the use of these glasses to check the wavelength calibration of a non-recording spectro- 
photometer is considered much inferior from the standpoints of time, convenience and reliability to the direct use of line sources as described in Sec. 2.1. The National Bureau of Standards has consistently refused to accept didymium glasses or holmium oxide glasses for calibration for either of these two purposes.

\subsubsection{General Electric Recording Spectrophotometer.}

The NBS didymium glass standards were carefully calibrated by point-by-point measurements on the König-Martens visual and Gibson photoelectric spectrophotometers with slit widths approximating the 10- and 20- nanometer slits used on the NBS General Electric spectrophotometer. Some of these values have been published (13).

The most suitable didymium glass for the purpose, considering type of curve and availability, is a Corning 5120 glass of $3.0 \mathrm{~mm}$ thickness. While it is not known how much the wavelengths of maximum absorption of this 5120 glass might vary from melt to melt, glasses from at least three melts have been measured, and there has never been any certain variation among the samples tested. For much work it is probably safe to use the values given in table 2.

Table 2. Wavelengths of maximum absorption for Corning 5120 glasses of $3.0 \mathrm{~mm}$ thickness as obtained at the National Bureau of standards for the slit widths indicated.

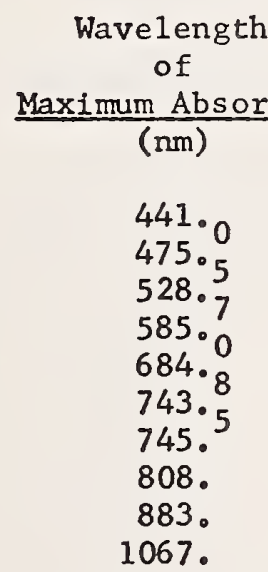

Approximate Spectrum
Interval
$\frac{\text { Transmitted by Slits }}{(\mathrm{nm})}$

$\begin{array}{ll}441.0 & 10 \\ 475.5 & 10 \\ 528.7 & 10 \\ 585.0 & 10 \\ 684.0 & 10 \\ 743.8 & 10 \\ 745.5 & 20 \\ 808 . & 20 \\ 883 . & 20 \\ 1067 . & 20\end{array}$

For those who wish greater certainty, however, the Bureau has obtained a supply of Corning 5120 glass in 2-inch polished squares and of $3.0 \mathrm{~mm}$ thickness. These are measured and the values reported in accordance with NBS test fee schedule 202.105, items d to $f$. The measurements consist of recording a curve of the test glass on the same sheet as the curve of the NBS standard glass and deriving values of the wavelengths of minimum transmittance of the former relative to 
those of the latter. The over-all uncertainties of the values so reported are considered to be not greater than $\pm 1 \mathrm{~nm}$ from $441.0 \mathrm{~nm}$ to $743.5 \mathrm{~nm}$, and not greater than $\pm 2 \mathrm{~nm}$ from $7 \overline{4} 5$ to $1067 \mathrm{~nm}$.

Method's of use of a calibrated didymium glass on a G. E. recording spectrophotometer are described in references (1), (10), and (13).

\subsubsection{Cary Model 14 recording spectrophotometer.}

The NBS holmium oxide glass standards were carefully calibrated by using a Cary Model 14 recording spectrophotometer, the wavelength indicating dial of which had previously been calibrated by means of a number of sources having wavelengths throughout the ultraviolet anc visible spectral regions. Measurements of the wavelengths of minimum transmittance were made as functions of slit width over the range 0.06 to 5.0 nanometers of spectral width. Eleven sharp absorption bands were found to be sufficiently symmetrical that the wavelengths of minimum transmittance indicated by the recorder remained constant for slit widths up to about 2 nanometers.

The most suitable holmium oxide glass for the purpose is a Corning 3130 glass of approximately 2.5 mm thickness. It is not known how much the wavelengths of minimum transmittance of this 3130 glass might very from melt to melt. It is known that, for some 3130 glasses, the absorption of the base glass prevents the use of the glass for wavelength calibration in the ultraviolet near 241 nanometers. For much work it is probably safe to use the values given in the following table.

Wavelengths of minimum transmittance for Corning 3130 glasses of $2.5 \mathrm{~mm}$ thickness as obtained at the National Bureau of Standards for slit widths less than $2 \mathrm{~nm}$.

\author{
Useful wavelengths \\ between 240 and $370 \mathrm{~nm}$
}

241.5

279.3

287.6

333.8

360.8
Useful wavelengths between 360 and $650 \mathrm{~nm}$

360.8

385.8

418.5

453.4

459.9

536.4

637.5

For those who require that the base glass of the standard transmit sufficiently for the standard to be useful at 241 nanometers, the Bureau has obtained a supply of Corning 3130 glass in 2-inch polished squares and of $2.5 \mathrm{~mm}$ thickness. These are measured and the values reported in accordance with NBS test fee schedule 202.105, items $g$ to $i$. 
The measurements consist of recording a curve of the test glass on the same sheet as the curve of the NBS standard glass and deriving values of the waveleng - s of minimum transmittance of the former relative to those of the latter. The over-all uncertainties of the values so reported are considered to be not greater than $\pm 0.5 \mathrm{~nm}$. The present supply of holmium oxide glass contains striae, and in some cases strains, which have not appreciably altered the wavelengths of minimum transmittance.

The methods of use of a calibrated holmium oxide glass on a Cary Model 14 recording spectrophotometer are similar to those described in references (1), (10), and (13) relating to the method of use of a didymium glass on a G. E. recording spectrophotometer. 
1. Kasson S. Gibson, Spectrophotometry (200 to $1000 \mathrm{mi} 11$ imicrons) NBS Circular 484 (1949)。

2. Massachusetts Institute of Technology Wavelength Tables, measured and compiled under the direction of George R。 Harrison (John Wiley \& Sons, Inc., New York, 1939)。

3. Spectrophotometry, report of O.S॰A. Progress Committee for 1922-23, K. S。 Gibson, Chairman, J。 Opt. Soc。Am。\& Rev。Sci。Inst。10, 169 (1925)。

4. N. C. Beese, Cesium vapor lamps, J。 Opt。 Soc. Am。 36, 555 (1946)。

5. Kasson S. Gibson and Margaret Mo Balcom, Transmission measurements with the Beckman quartz spectrophotometer, J. Research NBS 38, 601 (1947) RP1798; also J. Opt. Soc。 Am。37, 593 (1947)。

6. M。 Garbuny, Relative Intensitäten und Übergangswehrscheimlichkeiten der rotgelben Neonlinien, Zeit。 Physik 107, 362 (1937)。

7. Ho Jo McNicholas, Equipment for routine spectral transmission and reflection measurements, BS $\mathrm{J}$ 。 Research 1, 793 (1928) RP30.

8. K. S. Gibson, Direct-reading photoelectric measurement of spectral transmission, Jo Opt. Soc. Am。 and Rev。 Sci. Inst。 7. 693 (1923); also described in J。 Opt. Soc. Am. 21, 564 (1931)。

9. Ho Ho Cary and Arnold 0. Beckman, A quartz photoelectric spectrophotometer, J。 Opt。 Soc。Am. 31, 682 (1941)。

10. Kasson S. Gibson and Harry Jo Keegan, Calibration and operation of the General Electric recording spectrophotometer of the National Bureau of Standards, J. Opt. Soc. Am。28, 372 (1938).

11. H. Jo Keegan, J. C. Schleter, and V. R. Weidner, Ultraviolet wavelength standard for spectrophotometry, J. Opt. Soc。Am. 51, 1470 (1961).

12. George L. Buc and E. I. Stearns, Uses of retardation plates in spectrophotometry, II, Calibration of wavelength, J. Opt. Soc. Am. 35, 465 (1945)。

13. Harry J. Keegan and Kasson S. Gibson, On the use of working standards of didymium and Vitrolite glasses for spectrophotometric measurements, J. Opt. Soc. Am. 34, 770 (1944). 
 \\ Val. 76A, Na. 5, September-October 1972 \\ An Accurate Spectrophotometer for Measuring the Transmittance of Solid and Liquid Materials
}

\section{R. Mavrodineanu}

\author{
Analytical Chemistry Division, National Bureau of Standards, Washington, D.C. 20234
}

(May 31, 1972)

\begin{abstract}
The optical transmittance of solids and liquids as well as the molar absorptivity of various chemical species are parameters of fundamental significance in characterizing these materials. Meaningful transmittance data can be obtained only when the measurements are performed with well-known accuracy and precision. To perform such measurements, a high accuracy spectrophotometer was designed and assembled at NBS. Analytical Chemistry Division, and will be described in this paper. This singlebeam instrument is composed of a constant radiation source, a monochromator, a sample carriage, an integrating sphere-photomultiplier assembly followed by appropriate electronics, and a read out system consisting of a digital voltmeter and a computer data acquisition and handling provision. The accuracy of transmittance measurements is determined by the light-addition principle used in conjunction with a two-aperture arrangement. The spectrophotometer can be used in manual or automatic modes of operation. A detailed discussion of the data obtained with this instrument, used in both modes, will be presented together with its application to the certification of solid and liquid Standard Reference Materials for checking the photometric scales of conventional spectrophotometers.
\end{abstract}

Key words: Absorbance; automation of accurate spectrophotometer; instrumentation, spectrophotometric; spectrophotometry, high accuracy; standard reference material in spectrophotometry; transmittance.

\section{Introduction}

Optical transmittance is due to an intrinsic property of matter and characterizes a particular transparent material. Since this parameter is not known a priori, it must be determined by experimental procedures.

True transmittance values can be obtained only by using accurate measuring techniques and by taking into consideration all factors which can affect and distort the data.'

1 The optical transmittance of a solid material includes the reflection losses which occur at the air-solid interface.

The air-solid interface. The internal transmitlance is tefined as the transmittance of the material corrected for reflection losses (2). This internal transmittance can be calculated in principle from the
transmittance by using the well known Fresnel equations ( 1 , pp. 98 to 100 ). For

$$
R_{\mathrm{A}}=\frac{\left(n_{\mathrm{A}}-1\right)^{2}+n_{\lambda}^{2} a_{\lambda}^{2}}{\left(n_{\mathrm{A}}+1\right)^{2}+n_{\lambda}^{2} a_{\lambda}^{2}}
$$

For a nonabsorbing material and collimated radiation:

$$
R_{\mathrm{A}}=\frac{\left(n_{\mathrm{A}}-1\right)^{2}}{\left(n_{\mathrm{A}}+1\right)^{2}}
$$

For glass, $n$ is approximately 1.5 in the visible region of the spectrum, and $R$ will be about 4 percent at every air glass interface.

$$
R_{\alpha}^{\perp}=\frac{\sin ^{2}(\alpha-\beta)_{A}}{\sin ^{2}(\alpha+\beta)_{\alpha}}
$$

for perpendicular polarized radiation, and

$$
R_{\mathrm{a}}^{\prime}=\frac{\tan ^{2}(\alpha-\beta)_{x}}{\tan ^{2}(\alpha+\beta)_{x}}
$$

for parallel polarized radiation. where $\alpha$ and $\beta$ are the angles of incidence and refraction respectively

ln collimated radiation and in ajr, $\alpha=\beta=0$ and $R^{1}=R^{\|}=K$
Transmittance is the ratio of two radiation flux intensities. It is therefore necessary that the photometric scale of the spectrophotometer used to perform the measurements be accurate. The transmittance of a particular material is also a function of wavelength; hence the wavelength scale of the monochromator should also be accurate, and appropriate spectral bandpasses should be used. The measurements should be made using collimated radiations. Such radiations define unambiguously the actual path length through the trans. mitting medium, the reflection losses, and eliminate the effects of polarized radiations that are produced at the surface of the sample. Other important factors which must be considered are: homogeneity and stability of the sample, radiation scatter inside the sample, interference phenomena, stray radiation, polarization, fluorescence, temperature, particulate matter, and sur. face conditions. Since transmittance measurements depend on a diversity of factors, meaningful values can be obtained only by defining the experimental conditions for obtaining transmittance data $[1,2] .^{2}$ Spectrophotometers are used to perform two types of measurements:

(1) Quantitative determination of chemical species using the relation between optical transmission of the material, and the concentration as a measuring parameter. Under these circumstances, the photometric scale

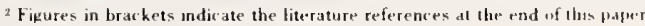


of the spectrophotometer is calibrated in meaningful units, using a series of referenne solutions having known concentrations of the species to be determined, rather than values of optical transmittance.

The accuracy of the measurements is related solely to the accuracy with which the concentration of the reference solutions is known and to the precision (stability, sensitivity, reproducibility) of the spectrophotometric method and instrument used. The accuracy of the photometric scale per se, is not a critical factor in such measurements.

The precision, stability, and reproducibility of the instrument $c$ an be checked before each series of measurements by careful use of solid or liquid reference filters having well established transmittance values.

(2) Determination of the optical transmission characteristics of solid or liquid materials, and the determination of molar absorptivities of chemical compounds. In both cases the accuracy of the photometric scale of the measuring instrument, among other things, is essential to provide true values. Ways to establish and check this important parameter are critically needed.

Since conventional spectrophotometers do not provide means to check photometric accuracy or to evaluate the possible sources of systematic errors, it was decided in 1969 to design and construct a research spectrophotometer on which transmittance measurements could be performed with well defined accuracy. Such an instrument would be used to determine optical transmittance of selected solids and liquids at various wavelengths. These materials can be used as standard reference materials (SRM's) to check the accuracy of the photometric scale of conventional spectrophotometers. The same certified SRM's could likewise be used to monitor the precision, stability, and reproducibility of those instruments $[3,4]$.

After a comprehensive examination of the literature in this field [5 to 34] arranged in chronological order, an instrument was developed which is similar in principle to the instrument at the National Physical Laboratory (NPL), Teddington, England, where a long tradition of high accuracy spectrophotometry exists. The instrument described in this work performs. measurements of radiant energy in the visible and ultraviolet region of the spectrum, with well established and high photometric accuracy. Transmittance measurements on solids and liquids can be made with this instrument using collimated as well as noncollimated beam geometry. The wavelength accuracy and spectral bandpass achievable are adequate to avoid degradation of photometric accuracy, and the other interferences mentioned have been given careful consideration, and, in most cases, have been assessed quantitatively.

The transmittance measurements on the optically neutral glass filters discussed in this work have been made with a noncollimated beam geometry corresponding to an aperture of about $f: 10$. The image of the exit slit of the monochromator $(8 \mathrm{mmx} 0.5 \mathrm{~mm})$ was produced at the center of the entrance face of the filter. All measurements have been made against air for the nonattenuated radiation flux, and no correction for reflection losses was made. Transmittance measurements made with noncollimated radiation by projecting the image of the exit slit of the monochromator on the entrance face of the sample using an opening of $f: 10$ (total angle of about $7^{\circ}$ or $8^{\circ}$ ), may differ by several parts in $10^{4}$ of the value when compared with similar measurements made with collimated radiations, as indicated in this Journal by K. Mielenz.

Noncollimated beam geometry was applied in this work to approach the measuring conditions used in most of the conventional spectrophotometers which are available today. A brief description of this instrument was given earlier in reference [3].

\section{Description of the Instrument ${ }^{3}$}

The high accuracy spectrophotometer, completed and tested in 1970, is a single beam instrument which contains the following components: (a) a constant radiation source, (b) a monochromator, (c) a sample holder, (d) a system to check the accuracy of the photometric measurements, (e) an integrating sphere attached to a photomultiplier-digital voltmeter unit, and ( $f$ ) the data presentation system. Figure $l$ illustrates schematically the arrangement of these various components. A circular neutral wedge is placed after the light source to select various levels of radiation intensities required for measurements. A description of the components is presented in the following sections.

a. The Radiation Source. Since the instrument is a single-beam type, it is essential that the radiation source be constant and homogeneout. Additional desirable conditions are: capability of monitoring the current supplied to the source and radiation similar to that from a Planckian radiator. The source is similar in design to that developed and used at NBS by H. J. Kostkowski and R. D. Lee of the Institute for Basic Standards. This source was duplicated in our instrument with the kind assistance of its developers.

The source is used in the spectral range $360 \mathrm{~nm}$ to $800 \mathrm{~nm}$ and consists of a tungsten incandescent filament lamp with a tungsten ribbon $8 \mathrm{~mm}$ long by $2 \mathrm{~mm}$ wide. The connections to the lamp terminals are soldered to minimize contact problems (see fig. 6). The direct current required to operate this lamp at approximately $3000 \mathrm{~K}$ is $18 \mathrm{~A}$ across a $6 \mathrm{~V}$ drop; our source is operated at $5 \mathrm{~V}$ and $15 \mathrm{~A}$. The d.c. power supply is capable of delivering $15 \mathrm{~V}$ and $50 \mathrm{~A}$, and can be operated in constant current or constant voltage modes. To achieve the constant current mode an external sensing resistor of $0.1 \Omega$ and $50 \mathrm{~A}$ and a current control circuit are placed in series with the power supply. A feedback voltage across this resistor is connected to the sensing system. The character

The commercial instruments and parts used in the construction of the opectrophotometer are identified in the addendum. 


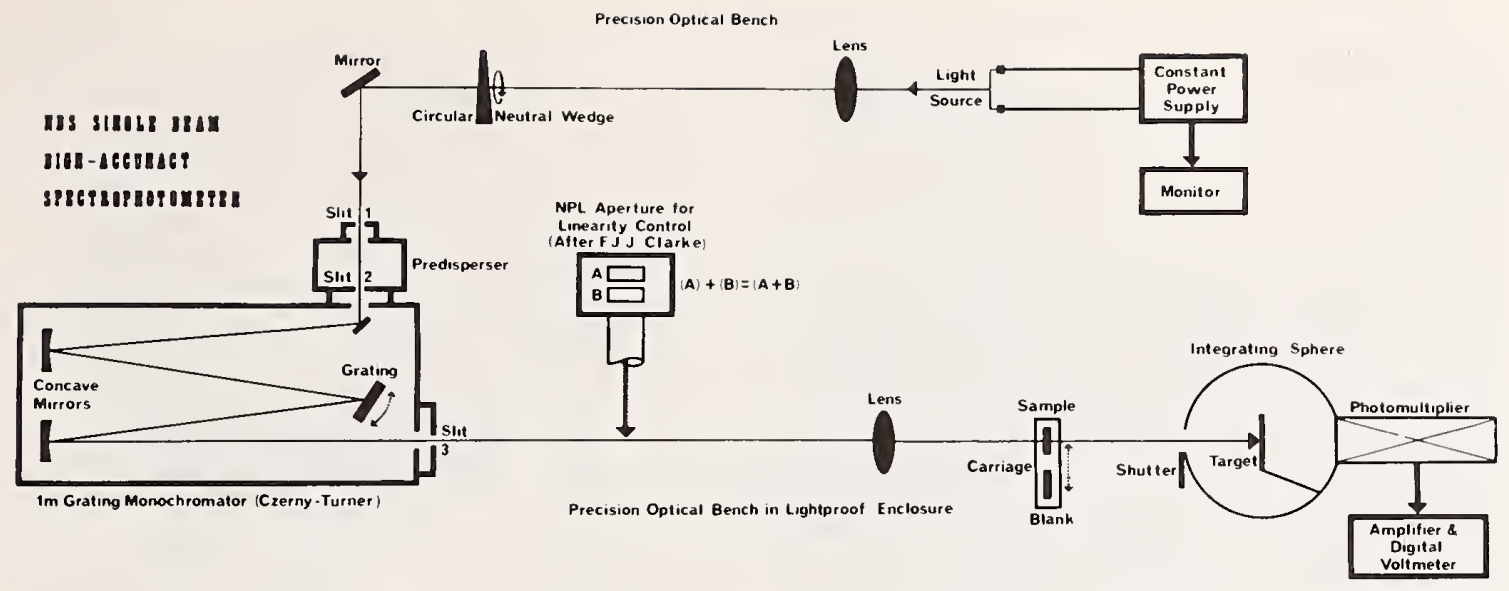

FICURE 1. Principle of the single beam high accuracy spectrophotometer. The aperture unit is placed on the optical bench only when linearit $y$ measurements are performed.

istic of this function is the ability to automatically change its output voltage to maintain a constant current to the load resistor, which, in our case, is the lamp source. The nominal current regulation obtained is better than 0.01 percent, and the stability over an 8 hour period, at constant load temperature, is better than 0.02 percent. The stability of the current delivered to the lamp is monitored with a high accuracy potentiometer used in conjunction with a null meter. This meter is sensitive to variations in the current supplied to the lamp from 1 part in 1000 to 1 part in $1,000,000$ per division (fig. $l$ and fig. 14). The potentiometer is connected to the current source across a resistor $(0.01 \Omega$ and $100 \mathrm{~A})$ placed in series with the lamp.

The demagnified ( 2 to 1 ) image of the ribbon filament is projected on the entrance slit of the predisperser by a fused quartz (nonfluorescent $\mathrm{SiO}_{2}$ ) lens whose focal distance is $254 \mathrm{~mm}$ and diameter is $44 \mathrm{~mm}$. This and the other lenses used in the optical system, were calculated by K. Mielenz of the Institute for Basic Standards at NBS. The lenses are mounted in carriers which permit orientation in any position. A circular neutral wedge is placed between the light source and the predisperser. This wedge, evaporated inconel on a fused quartz disc ( $150 \mathrm{~mm}$ diam), is linear in density and provides a light attenuation of 100 to 1 . The wedge is motor driven (l rev. per s) to select proper radiation intensity levels as required by the measurements (figs. 2, 3, and 4). The radiation source used for measurements in the ultraviolet region to $275 \mathrm{~nm}$ is a single coil tungsten-bromine incandescent lamp (fig. 5) supplied by an adequate power source; below $275 \mathrm{~nm}$, a deuterium discharge lamp is contemplated.

b. The Monochromator. The monochromator is a l-m Czerny-Turner type grating instrument with a dispersion of $0.8 \mathrm{~nm} / \mathrm{mm}$. The flat grating has 1200 grooves per $\mathrm{mm}$ covering a surface of $100 \times 100 \mathrm{~mm}$.
The monochromator is provided with a predispersing attachment to reduce the stray light (fig. 3 ). This pre-

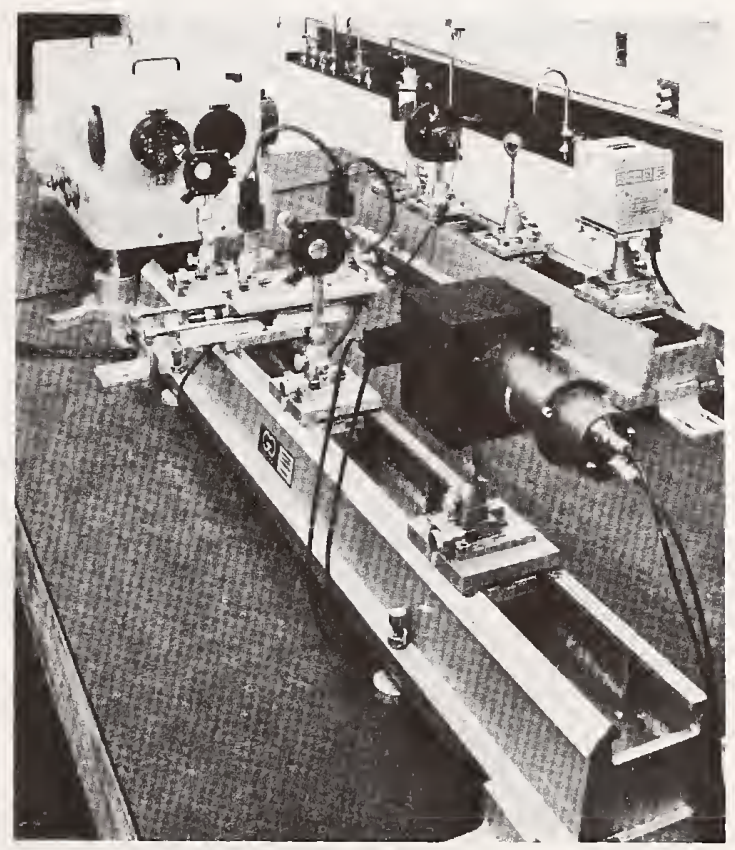

Figure 2. General views of the spectrophotometer. Rear: optical bench carrying the tungsten-halogen radiation source used for checking the alignment of optical component s, followed by a quartz lens, the circular quartz neutral wedge, and a flat mirror. Left: the $1-m$ Czerny-Turner grating monochromator (the predisperser is not illustrated here). Front: optical bench carrying a quartz lens, the single-sample and blank carriage, a second quartz lens, and the integrating sphere with the photomultiplier housing. 


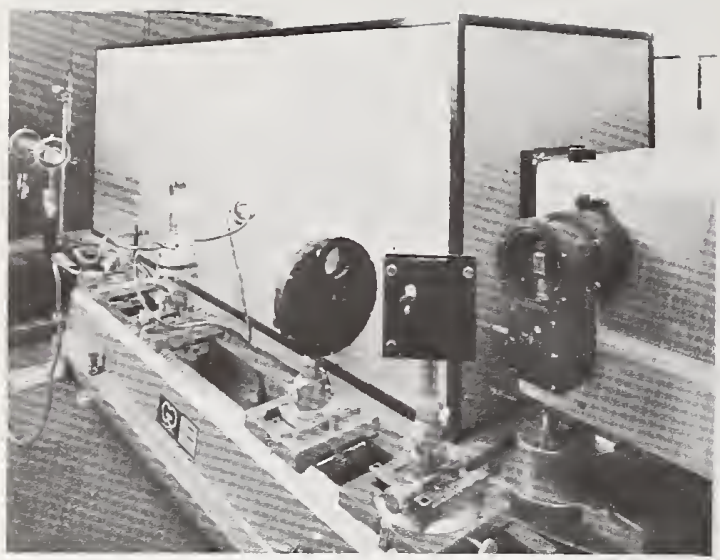

Figuri 3. Close view of the tungten ribbon filament lamp on its adjustable holder, followed by the quartz lens-circular neutral wedge assembly, and by the flat mirror in its adjustable holder. The $30^{\circ}$ quartz prism Littrow type predisperser is located at the entrance slit of the $1 \mathrm{-m}$ grating monochromator. Extreme left: neon gas laser used to check the optical alignment, and mercury discharge lamp for wavelength calibration. When in use, the tungsten ribbon lamp is surrounded by an enclosure with black walls ( $50 \mathrm{~cm} \times 50 \mathrm{~cm} \times 70 \mathrm{~cm}$ high). Rear: enclosure containing the optical units illustrated in figure 2.

disperser is a small quartz prism monochromator connected to the scanning system of the $1-m$ instrument. A wavelength counter permits readings to $0.1 \mathrm{~nm}$ and the scanning speed can be varied from 0.05 $\mathrm{nm}$ to $200 \mathrm{~nm} / \mathrm{min}$ by a 12 speed synchronous electric motor.

The optical components are placed on precision lathe bed type optical benches which are 160 and $120 \mathrm{~cm}$ long, and are equipped with appropriate carriers provided with $x-y-z$ adjustments.

c. Sample Carrying Systems. The spectrophotometer is provided with two sample carrying systems. Une system measures one sample and its blank, while the other system permits sequential measurements for seven samples and eight reference reading positions against air, and can be operated manually or automatically through a computer interfaced with the instrument.

The single sample carrying unit consists of a platform provided with two vertical holders which can accept $\frac{3}{4}$-in $(14 \mathrm{~mm})$ rods and a variety of sample supports (fig. 2). These holders can be moved laterally through a rack and pinion arrangement. The platform is mounted on 4 ball bushings which ride on two horizontal rods and can be moved pneumatically across the optical axis. The pneumatic operation was recommended by G. E. Moore and J. T. Sterling of the Institute for Materials Research at NBS and by L. Owen, a guest worker at NBS. The travel dis. tance is 8 in $(20 \mathrm{~cm})$ and the linear movement is smooth; the position of the platform and the sample in and out of the optical beam, can be reproduced within $0.025 \mathrm{~mm}$. This unit is illustrated in figure 2

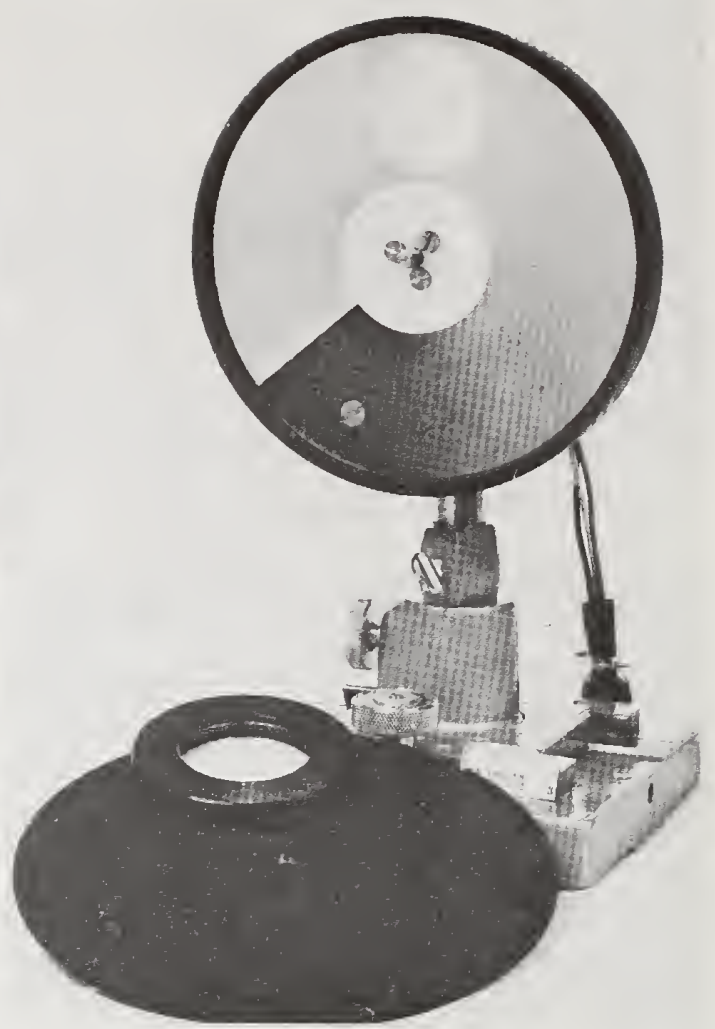

Figure 4. Close view of the circular, neutral wedge. The front plate which carries the fused silica lens was removed to show the fused silica disc with the evaporated metal layer.

and is located between the two quartz lenses. The sample holder is designed to accept conventional solid or liquid filter holders which fit most spectrophotometers. These holders are provided with a thermostating jacket, and can be rotated in the horizontal plane through a $10 \mathrm{~cm}$ diameter rotating table.

A filter holder which permits the rotation and scanning of the sample in the $x-y$ direction is also available (fig. 7). It is provided with micrometer screws having a total linear motion of $25 \mathrm{~mm}$ with $0.01 \mathrm{~mm}$ per division. The seven-sample carrying unit is illustrated in figures 8 and 9 and consists of a semicircular aluminum-alloy plate placed horizontally on an appropriate carrier on the optical bench along the optical axis. This plate, which is $32 \mathrm{~cm}$ in diameter and $2.5 \mathrm{~cm}$ thick, can be rotated clockwise through a pneumatically operated precision ratchet system in increments of $12^{\circ}$. The stepwise rotation utilizes a solenoid valve which is operated electrically by a switch located outside the enclosure. This switch can be operated manually or automatically by computer (fig. 14). 


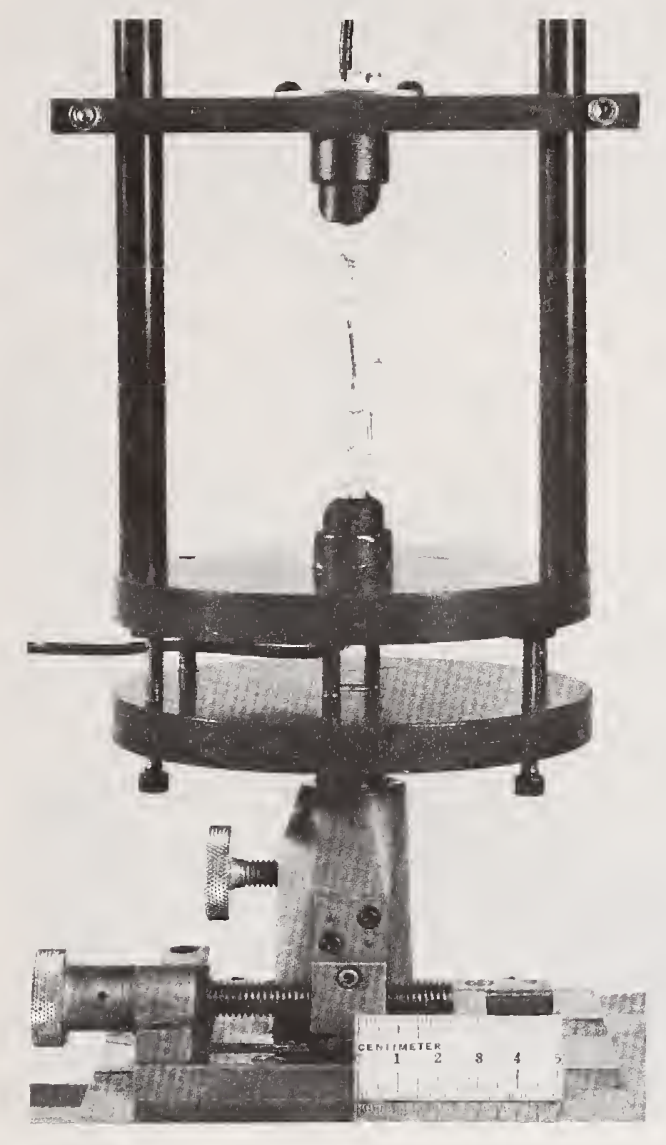

Figure 5. Single coil tungsten halogen lamp in the adjustable holder.

The semicircular plate carries seven sample holders similar to those used for the single sample system described earlier. The holders are placed at $24^{\circ}$ intervals and are separated by blank spacings. About $\mathrm{l}$ at $\mathrm{m}$ of air pressure is used to operate the plate and the rotation is set at 2 s per $12^{\circ}$ step when the automatic computer operating mode is used.

d. System to Check the Accuracy of the Photometric Reading. Since the high accuracy spectrophotometer is single beam, accurate photometric data are obtained when there is a linear relation between the measured radiation flux and the corresponding response of the photodetector.

l,inearity of photodetectors can be measured by several means: the inverse square law $[7,15]$ : the use of optical elements having a known transmittance which can be determined by other means [17] and the light addition principle of Elster and Ceitel using a plurality of ligrht sources $[5,6,8,9,10,13,18,19,20,28,31,33$, $34 \mid$ or multiple apertures $[11,12,14,16,21,23,25,26$, 27, 30|. A novel approach to the problem of accurate

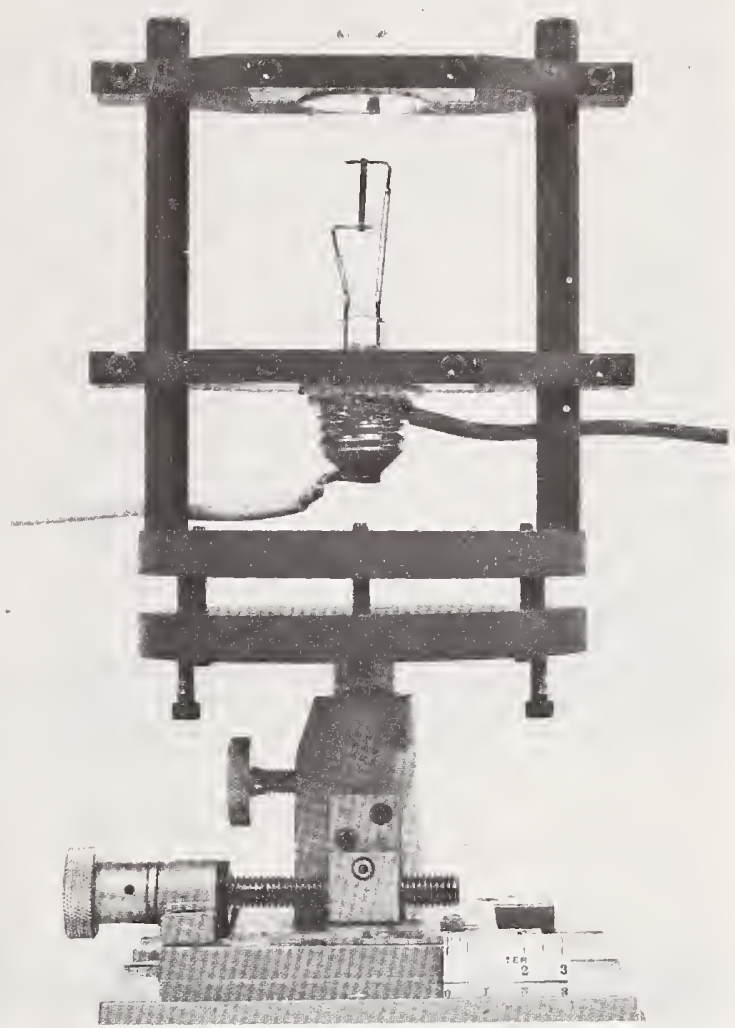

Figure 6. The tungsten ribbion filament lamp in the newly designed adjustable holder. I he platform which carries the lamp is similar to that described in figure 5 and can be oriented in the horizontal plane through the six screws spaced around the edges of the platform at $60^{\circ}$ intervals. Three screws push the platform while the other three pull.

The current-supplying wires are soldered directly to the lamp terminals to eliminate contact problems

photometric measurements was described by $\mathrm{O}$. C. Jones and F. J. J. Clarke $[24,29]$ and by F. Desvignes and J. Ohnet [32]. A critical discussion of some aspects of accurate spectrophotometry will be found in an NBS manuscript by (,ibson and associates [22]. The radiation addition principle, using two apertures with one source of radiation, was chosen for our work. The aperture method for checking the linearity of photometric data was in use at the National Physical I aboratory from about 1930 onwards, and one form of it was described by Preston and Cuckow [11] in conjunction with a single beam spectrophotometer. using a five aperture screen. One year later, Buchmüller and König [12] described and used a two aperture unit. At NBS. Barbrow [14] used a 10 aperture arranwment, while Harding [16] and Cordle and Habell [25] a, NII, described a two aperture system. Multiapertures were used by Hoppmann [21]. Bischoff [23]. Sanders [26] and Nonaka and Kashima [27|. Finally. Clarke [30] 


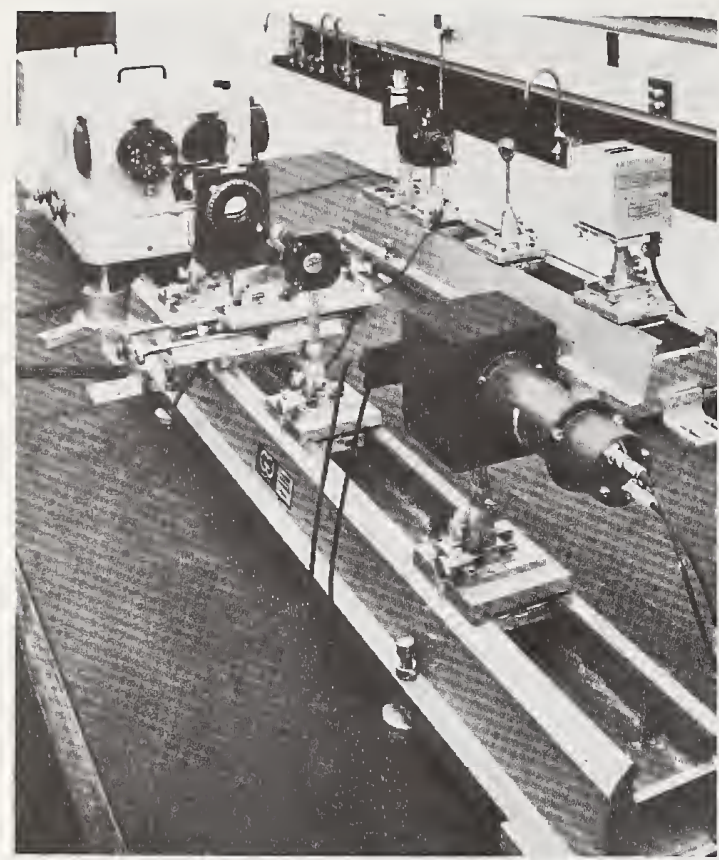

Figure 7. Same as figure 2 except tor the sample holder which in this case is capable of rotating the sample $360^{\circ}$ and to disolace it in the $x-y$ direction through the micrometer screws.

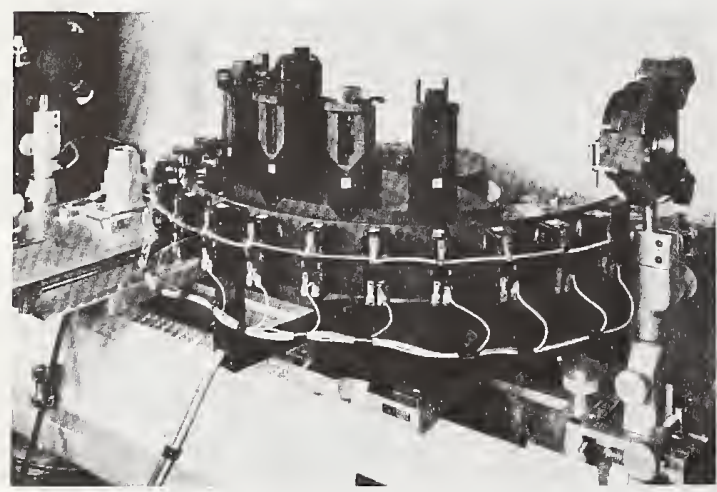

Figure 8. Circular platform carrying seven filter holders. The $1 \mathrm{~b}$ position switches ( 7 sample posilions and 8 blank positions) are visible along with the two quartz lenses. The exit slit of the monochromator is at left.

discussed in detail the use of a two aperture system to check the accuracy of photometric dat a obtained on the spectrophotometer at NII. It is this two aperture system which is used at NBS.

The two aperture unit consists of a metal plate (130 $\mathrm{mm}$ by $100 \mathrm{~mm}$ ) containing two rectangular

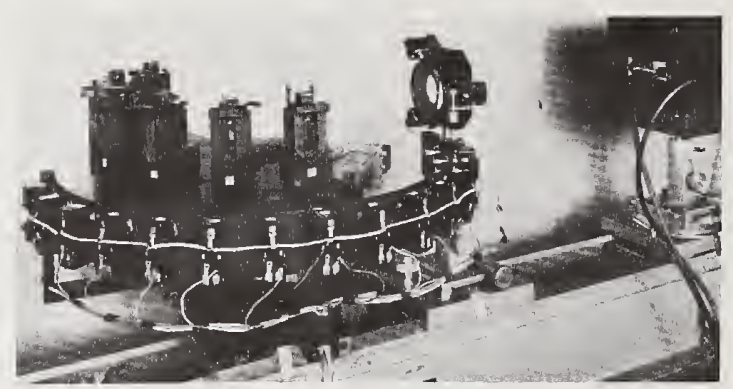

Figure 9. Same as figure 8 . The pneumatic cylinder which rotates the circular platform through a ratchet mechanism is visible at the rear of the platform. The integrating sphere with its pneumatic shutter is seen at right.

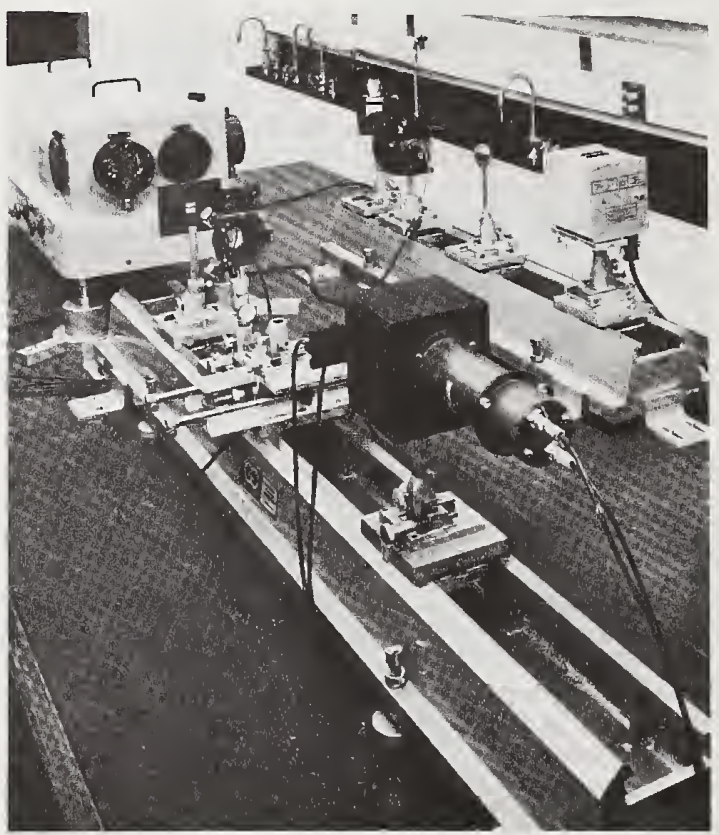

Figure 10. Same as figure 2. In this case the dual-aperture unit for linearity control is located on the optical bench after the exit slit of the monochromator.

windows, $A$ and $B,(20 \mathrm{~mm}$ by $8 \mathrm{~mm}$ ) located one above the other (figs. 10,11,12). Each aperture can be closed by a light-tight shutter which is operated pneumatically by remote control (fig. 14). The aperture plate is placed in the optical path after the exit slit of the monochromator and within the optical solid angle of the instrument. The image of the apertures is then projected on the target of the integrating sphere. A fused quartz lens with a focal distance of $190 \mathrm{~mm}$ and a diameter of $60 \mathrm{~mm}$ is used for this purpose. The arrangement is illustrated in figure 10 . No optical element 


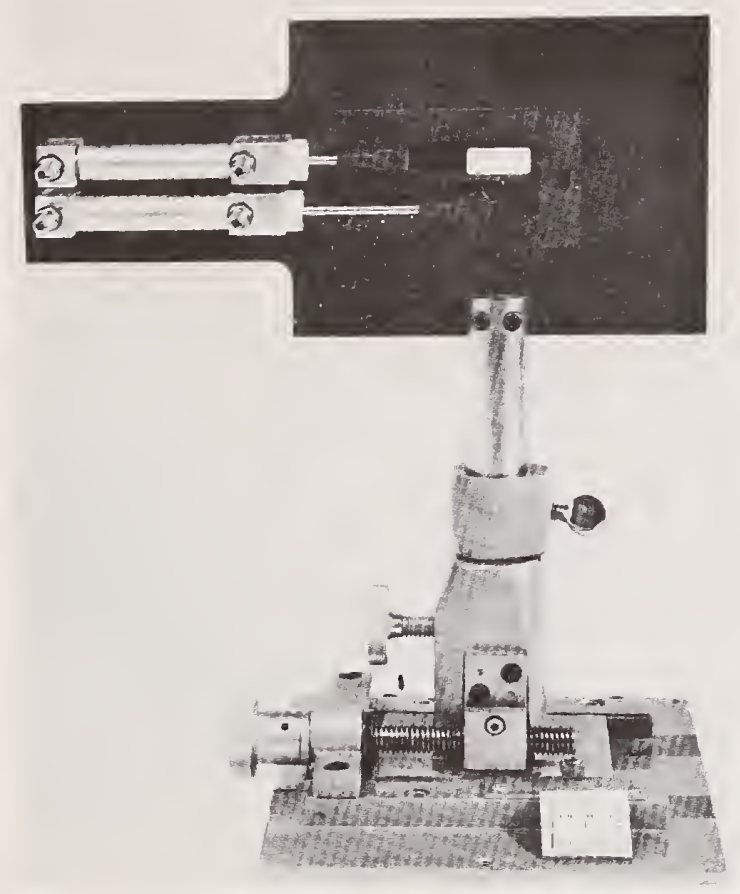

Figure 11. Detail of the dual-aperture unit showing its construction and the pneumatic system which operates the two shutters One aperture is open, the other is ciosed.

should be placed between the aperture plate and the monochromator. The linearity check consists of measuring the photocurrent produced when aperture $A$ is open then closed, and then aperture $B$ is open and then closed. The value of $(A)+(B)$ is compared with the values obtained with both apertures $(A+B)$ open. If the system is linear these two values should be identical:

$$
(A)+(B)=(A+B) \text {. }
$$

If this is not the case, the system shows nonlinearity which is proportional to the amount by which the sum of $(A)+(B)$ differs from $(A+B)$. This difference is then used to correct the transmittance values measured on the solid or liquid filters.

e. Integrating Sphere and Photomultiplier Arrangement. The radiations emitted from the exit slit of the monochromator and passing through the aperture or the filter are received on the target of the integrating sphere. This sphere is illustrated in figures $2,7,9$, and 10 . A block of aluminum made from identical halves was cut to produce a half sphere in each block. The halves were joined together to form a hollow sphere. Its diameter is $125 \mathrm{~mm}$ and a target, made from a circular plate, $35 \mathrm{~mm}$ in diameter, is located at the center of the sphere. The front surface of the sphere has a $20 \mathrm{~mm}$ diameter opening. This

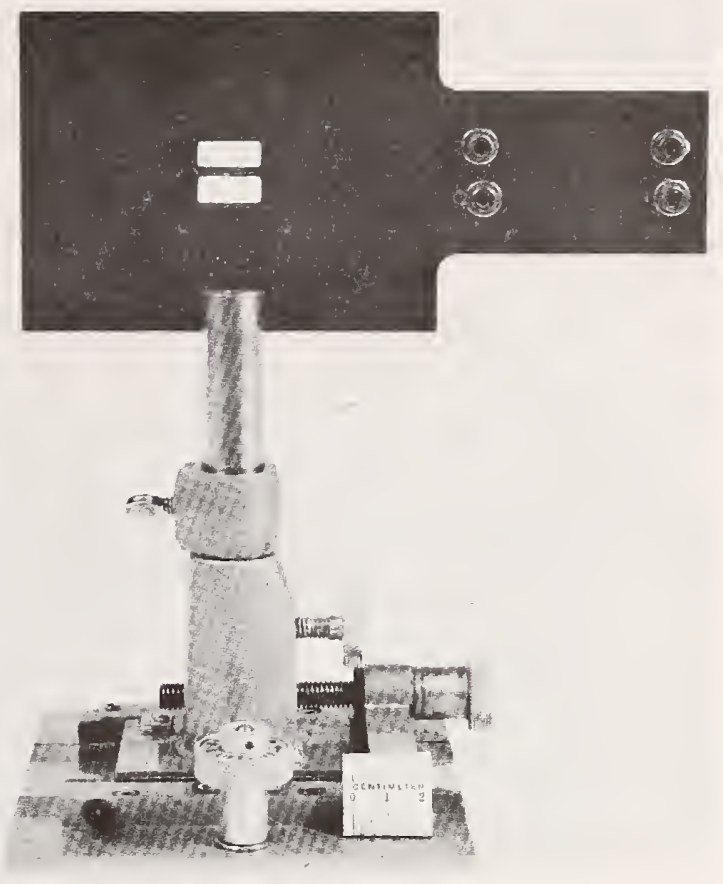

Figure 12. Front view of the dual-aperture unit, with both apertures open.

opening can be closed by a shutter which is operated remotely by a pneumatic system. A $50 \mathrm{~mm}$ diameter opening is at the opposite end to which the housing of the photomultiplier is attached by an " $O$ " ring to provide a light-tight joint. The inside of the sphere is coated using a suspension of $\mathrm{BaSO}_{4}$; the outside is painted black.

Under these circumstances the sensitive surface of the photodetector receives the radiations originating from the exit slit of the monochromator only after these radiations have undergone at least two diffuse reflections.

The photomultiplier is a $50 \mathrm{~mm}$ flat-faced, silica end window tube with a $44 \mathrm{~mm}$ cathode and 11 venetian blind dynodes having CsSb secondary emitting surfaces. The cathode is an S-20 or tri-alkali type. The spectral range of this tube is from below $200.0 \mathrm{~nm}$ to $850.0 \mathrm{~nm}$. The operating volt age used is $850 \mathrm{~V}$. The photomultiplier output is supplied to a current-tovoltage converter consisting of an operational amplifier with high precision feedback resistors with values of $10^{6}, 3 \times 10^{6}, 10^{7}, 3 \times 10^{7}$, and $10^{8} \Omega$. Dark current compensation is also available. This electronic system, described in figure 13 was designed and assembled by $K$. W. Yee of the NBS Electronic ln. strumentation Section. The output from the currentto-voltage unit is connected to a digital voltmeter, illustrated in figure 14 , with one microvolt resolution on the $1 \mathrm{~V}$ full scale range. 


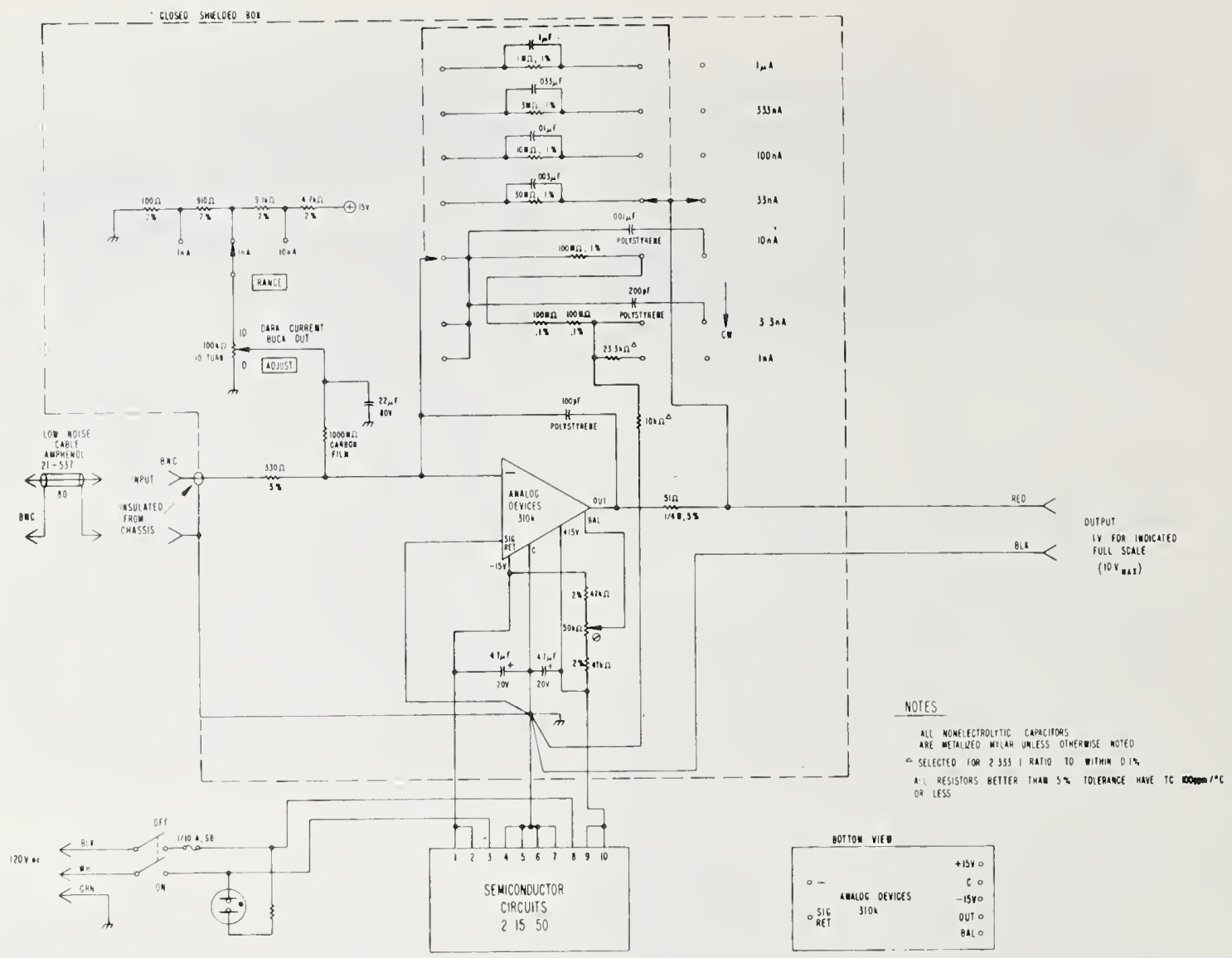

Figure. 13. Schematic of the current-to-voltage circuitry. Courtesy of K. W. Yee.

The optical components located after the exit slit of the monochromator, including the photomultiplier tube, are enclosed in a light-tight box $200 \mathrm{~cm}$ long, 70 $\mathrm{cm}$ wide and $76 \mathrm{~cm}$ deep (fig. 3). The removable front panel is provided with a sliding door to permit rapid access to the filter-holder system. The box contains outlets for the compressed air which operates the apertures, sample carriage and integrating sphere shutter, and for the electrical connection from the photomultiplier. The inside walls are lined with thermal insulation painted black. When in use, all nonblack metal parts are covered with a black cloth to reduce stray light. The entire equipment is placed on a vibration isolation table $3.66 \mathrm{~m}$ by $1.52 \mathrm{~m}$. The optical benches and the monochromator are secured by stops which are attached to the table surface. The alignment of the optical parts is made and checked periodically with a low-power laser shown in figure $3(\mathrm{CW}$ gas laser, output power $2 \mathrm{~mW}, \lambda 6328 \AA$ ) and with a high intensity tungsten-halogen lamp shown in figure 5 . f. Data Collection and Presentation Systems. The data output from the dicital voltmeter (DVM). corresponding to the current generated at the photomultiplier tube by the radiations passing through the aperture system $(A, B, A+B)$ or the samples $(I)$ and blanks $\left(I_{0}\right)$, can be obtained by visual means or computer operation. Both methods have been used in this work with good results. In the visual mode, the operator examines the dicrital voltmeter display and takes a mental average of the data. The display rate is adjusted to about one reading per second.

When measurements are taken by computer, the display of the digital voltmeter is adjusted to a faster rate: for instance, 10 to 20 data per second, depending on the capabilities of the instrument and measurement requirements. In our work, we use 10 data per second and collect 50 individual data for each measurement. This information is fed to the computer which calculates and prints the results as averages with the corresponding standard deviation, relative standard 


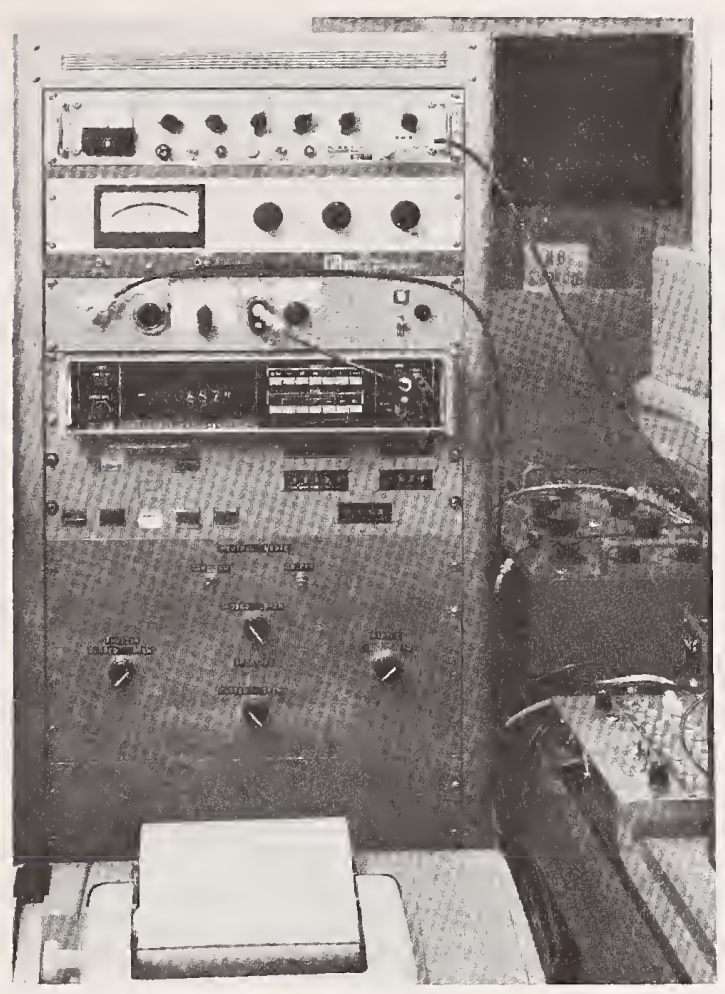

Figure 14. Console containing the power supply for the photomultiplier tube. the de null detector, the current-to-voltage converter, the digital voltmeter, the command panel for computer operation, and the command panel for the pneumatic operation of the shutter, aperture system, and single sample carriage. The electric switches for operating the circular neutral wedge are also located on this panel.

Middle right potentiometer for monitoring the de current supplied to the tungsten ribbon filament lamp.

At bottom left: teletype for data presentation.

Right: light panel which indicates the position of the automatic seven sample holder.

deviation, and sample position number to identify the measurement. When transmittance measurements are made on individual samples or when linearity checks are performed, the readings are initiated manually for every position. When the seven sample holder is used for sequential measurements, the operation is performed automatically by the computer. It is programmed to take a predetermined number of individuat DVM readings (50), print the arithmetic averaye, followed by the standard deviation, relative standard deviation, percent transmittance and sample position (fig. 15). At the conclusion of each measurement, the computer initiates a signal which rotates the holder to the next position. This is followed by the data taking and sample changing sequence until the measurements are stopped manually or automatically by a provision made in the computer program.
CALIBKATION ONF SHM930 AT $440 \mathrm{NM}$ SAMPLE NUMBF. ANO POSITION: $1-70$ IN $2: 1-79$ iN $4 ; 2=79$ IN $A$; REFEFFNCE IN B: $3-79$ IN 10 :
$1-91$ IN $12 ; 3-91$ IN 14

$P \cap S$
1
2
3
4
5
6
7
8
9
10
11
12
13
14
15
1
2
3
4
5
6
7
8
9
10
11
12
13
14
15
1
2
3
4
5
6
7
8
9
10
11
12
13
14
15

15
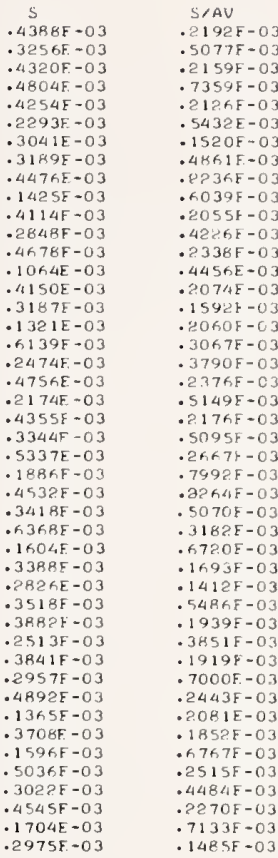

PFRCENT T

32.044

$32 \cdot+23$

2.1 .095

32.741

11.7 H5

33.6 .74

11.4 .27

$32.03 f$

$32 \cdot+03$

21.095

32.785

11.790

33.675

11.924

32.035

32. $\mathrm{fOO}$

21.097

32.774

$11.7 \mathrm{kP}$

33.658

11.928

Figure 15. Computer data presentation

The programming of the entire computer operation was developed by J. Aronson, R. Freemire, and J. Wing. The computer-instrument interfacing was performed by F. Ruegg and R. Shideler of the NBS Analytical Chemistry Division, Technical Service Group, under the supervision of J. DeVoe.

\section{Stability of the Electronic System}

As a rule, before taking measurements with the spectrophotometer, a warmup period of one hour is required. The room temperature is kept at $24 \pm 1{ }^{\circ} \mathrm{C}$, and the relative humidity is 35 percent. The particulate matter is controlled through special filters which rates the room in the 100,000 class.

The dark current of the photomuliplier tune was measured by taking 15 replications each consisting of the average of 50 individual digital voltmeter readings. These measurements were made using $850 \mathrm{~V}$ at the anode. The average dark current under these circumstances produced $0.000682 \mathrm{~V}$ with a relative standard deviation of 0.71 percent.

In all of our work, a dark current buck-out arrangement was used. A series of measurements were performed to determine the stability of this dark current compensation. To this effect, 15 consecutive measurements, each representing the average of $50 \mathrm{indi}$ 
vidual digital voltmeter readings, were made and the average dark current value was $0.000024 \mathrm{~V}$ with a relative standard deviation of 23.1 percent.

Four tests were made to determine the stability of the electronic system and the radiation source using the computer data ac $q u$ usition mode.

a. Stability of the Current-to-Voltage Converter. A constant voltage was supplied to the converter using the dark current compensation provided on the unit. Fifty individual measurements were taken every 5 seconds and the average value was printed along with its percent standard deviation. The measurements were then repeated 15 times and an average of the 15 values was calculated along with the corresponding percent standard deviation. These measurements were then repeated three times. The results are summarized in table 1. This table also presents the values for the first group and the average values and corresponding percent standard deviation for the two consecutive groups. It can be seen from the stability of the current-to-voltage unit that measurements can be performed with a reproducibility of about 0.0012 (at the $67 \%$ confidence level) expressed as percent standard deviation for a single determination. The time interval between the first and last group of measurements was $15 \mathrm{~min}$.

TABLE 1. Stability of the current-to-voleage converter alone measured in three groups of 15 replications each

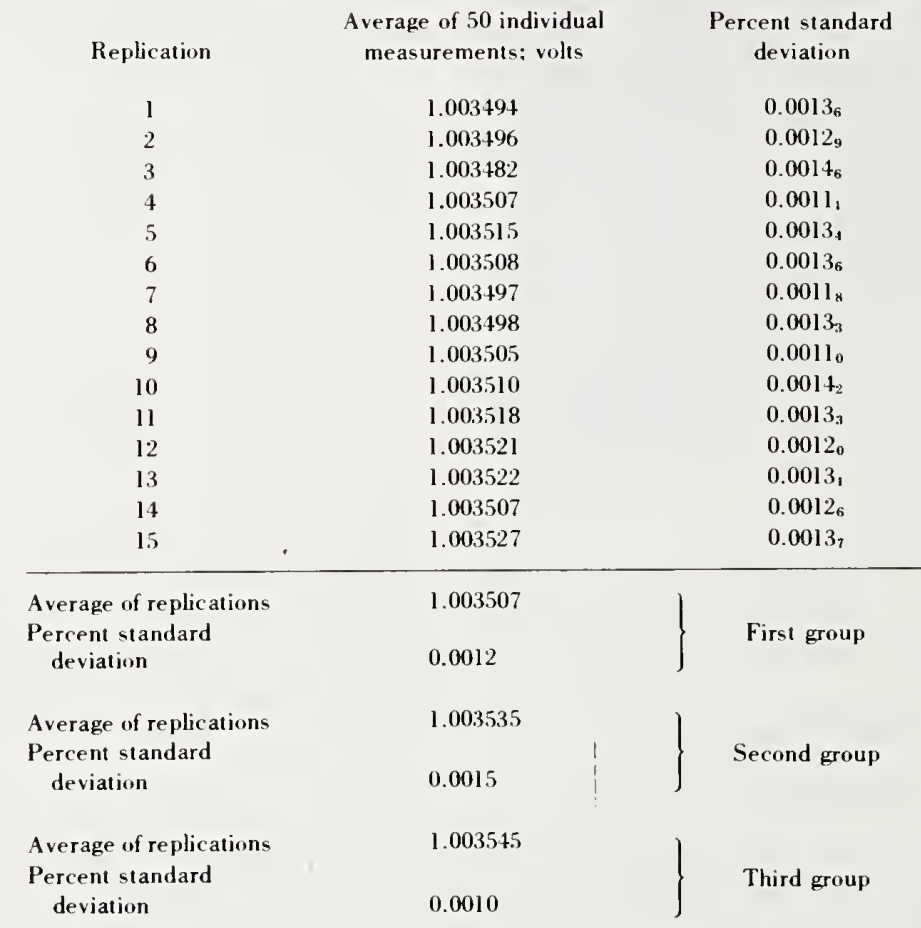

b. Stability of the Current-to-Voltage Converter Plus the Photomultiplier Tube Supplied with $850 \mathrm{~V}$ and in Total Darkness. The measurements were made as previously described and the results are presented in table 2 .

c. Stability of the Current-to-Voltage Converter and the Photomultiplier Tube Supplied with $850 \mathrm{~V}$ and Exposed to the Radiation of a Tritium Activated Fluorescence Source. A constant radiation source consisting of a tritium activated phosphor was placed before the integrating sphere and a series of measurements were taken following the technique described above. Table 3 shows the results. d. Stability of the Current-to-Voltage Converter, the Photomultiplier Tube Supplied with $850 \mathrm{~V}$, and the Tungsten Ribbon Filament Lamp. The same measuring procedure as mentioned in $a, b$, and $c$ was used here. In this case, however, the incandescent tungsten lamp was used as the source of radiation. Table 4 summarizes the results of four groups of measurements over a period of 20 min. This last series of measurements indicate that the single-beam spectrophotometer is capable of producing measurements of radiation fluxes with a percent standard deviation of about $0.022_{5}$ for single measurements with $2.00 \mathrm{~V}$ at the photomultiplier tube anode. 
TABLE 2. Stability of the current-to-voltage converter and the photomultiplier tube at $850 \mathrm{~V}$ in total darkness

\begin{tabular}{|c|c|c|}
\hline Replication & $\begin{array}{l}\text { Average of } 50 \text { individual } \\
\text { measurements; volts }\end{array}$ & $\begin{array}{c}\text { Percent standard } \\
\text { deviation }\end{array}$ \\
\hline 1 & 1.012329 & 0.027 \\
\hline 2 & 1.012342 & $0.048_{8}$ \\
\hline 3 & 1.012322 & $0.027_{2}$ \\
\hline 4 & 1.012320 & $0.033_{8}$ \\
\hline 5 & 1.012394 & $0.043_{5}$ \\
\hline 6 & 1.012421 & $0.015_{3}$ \\
\hline 7 & 1.012404 & $0.018_{4}$ \\
\hline 8 & 1.012406 & $0.029_{6}$ \\
\hline 9 & 1.012365 & $0.019_{6}$ \\
\hline 10 & 1.012402 & $0.019_{1}$ \\
\hline 11 & 1.012465 & $0.025_{2}$ \\
\hline 12 & 1.012412 & $0.061_{5}$ \\
\hline 13 & 1.012451 & $0.023_{5}$ \\
\hline 14 & 1.012417 & $0.029_{8}$ \\
\hline 15 & 1.012481 & $0.024_{8}$ \\
\hline \multirow{3}{*}{$\begin{array}{l}\text { Average of replications } \\
\text { Percent standard } \\
\text { deviation }\end{array}$} & 1.012395 & \multirow{3}{*}{ First group } \\
\hline & & \\
\hline & 0.0050 & \\
\hline \multirow{3}{*}{$\begin{array}{l}\text { Average of replications } \\
\text { Percent standard } \\
\text { deviation }\end{array}$} & 1.012467 & \multirow{3}{*}{ Second group } \\
\hline & & \\
\hline & 0.0033 & \\
\hline \multirow{2}{*}{$\begin{array}{l}\text { Average of replications } \\
\text { Percent standard } \\
\text { deviation }\end{array}$} & 1.012510 & \multirow[b]{2}{*}{ Third group } \\
\hline & 0.0035 & \\
\hline
\end{tabular}

In these measurements the stability of the direct current (nominal $5 \mathrm{~V} ; 14 \mathrm{~A}$ ) supplied to the tungsten ribbon lamp was monitored with the potentiometer, and the variation of this current was less than one part in $10^{5}$ during a series of 15 consecutive measurements $(5 \mathrm{~min})$.

Following the four stability tests discussed earlier, a consecutive series of six measurements were made to determine the reproducibility of transmittance measurements. To this effect seven Schott NG-4 neutral glass filters were placed in the automatic sample carrying system and the data acquisition and sample changing operations were performed automatically through the computer unit. As mentioned previously. the sample carrying system can accept seven samples in positions $2: 4 ; 6 ; 8 ; 10 ; 12 ; 14$, and eight intermediate positions $1 ; 3 ; 5 ; 7 ; 9 ; 11 ; 13 ; 15$. The odd numbers correspond to measurements of the nonattenuated radiation beam passing through air and are marked $I_{0}$, while the even numbers correspond to measurements of the attenuated radiations after passing through the absorbing material and are marked $I$. The uncorrected transmittance, $T$, is then

$$
T=\frac{l}{I_{0}}
$$

The radiation flux from the tungsten ribbon filament lamp was attenuated with the circular neutral wedge until a photocurrent corresponding to about $2.0020 \mathrm{~V}$ was obtained for the nonattenuated beam $I_{0}$. The photomultiplier tube was supplied with $850 \mathrm{~V}$ and the 30 $\mathrm{M} \Omega$ resistor was lised at the current-to-voltage converter. For every position, 50 digital volt meter readings were taken by the computer at a rate of 10 to 15 per second. The average value was printed along with the sample position, the standard deviation, the relative standard deviation, and the transmittance values for the glass filters $2 ; 4 ; 6: 8 ; 10 ; 12$; and 14 :

$$
T_{2}=\frac{I_{2}}{\frac{I_{1}^{0}+I_{3}^{0}}{2}} ; T_{4}=\frac{I_{4}}{\frac{I_{3}^{0}+I_{5}^{0}}{2}} ; T_{6}=\frac{I_{6}}{\frac{I_{5}^{0}+I_{7}^{0}}{2}} ; \text { etc. } \ldots .
$$

until the seven glass filters were measured. This sequence was repeated six times and the results are given in table 5 .

As can be seen from these data, the reproducibility of sequential transmittance measurements can be performed with an average standard deviation of 0.010 percent for a single determination.

\section{Wavelength Calibration}

The wavelength scale of the monochromator is provided with a counter which indicates wavelength directly in ằngstroms. This counter is checked for 
TABle 3. Stability of the current-to-voltage converter and the photomultiplier tube at $850 \mathrm{~V}$ and exposed to the radiation of a tritium activated fluorescent source

\begin{tabular}{|c|c|c|}
\hline Replication & $\begin{array}{l}\text { Average of } 50 \text { individual } \\
\text { measurements; volts }\end{array}$ & $\begin{array}{c}\text { Percent slandard } \\
\text { deviation }\end{array}$ \\
\hline 1 & 1.536345 & $0.027_{\mathrm{s}}$ \\
\hline 2 & 1.536326 & $0.030_{2}$ \\
\hline 3 & 1.536196 & $0.022_{\mathrm{s}}$ \\
\hline 4 & 1.536289 & $0.023_{\mathrm{s}}$ \\
\hline 5 & 1.536106 & $0.030_{9}$ \\
\hline 6 & 1.536117 & $0.031_{4}$ \\
\hline 7 & 1.535916 & 0.025 \\
\hline 8 & 1.536065 & $0.023_{8}$ \\
\hline 9 & 1.536179 & $0.029_{3}$ \\
\hline 10 & 1.536003 & $0.023_{3}$ \\
\hline 11 & 1.536083 & $0.021_{5}$ \\
\hline 12 & 1.535961 & $0.026_{3}$ \\
\hline 13 & 1.536052 & $0.031_{3}$ \\
\hline 14 & 1.536095 & $0.026_{6}$ \\
\hline 15 & 1.536092 & $0.026_{2}$ \\
\hline ge of replications & 1.536122 & \\
\hline nt standard & & Firsl group \\
\hline iation & 0.0082 & \\
\hline ge of replications & 1.535768 & \\
\hline nt slandard & & Second group \\
\hline iation & 0.0095 & \\
\hline ge of replications & 1.535522 & \\
\hline nt standard & & Third group \\
\hline iation & 0.0054 & \\
\hline
\end{tabular}

accuracy with a low pressure mercury discharge lamp placed befere the entrance slit of the monochromator. The following wavelengths were used for calibration: $3650.2 \AA ; 4046.6 \AA ; 4077.8 \AA ; 4339.2$ $\AA ; 4347.5 \AA ; 4358.4 \AA ; 4916.0 \AA ; 5460.7 \AA: 5769.6 \AA$; and $5790.7 \AA$. If additional reference wavelengths are needed, a Cd-Hg or a He-discharge lamp could be used for calibration. The wavelength counter was then checked using the procedure recommended by Gibson [2], and a slit of $0.1 \mathrm{~mm}$ which is equivalent to an effective spectral bandpass of $0.08 \mathrm{~nm}$. The deviation of the wavelength counter from the true value was found to be less than $\pm 0.1 \mathrm{~nm}$ : hence no wavelength correction was applied to the measurements discussed here.

\section{Stray Radiation}

Tests were made to determine the stray radiant energy (SRE) in the monochromator proper. as well as in the photometric arrangement. The measurement of stray radiation in the monochromator. that is, the radiation energy at wavelengths different from those of the nominal spectral bandpass transmitted through the instrument, is not easy or infallible. A detailed discussion of this instrumental parameter was given in an ASTM Tentative Method [35] and the pro- cedure recommended in this work was used to determine SRE in the blue and yellow spectral range. In this procedure, a solution of methylene blue, which has a strong absorption in the range from $\lambda 600$ to $660 \mathrm{~nm}$ is used. The SRE using a slit of $1 \mathrm{~mm}(0.8 \mathrm{~nm})$ was equal to or less than five parts in $10^{5}$.

The SRE generated inside the photometric system is defined as the radiant energy which falls on the photosensitive detector without passing through the absorbing sample. This SRE is usually produced by reflections and scattering of radiations on the optical and mechanical parts located between the exit slit of the monochromator and the integrating sphere. The measurements were performed using a slit of $1 \mathrm{~mm}$ by placing a front surface mirror at the sample position. which reflects to the instrument all radiations received from the exit slit imaged at the mirror surface. The size of this image was about $8 \mathrm{~mm}$ high and $1 \mathrm{~mm}$ wide. In this way, a maximum SRE was generated in the spectrophotometer. The measurements were then performed at $\lambda 577.3 \mathrm{~nm}$, using a radiation flux intensity five times greater than that used in routine transmittance measurements, by determining the dark current of the photomultiplier with the shutter in the closed position at the integration sphere. An average dark current of $0.040 \mathrm{mV}$ was observed. The mirror was then placed at the sample position, the shutter 
TABle 4. Stability of the current-to-voltage converter, the photomultiplier tube at $850 \mathrm{~V}$, and the tungsten ribbon filament lamp

\begin{tabular}{|c|c|c|}
\hline Replication & $\begin{array}{c}\text { Average of } 50 \text { individual } \\
\text { measurements; volts }\end{array}$ & $\begin{array}{c}\text { Percent standard } \\
\text { deviation }\end{array}$ \\
\hline 1 & 2.002395 & $0.038_{0}$ \\
\hline 2 & 2.001356 & $0.022_{6}$ \\
\hline 3 & 2.002145 & $0.024_{7}$ \\
\hline 4 & 2.000975 & $0.026_{2}$ \\
\hline 5 & 2.001944 & $0.020_{7}$ \\
\hline 6 & 2.000925 & $0.028_{1}$ \\
\hline 7 & 2.001832 & $0.026_{1}$ \\
\hline 8 & 2.000825 & $0.023_{5}$ \\
\hline 9 & 2.001551 & $0.026_{3}$ \\
\hline 10 & 2.000960 & $0.02 \mathrm{l}_{2}$ \\
\hline 11 & 2.001739 & $0.023_{1}$ \\
\hline 12 & 2.000851 & $0.024_{4}$ \\
\hline 1.3 & 2.001729 & $0.028_{2}$ \\
\hline 14 & 2.000825 & $0.023_{0}$ \\
\hline 15 & 2.001557 & $0.024_{4}$ \\
\hline Average of replications & 2.001441 & \\
\hline $\begin{array}{l}\text { Percent standard } \\
\text { deviation }\end{array}$ & 0.026 & First group \\
\hline Average of replications & 2.001517 & \\
\hline $\begin{array}{l}\text { Percent standard } \\
\text { deviation }\end{array}$ & 0.012 & Second group \\
\hline Average of replications & 2.000826 & \\
\hline $\begin{array}{l}\text { Percent standard } \\
\text { deviation }\end{array}$ & 0.025 & Third yroup \\
\hline Average of replications & 2.001268 & \\
\hline $\begin{array}{l}\text { Percent standard } \\
\text { deviation }\end{array}$ & 0.027 & Fourth group \\
\hline
\end{tabular}

TABl. 5. Reproducibility of transmittance measurements on seven Schott NG-4 glass filters No. $2 ; 4 ; 6 ; 8 ; 10$; 12 ; and 14

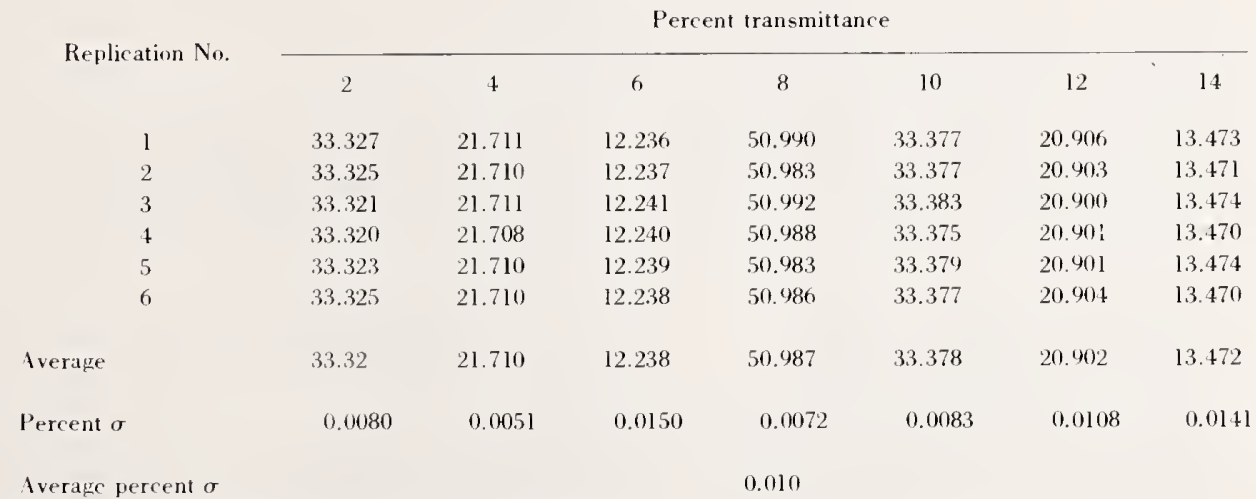

was opened and measurements were made again. The average value found was $0.037 \mathrm{mV}$. This indicated that no SRE could be detected under the experimental circumstances.

\section{Linearity Control}

The single-beam static optical system described in this work permits the unequivocal use of the radiation 
addition principle by means of the double-aperture method for determining departure from linearity of the entire optical, photometric, and electronic system, and thus of the photometric accuracy of transmittance measurements.

The double-aperture and its positioning on the optical bench was described earlier. Its use will now be illustrated, and follows the procedure developed and used at the National Physical Laboratory.

Since the linearity of photometric data for a given photomultiplier tube depends on the anode voltage, the values at the current-to-voltage converter, and the ambient temperature, all measurements were made using identical experimental conditions. These same conditions were maintained when transmittance meas. urements were performed. Since the linearity is, within 1 part in $10^{4}$, not usually a function of wavelength [36], all measurements were performed at $\lambda$ $565.0 \mathrm{~nm}$. A recent study of this parameter at NBS by Mielenz and Eckerle indicates that there may be a relation between wavelength and linearity at the level of 1 part in $10^{5}$ [38].

The intensity of the radiation flux produced by the tungsten ribbon lamp was attenuated with the circular neutral wedge until a photocurrent equivalent to $2.0020 \mathrm{~V}$ was obtained when both apertures, $\mathrm{A}$ and $\mathrm{B}$, were open. A setting of $850 \mathrm{~V}$ was used at the photomultiplier tube with a $30 \mathrm{M} \Omega$ resistor at the currentto-voltage converter. Fifty individual DVM readings were taken and the average value for $(A+B)$ was printed. Aperture $B$ was then closed, and $50 \mathrm{DVM}$ readings were taken. The average value for aperture $A$ was printed. The average value for aperture $B$ was then obtained in a similar manner by closing aperture $A$ and opening aperture $B$. This sequence was repeated three times, ending with an $(A+B)$ value.

Identical measurements were made over a range of attenuation corresponding to 4 cascaded steps of 2 to $l$ as illustrated in the actual example which follows:

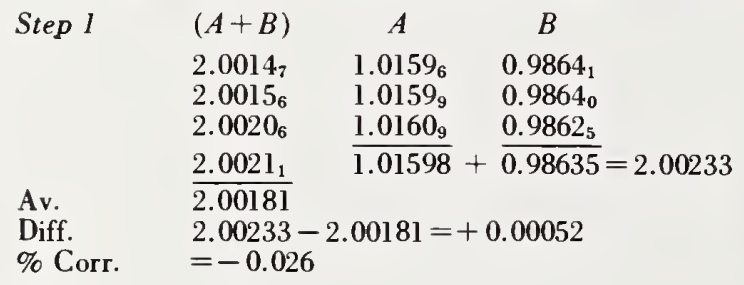

$\begin{array}{llcc}\text { Step 2 } & (A+B) & A & B \\ & 1.0004_{9} & 0.5102_{0} & 0.4910_{8} \\ & 1.0007_{8} & 0.5099_{6} & 0.4909_{1} \\ & 1.0006_{6} & \underline{0.5100_{4}} & 0.4911_{5} \\ & \frac{1.0009_{0}}{0.51007}+\overline{0.49105}=1.00112 \\ \text { Av. } & 1.00071 & \\ \text { Diff. } & 1.00112-1.00071=+0.00041 \\ \text { \% Corr. } & =-0.041\end{array}$

$\begin{array}{cccc}\text { Step } 3 & (A+B) & A & B \\ & 0.5006_{2} & 0.2565_{7} & 0.2443_{0}\end{array}$

$\begin{array}{llll} & 0.5005_{6} & 0.2567_{3} & 0.2443_{6} \\ & 0.5007_{0} & 0.2566_{5} & 0.2443_{2} \\ \text { Av. } & \frac{0.5006_{2}}{0.50063} & 0.25665 & \\ \text { Diff. } & 0.50098-0.50063=+0.00035 \\ \text { \% Corr. } & =-0.069 & \\ & & \\ \text { Step } 4 & (A+B) & A & B \\ & 0.2502_{0} & 0.1287_{2} & 0.1217_{5} \\ & 0.2502_{8} & 0.1285_{6} & 0.1216_{8} \\ & 0.2501_{9} & 0.1285_{4} & 0.1216_{6} \\ \text { Av. } & 0.2502_{3} & 0.12861 & 0.12170=0.25031 \\ \text { Diff. } & 0.25023 & & \\ \text { \% Corr. } & 0.25031-0.25023=+0.00008\end{array}$

The correction curve is established from these data by plotting voltages on the abscissa and the corresponding additive, correction value on the ordinate. These are tabulated below and illustrated in figure 16.

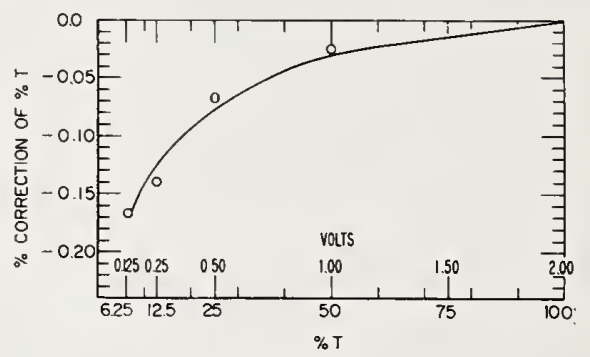

FlGURE 16. Linearity correction curve.

$\begin{array}{lcc}\text { Voltage } & \% T & \text { \% Correction of \% } T \\ & & \\ 2.00 & 100 & 0.0 \\ 1.00 & 50 & 0.026 \\ 0.50 & 25 & 0.067 \\ 0.25 & 12.5 & 0.14 \\ 0.125 & 6.25 & 0.167\end{array}$

When transmittance measurements are performed, the $I_{0}$ reading is initially set with the circular neutral wedge to a value near $2.0020 \mathrm{~V}$. The $I$ value is then measured. If the initial $I_{0}=2.00214 \mathrm{~V}$ and final $I_{0}=2.0022_{8} \mathrm{~V}$ and $I=0.54220 \mathrm{~V}$, then percent $T$ is:

$$
\frac{0.54220}{\frac{2.00214+2.00228}{2}} \times 100=27.081
$$

which is the noncorrected value. To correct this value, one takes from the ordinate of figure 16 the value corresponding to 0.54220 on the abscissa which, in this case, is 0.072 . The corrected percent $T$ value is then:

$$
27.081-\left(\frac{27.081 \times 0.072}{100}\right)=27.061 \text {. }
$$


Mielenz and Eckerle have studied recently the double aperture method for testing photometric linearity, and have used a curve-fitting procedure for finding the nonlinearity correction rather than the method described earlier (38).

\section{Sample Position}

A series of measurements were performed to determine the magnitude of error which could occur when the sample is oriented with its entrance face at an angle to, the incoming radiation beam. The single sample holder provided with the rotating table, as described in section II, paragraph c, was used. Transmittance measurements were performed by producing the image of the exit slit of the monochromator at the entrance face of the sample (aperture f:10). The data are shown in table 6 . The consequence of this condition on transmittance measurements is discussed by Mielenz in this Journal.
Table 6. Percent transmittance $(\% T)$, measured on three neutral glass filters $1.0 ; 1.5$; and $2.0 \mathrm{~mm}$ thick at $\lambda=440 \mathrm{~nm}$, at three angles of incidence

$\begin{array}{lccc}\begin{array}{l}\text { Angle of } \\ \text { incidence }\end{array} & \begin{array}{c}\text { Filter } \\ 1.0 \mathrm{~mm}\end{array} & \begin{array}{c}\text { Filter } \\ 1.5 \mathrm{~mm}\end{array} & \begin{array}{c}\text { Filter } \\ 2.0 \mathrm{~mm}\end{array} \\ \text { Normal incidence } & 32.91_{5} & 19.83_{8} & 11.60_{6} \\ 1^{\circ} & 32.89_{9} & 19.83_{3} & 11.60_{4} \\ 2^{\circ} & 32.89_{7} & 19.81_{9} & 11.59_{9} \\ 3^{\circ} & 32.88_{1} & 19.81_{2} & 11.58_{9}\end{array}$

Similar measurements were made to determine the identity of positions on the seven-sample automatic changer described in section II, paragraph c. For this experiment, seven neutral glass filters A; B; C; $D ; E ; F$; and $G$ were used and were positioned in holders $2 ; 4 ; 6 ; 8 ; 10 ; 12$; and 14 in three different arrangements as described by Garfinkel, Mann and Youden [39].

TABLE 7. Evaluation of the identity of the seven stations of the automatic sample changer

Percent Transmittance (\%T) at station number (St. No.) $2 ; 4 ; 6 ; 8 ; 10 ; 12$; and 14 for filters $A, B, C, D, E, F$, and $G$ at $\lambda=465.0 \mathrm{~nm}$

\begin{tabular}{|c|c|c|c|c|c|c|c|c|}
\hline Ru & No. & A & B & C & D & $\mathbf{E}$ & F & G \\
\hline & $\% T$ & 27.08 & 16.44 & 46.39 & 26.12 & 15.22 & 37.34 & 23.23 \\
\hline I & St. & & & & & & & \\
\hline & No. & 2 & 4 & 6 & 8 & 10 & 12 & 14 \\
\hline & $\% T$ & 27.07 & 16.40 & 46.39 & 26.11 & 15.21 & 37.34 & 23.23 \\
\hline II & St. & & & & & & & \\
\hline & No. & 14 & 2 & 4 & 6 & 8 & 10 & 12 \\
\hline & $\% T$ & 27.08 & 16.43 & 46.39 & 26.11 & 15.21 & 37.33 & 23.23 \\
\hline III & St. & & & & & & & \\
\hline & No. & 10 & 12 & 14 & 2 & 4 & 6 & 8 \\
\hline
\end{tabular}

Transmittance measurements were then performed on all filters for the three different arrangements and the results are given in table 7 . From these data it can be concluded that the seven stations are interchangeable and will produce measurements which will not differ by more than one part in one thousand.

\section{Influence of Polarized Radiations on Transmiftance Measurements}

This effect was determined by measuring the trans. mittance of a Schott NG-4 neutral glass filter at four wavelengths using radiations emerging from the predisperser-monochromator unit, and by projecting the image of the exit slit $(8 \mathrm{by} 0.5 \mathrm{~mm})$ at the entrance face of the filter with a convergent beam geometry corresponding to an $f: 10$ opening. The glass filter was checked prior to measurements with a polariscope for freedom of internal tensions. Column one of table 8 shows the results obtained when transmittance measurements were made using the radiations produced by the spectrophotometer. Column two shows the results

obtained when a polarizing sheet, with the vibration plane horizontal, was placed in front of the glass filter. The measurements obtained with the vibration plane in vertical position, are given in column three.

These measurements show that polarized radiations san affect transmittance measurements of solid glass filters when noncollimated beam geometry is used. This effect is predicted by the Fresnel equations mentioned in the introduction and should disappear when collimated radiations are used (1, pg. 100).

\section{Comparison of Transmittance Measurements}

Two sets of solid filters were used in a comparative test to determine the reproducibility of transmittance measurements between two laboratories. One set was made from three neutral glass Schott NG-4 filters having nominal percent transmittances of $10 ; 20$; and 30 . The second set was made as described elsewhere [4]. Three evaporated metal (Inconel) on fused quartz (nonfluorescent) plates having nominal percent 
TABLE 8. Effect of polarization on percent transmittance $(\% T)$ measured at four wavelengths on a Schott NG-4 glass filter

\begin{tabular}{|c|c|c|c|c|}
\hline \multirow[b]{2}{*}{$\begin{array}{l}\text { Wavelength } \\
\mathrm{nm}\end{array}$} & \multicolumn{3}{|c|}{$\% T$} & \multirow[b]{2}{*}{$\begin{array}{l}\text { \% Difference } \\
\% T_{5}-\% T_{3}\end{array}$} \\
\hline & $\begin{array}{l}\text { Produced by } \\
\text { spectro- } \\
\text { photometer }\end{array}$ & $\begin{array}{c}\text { Polarizer, } \\
\text { plane of } \\
\text { vibration } \\
\text { horizontal }\end{array}$ & $\begin{array}{c}\text { Polarizer, } \\
\text { plane of } \\
\text { vibration } \\
\text { vertical }\end{array}$ & \\
\hline & 1 & 2 & 3 & \\
\hline 440.0 & $19.81_{\text {^ }}$ & $19.80_{0}$ & $19.78_{8}$ & -0.15 \\
\hline 465.0 & $22.59_{7}$ & $22.60_{0}$ & $22.56_{9}$ & -0.12 \\
\hline 590.0 & $19.17 x$ & $19.17_{0}$ & $19.09_{y}$ & -0.41 \\
\hline 635.0 & 20.61 & $20.60_{2}$ & $20.54_{7}$ & -0.31 \\
\hline
\end{tabular}

transmittances of 25:50: and 75 were used. The trans. mittance measurements were performed on two sets of filters at the National Physical Laboratory (NPL) in England using their high accuracy spectrophotometer, and at NBS on the instrument described in this paper. The measurements at NBS were carried out before and after the measurements at NPL. All measurements were made with noncollimated convergent beam geometry. A rectangular surface of the filter about $3 \mathrm{~mm}$ by $8 \mathrm{~mm}$ was used at NPL and the beam was only slightly convergent. At NBS an area about $8 \mathrm{~mm}$ by $0.5 \mathrm{~mm}$ was used for the transmittance measurements.

The results given in table 9 indicate that an average difference of -0.19 percent of the values was obtained between the measurements carried out at NPL and at NBS. An average difference of -0.30 percent of the value was found when similar measurements were performed on the inconel-on-quartz filters, as shown in table 10 .

\section{Standard Reference Materials for Spectrophotometry}

The need for providing means and materials tr check the proper functioning of a spectrophotometer was discussed in some detail in previous publications $[3,4]$. At that time it was established that the accuracy of the photometric scale is a critical and most demanding parameter in spectrophotometry. Hence, particular attention was given to a number of ways for checking this parameter. Investigations showed that solid colored glass filters, exhibiting optical neutrality over the spectral range from $400.0 \mathrm{~nm}$ to $700.0 \mathrm{~nm}$, would constitute an acceptable Standard Reference Material (SRM). From the various colored glass

TABLE 9. Comparison between the percent transmittances $(\% T)$ measured on three Schott NG-4 glass filters at NPL and NBS

$\begin{array}{cccccc}\begin{array}{c}\text { Wavelength } \\ \text { nm }\end{array} & \begin{array}{c}\text { NBS, } \% T \\ \text { March 12, } \\ 1971\end{array} & \begin{array}{c}\text { NBS, } \% T \\ \text { May } 18 .\end{array} & \begin{array}{c}\text { NBS, } \% T \\ \text { average }\end{array} & \begin{array}{c}\text { NPL, } \% T \\ \text { February } \\ 1971\end{array} & \begin{array}{c}\% \text { Diff. } \\ \text { NBS to NPL }\end{array} \\ 440.0 & 12.92 & 12.91 & 12.91_{5} & 12.93 & -0.11 \\ 465.0 & 14.96_{5} & 14.98 & 14.97_{3} & 15.01 & -0.25 \\ 590.0 & 11.70 & 11.64 & 11.67 & 11.67 & 0.0 \\ 635.0 & 12.72 & 12.68 & 12.70 & 12.72 & -0.16 \\ & & & & & \\ 440.0 & 19.62_{5} & 19.58 & 19.60_{3} & 19.62 & -0.09 \\ 465.0 & 22.38_{5} & 22.35 & 22.36_{7} & 22.43 & -0.28 \\ 590.0 & 19.06 & 18.95 & 19.00_{5} & 19.01 & -0.03 \\ 635.0 & 20.45_{5} & 20.37 & 20.41_{3} & 20.47 & -0.23 \\ & & & & & \\ 440.0 & 32.89 & 32.86 & 32.87_{5} & 32.98 & -0.32 \\ 465.0 & 35.52 & 35.54 & 35.53 & 35.66 & -0.36 \\ 590.0 & 31.16_{5} & 31.10 & 31.13_{3} & 31.21 & -0.25 \\ 635.0 & 32.56_{5} & 32.52 & 32.54_{3} & 32.62 & -0.24\end{array}$

Average difference between NBS and NPL percent $T$ values $=-0.19$ percent.

filters available, Schott NG-4 "neutral glass" was selected, prepared and characterized. It is now offered by NBS as a means to check the photometric scale of spectrophotometers. 
TABLE 10. Comparison between the percent transmittances $(\% T)$ measured on three inconel-on-silica filters at NPL and NBS

\begin{tabular}{|c|c|c|c|c|c|}
\hline \multirow{2}{*}{$\begin{array}{c}\text { Wavelength } \\
\text { nm }\end{array}$} & \multicolumn{2}{|c|}{ NBS, $\% T$} & \multirow{2}{*}{$\begin{array}{c}\text { NBS, } \% T \\
\text { average }\end{array}$} & \multirow[b]{2}{*}{ NPL, $\% T$} & \multirow{2}{*}{$\begin{array}{c}\% \text { Diff. } \\
\text { NBS to NPL }\end{array}$} \\
\hline & 1 & 2 & & & \\
\hline 450.0 & 24.87 & 24.88 & $24.87_{5}$ & 24.93 & -0.18 \\
\hline 550.0 & 23.78 & 23.82 & 23.80 & 23.86 & -0.25 \\
\hline 650.0 & 23.38 & 23.39 & $23.38_{5}$ & 23.46 & -0.32 \\
\hline 450.0 & 49.35 & 49.33 & 49.34 & 49.56 & $-0.44^{*}$ \\
\hline 550.0 & 47.60 & 47.60 & 47.60 & 47.81 & -0.44 \\
\hline 650.0 & 46.85 & 46.85 & 46.85 & 47.14 & -0.64 \\
\hline 450.0 & 72.17 & 72.20 & $72.18_{5}$ & 72.30 & -0.16 \\
\hline 550.0 & 72.05 & 72.11 & 72.08 & 72.20 & -0.17 \\
\hline 650.0 & 72.20 & 72.34 & 72.27 & 72.33 & -0.08 \\
\hline
\end{tabular}

Average difference belween NBS and NPL percenı $T$ values $=-0.30$ percent.

*'This filter had a flaw in the form of a crack which was somelimes visible and other times invisible. The larger differences found in the measuremenls of this filler may be due 10 this flaw.

SRM 930, developed in the Analytical Chemistry Division and available since March 1971 consists of three glass filters. Each filter bears an identification number, and the upper left corner has been removed to indicate correct orientation in the metal holder (fig. 17).

The transmittance measurements were made with the high accuracy spectrophotometer described in this paper, and are certified with an uncertainty of \pm 0.5 percent of the value. This uncertainty is the sum of the random errors of \pm 0.1 percent (2SD limit) and of estimated biases which are \pm 0.4 percent. These biases are due to possible systematic errors originating principally from the inherent inhomogeneity and instability of the glass as well as from positioning of the filter. Measurements were made at $24{ }^{\circ} \mathrm{C}$, and variations within several degrees Celsius of this temperature will not significantly affect the calibration of the filters. The neutral NG-4 glass for the filters was provided by Schott of Mainz, Germany and is designated as "Jena Colored and Filter Glass." Nominal transmittance for a filter $1.5 \mathrm{~mm}$ thick is 20 percent at $400.0 \mathrm{~nm}$ wavelength and 32 percent at $700.0 \mathrm{~nm}$ wavelength. Between these limits the transmittance varies in a monotonic manner.

The filter is held in a frame and the size and shape of the filters and frames were selected, for practical considerations, to conform to the dimensions of the standardized cuvettes for which holders are supplied in most conventional spectrophotometers. The filters are approximately $1.0,1.5$, and $2.0 \mathrm{~mm}$ thick. Corresponding to these thicknesses are nominal transmittances of 30,20 , and 10 percent, respectively. These thicknesses were selected to provide a means for calibrating the photometric scale at three different levels.
The effective spectral bandpasses used to determine the certified values were equal to or smaller than $2.2 \mathrm{~nm}$ at $440.0 \mathrm{~nm} ; 2.7 \mathrm{~nm}$ at $465.0 \mathrm{~nm} ; 5.4 \mathrm{~nm}$ at $590.0 \mathrm{~nm}$; and $6.0 \mathrm{~nm}$ at $635.0 \mathrm{~nm}$. The transmittance measurements are made by producing the image of the slit (about $8 \mathrm{~mm}$ by $0.5 \mathrm{~mm}$ ) using a convergent beam geometry with an opening of $\mathrm{f}: 10$ corresponding to an angle of $7^{\circ}$ to $8^{\circ}$ in the middle of the entrance face of the filter. This beam geometry was used to reproduce the average experimental conditions found in most of the conventional spectrophotom. eters available today. Prior to the certification, each filter is examined for surface defects and thoroughly cleaned. If, through handling, the surface of the filter becomes contaminated, it may be cleaned with a small soft brush attached to a rubber tube connected to a vacuum source [40]. If contamination results from fingerprints, they must be removed before making measurements. This may be accomplished by removing the filter from its holder, breathing lightly on it, and rubbing the surface gently with optical lens tissue. The clean filter is then properly positioned in its holder. To remove and replace the filter in the holder, the spring-loaded plate should be lifted with care to prevent damage to the filter. As little handling as possible is recommended. SRM 930 should be used according to the directions on the certificate; consult the manufacturer of the instrument if differences are obtained that exceed those specified by the manufacturer.

Under no circumstances should other cleaning procedures which make use of detergent solutions, organic solvents, etc. be applied.

When a filter has become contaminated beyond cleaning by the procedure described in the certificate, it should be forwarded to NBS. After proper cleaning, the filters will be checked and, if needed. 


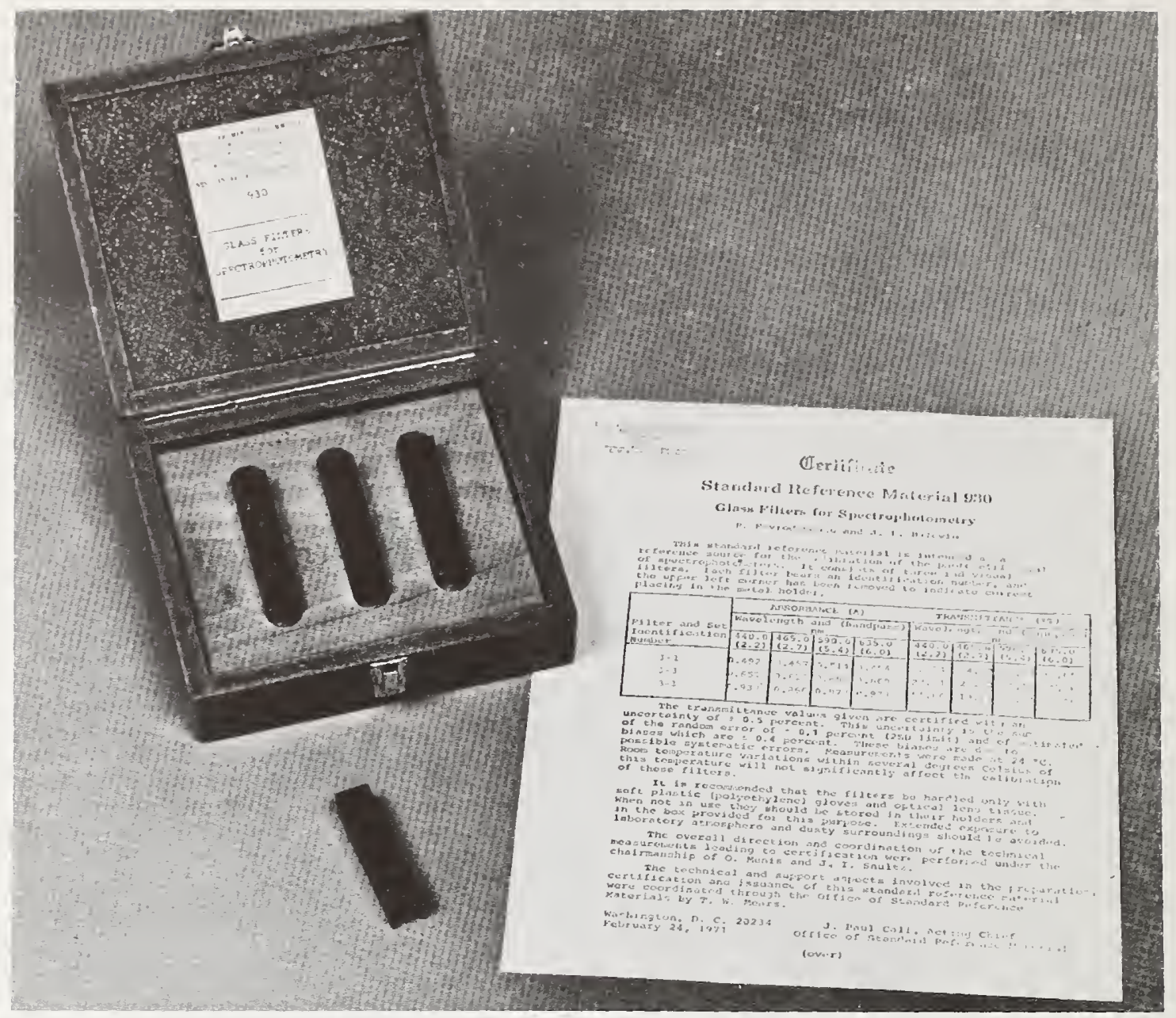

Figure 17. NBS Standard Reference Material 930 and calibration certificale.

recalibrated using the high accuracy spectrophotometer described in this work.

It was already stated that the accuracy of photometric scales defines only one of the parameters required for obtaining accurate transmittance values and molar absorptivities. Other factors must also be established. These are wavelength accuracy, adequate spertral bandpass, stray light, cell parameters (when solutions are measured). fluorescence, polarization, reflection, and temperature coefficient. Some of these variables were discussed in NBS Terhnical Notes 544 and 584 and arc also examined in this paper.

'the transmittance data griven in the certificate which areompanies rarh SRM 930 depend not only on the intrinsic properties of the glass and the exprimental measurement conditions, lut on the surface state of the glass. This parameter varies with time and exposure conditions. When glass is exposed to normal room atmosphere and temperature. its surface is corroded to an extent depending on the composi. tion, time of exposure, concentration, temperature and nature of the glass surface acting atrents. This action produces a rhange in the reflecting and transmitting properties of the material [41]. For instance. a well-known phenomenon called "blomming" of the glass is due to the formation of an Si() layer at the surface of the wlass. This layer. which increases the transmittance. acts as an antireflection coating. The speed with which such a layer is formed varies with the compusition of the grass. the atmosphere and timr. (ienerally speaking. several years are needed for a fresh surfare to reach equilibrium. This. and similar 
phenomena are presently being studied, along with means to stabilize the surface state of glass filters. Until more information is acquired in this field, we recommend that the colored glass filters issued as SRM 930 be rechecked annually to determine whether any physicochemical changes, which might affect the transmittance values, have occurred.

Another important factor is the need for defining and producing a clean glass surface. Until now the final cleaning of the $\mathrm{NG}-4$ filters was made with redistilled ethyl alcohol and pure water (thermally distilled and deionized). Other cleaning procedures are under consideration. The use of isopropyl alcohol in vapor or liquid form associated with mild ultrasonic action is being investigated [41].

The transmittance characteristics of the SRM 930 limit the use of this material to the visible region of the spectrum from about $400 \mathrm{~nm}$ to the near infrared. Since the ultraviolet region, from about $200 \mathrm{~nm}$ is also important to the analyst who uses spectrophotometric methods, exploratory work is underway to select and certify solid material for checking the photometric scale in this spectral region. Optical filters exhibiting small transmittance-wavelength dependence in the spectral range $200 \mathrm{~nm}$ to near infrared can be obtained by evaporating thin semitransparent layer of a metal on a suitable transparent substrate $[42,4]$, and such filters have been considered in this work. The metals selected were inconel and chromium which exhibit adequate transmission characteristics and good adhesion to the substrate. The substrate was nonfluorescent fused quartz. A series of filters were prepared by the optical shop at NBS according to the following specifications: a number of nonfluorescent optical quality fused quartz plates, $10 \mathrm{~mm} \times 25 \mathrm{~mm}$ and $1 \mathrm{~mm}$ thick, were cut and polished, Inconel or chromium metal was evaporated on the surface to produce nominal transmittances of 25, 50, and 75 percent. The surface bearing the evaporated metal was coated with a layer of optical cement which was transparent to the visible and ultraviolet radiations down to 230 $\mathrm{nm}$. A clear plate of the same material was used to cover and protect the evaporated metal layer.

The filter assembly was then marked at one corner to insure its proper positioning and the finished filter was placed in a metal holder of conventional size (approximate o.d. $13 \times 13 \times 57 \mathrm{~mm}$ ) fitting the cuvette holder found in most spectrophotometers. The metal holder was also marked at one side to permit positioning of the filter in a reproducible manner.

In addition to the evaporated metal filters, a number of units were prepared using only the clear uncoated fused quartz plates and assembled with the same optical cement. When desired, these clear filter assemblies could be used as reference samples in the blank compartment.

Before submitting the evaporated metal filters to transmittance measurements, a study was made of the effect of radiations on their transmittances. A filter was exposed to an accelerated test in which radiations had the same spectral distribution as the fluorescent lighting of the laboratory, except that they were 1000 times more intense. The filter was exposed for an equivalent of 36,000 hours of continuous irradiation. This test was made on a radiation accelerator made available by the Building Research Division of NBS. The percent transmittance was measured before and after the exposure and gave the following results:

\begin{tabular}{lcccc} 
& \multicolumn{4}{c}{ Transmittance, perc tt } \\
\cline { 2 - 5 } Wavelength, nm & 250 & 380 & 500 & 650 \\
& & & & \\
Before exposure & 44.48 & 51.35 & 48.90 & 47.41 \\
After exposure & 44.11 & 51.34 & 48.92 & 47.47
\end{tabular}

The relative standard deviation for a single determination of these measurements was 0.01 percent. As can be seen, the only significant relative change in transmittance of about 0.84 percent of the value occurred at $250 \mathrm{~nm}$.

Several sets of these filters were calibrated at five selected wavelengths, $250 \mathrm{~nm} ; 350 \mathrm{~nm} ; 450 \mathrm{~nm} ; 550$ $\mathrm{nm}$; and $650 \mathrm{~nm}$, using the cleaning and measuring procedures outlined for Schott NG-4 colored glass neutral filters. The results indicated that the reproducibility of transmittance measurements is good (percent standard deviation 0.009 to 0.024 ) and is comparable to those obtained for the colored glass filters at all wavelengths except $250 \mathrm{~nm}$. From the experimental data, it is evident that the transmittance of the evaporated metal filter at $250 \mathrm{~nm}$ is critical and, at present, no satisfactory explanation for this phenomenon can be given. A limitation of the evaporated metal filters is that they attenuate the intensity of radiation by reflecting a part of it, rather than absorbing. This can produce, in certain circumstances, undesirable stray light in the instrument and make the transmission measurements dependent on the geometry of the optical beam. However, since these filters are closer to optical neutrality than the colored glass filters, and since they can be used in the ultraviolet region as well, they were included in this work.

This limitation was apparent from the data obtained in a cooperative study conducted at C. Zeiss by $\mathrm{A}$. Reule using conventional spectrophotometers. On the other hand, a similar comparative test, made on the same filters by F. J. J. Clarke at NPL has produced the results presented in table 10. One can observe that, in spite of the limitations mentioned above, an agreement within -0.30 percent of the value was obtained between NBS and NPL measurements at the indicated wavelength.

Further studies will be needed to assess unambiguously the transmittance characteristics of evaporated metal-on-quartz filters, with or without a protective quartz plate, and to assess their suitability as Standard Reference Materials to check the photometric scale of spectrophotometers in the ultraviolet and visible part of the spectrum. 


\section{Addendum}

The identification of commercial instruments and products, is given in the Addendum only to permit reproduction of the work described in this paper. In no instances does such identification imply recommendation or endorsement by the National Bureau of Standards, nor does it imply that the particular equipment or product is necessarily the best available for the purpose.

Radiation source for visible-Microscope lamps, type 18A/T10/1P-6V: General Electric Co., Lamp Division, Nela Park, Cleveland, Ohio 44112. For ultraviolet: Atlas single coil halogen (Bromine) lamp, type P1/8, 30V, 250W: GTE Sylvania, Inc., 6610 Electronic Drive, Springfield, Virginia 22151.

Power supply for microscope lamp, Kepco, Model JQE 15-50-M-VP: Kepco, Inc., 131-38 Sanford Avenue, Flushing, New York 11352. For tungstenhalogen single filament lamp: same manufacturer, Model JQE-36-30 Mt-VP.

Potentioneter: Leeds and Northrup Model K3 with null meter and power supply. Resistors: Leeds and Northrup 0.1, $50 \mathrm{~A}$ and $0.01,100 \mathrm{~A}$ : Leeds and Northrup. Sumneytown, Pike, North Wales, Pa. 19454.

Nonfluorescent fused silica: Dynasil Corporation of America, Berlin, New Jersey 08009.

Neutral Density Attenuator and $\mathrm{BaSO}_{4}$ white paint: Eastman Kodak Co., Special Products Sales, Kodak Apparatus Division, Elmgrove Plant, Rochester, New York 14650.

Monochromator with predisperser: McPherson Instrument Corp., 530 Main Street, Acton, Massachusetts 01720 .

Optical benches with carriers and $x-y$ sample holder with micrometer control: Gaertner Scientific Corp., 1201 Wrightwood Ave., Chicago, lllinois 60614. Lens holders: Ardel Instrument Co., Inc., P. O. Box 992, Jamaica, New York 11431.

Ball bushing and rails: Thompson Industries, Inc., Manhasset, New York 11030.

Pneumatic cylinders and accessories: Clippard Instrument Laboratory, Inc., Cincinnati, Ohio 45239.

Rotating table: Ealing Optics Division, 2225 Massachusetts Avenue, Cambridge, Massachusetts 02140.

Thermostating holders for glass cells and glass filters: Cary Instruments, 2724 South Peck Road, Monrovia, California 91016.

Pneumatic ratchet system: Allenair Corp., P. O. Box 350, 255 East 2nd Street, Mineola, New York 11501.

Black paint-Nextel 101-c 10 Black: Reflective Products Division 3M, 2501 Hudson Road, St. Paul, Minnesota 55101.

Photomultiplier tube EM1-9558QA: Gencom Division, 80 Express Street, Plainview, New York 11803.

Power supply for photomultiplier tube: Model 415B and digital voltmeter $8400 \mathrm{~A}$ : John Fluke Manufacturing Co., P.O. 7428, Seattle, Washington 98133.
Thermal insulation: Photoshroud, Shumway Optical Instruments Corp., 2118 Beechgrove Place, Utica, New York 13501.

Vibration isolation table: Lansing Research Co., 705 Willow Avenue, Ithaca, New York 14850.

Low power laser; Model $195 \mathrm{cw}$ gas laser, output power 2 mw: Optics Technology, lnc., 901 California Avenue, Palo Alto, California 94304.

Tritium activated fluorescent source, Beta light Marker HM-110: Canrad Precision Industries, Inc.. 630 Fifth Avenue, New York, New York 10020.

Colored glass neutral filters, Schott NG-4: FishSchurmann Corp., 70 Portman Road, New Rochelle, New York 10802.

Spectral lamp: Oriel Optics Corp., 1 Market Street. Stamford, Connecticut 06902.

Polarization filters: Polaroid Corp.. 119 Windsor Street, Cambridge, Massachusetts 02139.

Computer: $24 \mathrm{~K}$ memory and 16 bit words. EMR computer, Division of Weston Instruments, lnc., Schlumberger Co., 8001 Bloomington Freeway. Minneapolis, Minnesota 55420.

The author gratefully acknowledges the assistance of the following persons, in addition to those already mentioned in the text:

F. J. J. Clarke, for the considerable assistance given through personal discussions on the philosophy and principles of high accuracy spectrophotometry at NPL.

Anne Compton, for advice and help during the experimental work carried-out at the high accuracy spectrophotometer at NPL.

G. E. V. Lambert, for information concerning glass filters (NPL).

K. D. Mielenz (NBS), for constructive discussions on the principles of spectrophotometry and for critically reviewing the manuscript.

W. H. Venable (NBS), for critically reviewing the manuscript.

K. L. Eckerle (NBS), for advice in measuring stray radiations and polarization produced in the monochromator.

C. R. Yokley (NBS), for advice on the radiation stability of incandescent tungsten filament lamps.

W. K. Haller (NBS), for valuable information on the properties of glass surfaces and optical glass filters.

H. H. Ku (NBS), for advice on interpretation of the data discussed in this paper.

NBS Instrument Shop, for constructing the mechanical parts described in this work.

NBS Optical Shop, for grinding the quartz lens used in this work.

D. S. Bright (NBS guest worker). for the programs written at various times during the initial phase of this work.

V. E. Gray (NBS), for assistance in performing the accelerated radiation tests.

H. J. Höfert and A. Reule (C. Zeiss, Oberkochen, Germany), for valuable information on linearity of 
photodetectors and for demonstration of the radiation addition method.

R. J. Carpenter (NBS), for constructive discussions on electronic circuitry and photodetectors.

L. Marzetta (NBS), for advice and assistance in assessing various functioning parameters of photomultiplier tubes.

O. Menis, Section Chief, Analytical Coordination Chemistry (NBS), for approving and encouraging the work reported in this paper.

J. I. Shultz, Assistant Section Chief, Analytical Coordination Chemistry (NBS), for critically reviewing the manuscript.

\section{References}

[1] Kortüm, G., Kolorimetrie-Photometrie und Spektrometrie 464 p., 4th ed. (Springer-Verlag, 1962).

[2] Gibson, K. S., Spectrophotometry, Nat. Bur. Stand. (U.S.) Circ. 484,48 pages ( 1949$)$

[3] Mavrodineanu, R., Spectrophotometry, instrumental develop ment, O. Menis and J. 1. Shultz, Eds., Nat. Bur. Stand (U.S.), Tech. Note 584, pp. 9-21 (1971).

[4] Mavrodineanu, R. Solid materials to check the photometric scale of spectrophotometers, O. Menis and J. I. Shultz, Eds. Nat. Bur. Stand. (U.S.), Tech. Note 544, pp. 6-17 (1970).

[5] Elster, J. and Geitel, H., Un the comparison of light intensities by photoelectric methods, Ann. Physik, Chemie 48, 625-635 (1893)

[6] Elster, J. and Geitel, H., I he photoelectric effect on potassium at low light levels. Phys. Ztsch. 13, 468-976 (1912).

[7] Koller, L. R., and Breeding, H. A., Characteristics of photoelectric tubes, General Electric Rev. 31, 476-479 (1928)

[8] Campbell, N. R., The experimental proof of a fundamenta photoelectric law, Trans. Opt. Soc. (London) 32, 61-65 (1930-1931).

[9] Fleury, P., An addition method for the precise study of the variation of the current output of a photoelectric cell as a function of the incident luminous flux, Compt. Rend. Acad. Sci. (France) 199, 195-197 (1934).

[10] Preston, J. S., and McDermott, L. H. The illumination re sponse characteristics of vacuum photoelectric cells of the Elster-Geitel Type, Proc. Phys. Soc. (London) 46, 256-272 (1934).

[11] Preston, J. S., and Cuckow, F. W., A photoelectric spectrophotometer of high accuracy, Proc. Phys. Soc. (London) 48, 869-880 (1936)

[12] Buchmüller, F., and König. H., Precision measurements on incandescent lamps using selenium photocells, Assoc. Suisse Electriciens, Bulletin 28,89-99 (1937).

[13] Atkinson, J. R., Campbell, N. R., Palmer, E. H., and Winch, G. T. The accuracy of rectifier-photoelectric cells, Proc. Phys. Soc. (London) 50, 934-946 (1938).

[14] Barbrow, L., A photometric procedure using barrier-layer photocells, J. Res. Nat. Bur. Stand. (U.S.), 25, 703-710 (1940) RP1348.

[15] Kaiser, H., Photographic-photometric calibration of step filters, Spectrochimica Acta 3, 518-537 (1947-1949).

[16] Harding, H. G. W., Precautions necessary for accurate measurements of optical density standards, Photoelectric Spectrom etry Group Bulletin 4, 79-86 (1951).
[17] Kortüm, G., and Maier, H., Dependence of photocurrent and illuminating intensity in photocells and photomultipliers, Z. Naturforschung $8 \mathbf{A}, 235-245$ ( 1953 ).

[18] Hansen, (.., Check of photometric function of spectrophotom eters, Mikrochimica Acta 1955, 410-415.

[19] Hermann, W., Noise and linearity check on photomultipliers, Z. Naturforschung 12A, 1006-1013 (1957).

[20] Reule, A., Checking the photometer scale of ahsorption instruments, Zeiss-Mitt. 1, 283-294 (1959).

[21] Hoppmann. H. An instrument for checking the proportionality of physical radiation receivers, Technisch-Wissenschaftliche Abhandlungen Der Osram.6esellschaft 7, 306-312 (1958).

[22] Gibson. G. L., Hammond, H. K., III, Holford, W. L.. and Nimeroff, I., Calibration of photometers, NBS Manuscript, Nov. 1, 1960

[23] Bischoff, K., Measurement of proportionality of radiation receivers over a large radiation intensity range, $Z$. Instr. 69 , $143-147$ (1961).

[24] Jones, O. C., and Clarke, F. J. J., A new photometric technique using a variable shutter device, Nature 191, 1290 (1961).

[25] Cordle, L.. C., and Habell, K. J., Photometry of telescopes and binoculars, National Physical Laboratory, Notes on Applied Science No. 14,18 pp. (1962).

[26] Sanders, C. L.., A photocell linearity tester, Appl. Optics 1, $207-271$ (1962).

[27] Nonaka, M., and Kashima, T., Linearity characteristics of multiplier phototubes, Japanese Journal Applied Physics 2, 785791 (1963)

[28] Hiifert, H. J., and Loof, H. Calibration of photometric scales of a reflection photometer, $Z$. Instrumentenkunde $72,139-143$ (1964).

[29] Clarke, F. J. J., Time ratio photometry, Lecture to the Optical Croup of the Institute of Physics and the Physical Society (June 9, 1966).

[30] Clarke, F. J. J., High accuracy spectrophotometry of three filters, NPL, Report No. 3042, 14 pp. (Nov. 4, 1968).

[31] Reule, A., Testing spectrophotometer linearity, Appl. Optics 7, $1023-1028(1968)$

[32] Desvignes, F., and Ohnet, J., Characteristics and measurement of properties of radiation receivers, Techniques Philips N.6, 1-18 (1968).

[33] Kunz, H. Representation of the temperature scale above 1337.58 $\mathrm{K}$ with photoelectric direct current pyrometers. Metrologa $\mathbf{5}$, 88-102 (1969)

[34| Kostkowski, H. J., Personal communication (NBS 1970).

[35] ASTM Tentative Method of Estimating Stray Radiant Energy, ASTM:E 387-69T.

[36] Clarke, F. J. J., Personal communication (NPL, August 1970).

[37] Mielenz, K. D.. and Eckerle, K.. Accuracy of oolarization attenuators (to be published), Appl. Optics (1972).

[38] Mielenz, K. D., and Eckerle, K. Spectrophotometer linearity testing using the double-aperture method, Appl. Opt. 11, 2294 (1972).

[39] Garfinkel, S. B., Mann, W. B., and Youden, W. J., Design and statistical procedures for the evaluation of an automatic gamma-ray point-source calibrator, J. Res. Nat. Bur. Stand. (U.S.), 70C (Eng and Instr.). No 2.53-63 (1966).

[40] Edisbury, J. R., Practical Hints on Absorption Spectrophotometry (Plenum Press, New York, 1967).

[41] Holland, L., The Properties of Glass Surfaces (Chapman and Hall, London, 1964)

[42] Hass, G., and 'Inun, R. E., Editors, Physics of Thin Films (Academic Press, 1967).

(Paper 76A5-729) 
Val. 77A, No. 6. November-December 1973

\title{
Reflection Correction for High-Accuracy Transmittance Measurements on Filter Glasses
}

\author{
K. D. Mielenz and R. Mavrodineanu \\ Institute for Materials Research, National Bureau of Standards, Washington, D.C. 20234
}

(July 27, 1973)

\begin{abstract}
Multiple reflections in the sample compartment of a spectrophotometer constitute a source of systematic bias in transmittance measurements on filter glasses. This bias may be removed by applying a numerical correction obtained from measurements on tilted samples in polarized light. For a highaccuracy spectrophotometer, this correction was found to be of the order of several $10^{-4}$ transmittance units, independent of polarization, but slightly wavelength dependent.
\end{abstract}

Key words: Correction for reflections; reflections, multiple; spectrophotometry, high accuracy: systematic bias in spectrophotometry; transmittance, correction.

\section{Introduction}

The sample compartment of most spectrophotometers is designed such that the monochromator exit slit is focused into the sample by a lens. and is refocused into the detector by another lens (fig. 1). This beam geometry is preferred by instrument designers for intensity reasons and other convenience gains, but may constitute a source of significant systematic errors of the measured data. One of these errors is caused by multiple reflections between the two lenses and the sample surfaces [1.2.3]. ${ }^{1}$

For high-accuracy applications this error can be eliminated by means of a numerical correction, $\Delta T$, which converts the measured transmittance, $T_{M}$, into the correct value

$$
\tau=T_{1}+\Delta T
$$

\footnotetext{
' Figures in brackets indirate the literature references at the end of this paper
}

A simple but accurate method to determine this correction is described in this paper.

The specific spectrophotometric application discussed is the measurement of the transmittance of glass filters to an accuracy of $\pm 10^{-4}$ transmittance units. For the particular high-accuracy spectrophotometer used [4], the correction $\Delta T$ was found to be of the order of several $10^{-4}$ transmittance units, independent of polarization throughout the visible spectrum, and applicable for filters with widely different indices of refraction. The correction was found to be slightly wavelength dependent.

\section{Theoretical Background}

A detailed discussion of the reflection errors affecting the measurement of filter transmittances may be found in reference [3]. A summary is given here in order to provide the theoretical foundation for the experimental work described in section 3 .

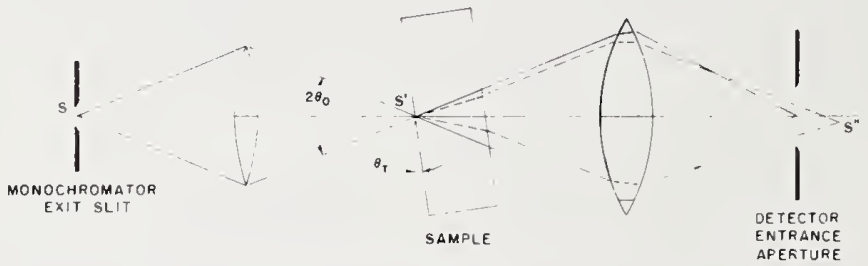

FigURE 1. Sample-compartment optics of a focused-beam spectrophotometer. 
The purpose of the measurement is assumed to be the determination of the normal-incidence transmittance,

$$
\tau=\frac{\tau_{i}(1-r)^{2}}{1-r^{2} \tau_{i}^{2}}
$$

of a glass filter surrounded by air. The filter is characterized by its thickness $t$ and complex refractive index $n(1+i \kappa)$, so that for each wavelength $\lambda$ the normal-incidence internal transmittance $\tau_{i}$ and Fresnel reflectance $r$ appearing in eq (2a) are given by

$$
\begin{gathered}
\tau_{i}=e^{-4 \pi n \kappa t / \lambda}, \\
r=\left(\frac{n-1}{n+1}\right)^{2} .
\end{gathered}
$$

This quantity $\tau$ can be measured accurately with specially designed instrumentation in which the sample is placed normal to a collimated beam of light, the collimation being effected by off-axis mirror optics in a manner which reduces reflection errors to a negligible level $[3,5]$. A conventional spect rophotometer does not permit such a direct measurement of $\tau$ because of the above-mentioned reflection error, even if its lenses were arranged to produce a collimated rather than the usual focused beam.

The cause of this error is illustrated in figures $2 a$ and 2b. According to the first of these, the radiant flux received by the detector during the clear-space measurement is

$$
\phi_{0}=T_{1} T_{2}\left(1+R_{1} R_{2}+\ldots\right),
$$

where the initial flux is taken as unity, and where $T_{1}$, $R_{1}, T_{2}$, and $R_{2}$ are the fractional fluxes transmitted or reflected into the detector by all components (lenses, slit jaws, detector housing, etc.) in front of and behind the sample area, respectively. When a sample with transmittance $T$ and reflectance $R$ is inserted, the flux into the detector is

$$
\phi=T_{1} T T_{2}\left(1+R_{1} R_{2} T^{2}+R R_{2}+R_{1} R+\ldots\right),
$$

as indicated in figure $2 \mathrm{~b}$. Within the approximation that all contributions due to four or more reflections are considered negligibly small, the measured transmittance is

$$
\begin{aligned}
\mathrm{T}_{M} & =\phi / \phi_{0} \\
& =T\left[1+\left(R_{1}+R_{2}\right) R-R_{1} R_{2}\left(1-T^{2}\right)\right] .
\end{aligned}
$$

The correction which must be applied to $T_{M}$ to eliminate the reflection bias is

$$
T-T_{M}=\Delta T+\Delta T^{\prime},
$$

where
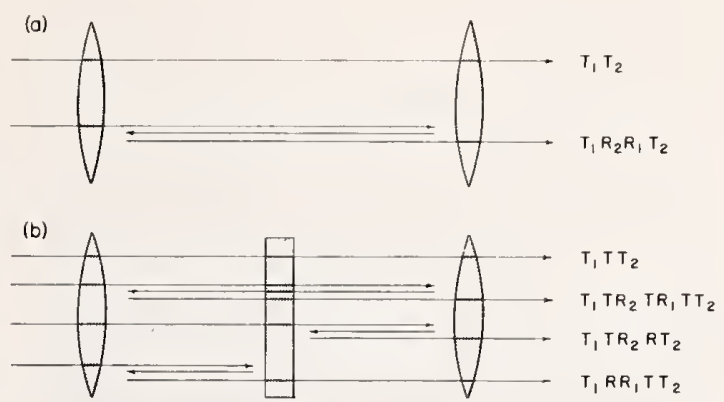

Ficure 2. Reflected beams in a spectrophotometer with lenses.

$$
\begin{gathered}
\Delta T=-\left(R_{1}+R_{2}\right) R T \\
\Delta T^{\prime}=R_{1} R_{2} T\left(1-T^{2}\right) .
\end{gathered}
$$

The first of these two error terms, $\Delta T$, is due to the fact that the insertion of the sample has created the two additional beams shown at the bottom of figure $2 b$. This error is greatest when the sample is normal to the optic axis, and may be eliminated by sufficiently tilting the sample so that these two beams no longer reach the detector. The other error component, $\Delta T^{\prime}$, arises from the fact that the second beam from the top in figure $2 b$ passes the sample three times, whereas the direct beam passes it only once. Since this residual error cannot be avoided by tilting the sample, it is clear that tilting is an effective means to eliminate reflection errors only if $\Delta T^{\prime}$ is substantially smaller than $\Delta T$. Equations $(4 \mathrm{~b}, \mathrm{c})$ suggest that this should be the case for any well-designed spectrophotometer for which these reflection errors are not unduly large. To show this, we assume that $R_{1}$ and $R_{2}$ are both of the order of a few percent, and that glass filters with an average transmittance $T \sim 0.5$ and reflectance $R \sim 0.08$ are used as samples. This leads to $\Delta T / \Delta T^{\prime} \sim 10$, showing $\Delta T^{\prime}$ to be a significantly smaller error in such circumstances. Whether or not this estimate holds must be ascertained individually for any given spectrophotometer.

Tilting the sample introduces obliquity errors, and therefore does not yield an accurate measurement of the normal-incidence transmittance $\tau$ unless further corrections are applied. These errors arise from a decrease of internal transmittance due to increased pathlengths in the sample for oblique light incidence and, secondly, from a variation of reflection losses at the sample boundaries with angle of incidence. The latter also introduces a dependence of measured transmittance on polarization.

For glass filters measured with a conventional spectrophotometer in which the monochromator exit slit is imaged onto the sample, these errors are given by

$$
\begin{aligned}
T=\tau\left[1+\left(1 / 2 n^{2}\right)\left(\ln \tau_{i}\right)\left(\theta_{T}^{2}\right.\right. & \left.+\frac{2}{3} \theta_{0}^{2}\right) \\
& \left. \pm(4 r / n) \theta_{T}^{2}+\ldots .\right],
\end{aligned}
$$


where $T$ is the measured transmittance (corrected for reflection errors); $\tau, \tau_{i}$, and $r$ are the normal-incidence values of transmittance, internal transmittance, and Fresnel reflectance as given by eqs $(2 \mathrm{a}, \mathrm{b}, \mathrm{c}) ; \theta_{T}$ and $\theta_{0}$ are the tilt angle and the cone angle of the incident light; and where the upper and lower signs of the last term pertain to the two cases in which the light is $S$ or $P$ polarized in the tilt plane. Equation (5) was derived in reference [3] under the assumption that the monochromator exit slit is sufficiently short to approximate a point source, and that the focusing lens is underfilled so that the grating or prism constitutes the limiting aperture. This aperture is assumed to be square. subtending the same angle $2 \theta_{0}$ in the horizontal and vertical planes. The sample is assumed to be tilted only in one of these planes. The small-angle approximation given in eq (5) is estimated to be accurate to $10^{-4}$ transmittance units for angles $\theta_{T}$ and $\theta_{0}$ up to about $10^{\circ}$.

For average transmittances and tilt angles of a few degrees, these obliquity effects are of the order of $10^{-3}$ transmittance units. Since this is the same magnitude as estimated above for the reflection error, it is clear that for a spectrophotometer with lenses an accurate measurement of the normal-incidence transmittance $\tau$ cannot be achieved without numerical correction for either source of error. If the sample is tilted in order to reduce the reflection error, an obliquity correction must be applied. Vice versa, a reflection correction is necessary if the sample is normal to the optic axis so that obliquity effects are minimized. Although these two alternatives are equivalent, the latter was chosen in this work since it constitutes the simpler approach for routine measurements of transmittance.

\section{Experimental Procedure}

The preceding theoretical discussion does not permit a precise calculation of the required reflection correction. Representing fractional fluxes which actually reach the detector, the quantities $R_{1}$ and $R_{2}$ appearing in equations $(4 \mathrm{~b}, \mathrm{c})$ are complicated and generally unknown functions of the relative positions of sample compartment elements, lens curvatures, location of aperture stops, and other beam-geometry factors. This makes it necessary to measure the correction. Such a measurement may be performed as follows.

Each of a series of filters with different transmittances is measured for different known tilt angles $\theta_{T}$, and for $S$ and $P$ polarization of the incident light. This yields a set of raw data $T_{11}$, such as plotted in figure $3 a$. These are transformed into corrected data $T$ by adding the tilt-correction given by eq (5),

$(\Delta T)_{\mathrm{tllt}}=-T_{u}\left[\left(1 / 2 n^{2}\right) \ln \left(\frac{T_{M}}{1-2 r}\right) \pm(4 r / n)\right] \theta_{T}^{2}$,

where the approximate values $T_{M}$ and $T_{M} /(1-2 r)$ were substituted for $\tau$ and $\tau_{i}$ on the right-hand side, and where estimates of $n$ and $r$ may be used. As indicated by figure $3 \mathrm{~b}$, these corrected transmittances $T$ are constant for sufficiently large positive or negative tilt

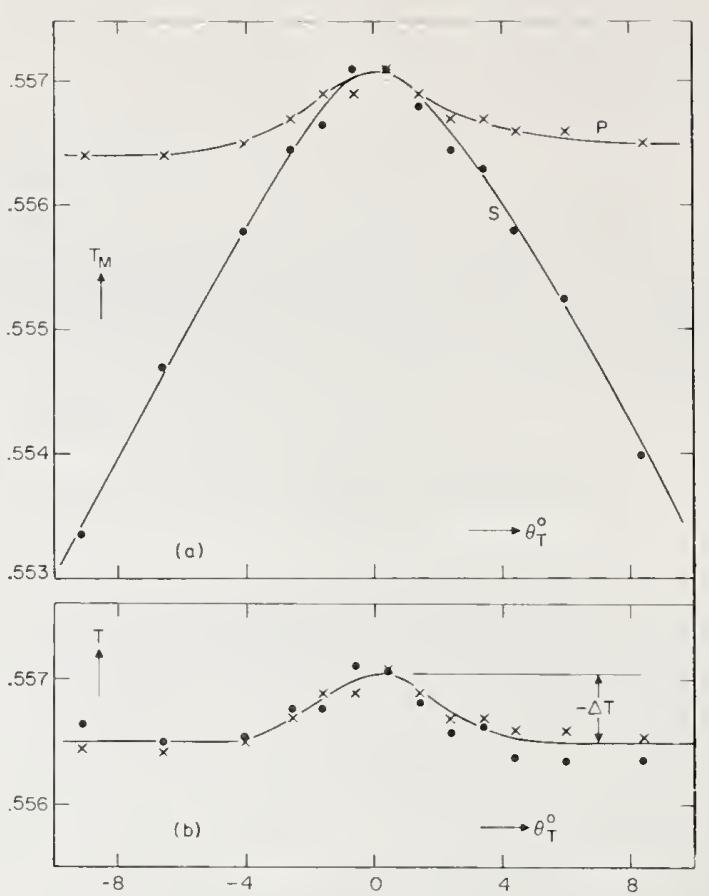

Figure 3. (a) Measured transmittance $\mathrm{T}_{\mathrm{M}}$ versus tilt angle $\theta_{\mathrm{T}}$ for 55 percent filter in $\mathrm{S}$ and $\mathrm{P}$ polarized light at $\lambda=574 \mathrm{~nm}$.

(b) The same data after application of tilt correction.

angles, but near normal incidence exhibit the "reflection hump' whose height represents the desired reflection correction $\Delta T$ to be applied for this particular value of transmittance. From the measurements performed on all of the filters one may then determine the dependence of $\Delta T$ on $T$, as illustrated by figure 4 . According to eq $(4 \mathrm{~b})$, this dependence should be linear. In the work described here, these measurements were made as follows.

A series of four Schott NG-4 glass filters with nominal transmittances $0.1,0.2,0.3$, and 0.5 , an evaporated metal-on-glass filter with a nominal transmittance 0.4 , and a clear glass plate were used. All of these samples were $50 \mathrm{~mm} \times 50 \mathrm{~mm} \times 2 \mathrm{~mm}$ in size, and flat and plane-parallel to within a few fringes of mercury. green light. The spectrophotometer used to perform the measurements was fully described in a previous issue of this journal [4], and will not be discussed here. The filters were placed in the sample compartment of this spectrophotometer on a vertical rectangular holder adapted to a rotary horizontal table with $10 \mathrm{~cm}$ diameter. This table had a scale divided in $360^{\circ}$ with a vernier reading to $5 \mathrm{~min}$, and was held on the singlesample carriage of the spectrophotometer (see ref. [4], fig. 2) with a vertical mounting rod. This sample carriage unit consists of a platform provided with vertical holders which can be moved laterally by a 


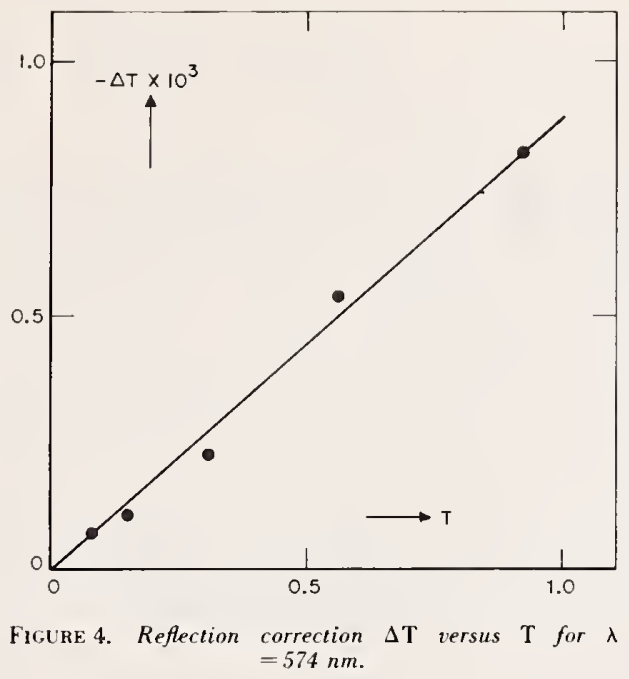

rack and pinion arrangement. The platform, mounted on four ball bushings which ride on two horizontal rods, can be moved pneumatically across the optical axis. This remote-controlled movement is smooth, and the sample position in and out of the beam is reproducible within $0.025 \mathrm{~mm}$.

A sheet polarizer of $9.5 \mathrm{~cm}$ diam was used to produce the $S$ and $P$ polarized radiation. This polarizer was held in a ball bearing rotating mount with a circular scale divided from 0 to $360^{\circ}$. It was placed on the optical bench in front of the entrance slit of the predisperser-monochromator aggregate of the spectrophotometer between the circular neutral wedge and the flat front-surface mirror (see ref. [4]. fig. 3). This placement of the polarizer on the source side of the spectrophotometer avoids the additional reflection errors which would occur if the polarizer were put in the sample compartment of the spectrophotometer, but requires that the monochromator does not significantly depolarize the incident radiation or rotate its plane of polarization. This was ascertained by testing the monochromator between crossed polarizers at the wavelengths at which the measurements were performed.

Each transmittance measurement was performed in $S$ and $P$ polarized radiation and for tilt angles varying by $\pm 10^{\circ}$ about the normal position. Each measurement resulted from the ratio $I / I_{0}$ of the attenuated to the unattenuated radiation value, each $I$ and $I_{0}$ being the average of 50 individual measurements. The measurements were repeated four times.

\section{Results}

Using the procedures outlined in section 3 , the numerical values of the reflection correction $\Delta T$ were determined for the four neutral-density glass filters and the clear glass plate, at the wavelength $\lambda=574 \mathrm{~nm}$. This yielded the result represented by the straight line in figure 4 ; namely,

$$
\Delta T / T=-8.9 \times 10^{-4}, \quad \text { for } \lambda=574 \mathrm{~nm} .
$$

Each of the individual values of $\Delta T$ could be measured to a precision better than $10^{-4}$ transmittance units. There was no evidence suggesting a dependence of $\Delta T$ on polarization.

Secondly, the measurements on the clear glass plate were repeated for $\lambda=400 \mathrm{~nm}$ and $650 \mathrm{~nm}$. Together with the previously obtained result for 574 $\mathrm{nm}$, this showed the wavelength dependence indicated in figure 5. This dependence is also linear, and may be expressed as

$$
\Delta T / T=-1.26 \times 10^{-6}(\lambda-574 \mathrm{~nm}), \quad \text { for } T=0.92 .
$$

These results were then combined into the final empirical expression.

$$
\Delta T / T=-8.9 \times 10^{-4}\left[1+1.4 \times 10^{-3}(\lambda-574 \mathrm{~nm})\right],
$$

for the correction $\Delta T$ to be applied for different transmittances $T$ and wavelengths $\lambda$. This formula agrees with all individual measurements of $\Delta T$ to within $\pm 5 \times 10^{-5}$ transmittance units.

The correction $\Delta T$ so obtained represents only the first of the two error terms appearing in eq (4a), above. The exact value of the second term $\Delta T^{\prime}$ cannot be determined within the context of this paper, but a quantitative estimate may now be obtained as follows. From eqs (4b) and (7a) it may be seen that, for this spectrophotometer and for the appropriate value $R$ $\sim 0.08$ for the filters used,

$$
\frac{1}{2}\left(R_{1}+R_{2}\right) \sim 6 \times 10^{-3} .
$$

Provided that this arithmetic average of $R_{1}$ and $R_{2}$ is not substantially different from their geometric average $\left(R_{1} R_{2}\right)^{1 / 2}$, it follows from eq $(4 \mathrm{~b})$ that

$$
\Delta T^{\prime} \sim 3.6 \times 10^{-5} T\left(1-T^{2}\right),
$$

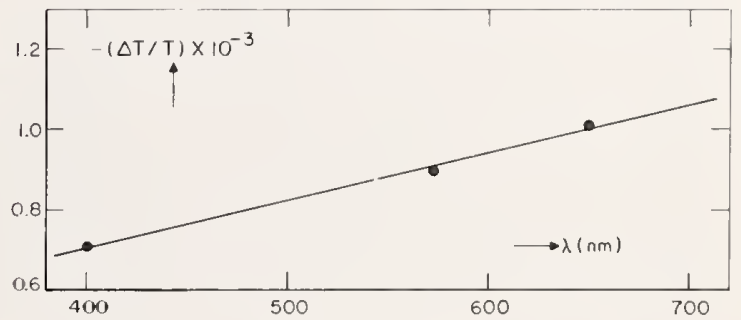

FlgURE 5. Reflection correction $\Delta \mathbf{T}$ versus $\lambda$ for $\mathbf{T}=0.92$ 
or $\Delta T^{\prime} \sim 1.4 \times 10^{-5}$ for $T=0.577$, for which this error is a maximum. Although this argument is not mathematically exact, it suggests that the residual reflection error $\Delta T^{\prime}$ is entirely negligible for the spectrophotometer used here.

According to eq (4b), the correction $\Delta T$ depends on the reflectance $R$ and, therefore, on the refractive index $n$ of the sample. Using eqs $(4 \mathrm{~b})$ and $(2 \mathrm{c})$ it is easily seen that

$$
d(\Delta T)=-\frac{8 r\left(R_{1}+R_{2}\right) T}{(n+1)^{2}} d n
$$

For $n=1.5, r=0.04, T=0.5$, and the above value (9a) for $\left(R_{1}+R_{2}\right)$, this is reduced to $d(\Delta T) \sim 3 \times 10^{-4}$ $d n$, showing that $\Delta T$ will not be affected by more than $10^{-4}$ transmittance units as long as $d n<0.3$, or 1.2 $<n<1.8$. Hence it may be concluded that the above values of $\Delta \mathrm{T}$ are applicable to virtually all filter glasses. Other types of samples, such as coated glasses, will of course require a different correction. For example, measurements on the evaporated metal-on-glass filter with transmittance 0.4 at $474 \mathrm{~nm}$ yielded a value, $\Delta T=-1.4 \times 10^{-3}$, which is about four times larger than indicated by figure 3 for uncoated samples.

\section{Conclusion}

Based upon this work, all transmittance measurements on glass filters with this high-accuracy spectrophotometer are performed with the sample accurately aligned normal to the optic axis. In addition to the reflection correction given by eq (8) and the detector nonlinearity correction discussed in reference [4], an $f$-number correction is applied to remove the residual bias due to the nonparallel radiation in the sample compartment. This latter correction is given by eq (5) as

$$
(\Delta T)_{f}=-\left(T / 3 n^{2}\right)\left(\ln \frac{T}{1-2 r}\right) \theta_{0}^{2}
$$

its magnitude is $1.3 \times 10^{-4}$ transmittance units, or less, for the $f / 10$ cone of light $\left(\theta_{0}=0.05 \mathrm{rad}\right)$ used. With these corrections applied, all measurements made with this high-accuracy spectrophotometer yield the normalincidence transmittance $\tau$ defined by eq (2a) within a $10^{-4}$ limit of instrumental accuracy.

This spectrophotometer was designed and constructed to permit calibration of solid and liquid filters for transmittance with a well-defined accuracy (4). These filters are used as Standard Reference Materials (SRM's) to check the photometric scale of conventional spectrophotometers. SRM 930a consists of a set of three glass filters (Schott NG-4) with nominal transmittances $0.1,0.2$, and 0.3 . Their transmittance values are certified to \pm 0.5 percent of the value, this uncertainty being the sum of random and systematic errors. The latter are principally due to the inherent in. homogeneity and instability of the glass, surface effects, and positioning the filters. They exceed by a large margin the instrumental corrections discussed in this paper. Hence, the certified transmittances of previously issued standard filters remain unaffected by these corrections.

\section{References}

[1] Gibson, K. S., and Balcom, M. M., J. Res. Nat. Bur. Stand. (U.S.), 38, 601 (1947).

[2] Goldring, L. S., Hawes, R. C., Hare, G. H., Beckman, A. O., and Stickney, M. E., Anal. Chem. 25, 869 (1953).

[3] Mielenz, K. D., J. Res. Nat. Bur. Stand. (U.S.), 76A (Phys. and Chem.), No. 5, 455-467 (Sept.-Oct. 1972).

[4] Mavrodineanu, R., J. Res. Nat. Bur. Stand. (U.S.), 76A (Phys. and Chem.), No. 5, 405-425 (Sept.-Oct. 1972).

[5] Mielenz, K. D., Eckerle, K. L., Madden, R. P., and Reader, J., Appl. Optics 12, 1630 (1973).

(Paper 77A6-792) 


\title{
JOURNAL OF RESEARCH of the Natianal Bureou af Standords - A. Physics ond Chemistry \\ Vol. 78A, No. 5, Seprember-October 1974 \\ Adaptation of a High-Accuracy Spectrophotometer for Ultraviolet Work
}

\author{
K. D. Mielenz, R. Mavrodineanu, and E. D. Cehelnik* \\ Institute for Materials Research, National Bureau of Standards, Washington, D.C. 20234
}

(May 31, 1974)

\begin{abstract}
A high-aceuracy spectrophutometer. originally designed for work at visible wavelengtls. was modified lo permit measurements in the uttraviolet withut degradation of its original performance. This was accomplished by equipping the spectoophotometer with a stable deuterium are source. a highly efficient averaging sphere with fiuorescent wavelength converter. a new grating. and achromatic sample connpartment uptics. The modified spectrophotometer will be used for the development uf new Standart Reference Vaterials. de well as for materials researeh. in the region between 200 and 300 moin.
\end{abstract}

Key works: Averaging sphere; deuterium arc lamp: Huorescent wavelentrth colluerter: yrating: spectrophutometry: standard reference materials; uhraviolet: $(1 \mathrm{~V}$ achromats: visible.

\section{Introduction}

A primary goal of the current NBS program in spectrophotometry has been the design of highaccuracy instrumentation for the certification of calibration standards and the development of improved measurement techniques. For transmittance measurements at visible wavelengths, this goal was accomplished by specially constructing two highly accurate single-heam spectrophotometers $[1,2],{ }^{1}$ which are presently used in the Institutes for Materials Research (IMR) and Basic Standards (IBS) for standards work at visible wavelengths $(400$ to $800 \mathrm{~nm}$, approximately). The instrumental accuracy achieved with these spectrophotometers is $10^{-4}$ transmittance units $(0.01$ percent). Although similar in some design aspects. these two spectrophotometers differ significantly in others, and therefore can be employed for in-house comparisons to ensure the accuracy and consistency of all spectrophotometric measurements at NBS. The purpose of this work was to extend these capabilities into the ultraviolet spectral region by developing the means for modifying either spectrophotometer for applications down to about $200 \mathrm{~nm}$.

The particular instrument that was modified was the IMR spectrophotometer described in reference [1]. As originally designed, this spectrophotometer employed a current-stabilized, 100-W tungsten ribbon lamp as the radiation source; a 1 -meter, f/8.7 Czerny-

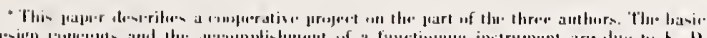

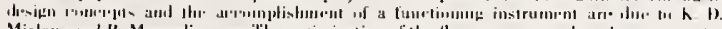

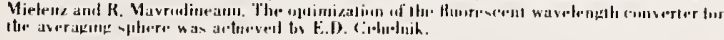

' Fikures in bralkels indiale the hiteraluse references at the end of this paper.
Turner grating monochromator (1200 lines/mm, 500-nm blaze) with a fused-silica prism predisperser as the dispersing element; and an 11-stage. S-20 photomultiplier tube attached to a $125-\mathrm{mm}, \mathrm{BaSO}_{4}$-coated averagin sphere as the signal detector. The tungsten lamp is imaged on the predisperser entrance slit by a fused-silica lens. Two additional fused-silica lenses are used in the sample compartment to focus the monochromator exit slit at the sample, and to refocus it into the averaging sphere [3]. The photomultiplier signal is measured by means of a current-to-voltage converter and a digital voltmeter, interfaced with a computer.

It may be estimated that, for a spectrophotometer of this type, a clear-space signal of at least $10^{-7} \mathrm{~A}$ is required if measurements are to be made with a standard deviation of at least $10^{-4}$ transmittance units [4]. The actual clear-space signal current obtained with this spectrophotometer at different wavelengths and for typical values of tunisten-lamp power, monochromator slit width, photomultiplier anode voltage, etc. is shown as curve (a) in figure 1 , and thus indicates an inadequate performance of the instrument in the spectral region below approximately $370 \mathrm{~nm}$. In order to effect the desired improvement of ultraviolet performance, the spectrophotometer was equipped with a deuterium arc source, a re-designed averayin. sphere, and a differently blazed grating. These components were chosen to achieve a wide spectral range (200 to $800 \mathrm{~nm}$ ) of the modified spectrophotometer. requiring only a change bark to the tungsten lamp for work above $400 \mathrm{~nm}$. In order to farilitate the usare of the instrument throughout this extenderl range. it was necessary to replace the two sample-compartment lenses by fused-silica, lithium-fuoride achromats. 


\section{Modification of Spectrophotometer}

\subsection{Deuterium Arc Lamp}

To a significant extent, the sharp drop of ultraviolet signal level shown by curve (a) in figure 1 is attrib.

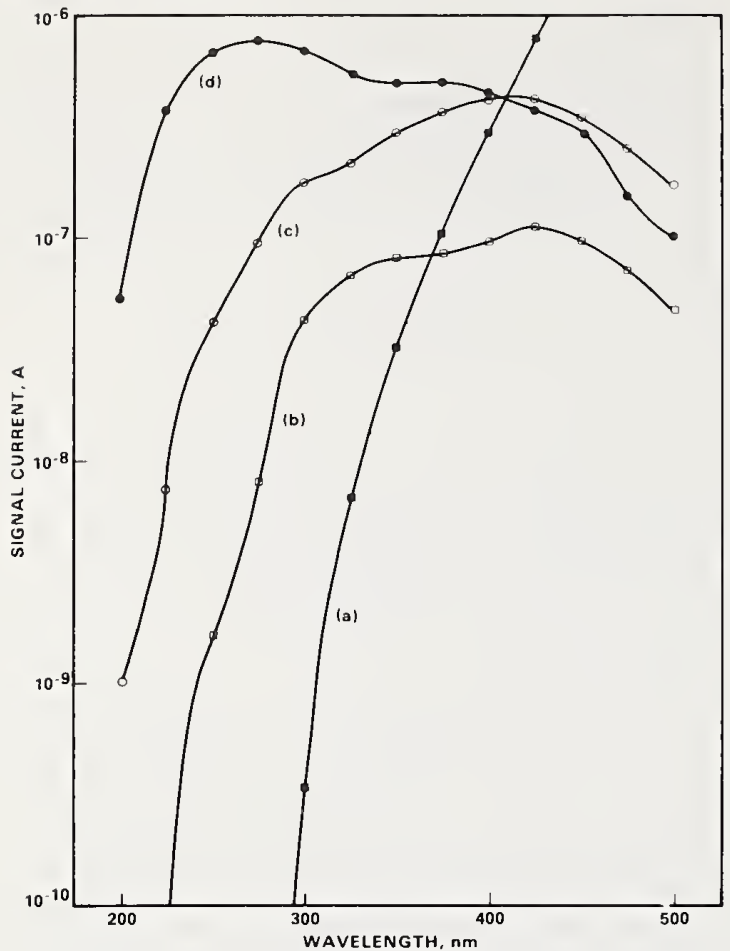

FüRE 1. Successive improtement of clear-spmace signal level of orizinal spertrophotometer (curve a) obtained by: (b) deuteriam arc lamp, (c) improved azeraging sphere. and $(d)$ new grating. utable to the tungsten lamp of the original spectrophotometer. A rapid decrease of radiant intensity with decreasing wavelength is typical for incandescent filament lamps, and therefore makes any source of this kind a poor choice for work at short wavelengths [5]. In contrast, a deuterium arc lamp exhibits an increase of radiant intensity with decreasing wavelength, and thus provides much better power levels in the ultraviolet.

A $60-$ W deuterium lamp with high-purity fusedsilica window was chosen for the modified spectrophotometer. This lamp has a line-free continuous emission in the ultraviolet extending to below $180 \mathrm{~nm}$, and is rated to have the same output at $200 \mathrm{~nm}$ as a $150-W$ xenon are lamp. In compaison to a $250-\mathrm{W}$ tungsten-bromide filament lamp, its output is about 1000 times greater at $250 \mathrm{~nm}$, and 4 times wreater at $300 \mathrm{~nm}$. For work above $400 \mathrm{~nm}$, tungsten lamps are preferable because of the decreasing intensity of the deuterium-arc spectrum and its line structure in the visible. The clear-space signal obtained after the deuterium lamp was installed in the spectrophotometer is shown as curve (b) in figure 1.

The stability of the radiant-intensity output of the deuterium lamp was tested by performing regularly repeated measurements of the spectrophotometer signal over extended periods of time. The long-term stability of lamp power so observed may be seen from figure 2, showing a gradually decreasing signal drift at the rates of $1.5,0.6$, and 0.08 percent per hour after the lamp had been operated for 1,3 , and $5 \mathrm{~h}$, respectively. The average short-term instability (random noise plus drift) of the deuterium lamp was found to be 0.02 percent for a total of 15 sets of 20 individual readings, taken at 5-s intervals and at arbitrary times during an 8 -h period of lamp operation. Since all data obtained with this spectrophotometer are derived by averaging a large number of individual measurements of transmittance, performed in a time-symmetrical sequence which eliminates the effects of drifting, this stability of the deuterium lamp is adequate for routine

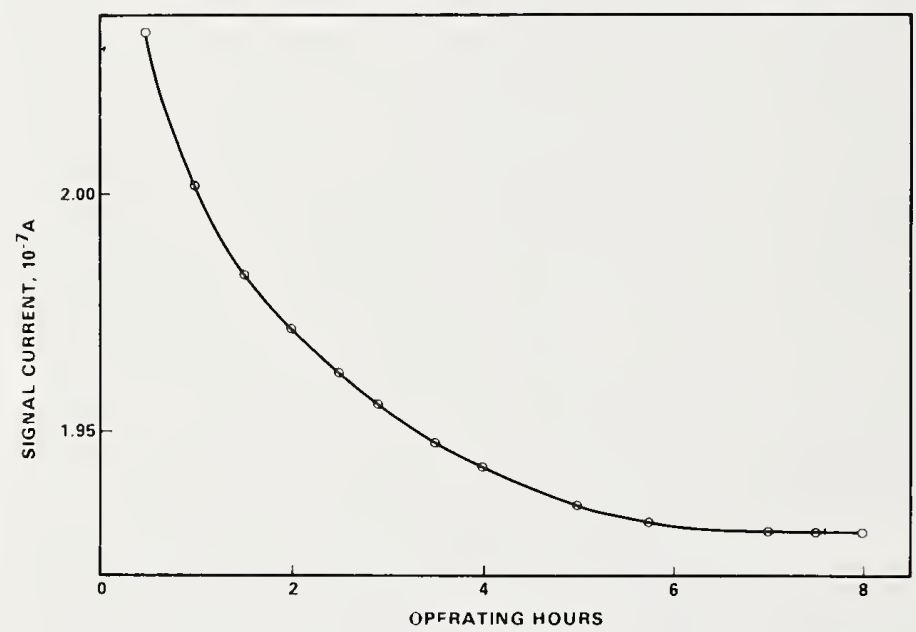

Findne 2. Long-term signal drift observed with deuterium lamp. 
measurements with a precision better than $10^{-4}$ transmittance units. The above results for the deuterium lamp compare favorably with the stability data found for a current-stabilized tungsten lamp [2].

\subsection{Averaging Sphere}

The original averaging sphere of the spectrophotometer was designed as shown in figure $3 \mathrm{a}$. It has an internal diameter of $125 \mathrm{~mm}$, and circular entrance and exit ports 20 and $50 \mathrm{~mm}$ in diameter, respectively. The circular target, $35 \mathrm{~mm}$ in diameter, is located at the center of the sphere. The inside of the sphere, both sides of the target, and the thin target support rod are coated with several layers of specially prepared barium sulfate and polyvinyl alcohol coatings as developed by Grum and Luckey [6]. The photomultiplier tube is attached to the sphere, so that its $50-\mathrm{mm}$ cathode is located $16 \mathrm{~mm}$ behind the exit port. The efficiency of this sphere was determined by successively measuring photomutiplier signals obtained at different wavelengths with and without sphere, using the deuterium arc lamp. These measurements showed a steep decrease of sphere efficiency from about 15 percent for visihle wavelengths near $500 \mathrm{~nm}$ to
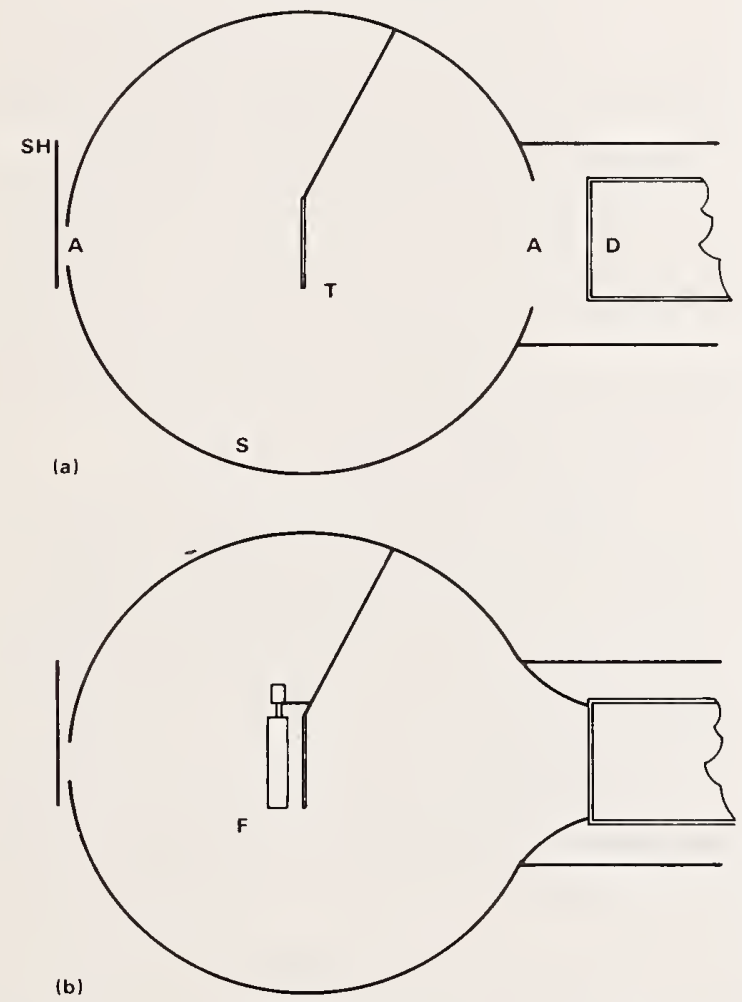

FIC:RE 3. Geometry of (n) original avernging sphere and (b) improved sphere.

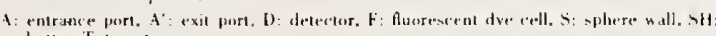
shuller. T: tarke-t. less than 0.1 percent at $200 \mathrm{~nm}$, and thus indicated the necessity to equip the spectrophotometer with an improved, more efficient sphcre [7].

According to theory [8], the efficiency of an averaging sphere of the type considered is, approximately,

$$
\phi_{0} / \phi=\left[r^{2} /(1-r)\right](1-e / d) d^{2} / 16 s^{2}
$$

where

$\phi=$ radiant flux into sphere.

$\phi_{D}=$ flux reaching detector,

$r=$ wall reflectance (assumed close to, but not equal to unity),

$s=$ sphere radius,

$d=$ radius of sensitive area of detector (assumed equal to radius of exit-port)

$e=$ distance between exit port and detector.

It may be seen from this equation that, to a large extent, the poor efficiency of the original spectrophotometer sphere is due to inadequate coupling of exit port and detector. The collection efficiency of the detecto: (i.e.; the fraction of the diffuse flux from the exit port which actually reaches the photocathode) appears in $\mathrm{Eq}(1)$ as the factor $(1-e / d)$. which in this case has the numerical value 0.64 and thus shows that more than one third of the available flux is lost through the gap between exit port and detector. Therefore, a large increase in efficiency could be gained by modifying the sphere as shown in figure $3 \mathrm{~b}$. The sphere wall was tapered in a pear-like fashion and was extended into the detector housing, so that the exit port is butted directly against the photocathode. This simple modification of the sphere resulted in a large increase of efficiency (from 15 to 70 percent at $500 \mathrm{~nm}$ ). However, the efficiency in the utraviolet (now 2.5 percent at $200 \mathrm{~nm}$ ) was still inadequate.

The averaging effectiveness of this sphere was tested by Mr. K. L. Eckerle of the Optical Radiation Section of NBS. The sphere was found to be insensitive to beam displacements from the target center of $\pm 1.5 \mathrm{~mm}$ within $a \pm 10^{-4}$ limit of signal variation. This is to be compared with a \pm 5 percent variation for $a \pm 1 \mathrm{~nm}$ beam displacement on the same photomultiplier used without the sphere.

The high efficiency of the modified sphere in the visible suggested that a near-optimal sphere geometry had been achieved, and that the limiting factor in the uttraviolet was now the reduced reflectance of the barium-sulfate sphere coating. In order to overcome this remaining difficulty, a fluorescent dye was used to shift the incident short-wave radiation into the longer wavelength region for which the reflectance of barium sulfate is high. This dye, which is contained in a cell placed in front of the sphere target as shown in figure $3 \mathrm{~b}$. had to be chosen such that virtually all of the incident flux at short wavelengths is absorbed and is converted into fluorescence with a quantum efficiency as nearly equal to unity as possible. In order to avoid impairing the high sphere efficiency at longer wavelengths, it was also required that visible light be not absorbed, so that it passes through the dye unaffected and is reflected from the target as before. The fluores- 
cent material selected was a $0.923 \mathrm{~g} / \mathrm{l}$ solution of 2,5 diphenyloxazole (PPO) in $n$-hexane in a $10 \times 10 \times 2$ $\mathrm{mm}$ high-purity fused-silica cell. It is effectively transparent for wavelengths above $360 \mathrm{~nm}$, and below 340 $\mathrm{nm}$ absorbs more than 99 percent of the incident radiation. Its estimated quantum efficiency is 0.9 . with the peak emission occurring near $370 \mathrm{~nm}$. The use of this dye proved highly successful, and resulted in a sphere efficiency of 20 percent at $200 \mathrm{~nm}$.

The marked enhancement of signal level obtained with this improved sphere is shown by comparing curve (c) in figure 1 with curve (b). The measured efficiency of the sphere is roughly constant and equal to 20 percent between 200 and $300 \mathrm{~nm}$, followed by a gradual increase to a constant level between 60 and 65 percent for wavelengths from 400 to beyond $650 \mathrm{~nm}$. A further increase of sphere efficiency was obtained in a final design by reducing the sphere diameter and further optimization of the dye [8].

It was also ascertained that the fluorescence wavelength converter did not affect the linearity of the detection system. Theoretically, the radiant intensity of fluorescence from the dye can be expressed as

$$
I_{e}=Q I_{a},
$$

where $Q$ is the quantum efficiency of the dye and $I_{a}$ is the intensity absorbed. The latter is given by Beer's law as

$$
I_{n}=I_{b}\left(1-10^{-\epsilon c b}\right)
$$

where $I_{o}$ is the initial intensity, and where $\epsilon, c$, and $b$ denote molar absorptivity, concentration, and path length, respectively. Thus, $I_{e}$ is proportional to $I_{v}$ under the applicable assumptions that Beer's law is valid and that the quantum efficiency of the dye is indepeident of intensity. This conclusion was verified by measuring the linearity of the detection system at one wavelength $(250 \mathrm{~nm})$ for which the dye is effective. and at another $(400 \mathrm{~nm})$ for which it is not. These two measurements, which were made using the doubleaperture method [9]. yielded indistinguishable results within the limits of experimental uncertainty. and also agreed with previously performed linearity measurements of the same photomultiplier tube at $575 \mathrm{~nm} \mathrm{[1].}$

\subsection{Grating}

The previously obtained clear-space signal level. curve (c) in figure 1, was still judged inadequate for accurate work at short wavelengths. Since the original grating of the spectrophotometer (blazed for $500 \mathrm{~nm}$ in the first order) had been chosen for work in the visible. it was obvious that a further improvement could be effected by substitution of another grating. This new grating has 600 lines $/ \mathrm{mm}$, is blazed for $200 \mathrm{~nm}$ in the first order. and resulted in the final clear-space signal current plotted as curve (d) in figure 1 . Since the signal level near $200 \mathrm{~nm}$ can easily be raised by adjusting the photomultiplier gain. the original goal of achieving a clear-space signal of at least $10^{-\overline{7}}$ A throughout the ultraviolet had thus been accomplished.

The loss of signal level in the visible due to the change of gratings [curves (d) and (c) in figure 1 is relatively small, and is more than offset by the higher efficiency of the new sphere [curves (c) and (b)]. Thus the modified spectrophotometer can be used above 400 $\mathrm{nm}$ by merely interchanging deuterium and tungsten lamps, without need to substitute gratings.

\subsection{Achromatic Sample-Compartment Optics}

In view of the wide spectral range of the modified spectrophotometer, the chromatic aberration of the original sample-compartment lenses proved to be a limiting factor of instrumental performance. Significant losses of signal level were caused by the fact that these lenses, when initially focused by eye. were out of focus in the ultraviolet and thus caused less-thanoptimal illumination of sample and detector.

If the monochromator exit slit is focused at the sample with unit magnification at a wavelength $\lambda_{0}$. the diameter of the blur circle in the sample plane for a wavelength $\lambda<\lambda_{0}$ can easily be shown to be equal to

$$
\delta=D\left[2 f\left(\lambda_{11}\right) / f(\lambda)-1\right],
$$

where $f$ is the focal length and $D$ is the effective diameter of the focusing lens. For the particular lenses of the original spectrophotometer $[f(200 \mathrm{~mm})=168 \mathrm{~mm}$. $f(500 \mathrm{~nm})=200 \mathrm{~nm}, D=38 \mathrm{~mm} \mid$. and assuming that the focusing was done at $500 \mathrm{~nm}$, the computed blurcircle diameter at $200 \mathrm{~mm}$ is $14 \mathrm{~mm}$. This numerical example illustrates the large defocusing caused by chromatic lenses in the sample compartment. although it should be pointed out that due to the opposing effect of the second lens a smaller blur circle is incurred at the detector. Nevertheless, it was found empirically that the ultraviolet signal level of the spectrophotometer could be improved as much as 30 percent by repositioning the sample-compartment lenses.

The most effective way to overcome this deficiency of the spectrophotometer would have been to use mirror optics. but since this would have required a redesign of the sample compartment and its enclosure it was more expedient to employ achromatic lenses. The lenses selected are f/3 lithium-fluoride. fusedsilica (non fluorescent) achromats with $200 \mathrm{~mm}$ focal length, best correction for longitudinal chromatic aberration between 200 and $400 \mathrm{~nm}$, and with anti-reflection coating for $400 \mathrm{~nm}$.

On account of the limited spectral regions for which the deuterium and tungsten lamps of the modified spectrophotometer are employed, it was not found necessary to use an achromat in the source compartment as well.

\section{Conclusion}

As a result of the work reported here. the modified high-accuracy spectrophotometer is now used. throughout the spectral region between 200 and $800 \mathrm{~nm}$. for 
the certification of solid and liquid Standard Reference Materials for routine applications in spectrophotometry, as well as for materials research aimed at establishing inorganic and organic molar absorptivity standards.

The modified spectrophotometer may also serve as a model for improved commercial instrumentation. In particular, it is anticipated that the development of a highly efficient averaging sphere for visible and ultraviolet wavelengths will lead to a more widespread use of spheres in routine spectrophotometry.

\section{References and Notes}

[1] Vavrodineanu. R.. J. Res. Nat. Bur. Stand. (U.S.). 76A (Phys. and Chem.), No. 5, 405-425 (Sept.-Oct. 1972).

[2] Vlelenz. K. D.. Eckerle. K. L.. Vladden. R. P.. and Reader. J. Appl. Optics 12, 1630-164l 11973); Mielenz. K. D.. and Eckerle. K. L... Nat. Bur. Stand. (U.S.). Tech. Note 729.60 pages (June 1972).

[3] The systematic error due to interreflection between the samplecompartment lenses is accounted for in all measurements made witl, this spectrophowmeter. See Vlielenz, K. D.. and Mavrodineanu. R., J. Res. Nat. Bur. Stand. (U.S.), 77A (Phys. and Chem.). No. 6.699-703 (Vov.-Der. 1973).

[4] K. D. Vlielenz. J. Res. Nat. Bur. Stand. (U.S.). 76A (Phys. and Chem.). No. 5. 455-467 (Sept.-Oct. 1972).
[5] Although tungsten-halogen lamps are frequently used in ultra violet spectrophotometry. such a source was unsuitable for this application. A 250-W' single-coil tungsten-hromide lamp was tried. but merely resulted in an over-all increase of signal level which could also have been ar hieved by choosing a nore intense tungsten lamp or increasing the photomultiplier gain.

The tungsten-brumide lamp exhibited essentially the same steep drop of signal tow ard shorter wavelengths as the tungsten lamp. and was found to be inadequate for accurate work below $320 \mathrm{~mm}$. A further difficulty is that tungsten-halogen lamps are generally too unstable for high-accuracy spectrophotometry in a single-beam geunetry. See Clarke. F. J. J. J. Res. Nat. Bur. Stand. (U.S.), 76A (Pliys. and Chem.), Vo, 5. 375-403 (Sept-Oct 1972).

[6] Grum. F.. and l.uckey, G. W.. Appl. Optics 7, 2289-2294 (1968).

[7] A significant improvement of the visible and ultraviolet signal levels was found with a flux averager consisting of two double. ground fused-silica plates. $1 \mathrm{~mm}$ in thickness and spaced by diffusely reflecting, cylindrical $\mathrm{Al}_{2} \mathrm{O}_{3}$ tube with $50 \mathrm{~mm}$ length and internal diameter. Although this type of averager has been used successfully for other applications (See Budde. W.. Proc. Fourth Imeko Symposium. Prague 1969, p. 167), the averaging effectiveness of the particular unit used in this work was inadequate for this application since a beam displacement of $\pm 1 \mathrm{~mm}$ at the entrance window of the averager still caused a 0.4 percent change in the photomultiplier signal. These measurements were performed by Mr. K. L. Eckerle of the Optical Radiation Section of NBS.

[8| Mielenz. K. D.. Mavrodineanu. R.. and Cehelnik. E. D.. Appl. Optics (to be published).

[9] Mielenz. K. D. and Eckerle. K. L.. Appl. Optics 11, 2294-2303 (1972).

(Paper 78A5-838) 
1916 Race St., Philadelphia, Pa., 19103

Reprinted from the Annual Book of ASTM Standards, Copyrighe ASTM

\section{Standard Method of ESTIMATING STRAY RADIANT ENERGY'}

This Standard is issued under the fixed designation E 387; the number immediately following the designation indicates the year of original adoption or, in the case of revision, the year of last revision. A number in parentheses indicates the year of last reapproval

\section{Scope}

I.l Stray energy (SRE) can be a significant source of error in spectrophotometric measurements. The danger of significant error is enhanced since its presence is often unsuspected. Also, SRE frequently increases with passage of time. Therefore, thorough periodic testing is highly important.

1.2 This method affords an estimate of radiant energy at wavelengths remote from those of the nominal pass band transmitted through the monochromator of an absorption spectrophotometer. Test-filter materials are described that discriminate between the desired wavelengths and those which contribute most to SRE for conventional commercial spectrophotometers used in the ultraviolet, the visible, the near infrared, and the alkali halide infrared ranges. These procedures apply to instruments of conventional design, with usual sources, detectors, and optical designs. The vacuum ultraviolet and the far infrared present special problems that are not discussed herein.

1.3 These procedures are neither all-inclusive nor infallible. Because of the nature of readily available filter materials, with a few exceptions the precedures are insensitive to SRE of shorter wavelengths in the ultraviolet or visible, or of lower frequencies in the infrared, and they are not necessarily valid for "spike" SRE nor for "nearby SRE." (See Appendixes for general discussion and definitions of these terms.) However, they are adequate in most cases and for typical applications. They do cover instruments using prisms or gratings, in either single or double monochromators.

1.4 The proportion of SRE encountered with a well-designed monochromator, used in a favorable spectral region, is a small fraction of I percent. With a double monochromator it may easily be less than $1 \mathrm{ppm}$ even with a broad-band continuum source. Under these conditions, it may be difficult to do more than determine that it falls below a certain level. Actual measurement often requires special techniques and instrument operating conditions that are not typical of those occurring during use. When absorption measurements with continuum sources are being made, it is frequently true that, owing to the effect of slit width on SRE in a double monochromator, these test procedures tend to give "conservative" results; that is, because larger slit widths than normal must be used to admit enough energy to the monochromator to permit evaluation of the SRE, the stray proportion indicated is greater than would normally be encountered in use.

1.5 The principal reason for a test procedure that is not exactly representative of normal operation is that the effects of SRE are "magnified" in sample measurements at high absorbance. It is usually necessary to increase sensitivity in some way during the test in order to evaluate the SRE adequately. This is usually accomplished by increasing slit width and so obtaining sufficient energy to allow meaningful measurement of the SRE after the monochromatic energy has been removed by the SRE filter. A further reason for increasing energy or sensitivity can be that

\footnotetext{
'This method is under the jurisdiction of ASTM Committee E-13 on Molecular Spectroscopy.

Current edition approved June 29, 1972. Published September 1972. Originally published as E $387-69 \mathrm{~T}$. Last previous edition E $387-69 \mathrm{~T}$.
}

By publication of this standard no position is taken with respect to the validity of any patent rights in connection therewith, and the American Society for Testing and Materials does not undertake to insure anyone utilizing the standard against liability for infringement of any Letters Patent nor assume any such liability.

"Reprinted by permission of the American Society for Testing and Materials from the 1972 ASTM

Book of Standards, Copyright 1970." 
many instruments have only absorbance scales, which obviously do not extend to zero transmittance. Even a SRE proportion as large as 1 percent may fall outside the measurement range.

1.6 Many instruments that use optical attenuators to balance sample absorption make relatively inaccurate measurements below 10 percent transmittance, because of poor attenuator linearity. All instruments should be carefully and frequently checked if used below about 1 percent transmittance because of the possibility of zero shift due to electrical pickup or other causes. For these reasons, the test procedure specifies that the measurements be made within 100 percent and 10 percent on the scale. Obviously this is not required if reliable photometric linearity and zero checks are made under the conditions prevailing during the test, and use of the 10 and 1 percent range may give lower and more accurately representative SRE values. In marginal cases this more elaborate test procedure, incorporating accepted ASTM tests for photometric linearity, may be justified.

1.7 High accuracy in SRE measurement is not required. A measurement reliable within 10 or 20 percent is always sufficient, but often many readings must be cascaded to obtain the final result, so that painstaking measurements are desirable.

\section{Summary of Method}

2.1 The following test procedure is written for transmittance-recording double-beam instruments. Modification for absorbance recording will be obvious. It is readily adapted for point-by-point operation by measuring at enough points to allow reasonably accurate interpolation between the points so as to provide essentially continuous information over the wavelength region covered, or by direct measurement at the desired specific wavelength.

2.2 After establishing that the instrument is adequately free of zero transmittance error, and measuring the baseline (100 percent) over the appropriate spectral range, a filter is inserted into the sample beam and its transmittance curve is recorded, starting in a region where it is nearly transparent and scanning slowly toward increasing absorption. The filter materials are selected for sharp cutoff, freedom from fluorescence, and sufficiently high absorption that their transmittance in the stop band can be neglected. They should be visually clear and free of bubbles and striae. SRE will then set the limit to the minimum transmittance observed, unless an adverse signal-to-noise ratio, a scale limitation of the photometer, or a false electrical zero intervenes.

2.3 These limitations may usually be overcome by increasing the slit width to admit more incident radiant energy on the filter. In a double-beam instrument, this may be accomplished by attenuating the reference beam with a screen, mask, or neutral filter. The following procedure assumes the use of etched screens, and measures their transmittance by their effect on the instrument reading.

2.4 The apparent transmittance of the filter is sensitive to spectral bandwidth. Since bandwidth increases with slit width, it is necessary that the transmittance of the screen be measured at a fixed slit width each time. The slits may then be allowed to open for the following steps of the test. The effect of such changes in slit width on the apparent transmittance of the filter becomes insignificant at the end of the test when the SRE becomes the dominant source of signal.

2.5 The scanning is continued, and the reference beam is attenuated further in as many steps as required, until the steeply falling transmittance curve levels off because of SRE. The product of all the reference attenuation fractions times the value of the transmittance reading at the plateau, corrected by the baseline value and the filter reflection loss, is taken as the proportion of SRE.

2.6 The proportion of SRE can in some cases increase with increasing slit width (see Appendix A4). Therefore, the smallest practical value of slit width should be used at the last step of the reference beam attenuator, as this corresponds most nearly with the normal operating conditions of the spectrophotometer.

2.7 Some instruments scan automatically only in one direction, which may not be the one specified in the test procedure. Manual 
control or scanning by hand may be necessary. Particularly note any precautions called for by the manufacturer's instructions in this case. If, for mechanical reasons, manual scanning is not feasible, the test procedure can be reversed, after making the checks of 100 percent line and zero, by going to the desired wavelength within the filter stop band, inserting neutral attenuators in the reference beam until the pen lies between 10 and 100 percent transmittance (preferably near 10 percent, widening the slits while doing so to restore normal pen response, scanning in reverse until 100 percent transmittance is reached, and removing the reference beam attenuators one at a time while measuring their attenuation, until all are out and a region where the filter is transparent is reached.

2.7.1 The only difficulty with this procedure lies in finding the narrower slit width that will give normal pen response after each reference beam attenuator is removed, and finding the transmittance change at that slit width. Several trials may be required.

2.7.2 When done carefully, this procedure gives the same result as the normal one, and in fact affords a way of checking the standard test results whenever both scan directions are permitted.

\section{Apparatus and Material}

3.1 Screens $^{2}$ of Etched Nickel, useful for reference beam attenuators are listed in Table 1 and footnote 2 . They may also be convenient for "quick check" transmittance "standards." The screens should be placed as far as possible from each other, and preferably at a point along the beam where it is as wide as possible. Usually a $1-\mathrm{cm}$ spacing between screens suffices to allow acceptable reproducibility' of results. Their exact transmittance varies with location in the beam, hence they should be mounted so they can be positioned reproducibly, and mechanical stability of all parts of the spectrometer should be established. The transmittance of two or more screens used in cascade or tandem is rarely equal to the product of their separate transmittances, and may be quite sensitive to lateral displacements with respect to each other, due to the moiré effect.
3.2 Test Filter Materials, shown in Table 2 , provide an array capable of satisfactorily covering nearly all normal ultraviolet and infrared spectral ranges. The first column shows the spectral range over which critical remote SRE measurements can be made. The second column shows the approximate 80 percent transmittance wavelength or wavenumber. Scanning for the following procedure should always begin at this point, or at one more remote from the test spectral range.

3.2.1 Filter diameters are not specified. They should be large enough to cover the entire beam with substantial safety margin. Because of the danger that radiant energy outside the nominal beam may bypass the filter and be scattered back into the beam it is advisable to mount them against a cell compartment window or in a much larger metal holder so as to block any such paths. If in doubt, test with an opaque object of the same size as the filter.

3.2.2 If there is any possibility that fluorescence of windows, cells, or sample solvents may be contributing to SRE in the ultraviolet range, locate the test filter immediately following the sample position in the beam, and test in the presence of such cell or solvent. Note that fluorescence of optical elements between the sample and the detector merely modifies the detector sensitivity. It does not constitute an effective source of SRE, since this fluorescent emission is not differentially absorbed or transmitted by the sample.

3.2.3 The useful spectral range of the sharp cutoff filters can be extended toward considerably more remote wavelengths, but if this is

${ }^{2}$ Available in sheet form from Perforated Products, Inc., 68 Harvard St., Brookline, Mass. 02146. Also as cut disks in holders from Cary Instruments, Monrovia, Calif. These holders fit the Cary cell blocks for cylindrical cells. They do not fit holders for rectangular cells. The holders They do not fit holders for rectangular cells. The holders
are also useful for glass filters for Bouguer's law absorbance linearity tests

$\begin{array}{cccc}\begin{array}{c}\text { Screen and } \\ \text { Holder Part } \\ \text { Number }\end{array} & \begin{array}{c}\text { Approximate } \\ \text { Mesh }\end{array} & \begin{array}{c}\text { Identification } \\ \text { Number }\end{array} & \begin{array}{c}\text { Nominal } \\ \text { Absorbance }\end{array} \\ 14041111 & 30 & 25 \mathrm{~K} & 0.5 \\ 14041112 & 60 & 30 \mathrm{R} & 1.1 \\ 1404113 & 120 & 40 \mathrm{~T} & 1.5 \\ 1404114 & 270 & 30 \mathrm{~W} & 2.0\end{array}$


done, it must be recognized that the measurement becomes progressively less significant. The apparent proportion of SRE may be reduced in such regions because the filter absorbs energy at wavelengths contributing significantly to SRE.

3.2 .4 Plates of Alkali Halide, about $6 \mathrm{~mm}$ thick for absorption cell windows are commonly on hand in analytical laboratories, and the 80 percent transmittance points are specified for this thickness. However, other thicknesses, over a range from about 4 to $15 \mathrm{~mm}$, can be substituted without invalidating the test.

3.2.5 Fused Silica, ${ }^{3}$ in the form of cell windows, is commonly available and useful over a thickness of 1 to 5 or $6 \mathrm{~mm}$. Crystal quartz is less desirable because of its birefringence, which may cause apparent cyclical transmittance variations with wavelength.

\section{Procedure}

4.1 Verify that pen response is "normal," that is, that normal damping (preferably slight underdamping) and designated response time and low (less than $1 / 2$ percent) dead zone exist. Follow the manufacturer's instructions, or test by moving a mask a small distance into and out of first the sample, then the reference beam.

4.2 Check the zero transmittance error with an opaque shutter or sample. Adjust the zero control or note the indicated zero and subtract it from subsequent readings.

4.2.1 In some infrared instruments the radiant energy from a rotating beam modulator can be compensated by an adjustable electrical signal. The amount of compensation required varies with wavelength and slit width. Make frequent zero checks during the SRE tests. It is desirable to interpose the opaque shutter ahead of the filter, and only briefly, so that radiation from the filter is self-compensated. A shutter made of thick insulating board, such as Celotex, ${ }^{4}$ or several thicknesses of cardboard separated by air spaces, is recommended, preferably brought to instrument temperature by being stored in the sample compartment.

4.3 Record a 100 percent line over the de- sired wavelength range for a single filter. If the slit system is controlled by a servo system to maintain a constant reference signal, leave this control on; otherwise put the slits under manual control or leave off (immobile). In the latter cases, check pen response frequently during the scan, and change the slit width if and when pen response becomes sluggish or markedly underdamped. Check by quickly inserting and removing an opaque object in the sample beam. At each change point, record the wavelength and new slit width, so that they can be reproduced in step 4.5 .

4.3.1 If the spectrophotometer is provided with a single beam mode in which the sample signal is compared with a fixed electrical reference signal, use this provision to check and readjust slit width instead of the less reliable pen response test.

4.4 Insert the filter in the sample beam.

4.5 Scan slowly from high transmittance to low. When about 10 percent transmittance is reached, stop the scan but leave the pen on and the chart running, recording the pen position for several full pen periods (multiples of five times the time constant for an exponential response function).

4.6 Insert in the reference beam a "neutral" beam attenuator, such as a screen selected from the list shown in Table 1, and having about 12 to 20 percent transmittance.

4.7 Record the resulting increased apparent transmittance for at least 20 times the nominal response period of the instrument. (The lengthened time is required because the reduced reference beam energy results in sluggish pen response.) If possible, displace the optical attenuator, or the pen, or both, by hand first in one direction, then the other, and allow to recover to make sure that the photometric system still functions.

4.8 Note on the record the ratio of transmittance values, or "setback," that corresponds to the displacement at fixed slit width.

\footnotetext{
Corning 7940 glass, General Eleciric Type 151 glass, Hereaus Suprasil, Ulırasil, or Thermal American Spectrosil have been found satisfaclory.

Celotex is a Irademark of the Celotex Corp.
} 
4.9 Turn on the slits or otherwise adjust them to give normal reference signal levels.

Note 1 -As indicated in Appendix A4, the change in slit width may sometimes change the value of SRE. The displacement resulting from slit width change may be due in small part to this, or to possible shift of zero resulting from the change in illumination conditions resulting from the slit width change, but is mainly due to the accompanying change of spectral bandwidth.

4.10 Continue scanning in the direction toward decreasing transmittance of the filter until the indicated transmittance again falls to about 10 percent.

4.11 Repeat steps 4.5 through 4.9 , replacing the reference beam attenuator of step 4.6 by another with about 12 percent of the transmittance of the previously used filter, or about 0.9 absorbance more; or add a second attenuator, spaced from the first and having about the same transmittance as the first.

4.12 Again measure and note the new transmittance change resulting from the reference beam attenuation at fixed slit width.

4.13 Repeat steps 4.11 and 4.12 with a succession of additional reference beam attenuators until the indicated transmittance reaches a minimum, or until the slits reach their maximum value (Note 2 ). If the indicated transmittance does reach a minimum, select the reference beam attenuator for the last setback such that the scale reading is about 10 percent for even less, if the zero point is verified). If necessary, after selecting the attenuator for the last setback, return to the preceding attenuator and recording conditions before measuring the final setback.

Note 2- To qualify the instrument for a particular application, it is usually only required that the SRE fall below a given proportion. It is then of course not necessary to continue adding reference attenuators beyond the point required to demonstrate compliance.

\section{Calculation}

5.I Calculate the SRE proportion as the product of all the "setbacks" times the final transmittance fraction at the desired wavelength, divided by the transmittance fraction of the 100 percent line at this wavelength, measured in step 4.3, and divided by the filter transmittance in the pass band, due to reflection loss, of about 0.90 .

Note 3-Since the instrument SP.E often increases with increasing slit width, the value obtained will ordinarily indicate a greater proportion of SRE than is normally encountered in use. If the final slit width corresponds to a normal use value. the SRE proportion will be correct for that value. Such a condition may sometimes by obtained by starting the series of measurements at unusually high values of amplification or at high photomultiplier dynode voltage, accepting more than normal noise on the records of the SRE test. If this is done. it is doubly important to be sure that the photometer scale still reads correctly near zero transmittance under the higher gain condition.

\section{Illustrative Example}

6.1 A stray radiant energy test was done on a Cary Model 15 Spectrophotometer following the procedure described in Section 4. The resulting recording is shown as Fig. I. The chart reads from right to left. The steps of the procedure are marked by the corresponding numbers of the paragraphs in Section 4. Step 4.1 was performed but was omitted on the chart. However, it is evident from the pen test shown in step 4.7 that the pen dead zone is small and its response sufficiently fast even with a reduction of total radiant energy to less than $1 / 9$ of normal.

6.2 Calculate in accordance with Section 5 as follows:

$$
\begin{aligned}
\text { SRE } & =0.108 \times 0.118 \times 0.111 \times 0.151 \times 0.183 \\
& \times 0.0128 / 0996 \times 1 / 0.885 \\
= & 5.67 \times 10^{-1} \text { or } 0.000057 \text { percent }
\end{aligned}
$$

\section{APPENDIXES}

\section{Al. General Concepts}

Al.l Stray radiant energy in a spectrophotometer is difficult both to define and to measure. It is often defined as the proportion of transmitted radi- ant energy of wavelengths outside the nominal pass band of the monochromator to the total energy transmitted. However, since only signal-producing 
radiant energy is significant, it is obvious that the relevant measure is the integral of the product of energy and detector sensitivity over all wavelengths except the pass band divided by the corresponding total. In practice it is impossible to make the test conform exactly to this definition, so a more empirical definition, based upon an accepted test procedure, such as that described herein. must be used

A 1.2 Only for a Raman spectrophotometer is SRE measurement relatively straightforward. Here it is possible 10 employ a very narrow, very intense band of frequencies. The SRE is determined by the "slit function" normalized to unity peak height: that is by the intensity of this monochromatic radiant energy which is transmitted by the monochromator, over the spectral interval of interest. The intensity of frequency-shifted rudiant energy is so feeble that it does not itself constitute a significant source of SRE.

11.2.1 Yet even in this case problems are en countered It is not legitimate, for example, to beam a laser directly into the monochromator lor the measurement, because in so doing only a small fraction of the aperture is illuminated, and the slit is coherently illuminated, so that neither typical scattering nor typical aberrations are produced. The test illumination and the monochromator control settings must fairly reproduce the conditions during use. But if the exc ing energy is scattered into the entrance optical train, the scattering medium must itself be free of appreciable fluorescence and Raman scattering. Very few substances are suitable, if a well designed double monochromator is being evaluated.

A 1.2.2 For a Raman spectrophotometer, in common with most emission instruments, values of SRE observed are usually small compared with absorption instruments, because they arise only from the single line. or a few isolated lines, rather than from the integrated effect of all the wavelengths of a continuum source.

Al.3 For absorption spectrophotometers, the definition and measurement problems are much more difficult. SRE is not uniquely a function of the monochromator itself, but varies with the spectral distribution of the source and of the detector sensitivity, and with other factors discussed below. Also, suitable test materials are scarce. The ideal filter for measuring SRE should have intense absorption over a spectral region of adjustable nominal wavelength and bandwidth, and negligible absorption at other wavelengths. Such absorbers do not exist One takes advantage of absorption edges such as those seen with alkali halide crystals, certain liquids, and sharp cutoff glass hilters, and supplements these by finding a variety of substances having narrow, intense absorption bands. There are spectral regions for which no fully satisfactory filter material has been proposed.

A 1.3.1 The tests herein are of limited scope because sharp cutoff filters transparent for the ultraviolet but absorbing in the visible, or transparent in the lower frequency infrared but absorbing higher frequencies, are not in general available. Fortu- nately, the available filters, from which a recommended set was selected, usually suffice to disclose significant SRE of remote wavelengths. This is because SRE caused by gross scattering arises principally from spectral regions where detector sensitivity and source intensits is high, and such sharp cutoff hilters transmit efficiently these regions. If. however, there is an reason to suspect the presence of SRE of wavelengths within the stop hand of the filter. for example when a grating is used in second order in the higher lrequenci infrared and the stray might be of first order frequency, or il Beer's law departures are observed when preparing calibration curves (1), the following supplemental test should be used

A 1.3.1.I Obtain a filter that transmits efficiently all wavelengths within the desired monochromator pass band, but rejects the frequencies outside this band that might he causing troubie. Interference filters having suitable characteristics are commercially available for the infrared, visible, and near ultraviolet ranges. Measure the absorhance of samples with and without the hilter, setting the zero absorbance level also with and without the filter. respectively. Appreciable differences of measured absorbance, especially at high sample absorbance. indicate trouble from SRE. Samples should then be measured with the narrow band filter in the beam, or filters effective for rejecting the SRE can be employed (see A 1.3.7). This test is recommended only as a supplement because of high cost for the array of test hiters if it is to be applied for general instrument evaluation, as well as the large amoun of testing time required. It is nevertheless strongly recommended for critical applications.

A 1.3.2 Depending on the particular measurement to which the instrument is to be applied, one may be concerned only with SRE of relatively remote wavelengths, or may hind so-called "nearby scattering" (sometimes defined as radiant energy outside the pass band but within several bandwidths of the nominal wavelength). of significance. For example, measurements of aromatic compounds in the gas phase may impose very strict requirements on scattering of wavelengths adjacent to those absorbed (2). A monochromator. entirely suited for liquid-phase measurements on the same compounds might give highly erratic and inaccurate measurements in the gas phase application

Al 3.3 Because of these considerations, it is not practical to specify SRE in an absorption spectrophotometer in absolute terms. Nevertheless, test procedures have been developed that give detinite values: ones that are valid for certifying the suitability of a particular monochromator or spectrophotometer for most of the important applications. and that additionally allow instruments to be compared when similar detectors and sources are used. SRE is then defined as the fraction of the total energy that is contributed by wavelengths different

The boldface numbers in parentheses refer to the list of references at the end of this method 
from those of the spectral band passed by the monochromator, as indicated bi the lest.

Al.3.4 SRE if preseme in significant amounts is dargerous because it is often unsuspected. With the passage of time, increasing SRE frequently aciompanies gradual deterioration of the optics in a spectrophotometer. Thorough testing annually is recommended. with more frequent tests for certain critical applications.

Al.3.5 It might be assuned that it is only necessary to know the magnitude of SRE in order to make corrections on indicated absorbance balues. I little rellection, however, will demonstrate the harard of attempting such corrections except in special circumstances. Samples mas absorb even more strongly in spectral regions where SRE is intense than thes do in the region being measured. Under such circumstances, the effect of SRE will be to increase rather than to decrease indicated absorbance values. In accurate correction for SRE nould require a cetailed knowledge of the sample absorption spectrum and of the spectral distribution of SRL and detector spectral response, and is rarels feasible.

1i.3.6 For situations in which the sample does not absorb in the spectras region over which the SRE is distributed. Slavin (3) shous a plot of absorbance error versus absorbance. While it mav veent too obvious to mention. it must be realized that the relative error in absorbance is in this case larger than the proportion of SRE. Small relative errors in absorbance $(A)$ are given by the following equation:

$$
14 / A=\left[-0.43+\left(10^{4}\right), 1\right] / A
$$

where $s$ is the fraction of SRE to energy within the nominal pass band. For example, if the fraction of SRE is 0.001 for a mcasurement made at an absorbance of 1.5 , the relative error in aboorbance is -0.0091 , or about nine times the proportion of stras to monochromatic radiant energs

Al.3.7 while the data obtained with optical filters do not allow one to correct for SRE. their use to reduce SRE can be vers valuable in improsing performance, particularl of single monochromator instruments. An example is the use of the Corning No. 9863 (7-54) red-purple Cores filter for work between 260 and $380 \mathrm{~nm}$ (4). In gencral, the same tests lor SRE that serve to measure the performance of the monochromator aione grve correct values for a monochromator-fiter combination.

A I.3.8 It is alsq possible to use sharp culof filters to provide a kind of automatic SRE correction by substituting the sharp cutoff filter for an opaque shutter when establishing the zero transinitlance point of a spectrophotometer (5). If this is done with the sample in place, it also autonaticalls corrects for errors due to sample absorption at other wavelengths, provided thes fall outside the rejection band of the hilter. Thi technique is especially useful in infrared measurements, using alkali halide crystal plates as the absorption filters. Allowance is made for the reflection losses of the filter, for instance, bi using a transparent plate of matching reflection loss to transmit the desired wavelengths.

\section{A2. Test Materials}

A2.1 Sharp cutolf tilters are the most generally available for SRE evaluation. As noted in AI.3. SRE caused bi random scattering within the monochromator is principally of longer wavelengths when instruments are used in the ultraviolet. and of shorter wavelengths when instruments are used in the infrared. Fortunatels, sharp cutoff filters having high transmission efficiencies in the wavelength regions principally responsible for SRE are available in both instances.

A2.2 Glass lilters for ultraviolet use can be valuable. but nust be regarded with suspicion. because noos glasses exhibit significant fluorescence (6). Unlortunatel phototubes are frequently more sensitive to the fluorescent wavelengths than to the short ultraviolet wavelengths that excite fluorescence efficiently. If the apparent SRE is found to be increased by locating the filter close to the phototube, or is decreased by preceding the glass filter with a solution filter of slightly shorter wavelength cutoff, glass fluorescence mas be limiting the SRE readings. For less exacting applications. and for tests on single monochromators, glass blters are very useful and convenient. Since differ- ent batches of glass may exhibit dilferent degrees of fluorescence. caution with the use of glass tilters is indicated.

A2.3 Sharp cutoff solution filters halse becil investigated by several workers $(7,8,9)$, di have cristal hilters for the infrared (10).

A2.4 Filters for reducing infrured SRF have been mainly of two types: seatter filters $(11,9)$, including grating filters (12), and thin film interterence filters $(13,14,15)$.

A2.5 In certain cases. narrou pass band aburbers have proved useful for evaluating vattering of both nearbi and remote walelengthr. Examples are the most intense bands in the ben/enc valpor spectrum near $260 \mathrm{~nm}$ (16). hot mercurs bupor :11 254 $\mathrm{nm}$ (2) and polystrene film at 13,3 and $14+\mu \mathrm{m}$ (17). Other substances found uselul are $1 \mathrm{~cm}$ of 0.05 percent aqueous solution of methilene blue. near $650 \mathrm{~nm}$, and $5 \mathrm{~cm}$ of methylene bromide liquid at $1.43 \mu \mathrm{m}(\mathbf{1 8})$. Of course the hands used must be well resolved in order to give reproducible results. Because of la rge variations in resolution between commercial instrument models. no general methods based on such bands can be recommended. 


\section{A3. Stray Radiant Energy as Affected by Optical System Design}

A3.I No part of the optical system of a spectrophotometer is completely free of influence on SRE. For example, masks on the source side of the monochromator will reduce SRE if located optically conjugate to the aperture stop of the monochromator and made slightly smaller than the aperture stop image traced by reversed rays. In this way illumination of the mask that defines the aperture stop inside the monochromator is limited so that diffraction or scattering from mask edges and mask surface imperfections is lessened. Similarly, in the beam between the monochromator and the detector, a mask conjugate with the monochromator aperture stop (if such a position exists) will trap radiant energy that may be scattered within the monochromator and that passes through the exit slit from some region other than the area of the aperture stop whence the monochromatic radiant energy is intentionally passed to the external optics.

A3.2 Within the monochromator itself, a critical consideration is the freedom from scattering imperfections of the optical elements, and the surface perfection of mirrors, lenses, and dispersing elements. Even with the best techniques for polishing optical surfaces, departures from perfect smoothness occur (19), and in prism monochromators are principally responsible for the small-angle deviations of the emergent beams which are responsible for "nearby scattering," or tailing off of the slit function of the monochromator

A3.3 Even if the first optical elements within the monochromator and the entering aperture stop are not overhlled, the process of dispersion causes rays to be deviated in such a way as to illuminate much of the interior of the monochromator with energetic radiation. In a monochromator in which the off-axis angle of a collimator is too small, energy can be returned from the collimator to the dispersing element and after again being dispersed can fall by specular paths directly on the exit slit. This is often called "double dispersion", or "secondary dispersion." The best remedy is to increase the off-axis angle of the collimator, if the resulting aberrations can be tolerated. If not, such specular ray paths may be interrupted by judiciously masking off a part of the aperture stop, often without excessive loss of monochromator iransmission efficiency. If this problem is ignored, it can easily turn out that it produces significant SRE only over a narrow spectral region, so that a monochromator that gives excellent tests for SRE over much of its working region, and possible in all regions where such tests are easily made, may be seriously deficient over some particular narrow spectral range.

A3.4 An advantage of the Czerny-Turner or Wadsworth-type monochromators over the Littrow monochromator is that only a part of the dispersed energy falls on the exit collimator. The flux density on this mirror is therefore less than one half that of the Littrow arrangement, and its scattering im- perfections produce a correspondingly reduced amount of trouble.

A3.5 Grating monochromators in general transmit efficiently other orders than the intended order. This source of SRE is troublesome in the infrared. since it leads to relatively efficient transmission of a number of wavelengths at which usual sources emi strongly and detectors are sensitive $\mathbf{2 0}$ ). It is especially troublesome when the grating is operated near the blaze angle, where quite narrow, easily overlooked bands of stray energy may arise.

A3.6 As Keahl et al (20) have shown, the interference filters that are commonly used for SRE re duction in infrared grating monochromators may have "spike" leaks which can cause very serious narrow band SRE problems. The same authors further note that higher orders of SRE can also be efficiently transmitted by an "order sorting" prism monochromator in tandem with the grating monochromator, if the prism monochromator is operated under such low resolution conditions that more than one order falls within its spectral pass band

A3.7 Another often overlooked source of SRE in a spectrophotometer is fluorescence from the absorption cell or sample itself. It is entirely possible to set up conditions under which a solution can show apparent negative absorption because of the higher sensitivity of the detector for the fluorescence radiant energy generated on absorption of the ultraviolet energy, than for the monochromatic radiant energy itself. Glass or solution sharp cutoff filters provide a quick test for such difficulties when located alternately first ahead of the sample then following it in the optical train. Also, as noted for glass filters themselves, a shift of apparent sample transmittance with a change of its proximity to the phototube strongly suggests significant fluorescence, although it can also be causeo by scattering, beam deflection, or pathlength change

A3.8 Another source of SRE may be lack of masking in the sample compartment to confine the beam within the sample cuvette. Even if the beam falls well inside the cell windows when examined by the rules of geometrical optics, diffraction at narrow slit widths, or sample turbidity, can cause it to spread so that appreciable energy is transmitted through the cell walls or otherwise to the detector. A check for the error caused by diffraction can be made with India ink or a similar "total absorber" in the cell

A3.9 Similarly, a leak past the shutter used for determining instrument zero, or a leak admitting room light, can give erroneous results

A3.10 Electrical pickup can cause reading errors very similar to those due to SRE. A check can be made by turning off the slit and source and looking for drifts of the pen in a recording spectrophotometer, or following procedures given by the manufacturer. 


\section{A4. Variation with SLit Width and Height}

A4.1 If the assumption is made that the scattering process follows the Lambert distribution law. it is possible to state a simple theory for the ideal monochromator which allows prediction of the way in which the proportion of SRE varies with monochromator slit width and slit height, and which is at least approximately followed in practice. Several cases occur:

A4.1.1 Single Monochromator with "White" Conlinuum Source - The proportion of SRE does not vary with slit width (when the entrance and exit slits are opened and closed simultaneously). The energy within the pass band is proportional to the square of the slit width because it is linearly proportional to the width of the entrance slit, which admits energy to the monochromator, and also to the spectral bandwidth, is proportional to the slit width. The SRE also is proportional to the square of the slit width, because it is linearly proportional to the width of the entrance slit, which controls aperture illumination, and also to the width of the exit slit, which affect the solid angle for the transmission of scattered energy.

A4.1.1.I Transmission of monochromatic energy varies only linearly with slit height, because slit height has negligible effect on bandwidth; whereas SRE varies with the square of the slit height, just as with slit width. The proportion of SRE therefore increases linearly with slit height. (Actually, experiments to confirm. this relationship show that, with graftings, the scattering is predominantly in the direction perpendicular to the grating rulings, and the proportion of scattering varies as a fractional power of the slit height.)

A4.1.2 Single Monochromator with Pure Narrow Line Source Ideally, all of the energy in a monochromatic line that is admitted by the entrance slit is transmitted by the exit slit when the monochromator is set at the wavelength of the line; thus the monochromatic energy is proportional to the entrance slit width and height. When the monochromator is displaced from the nominal wavelength. the intensity of the scattered energy is varied by both entrance and exit slit width and height, and thus is proportional to the square of these parameters. The proportion of SRE at remote wavelengths to monochromatic energy at the nominal wavelength is proportional to slit width and height.

A4.1.3 Double Monochromator with Continuum Source - In the first monochromator section, as indicated in A4.I.I, the proportion of energy of the nominal wavelength is independent of the slit width and varies with the first power of slit height. (lt is assumed that all slits, including the intermediate slit, are varied in width by the slit control.) The scattered energy from the first monochromator that is transmitted into the second monochromator is rescattered by its optical surfaces. The amount emerging varies with the solid angle subtended by the exit slit as viewed from the scattering surface. Hence, it is proportional to both width and height of the exit slit. Thus, the fraction of stray-to-monochromatic energy is very'much reduced by the second monochromator, and it varies with the slit width and with the square of the slit height. The sensitivity to slit height makes clear the utility of a slit-height control.

A4.1.4 Double Monochromator with Line Source - The same argument as for the double monochromator with continuum source applies, except that the monochromatic energy varies only with en. trance slit height and width. Therefore, the proportion of stray-to-monochromatic radiant energy varies with the square of both the slit width and the slit height.

A4.2 Because of these relationships, it is important that tests for SRE be made in most cases at slit widths and heights representative of those actually used in the application of the instrument. Unfortunately many published results on SRE measurements are made with nontypically narrow slits or with shortened slits, or both. It is often easy to arrange test conditions that give SRE proportions substantially different from those which would be found under conditions appropriate to applications. Hence, a SRE proportion given without specifying test procedure is essentially meaningless.

.

\section{REFERENCES}

(1) Hogness, T. R., Zscheile, F. P., Jr., and Sidwell, A. E., Jr., "Photoelectric Spectrophotometry. An Apparatus for the Ultra-Violet and Visible Spectral Regions: Its Construction, Calibration, and Application to Chemical Problems," Journal of Physical Chemistry. JPCUA, Vol 41, 1937, p. 379

(2) Tunnicliff, D. D. "Measurement of Nearby Stray Radiation in Ultraviolet Spectrophotometry," Journal of the Optical Society of America, JOSAA, Vol 45, 1955, p. 1963.
(3) Slavin, W. "Stray Light in Ultraviolet, Visible and Near-Infrared Spectrophotometry," Analitical Chemistry, ANCHA, Vol 35, 1963, p. 561 .

(4) Cary, H. H., and Beckman, A. O., "A Quartz Photoelectric Spectrophotometer," Journal of the Optical Society of America, JOSA A, Vol 31, 1941, p. 682.

(5) Wright, N., and Randall, H. M., "Far Infrared Absorption Spectra of $\mathrm{NH}_{3}$ and Phosphine Gases," Phisical Review, PHRVA, 
Vol 44, 1933, p. 391

(6) French, C. S., "Fluorescence Spectra of Sharp-Cut Filters," Applied Optics, APOPA. Vol 4, 1965, p. 514

(7) McBride, W. R., "Optical Materials for Transmission Filters in the Middle Ultraviolet," Journal of the Optical Society of America, JOSAA, Vol 53, 1963, p. 519.

(8) Paulson, R. E., "Test Methods in Spectrophotometry: Stray Light Determination," $A p$ plied Optics, APOPA, Vol 3, 1964, p. 99.

(9) Pfund, A. H., "Infrared Filters of Controllable Transmission," Physical Review, PHRVA, Vol 36, 1930, p. 71.

(10) Smith, R. A. Jones, F. E., and Chasmar, R. P., The Detection and Measuremem of InfraRed Radiation," Oxford University Press, London, 1957.

(11) Gorton, A. F., "Reflection From and Transmission Through Rough Surfaces," Phisical Review, PHRVA, Vol 7, 1916, p. 66.

(12) White, J. U., "Gratings as Broad Band Filters for the Infra-Red," Journal of the Optical Society of America, JOSAA, Vol 37, 1947, p. 713.

(13) Bates, B., and Bradley, D. J., "Interference Filters for the Far Ultraviolet," Applied OP- tics, APOPA, Vol 5, 1966, p. 971

(14) Hadley, L. N., ano Dennison, D. M., "Reflection and Transmission Interference Filters," Journal of the Optical Society of America, JOSAA, Vol 53, 1963, p. 5I9.

(15) Wolfe, W. L., Ed., "Handbook of Military Infrared Technology," Superintendent of Documents, U. S. Government Printing Office, Washington, D. C. 20402.

(16) Cary, H. H., Cary Instruments, Monrovia, Calif., unpublished work.

(17) "Tables of Wavenumbers for the Calibration of Infrased Spectrometers," International Union of Pure and Applied Chemistry, Butterworths, 1961

(18) Hawes, R. C., Cary Instruments, Monrovia, Calif., unpublished work

(19) Koehler, W. F., "Multiple Beam Fringes of Equal Chromatic Order. Part VII. Mechanism of Polishing Glass," Journal of the Optical Society of America, JOSAA, Vol 45, 1955, p. 1015 .

(20) Keahl, J., Sloane, H. J., and Ulrich, W. F., "The Origin and Effect of Stray Light," The Analyzer, Beckman Instruments house organ, ANAYA, November, 1965, p. 9.

TABLE I Perforated Screens

\begin{tabular}{ccc}
\hline $\begin{array}{c}\text { Identification } \\
\text { Number }\end{array}$ & $\begin{array}{c}\text { Nominal } \\
\text { Transmittance }\end{array}$ & $\begin{array}{c}\text { Nominal } \\
\text { Absorbance }\end{array}$ \\
\hline $20 \mathrm{G}$ & 0.50 & 0.30 \\
$15 \mathrm{H}$ & 0.41 & 0.39 \\
$15 \mathrm{~L}$ & 0.29 & 0.54 \\
$10 \mathrm{~N}$ & 0.20 & 0.70 \\
$12 \mathrm{1} / 2 \mathrm{P}$ & 0.14 & 0.84 \\
$10 \mathrm{~S}$ & 0.07 & 1.20 \\
$30 \mathrm{~T}$ & 0.03 & 1.50 \\
$20 \mathrm{~W}$ & 0.01 & 2.00 \\
\hline
\end{tabular}

"The identification number is that of Perforated Prod. ucts, Inc., 68 Harvard St., Brookline, Mass. 02146 . Screens from this manufacturer are the only ones so far tested in committee work. Screens may be available from other manufacturers. 
TABLE 2 Filters for Tests of Stray Radiant Energy

\begin{tabular}{|c|c|c|c|c|}
\hline Spectral Range ${ }^{\circ}$ & $\begin{array}{l}\text { Transmittance, } \\
80 \text { Percent } \\
\text { Wavelength or } \\
\text { Wavenumber }\end{array}$ & Filter $^{r}$ & Source ${ }^{d}$ & Detector \\
\hline \multicolumn{5}{|c|}{ A. Sharp Cutoft Types } \\
\hline $\begin{array}{l}165 \text { to } 173.5 \mathrm{~nm} \\
170 \text { to } 183.5 \mathrm{~nm} \\
175 \text { to } 200 \mathrm{~nm} \\
195 \text { to } 223 \mathrm{~nm} \\
210 \text { to } 259 \mathrm{~nm} \\
250 \text { to } 320 \mathrm{~nm} \\
300 \text { to } 385 \mathrm{~nm} \\
2050 \text { to } 1200 \mathrm{~cm}^{-1} \\
1140 \text { to } 800 \mathrm{~cm}^{-1} \\
760 \text { to } 600 \mathrm{~cm}^{-1} \\
630 \text { to } 400 \mathrm{~cm}^{-1} \\
410 \text { to } 250 \mathrm{~cm}^{-1} \\
240 \text { to } 200 \mathrm{~cm}^{-1}\end{array}$ & $\begin{array}{l}183 \mathrm{~nm} \\
195 \mathrm{~nm} \\
214 \mathrm{~nm} \\
232 \mathrm{~nm} \\
271 \mathrm{~nm} \\
339 \mathrm{~nm} \\
420 \mathrm{~nm} \\
2800 \mathrm{~cm}^{-1} \\
1760 \mathrm{~cm}^{-1} \\
1240 \mathrm{~cm}^{-1} \\
1030 \mathrm{~cm}^{-1} \\
650 \mathrm{~cm}^{-1} \\
420 \mathrm{~cm}^{-1}\end{array}$ & $\begin{array}{l}0.01 \mathrm{~cm} \mathrm{H}_{2} \mathrm{O}^{\prime} \\
1.00 \mathrm{~cm} \mathrm{H}_{2} \mathrm{O}^{\prime} \\
1.00 \mathrm{~cm} 12 \mathrm{~g} / \text { liter } \mathrm{KCl} \text { aqueous' } \\
1.00 \mathrm{~cm} 10 \mathrm{~g} \text { /liter } \mathrm{NaBr} \text { aqueous } \\
1.00 \mathrm{~cm} 10 \mathrm{~g} / \text { liter } \mathrm{Nal} \text { aqueous } \\
1.00 \mathrm{~cm} \text { acetone } \\
1.00 \mathrm{~cm} 50 \mathrm{~g} / \text { liter }^{\prime} \mathrm{NaNO}_{2} \text { aqueous } \\
2.0 \mathrm{~mm} \text { fused silica }{ }^{*}(2) \\
6 \mathrm{~mm} \mathrm{LiF} \\
6 \mathrm{~mm} \mathrm{CaF} \\
6 \mathrm{~mm} \mathrm{NaF} \\
6 \mathrm{~mm} \mathrm{NaCl} \\
6 \mathrm{~mm} \mathrm{KBr}\end{array}$ & $\begin{array}{l}\text { UV } \\
\text { UV } \\
\text { UV } \\
\text { UV } \\
\text { UV } \\
\text { UV } \\
\text { VIS } \\
\text { IR } \\
\text { IR } \\
\text { IR } \\
\text { IR } \\
\text { IR } \\
\text { IR }\end{array}$ & $\begin{array}{l}\text { UV } \\
\text { UV } \\
\text { UV } \\
\text { UV } \\
\text { UV } \\
\text { UV } \\
\text { UV } \\
\text { IR } \\
\text { IR } \\
\text { IR } \\
\text { IR } \\
\text { IR } \\
\text { IR }\end{array}$ \\
\hline \multicolumn{5}{|c|}{ B. Pass-Band Filters } \\
\hline $\begin{array}{l}600 \text { to } 660 \mathrm{~nm} \\
\text { I. } 66 \text { to } 1.75 \mu \mathrm{m}\end{array}$ & $\cdots$ & $\begin{array}{l}1.00 \mathrm{~cm} 0.005 \text { percent methylene } \\
\text { blue aqueous } \\
5.0 \mathrm{~cm} \mathrm{CH}_{2} \mathrm{Br}_{2}{ }^{\prime}\end{array}$ & $\begin{array}{l}\text { VIS } \\
\text { NIR }\end{array}$ & $\begin{array}{l}\text { VIS or NIR } \\
\text { NIR }\end{array}$ \\
\hline
\end{tabular}

- Longer wavelength (or higher wavenumber, for infrared range) gives $10^{- \text {" }}$ transmittance point.

- Transmittance value not corrected for reflection loss.

'Solution filters should be placed in sample cuveltes appropriate to the range covered. Solid filters are best retained in metal holders.

"Under "source" is tabulated the usual and appropriate source for each spectral range:

UV - Source is either a deuterium or hydrogen discharge lamp or a xenon short arc.

VIS - Source is a tungsten filament lamp at 2850 to $3300 \mathrm{~K}$. If a xenon arc is substituted, precautions to avoid UV stray should be taken. such as interposition of a Corning No. 7380 or No. 339l filter, for both test and use of the instrument at wavelengths longer than $410 \mathrm{~nm}$.

NIR - Source is a tungsten filament lamp at 2500 to $3200 \mathrm{~K}$

IR - Source is a Nernst glower at 1500 to $1800 \mathrm{~K}$, or Globar, or coated Nichrome ribbon, at 1300 to $1500 \mathrm{~K}$. Because the proportion of SRE varies with source temperature, the source current should be set to the value used for analysis.

'Considerable flexibility in detectors selected is common. The following lists only some of those most frequently employed:

UV-Photomultiplier or diode phototubes with S-5, S-19, or similar spectral response function, such as types IP28, 7200, or R-106.

VIS UV types, plus photomultiplier or diode phototubes with S-4, S-5, or S-19 response; extended red threshold types such as $7265(\mathrm{~S}-20)$, or R-136. Photoconductor (PbS) detectors.

NIR - Photobubes with S-I response to $1.2 \mu \mathrm{m}$, photoconductor ( $\mathrm{PbS}, \mathrm{PbSe}$ or $\mathrm{PbTe}$ ) detectors.

IR-Thermocouples, bolometers, Golay detectors

'Apparent absorbance is strongly affected by dissolved oxygen. Bubble pure nitrogen through liquid for several minutes immediately before use. Use only recently distilled (not demineralized) water.

"Filters such as these, which absorb over a wide range in the infrared, may be warmed sufficiently by the source beam to reradiate, and so produce significant zero shifts which vary with wavelength and with time of exposure to the beam. This effect is greatly reduced by using two filters, separated by at least $1 \mathrm{~cm}$ along the beam axis. The reradiation from the first is then mostly absorbed by the second. A slightly less effective alternative is to use a Lif disc for the first filter. If zero shift is troublesome with the LiF filter, a $\mathrm{CaF}_{2}$ disk can be used ahead of the LiF filter.

${ }^{A}$ Passes blue to yellow light efficiently. The 0.005 percent methylene blue solution must be made up freshly from a 0.5 percent stock solution in 2 percent $\mathrm{KH}_{2} \mathrm{PO}_{4}$, preserved with I part of phenylmercuric acetate (Eastman No. P4267 in 50,000 parts of solution)

'Distillation Products Industries, Eastman Organic Chemicals. No. 1903. Passes from ultraviolet to I.5 $\mu \mathrm{m}$ radiant energy efficiently, except for a narrow, intense band at $1.4 \mu \mathrm{m}$, which is suitable for "nearby stray" evaluation in NIR grating monochromators. 
99. E 387

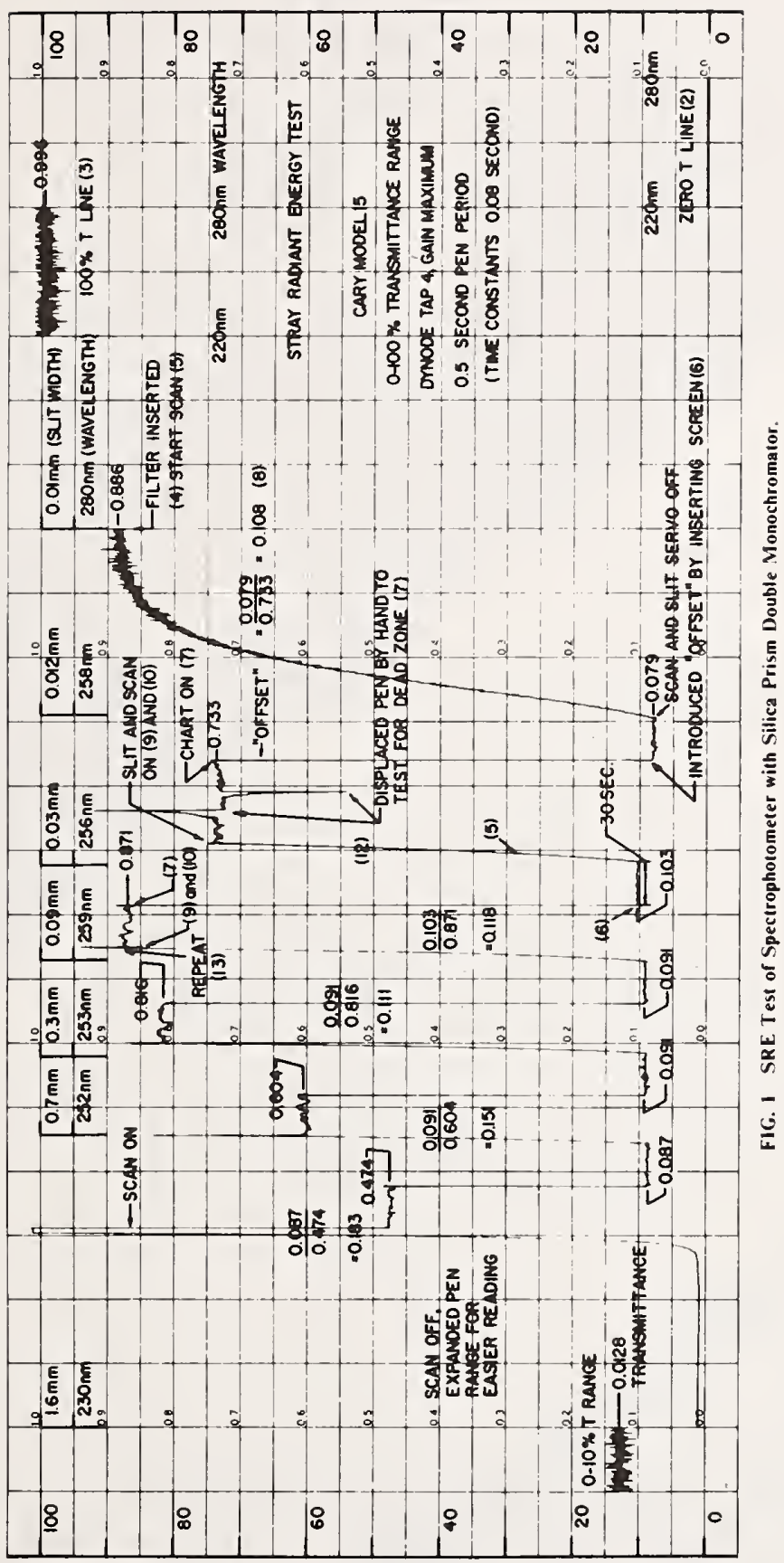


NBS-114A \{REV.7-73\}

\begin{tabular}{|c|c|c|c|}
\hline $\begin{array}{l}\text { U.S. DEPT. OF COMM. } \\
\text { BIBLIOGRAPHIC DATA } \\
\text { SHEET }\end{array}$ & $\begin{array}{l}\text { 1. PUBLICATION OR REPORT NO. } \\
\text { NBS SP-260-51 }\end{array}$ & $\begin{array}{l}\text { 2. Gov't Accession } \\
\text { No. }\end{array}$ & 3. Recipient's Accession No. \\
\hline \multicolumn{3}{|c|}{$\begin{array}{l}\text { 4. TITLE AND SUBTITIE Standard Reference Materials: } \\
\text { Glass Filters as a Standard Reference Material } \\
\text { for Spectrophotometry } \\
\text { Selection, Preparation, Certification, Use SRM } 930\end{array}$} & \begin{tabular}{|l|} 
5. Publication Date \\
November 1975 \\
6. Performing Organization Code
\end{tabular} \\
\hline \multicolumn{3}{|c|}{$\begin{array}{l}\text { 7. AUTHOR(S) } \\
\text { R. Mavrodineanu and J.R. Baldwin }\end{array}$} & 8. Performing Organ. Report No. \\
\hline \multicolumn{3}{|c|}{$\begin{array}{l}\text { 9. PERFORMING ORGANIZATION NAME AND ADDRESS } \\
\text { NATIONAL BUREAU OF STANDARDS } \\
\text { DEPARTMENT OF COMMERCE } \\
\text { WASHINGTON, D.C. } 20234\end{array}$} & 11. Contract/Grant No. \\
\hline \multirow{2}{*}{\multicolumn{3}{|c|}{ 12. Sponsoring Organization Name and Complete Address (Street, City, State, ZIP) }} & $\begin{array}{l}\text { 13. Type of Report \& Period } \\
\text { Covered } \\
\text { Final }\end{array}$ \\
\hline & & & 14. Sponsoring Agency Code \\
\hline
\end{tabular}

15. SUPPLEMENTARY NOTES

16. ABSTRACT (A 200-word or less factual summary of most significant information. If document includes a significant bibliography or literature survey, mention it here.)

This publication describes various factors which can affect the proper functioning of a spectrophotometer and suggests means and procedures to assess and control these factors. Particular consideration is given to the long and short term stability of a spectrophotometer, to the wavelength accuracy, the spectral bandpass, the stray radiation, and the accuracy of the transmittance or absorbance scale. A description is given of the means and Standard Reference Materials (SRM's) which can be used to control these factors, together with the methods for the preparation, certification, and use of such materials (SRM 930). The results obtained in actual use of SRM 930 are examined in some detail. An Appendix contains the reproduction of several publications relevant to the subject discussed in this work.

17. KEY WORDS (six to twelve entries; alphabetical order; capitalize only the first letter of the first key word unless a proper name; separated by semicolons) Accuracy in spectrophotometry; glass filters; spectral bandpass; spectrophotometry; standard reference materials; stray radiation; testing of spectrophotometers; transmittance (absorbance) accuracy; wavelength accuracy.

\begin{tabular}{|c|c|c|}
\hline $\begin{array}{l}\text { 18. AVAILABILITY } \mathbf{X} \text { Unlimited } \\
\text { [ For Official Distribution. Do Not Release to NTIS }\end{array}$ & $\begin{array}{l}\text { 19. SECURITY CLASS } \\
\text { (THIS REPURT) } \\
\text { UNCL ASSIFIED }\end{array}$ & $\begin{array}{l}\text { 21. NO. OF PAGES } \\
118\end{array}$ \\
\hline 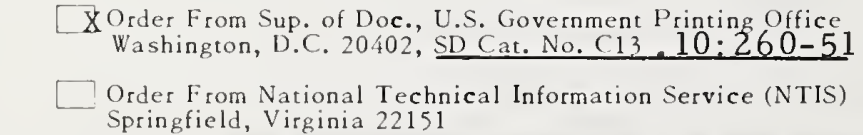 & $\begin{array}{l}\text { 20. SECURITY CLASS } \\
\text { (THIS PAGE) } \\
\text { UNCLASSIFIED }\end{array}$ & $\begin{array}{l}\text { 22. Price } \\
\$ 1.90\end{array}$ \\
\hline
\end{tabular}




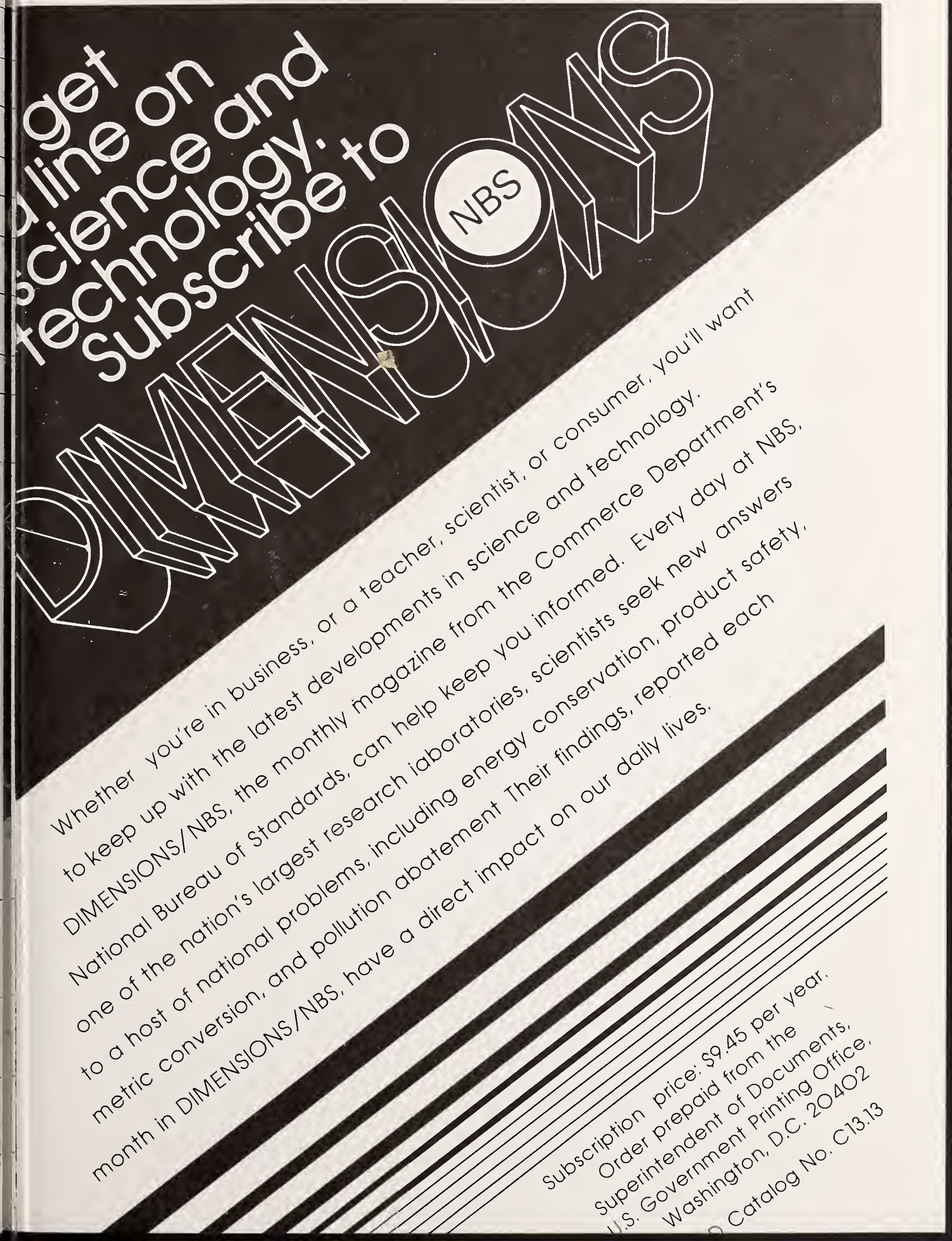




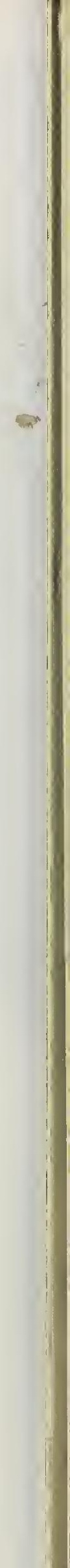




\section{PERIODICALS}

JOURNAL OF RESEARCH reports National Bureau of Standards research and development in physics, mathematics, and chemistry. It is published in two sections, available separately:

- Physics and Chemistry (Section A)

Papers of interest primarily to scientists working in these fields. This section covers a broad range of physical and chemical research, with major emphasis on standards of physical measurement, fundamental constants, and properties of matter. Issued six times a year. Annual subscription: Domestic, $\$ 17.00$; Foreign, $\$ 21.25$.

\section{- Mathematical Sciences (Section B)}

Studies and compilations designed mainly for the mathematician and theoretical physicist. Topics in mathematical statistics, theory of experiment design, numerical analysis, theoretical physics and chernistry, logical design and programming of computers and computer systems. Short numerical tables. Issued quarterly. Annual subscription: Domestic, $\$ 9.00$; Foreign, $\$ 11.25$.

DIMENSIONS/NBS (formerly Technical News Bulletin)-This monthly magazine is published to inform scientists, engineers, businessmen, industry, teachers, students, and consumers of 'the latest advances in science and technology, with primary emphasis on the work at NBS. The magazine highlights and reviews such issues as energy research, fire protection, building technology, metric conversion, pollution abatement, health and safety, and consumer product performance. In addition, it reports the results of Bureau programs in measurement standards and techniques, properties of matter and materials, engineering standards and services, instrumentation, and automatic data processing.

Annual subscription: Domestic, $\$ 9.45$; Foreign, $\$ 11.85$.

\section{NONPERIODICALS}

Monographs-Major contributions to the technical,literature on various subjects related to the Bureau's scientific and technical activities.

Handbooks-Recommended codes of engineering and industrial practice (including safety codes) developed in cooperation with interested industries, professional organizations, and regulatory bodies.

Special Publications-Include proceedings of conferences sponsored by NBS, NBS annual reports, and other special publications appropriate to this grouping such as wall charts, pocket cards, and bibliographies.

Applied Mathematics Series-Mathematical tables, manuals, and studies of special interest to physicists, engineers, chemists, biologists, mathematicians, computer programmers, and others engaged in scientific and technical work.

National Standard Reference Data Series-Provides quantitative data on the physical and chemical properties of materials, compiled from the world's literature and critically evaluated. Developed under a world-wide program coordinated by NBS. Program under authority of National Standard Data Act (Public Law 90-396).

NOTE: At present the principal publication outlet for these data is the Journal of Physical and Chemical Reference Data (JPCRD) published quarterly for NBS by the American Chemical Society (ACS) and the American Institute of Physics (AIP). Subscriptions, reprints, and supplements available from ACS, 1155 Sixteenth St. N. W., Wash. D. C. 20056.

Building Science Series-Disseminates technical information developed at the Bureau on building materials, components, systems, and whole structures. The series presents research results, test methods, and performance criteria related to the structural and environmental functions and the durability and safety characteristics of building elements and systems.

Technical Notes-Studies or reports which are complete in themselves but restrictive in their treatment of a subject. Analogous to monographs but not so comprehensive in scope or definitive in treatment of the subject area. Often serve as a vehicle for final reports of work performed at NBS under the sponsorship of other government agencies.

Voluntary Product Standards-Developed under procedures published by the Department of Commerce in Part 10, Title 15, of the Code of Federal Regulations. The purpose of the standards is to establish nationally recognized requirements for products, and to provide all concerned interests with a basis for common understanding of the characteristics of the products. NBS administers this program as a supplement to the activities of the private sector standardizing organizations.

Federal Information Processing Standards Publications (FIPS PUBS)-Publications in this series collectively constitute the Federal Information Processing Standards Register. Register serves as the official source of information in the Federal Government regarding standards issued by NBS pursuant to the Federal Property and Administrative Services Act of 1949 as amended, Public Law 89-306 (79 Stat. 1127), and as implemented by Executive Order 11717 (38 FR 12315, dated May 11, 1973) and Part 6 of Title 15 CFR (Code of Federal Regulations).

Consumer Information Series-Practical information, based on NBS research and experience, covering areas of interest to the consumer. Easily understandable language and illustrations provide useful background knowledge for shopping in today's technological marketplace.

NBS Interagency Reports (NBSIR)-A special series of interim or final reports on work performed by NBS for outside sponsors (both government and non-government). In general, initial distribution is handled by the sponsor; public distribution is by the National Technical Information Service (Springfield, Va. 22161) in paper copy or microfiche form.

Order NBS publications (except NBSIR's and Bibliographic Subscription Services) from: Superintendent of Documents, Government Printing Office, Washington, D.C. 20402 .

\section{BIBLIOGRAPHIC SUBSCRIPTION SERVICES}

The following current-awareness and literature-survey bibliographies are issued periodically by the Bureau:

Cryogenic Data Center Current Awareness Service

A literature survey issued biweekly. Annual subscription: Domestic, $\$ 20.00$; foreign, $\$ 25.00$.

Liquefied Natural Gas. A literature survey issued quarterly. Annual subscription: $\$ 20.00$.

Superconducting Devices and Materials. A literature survey issued quarterly. Annual subscription: $\$ 20.00$. Send subscription orders and remittances for the preceding bibliographic services to National Technical Information Service, Springfield, Va. 22161.

Electromagnetic Metrology Current Awareness Service Issued monthly. Annual subscription: $\$ 100.00$ (Special rates for multi-subscriptions). Send subscription order and remittance to Electromagnetics Division, National Bureau of Standards, Boulder, Colo. 80302. 
U.S. DEPARTMENT OF COMMERCE

National Bureau of Standards

Washington, D.C. 20234

PDSTAGE AND FEES PAID

DFFICIAL BUSINESS

U.S. DEPARTMENT DF CDMMERCE

COM-235

Penalty for Private Use, $\$ 300$

SPECIAL FOURTH-CLASS RATE

BOOK 



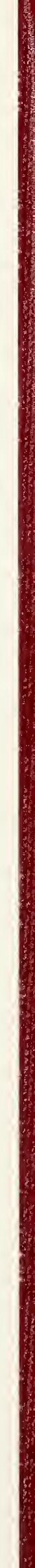


